Florida International University FIU Digital Commons

\title{
Freshwater Resource Supply Modeling for Developed and Undeveloped Watersheds
}

Kelly C. Gustafson

Florida International University, kgust003@fiu.edu

DOI: $10.25148 /$ etd.FI14110714

Follow this and additional works at: https:// digitalcommons.fiu.edu/etd

Part of the Hydrology Commons, Sustainability Commons, and the Water Resource Management Commons

\section{Recommended Citation}

Gustafson, Kelly C., "Freshwater Resource Supply Modeling for Developed and Undeveloped Watersheds" (2014). FIU Electronic Theses and Dissertations. 1589.

https://digitalcommons.fiu.edu/etd/1589 


\title{
FLORIDA INTERNATIONAL UNIVERSITY
}

Miami, Florida

FRESHWATER RESOURCE SUPPLY MODELING

FOR DEVELOPED AND UNDEVELOPED WATERSHEDS

\author{
A thesis submitted in partial fulfillment of \\ the requirements for the degree of \\ MASTER OF SCIENCE \\ in \\ ENVIRONMENTAL STUDIES \\ by \\ Kelly Cortney Gustafson
}


To: Interim Dean Michael R. Heithaus

College of Arts and Sciences

This thesis, written by Kelly Cortney Gustafson, and entitled Freshwater Resource Supply Modeling for Developed and Undeveloped Watersheds, having been approved in respect to style and intellectual content, is referred to you for judgment.

We have read this thesis and recommend that it be approved.

Michael Sukop

Assefa Melesse

Fernando Miralles-Wilhelm, Major Professor

Date of Defense: July 29, 2014

The thesis of Kelly Cortney Gustafson is approved.

Interim Dean Michael R. Heithaus

College of Arts and Sciences

Dean Lakshmi N. Reddi

University Graduate School

Florida International University, 2014 
(C) Copyright 2014 by Kelly Cortney Gustafson

All rights reserved. 


\section{DEDICATION}

I dedicate this thesis, first, to my parents, Tom and Lynn Gustafson, and to my siblings, Rachel and Andrew Gustafson for their unconditional love and confidence. I would also like to dedicate this thesis to my fiancé, Nicholas Toro, for his patience and support throughout my thesis research. Finally, I dedicate this research to Melanie Carstens who taught me the fundamentals of education and inspired me to learn. My sincerest gratitude is extended to them all. 


\section{ACKNOWLEDGMENTS}

I would like to acknowledge Florida International University for the opportunity to pursue this research. Further, I would like to acknowledge the NASA WaterSCAPES University Research Center (URC) for providing a foundation for students to expand their research and academic potential. Without the NASA-WaterSCAPES funding none of this work would have been possible. Finally, I would also like to acknowledge my major professor, Fernando MirallesWilhelm, my committee members, Dr. Michael Sukop and Dr. Assefa Melesse, as well as the research team at University of Maryland; Eugenia Kalnay, Safa Motesharrei, Jorge Rivas and Fang Zhao. Without their support, enthusiasm, assistance and guidance the completion of this work would have not been possible. 


\title{
ABSTRACT OF THE THESIS \\ FRESHWATER RESOURCES SUPPLY MODELING \\ FOR DEVELOPED AND UNDEVELOPED WATERSHEDS
}

by

\author{
Kelly Cortney Gustafson
}

Florida International University, 2014

Miami, Florida

Professor Fernando Miralles-Wilhelm, Major Professor

Globally, the current state of freshwater resource management is insufficient and impeding the chance at a sustainable future. Human interference within the natural hydrologic cycle is becoming dangerously irreversible and the need to redefine resource managerial approaches is imminent.

This research involves the development of a coupled natural-human freshwater resource supply model using a System Dynamics approach. The model was applied to two case studies, Somalia, Africa and the Phoenix Active Management Area in Arizona, USA. It is suggested that System Dynamic modeling would be an invaluable tool for achieving sustainable freshwater resource management in individual watersheds. Through a series of thought experiments, a thorough understanding of the systems' dynamic behaviors is obtainable for freshwater resource managers and policy-makers to examine various courses of action for alleviating freshwater supply concerns. This thesis reviews the model, its development and an analysis of several thought experiments applied to the case studies. 


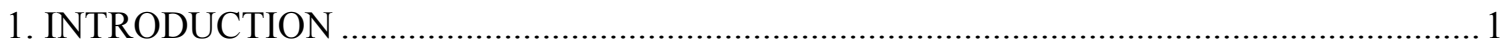

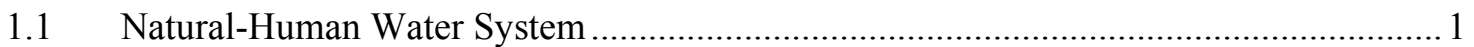

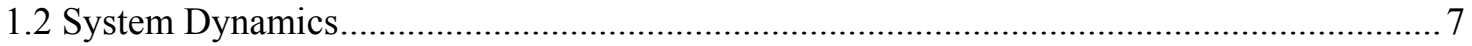

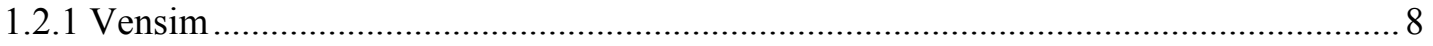

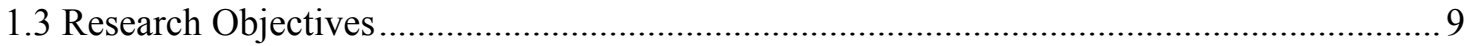

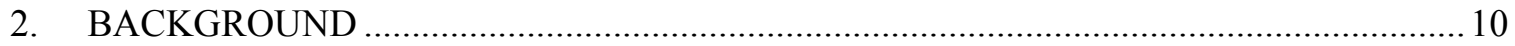

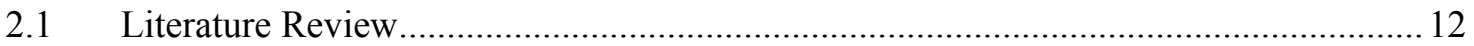

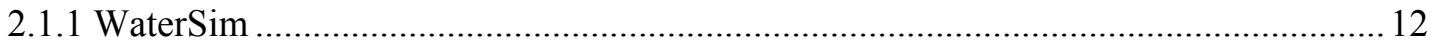

2.1.2 Florida Municipal Water Conservation Policy Model .................................................. 14

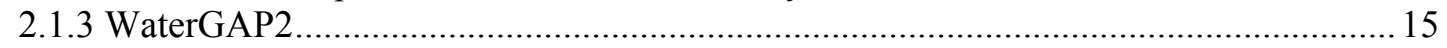

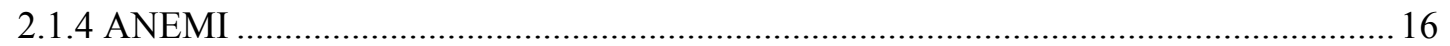

2.1.5 Review Summary ………………………………………………………….... 17

2.2 COWA: A Coupled Natural-Human Water Model........................................................... 17

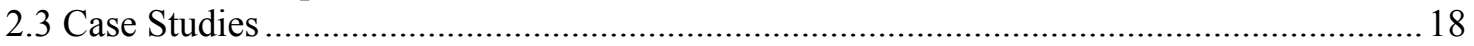

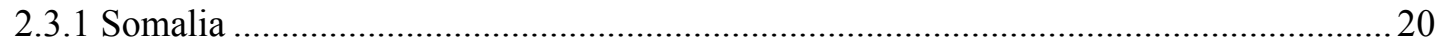

2.3.2 Phoenix Active Management Area (PAMA), Arizona ………………………………...2

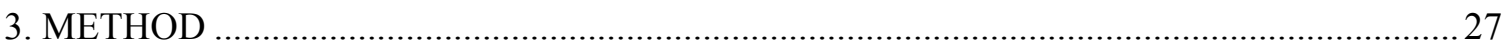

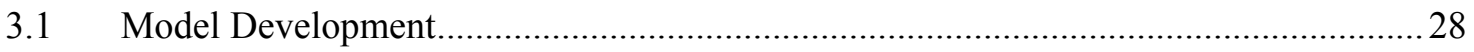

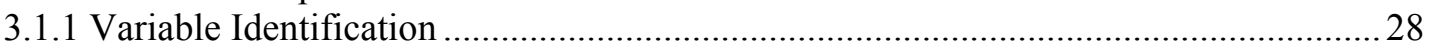

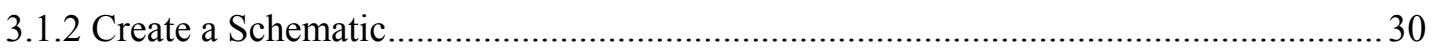

3.1.3 Graphical Model Development................................................................................... 32

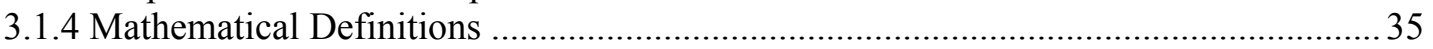

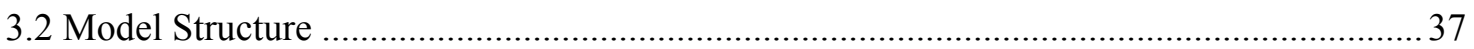

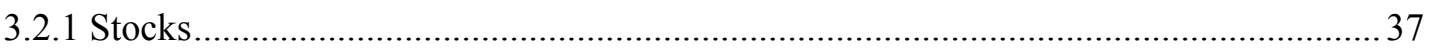

3.2.2 Demand by Population............................................................................................ 43

3.2.3 Collection and Transfer Efficiency ……………………………………………........ 44

3.2.4 Freshwater Supply ...................................................................................... 45

3.2.5 Consumed Water Returned to Sources ……………………………………………. 48

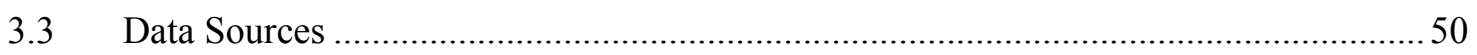

3.4 Parameters and Exogenous Variable Definitions ..............................................................51

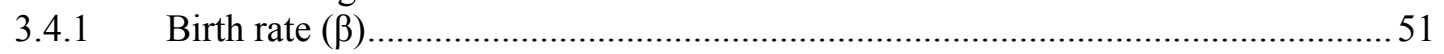

3.4.2 Death rate, Minimum and Maximum $\left(\alpha_{\mathrm{m}}\right.$ and $\left.\alpha_{\mathrm{M}}\right)$............................................5 53

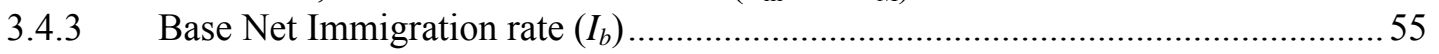

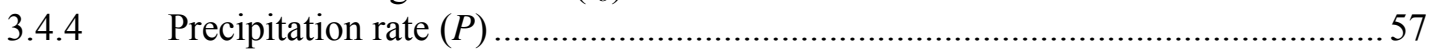

3.4.5 Evapotranspiration rate (E) .......................................................................59

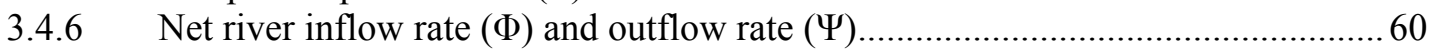

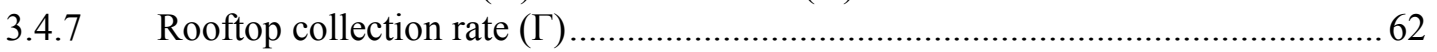

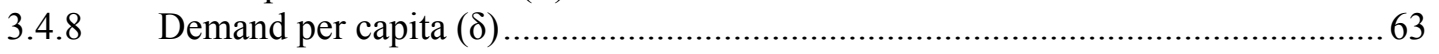

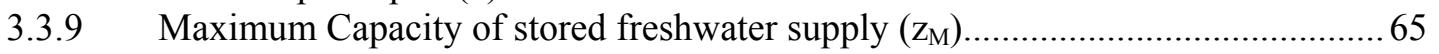

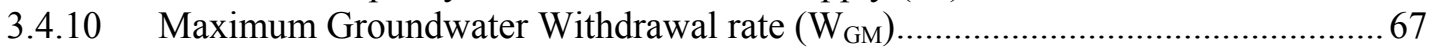

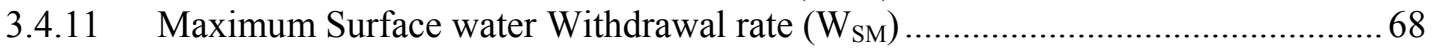

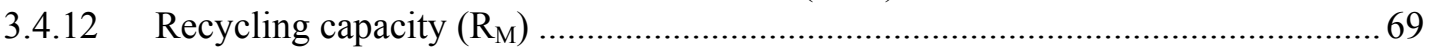

3.4.13 Infiltration rate $(f)$................................................................................. 70 


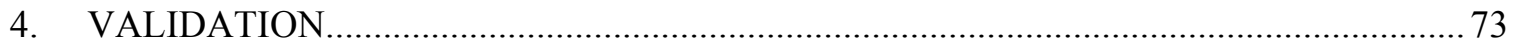

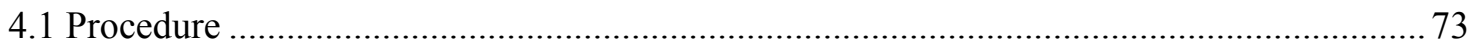

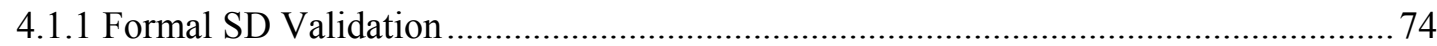

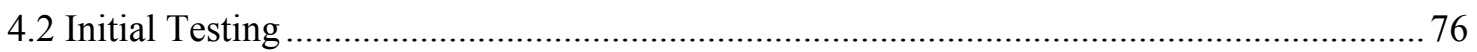

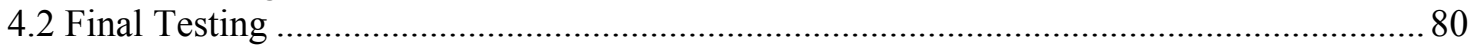

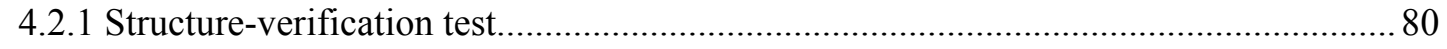

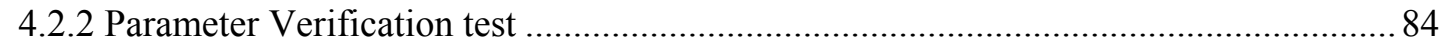

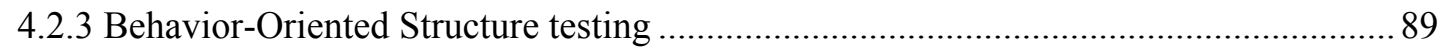

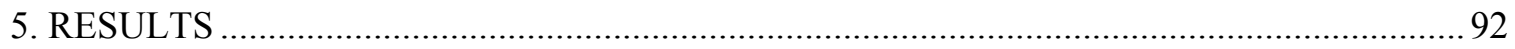

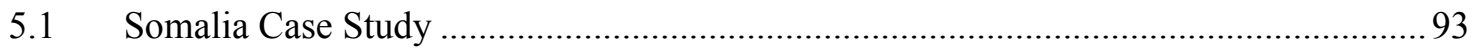

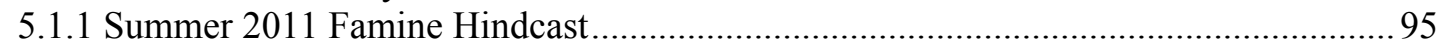

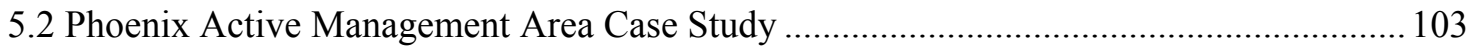

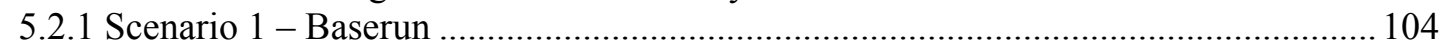

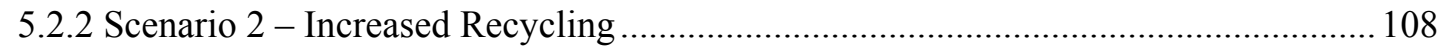

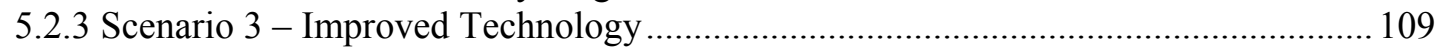

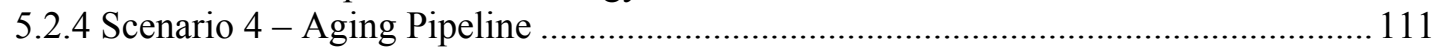

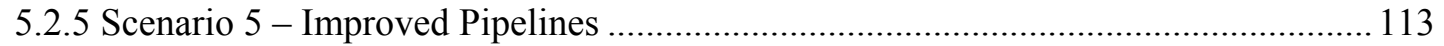

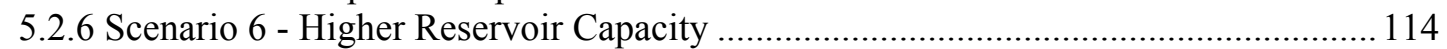

5.2.7 Scenario 7 - Higher Reservoir Capacity, Stricter GW Withdrawal Policy .................116

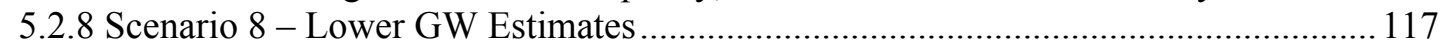

5.2.9 Scenario 9 - Lower GW Estimate, Stricter Withdrawal Policy.................................. 118

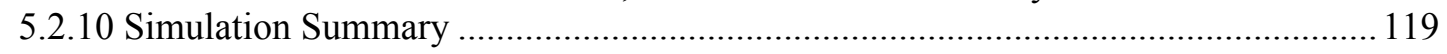

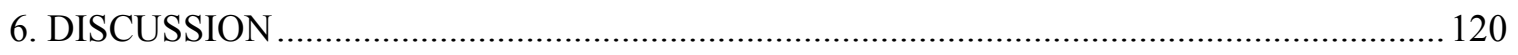

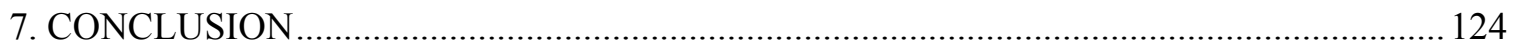

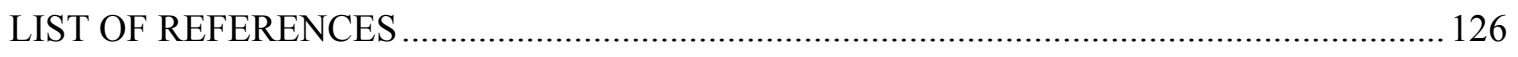

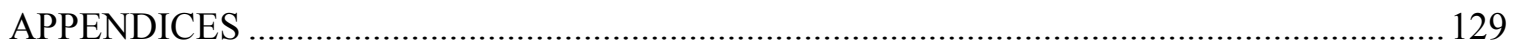




\section{LIST OF TABLES}

TABLE

PAGE

Table 1: Global estimated distribution of total freshwater, by water source (USGS, 2014) .......... 4

Table 2: The Dublin Principles (Moriarty, Butterworth, \& Batchelor, 2004) ............................. 11

Table 3: Comparable Natural-Human Water Resource SD Models ......................................... 12

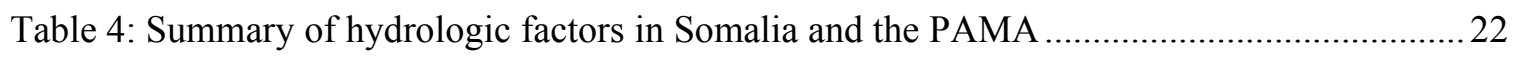

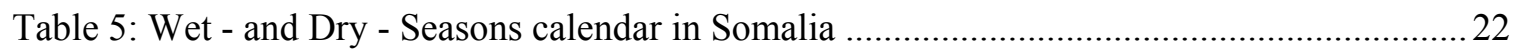

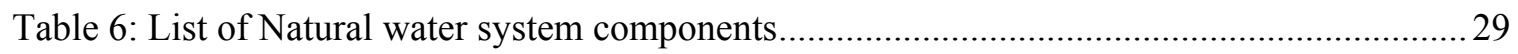

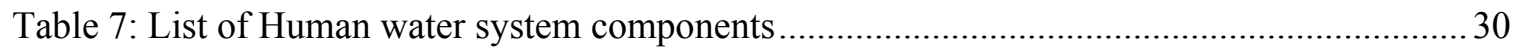

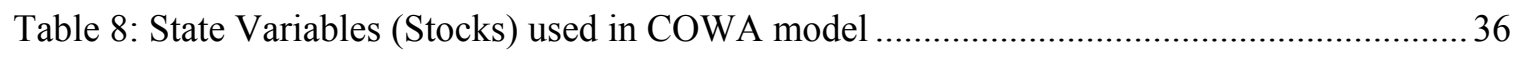

Table 9: Definition of Auxiliary Variable Functions used in model equations ............................. 36

Table 10: Description of parameter used in COWA model ..................................................... 37

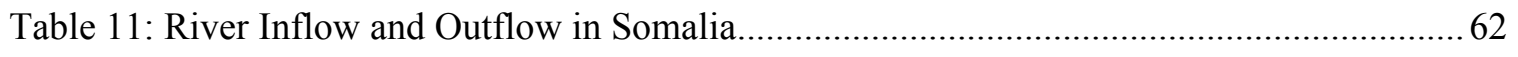

Table 12: Surface and Groundwater demand in PAMA (ADWR, 2010) ..................................... 65

Table 13: Estimated Surface and Groundwater demand in Somalia (SWALIM, 2007)...............65

Table 14: Estimated freshwater supply storage capacity in Somalia, by region and storage type

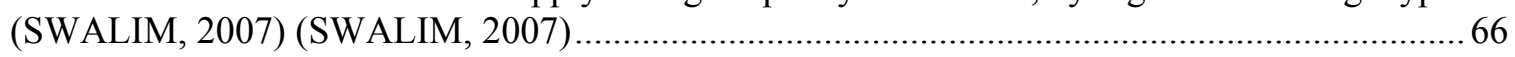

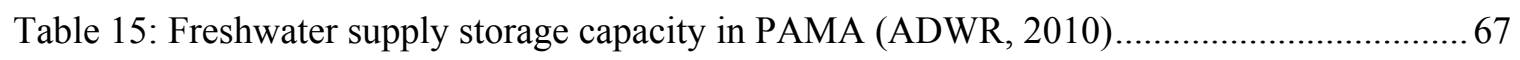

Table 16: Input data for Somali and PAMA case studies ...................................................... 73

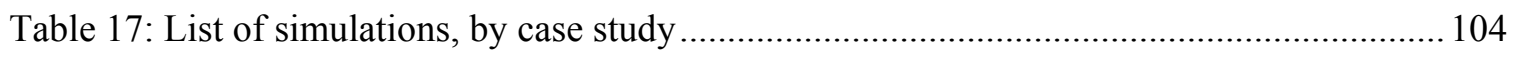




\section{LIST OF FIGURES}

FIGURE

PAGE

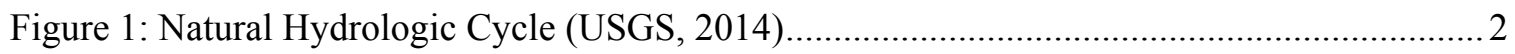

Figure 2: The Human Water System (Source: Environmental Protection Agency (EPA)) ............ 5

Figure 3: Projected world population growth behaviors given different fertility variants (UN, 2013) 6

Figure 4: Location of Somalia (Source: Somali Center for Water and Environment) .21

Figure 5: Map of Phoenix Active Management Area, sub-basins, major river networks and selected river gauge stations 25

Figure 6: Location of Somalia (red) and PAMA (blue) (Google Earth, 2014) .............................26

Figure 7: SD Model Development Process (Forrester J. , 1994) ....................................................28

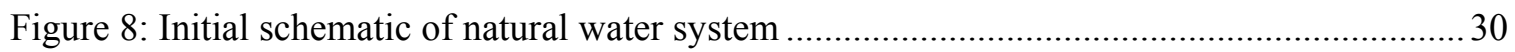

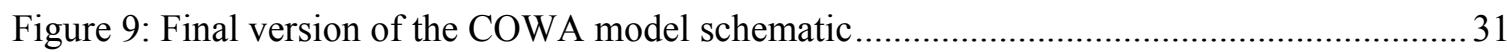

Figure 10: Graphical structure of the natural system in the Vensim program ............................... 32

Figure 11: The SD model structure of a Coupled Natural-Human Freshwater Resource Supply

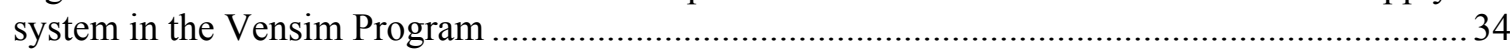

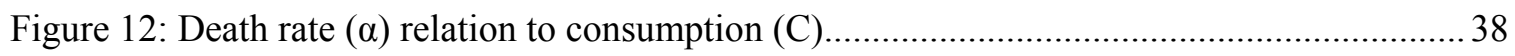

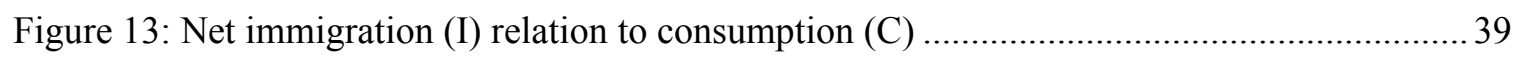

Figure 14: Withdrawal relation with maximum capacity of withdrawal, sources and demand of reserves

Figure 15: Conceptualization of portioning ratios of consumed water.

Figure 16: Famine Intensity Scale (Howe \& Devereux, 2004)...... Error! Bookmark not defined.

Figure 17: Customized lookup graph for COWA precipitation rate formulation in Somalia case study

Figure 18: Customized lookup graph for COWA evapotranspiration rate formulation in Somalia case study 60

Figure 19: Location of river gauge stations used for data to estimate Net River Inflow and Net

River Outflow in Somalia 62 


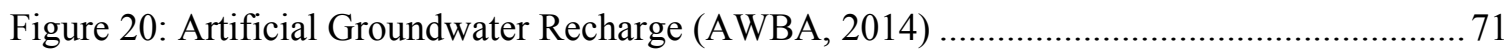

Figure 21: Structure of formal validation process for SD models (Barlas, 1994) ........................ 75

Figure 22: Original version of COWA in Vensim, compared with final version ......................... 77

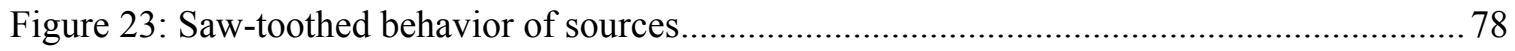

Figure 24: The US case study simulated output of sources vs. supply stocks ........................... 79

Figure 25: Observed population in Juba Basin as compared to simulation COWA population ....91

Figure 26: Observed and projected population in PAMA as compared to simulated population

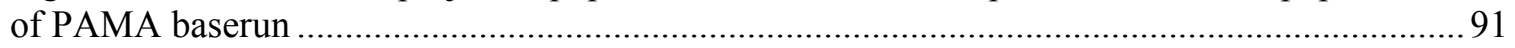

Figure 27: Analysis process for theoretical validation of thought experiments...........................94

Figure 28: Long-term Average Precipitation in Somalia and Selected Stations........................... 96

Figure 29: Long-term Average PET in Somalia and Selected Stations ......................................97

Figure 30: Somalia Hindcasting Results for Freshwater Sources and Freshwater Supply stocks . 99

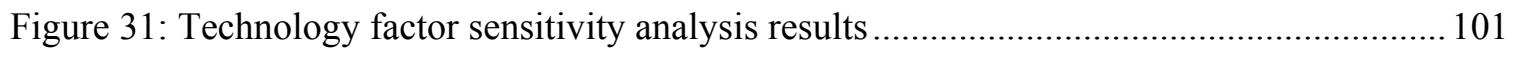

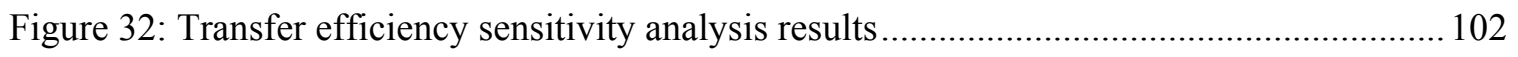

Figure 33: Scenario 1 -Simulated behavior patterns of selected system components................. 106

Figure 34: Scenario 2 - simulated behavior patterns of selected system components ................. 108

Figure 35: Scenario 3 - Simulated behavior patterns of selected system components ................ 110

Figure 36: Scenario 4 - Simulated behavior patterns of selected system components ................ 112

Figure 37: Scenario 5 - Simulated behavior patterns of selected system components ................ 114

Figure 38: Scenario 6 - Simulated behavior patterns of selected system components ................ 115

Figure 39: Scenario 7 - Simulated behavior patterns of selected system components ................ 117

Figure 40: Scenario 8 - Simulated behavior patterns of selected system components ................ 118

Figure 42: Final Population and Final Groundwater Source levels for nine simulations ............ 120

Figure 43: SimArc - A schematic of an application from Similie and ArcView ....................... 123

Figure 44: Future expectations of COWA, coupling among four models ................................ 124 
Figure 45: The $2009 \mathrm{Gu}$ season rainfall map of Somalia.

Figure 46: 2009 Deyr season rainfall map of Somalia.

Figure 47: The $2010 \mathrm{Gu}$ season rainfall map of Somalia.

Figure 48: The $2010 \mathrm{Gu}$ season rainfall map of Somalia (cont.).

Figure 49: 2010 Deyr season rainfall map of Somalia. 130

Figure 50: The 2011 GU season rainfall map of Somalia... 130

Figure 51: The $2011 \mathrm{Gu}$ season rainfall map of Somalia (con't.) 130 


\section{LIST OF SYMBOLS}

assurance factor

birth rate

consumption per capita

Consumption per capita threshold

$\mathrm{C}_{\text {th }}$

consumption to sewer rate

consumptive to sewer ratio

$\sigma$

death rate

$\alpha$

demand per capita

effective demand

D

evaporation rate

E

Freshwater Sources

immigration rate

initial time

$\mathrm{t}_{0}$

initial population

$\mathrm{X}_{0}$

initial value of freshwater sources

$\mathrm{Y}_{0}$

leak to sources delay

$\lambda$

leak to sources

$\Lambda$

leakage rate

L

max death rate

$\alpha_{M}$

max stored freshwater supply

$Z_{M}$

max withdrawal rate

$\mathrm{W}_{\mathrm{M}}$

min death rate

$\alpha_{\mathrm{m}}$

non-recycled to sources

$\mathrm{N}$ 
non-recycled to sources ratio

Population

$\mathrm{X}$

precipitation rate

$\mathrm{P}$

recycling capacity

$\mathrm{R}_{\mathrm{M}}$

recycled water rate

$\mathrm{R}$

river inflow rate

$\Phi$

river outflow rate

$\Psi$

rooftop collection rate

$\Gamma$

runoff to sources

$\Omega$

runoff to sources ratio

$\omega$

Stored Freshwater Supply

$\mathrm{Z}_{\mathrm{M}}$

supply collection rate

K

technology factor

$\tau$

total demand

$\Delta$

transfer efficiency

$\eta$

withdrawal rate

W 


\section{LIST OF ABBREVIATIONS AND ACRONYMS}

Arizona Department of Water Resources

ADWR

Arizona Department of Health Services

ADHS

Center for Disease Control and Prevention

$\mathrm{CDC}$

Coupled Natural-Human Water Model

COWA

Food Security and Nutrition Analysis Unit

FSNAU

Food and Agriculture Organization

FAO

Integrated Water Resource Management

IWRM

Phoenix Active Management Area

PAMA

Somalia Water and Land Information Management

SWALIM

United Nations Development Programme

UNDP

United Nations Statistics Division

UNSD

United States Census Bureau

USCB

United States Geological Survey

USGS 


\section{INTRODUCTION}

In this research, the dynamics of a coupled natural and human freshwater system will be explored. With the development of a system dynamics model, called the COupled natural-human WAter (COWA) model, the interrelations of the system's components will be tested and discussed. First, the concept of natural-human water systems and the approach of system dynamics modeling will be introduced, followed by the research objective and purpose of the model developed for this research. The second portion of this thesis will summarize related literature on the topic of system dynamics modeling for coupled natural-human water systems as well as introduce the COWA model and the applied case studies. The third and fourth sections examine the development and validation processes of the model, respectively. Finally, the fifth section reviews a suite of thought experiments run on the case studies followed by a discussion and conclusion of the research, in sections six and seven, respectively.

\subsection{Natural-Human Water System}

The natural-human water system is defined by the coupled interactions occurring between the natural hydrologic cycle and the anthropogenic impacts from extracting, consuming, redistributing and returning the freshwater back to the natural system. A comprehensive understanding of this coupled system begins with an understanding of the natural and human systems separately.

All of Earth's water, in lakes, rivers, aquifers, oceans and the atmosphere, is constantly cycling through three phases; liquid water, water vapor and solid ice. These water phases cycle through several hydrologic processes (e.g., precipitation, condensation, evaporation, etc.) around the globe delivering and absorbing freshwater, forming the Hydrologic Cycle. A visual explanation of the hydrologic cycle is illustrated in Figure 1, identifying the key pathways, components and processes at work in this natural, dynamic water system. These phase-changing cycles differ in speed, oscillate between seasons and are driven primarily by temperature. The 
continuous movement of water supply filters and redistributes the freshwater required for the survival of most living organisms, making it one of the most important systems on Earth.

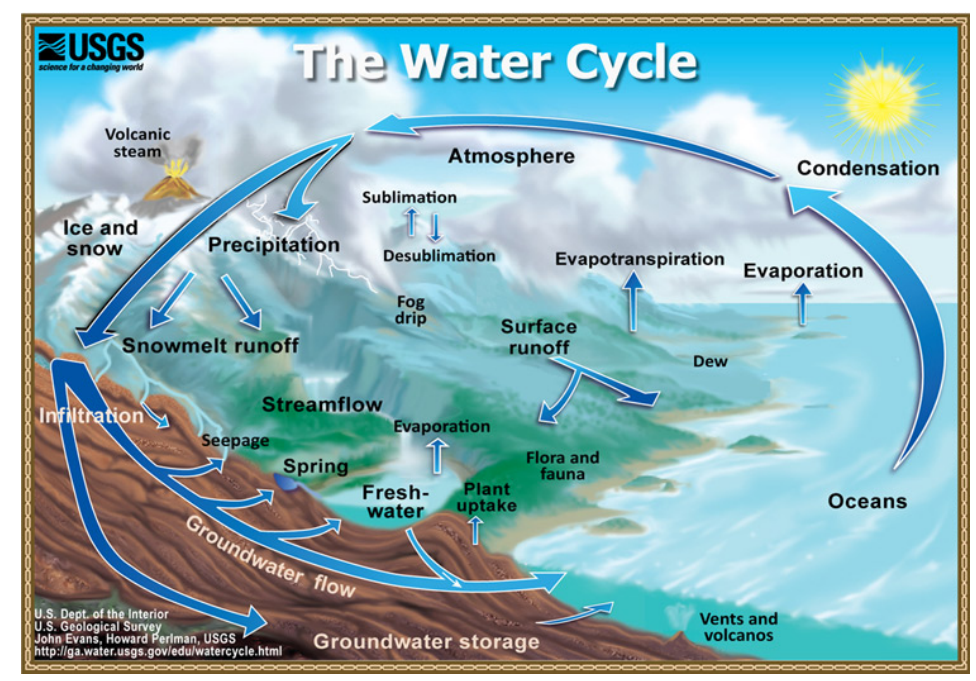

Figure 1: Natural Hydrologic Cycle (USGS, 2014)

Historically, human societies have freely utilized surface freshwater bodies (i.e., lakes and rivers), for their water needs. Though surface freshwater resources are open and readily accessible, in comparison, groundwater resources have a vastly larger quantity to tap into. With the onset of technological advancements and rapid societal development, the majority of water used for anthropogenic purposes is withdrawn from aquifers deep below the Earth's surface. However, only $0.0072 \%$ of the total water on Earth is fresh and readily accessible in lakes and rivers, and only $0.76 \%$ of total water is stored as fresh groundwater, see Table 1 . Most water is either stored in oceans, too saline to consume, or frozen in glaciers and ice caps. As a result of frivolous human consumption of freshwater resources, the hydrologic cycle's rate of natural replenishment for surface and ground freshwater reservoirs is in constant struggle with the rate at which humans are removing water from the natural system. 


\begin{tabular}{|c|c|c|c|c|}
\hline \multicolumn{5}{|c|}{$\begin{array}{l}\text { One estimate of global water distribution } \\
\text { (Percentages are rounded, so will not add to 100) }\end{array}$} \\
\hline Water source & $\begin{array}{l}\text { Water volume, in cubic } \\
\text { miles }\end{array}$ & $\begin{array}{l}\text { Water volume, in cubic } \\
\text { kilometers }\end{array}$ & $\begin{array}{l}\text { Percent of } \\
\text { freshwater }\end{array}$ & $\begin{array}{l}\text { Percent of } \\
\text { total water }\end{array}$ \\
\hline Oceans, Seas, \& Bays & $321,000,000$ & $1,338,000,000$ & -- & 96.5 \\
\hline $\begin{array}{l}\text { Ice caps, Glaciers, \& Permanent } \\
\text { Snow }\end{array}$ & $5,773,000$ & $24,064,000$ & 68.7 & 1.74 \\
\hline Ground water & $5,614,000$ & $23,400,000$ & -- & 1.69 \\
\hline Fresh & $2,526,000$ & $10,530,000$ & 30.1 & 0.76 \\
\hline Saline & $3,088,000$ & $12,870,000$ & -- & 0.93 \\
\hline Soil Moisture & 3,959 & 16,500 & 0.05 & 0.001 \\
\hline Ground Ice \& Permafrost & 71,970 & 300,000 & 0.86 & 0.022 \\
\hline Lakes & 42,320 & 176,400 & -- & 0.013 \\
\hline Fresh & 21,830 & 91,000 & 0.26 & 0.007 \\
\hline Saline & 20,490 & 85,400 & -- & 0.006 \\
\hline Atmosphere & 3,095 & 12,900 & 0.04 & 0.001 \\
\hline Swamp Water & 2,752 & 11,470 & 0.03 & 0.0008 \\
\hline Rivers & 509 & 2,120 & 0.006 & 0.0002 \\
\hline Biological Water & 269 & 1,120 & 0.003 & 0.0001 \\
\hline \multicolumn{5}{|c|}{$\begin{array}{c}\text { Source: Igor Shiklomanov's chapter "World fresh water resources" in Peter H. Gleick (editor), 1993, Water in Crisis: A Guide to the World's } \\
\text { Fresh Water Resources (Oxford University Press, New York). }\end{array}$} \\
\hline
\end{tabular}


Table 1: Global estimated distribution of total freshwater, by water source (USGS, 2014) 
The withdrawals and alterations (e.g., dams) made on the natural water system, as a result of actions taken by the human system, create further complications for an already highly dynamic cycle. Shown in Figure 2 is a sample illustration of the proposed human water cycle, as defined by the Environmental Protection Agency (EPA), to be modeled as the anthropogenic side of the COWA model. The image helped visualized the system's components but was not used as a strict blueprint because of its specificity to 'wet weather flows' rather than a more generalized human

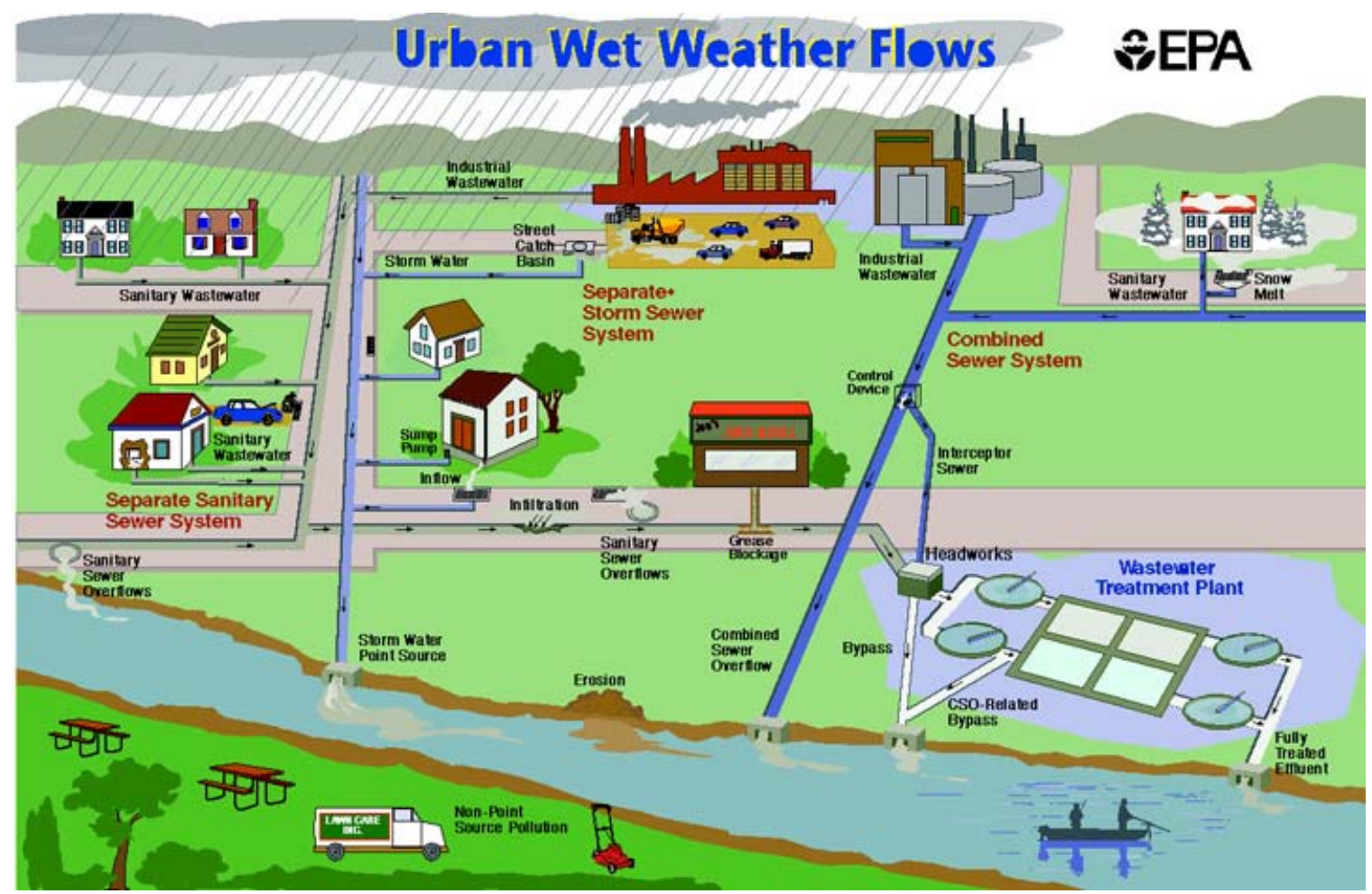

water system.

\section{Figure 2: The Human Water System (Source: Environmental Protection Agency (EPA))}

When humans withdrawal freshwater from natural resources for irrigation, manufacturing or any other anthropogenic use, typically, this water is treated, used and released back into the natural system. In some more developed areas, wastewater is treated before returned back to the natural sources but in many other regions of the world such precautions are not taken. Therefore, not only 
are natural flows interrupted through withdrawals, negatively impacting the quantity of freshwater, but the quality of the freshwater is disturbed by unregulated discarding of wastewater as well. Proper and responsible management of the natural-human water system requires a large amount of local interdisciplinary information but more importantly, management needs a full understanding of all the system's parts and their interactions.

With the current human population around 7 billion and predicted future population growth, see Figure 3, freshwater resources are at high risk of depletion. The consequences associated with freshwater resource depletion are not only potentially devastating and widespread but relatively immediate as well, once the 'tipping point' has been crossed. Spanning from temporary

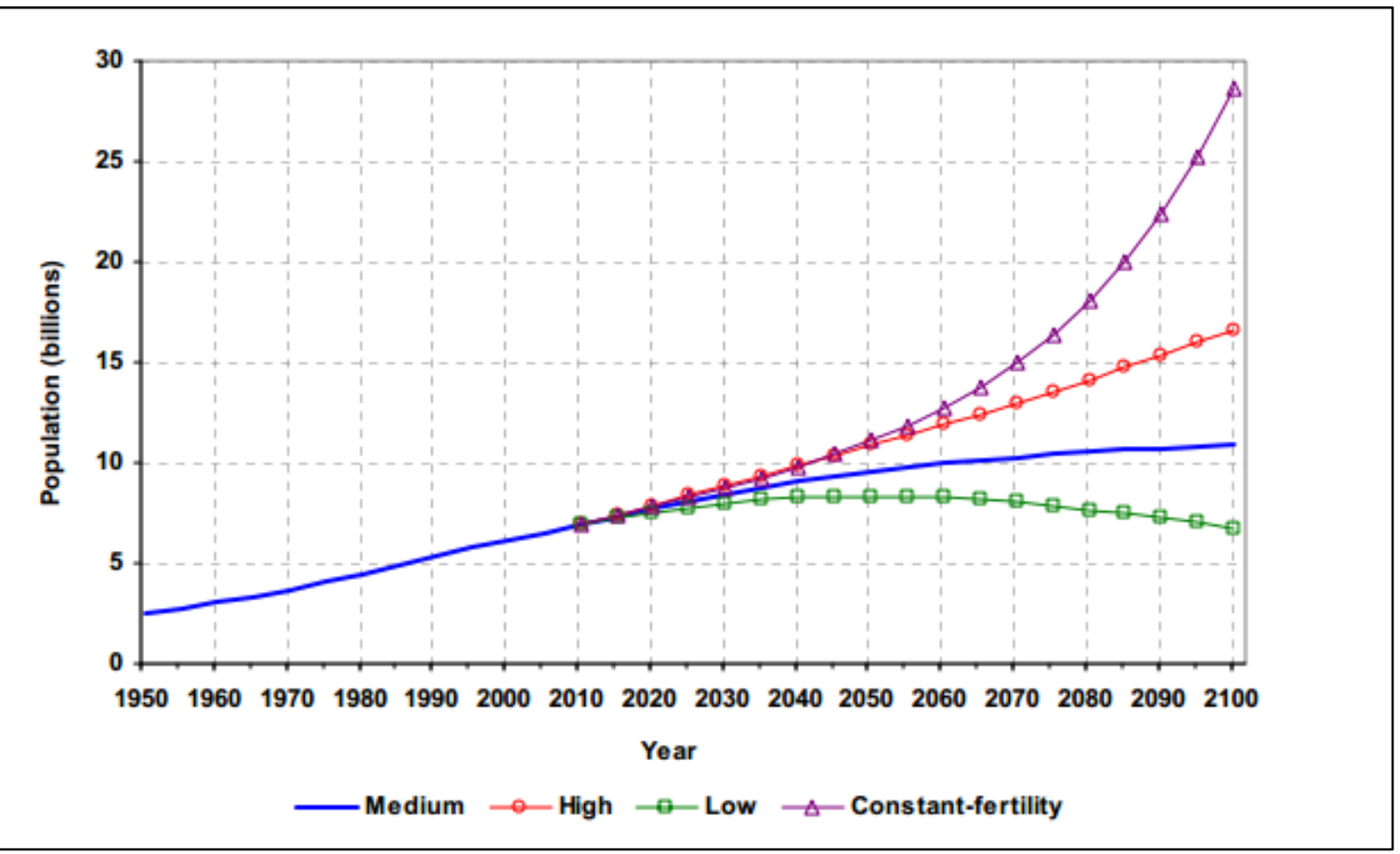

Figure 3: Projected world population growth behaviors given different fertility variants (UN, 2013)

drought to extended famine, it is seemingly impossible to have a healthy and sustainable society without a healthy and sustainable hydrologic cycle. Having the capacity to sustainably manage the natural-human freshwater system could drastically change the progress of future development of global societies and avoid the serious consequences of water-scarcity. 
Finally, it is important to mention that climate change also plays a role in the dynamics of the natural-human water system. As new temperature extremes and their durations increase, locations adapted to more moderate changes could experience serious weather events, e.g., droughts and flooding. As a result of the deep uncertainty and controversy surrounding climate change and impacts of global warming, this research does not further discuss such impacts on the natural-human water system. However, regardless of the extent of future climate change, the inevitable population increase warrants concern for implementing more sustainable freshwater resource management.

A thorough understanding of the integrated human-natural water system is essential to alleviating the sustainability concern. Freshwater resource management decisions can have significant repercussions on the natural hydrologic cycle and stressing the natural water system tends to feedback stress onto the human system. Knowing the behavior of these complex relations, between the natural and human water systems, will allow for more informed decisionmaking on behalf of both human's and the environment's best interest.

\subsection{System Dynamics}

Systems, such as the hydrologic cycle, with several intricately working parts, require sophisticated analysis to help understand the behaviors and relationships operating within the system. Simulations can provide the information necessary to make appropriate and informed decisions that will impact the system in the future. As awareness of natural resource depletion grows, sustainability of managerial decisions has become increasingly important. In this context, System Dynamics (SD), has become a key tool in modern-day resource management. In a constantly changing world, it is necessary to adapt to new conditions. Globally, natural freshwater resource management needs improved and innovative tools that meet the demands of the environment and society, today and in the future. It is suggested in this research that the 
system dynamics approach to modeling allows for freshwater resource management to be done more informed and sustainably.

System Dynamics (SD) modeling is a computer-based approach to simulate complex and dynamic systems. SD is a modeling technique that can be used to help understand economic, environmental, industrial, social and any other multifaceted system with dynamic relationships between its components. The process requires a dynamic definition of the system, including identifying all relevant components, followed by constructing a schematic of the system's structure. Components of the system are then mathematically defined as first-order differential equations to explain the relationships between them through time. The structural skeleton of a SD model is composed of a series of stocks (levels), in the form of boxes, and flows (rates), in the form of arrows, which interact through a chain of feedbacks between the exogenous triggers and the endogenous relationships.

\subsubsection{Vensim}

Vensim ${ }^{\circledR}$ is a SD modeling and simulation software created by Ventana Systems. The Vensim Professional version 5.10x3 is the system dynamics tool used in this research. It was chosen on the basis of its ability to detect inconsistencies, its flexibility with data modification and its relatively simple graphical user interface (GUI). Vensim gives ease to locating errors by highlighting variables with conflicting units or illogical governing equations and allows for onthe-fly changes to variables quantities with the use of the SyntheSim instrument. The SyntheSim tool provides a slide bar below each parameter, allowing the user to adjust selected values while simultaneously viewing the changes to the system through interactive graphs. Vensim also provides the option for various graphical outputs including bar, line, and sensitivity graphs, as well as a table of the time series data generated for each variable and a catalogue of all variables, their explanations, defining equations and values in document format. 
Unfortunately, Vensim does have some inconvenient limitations such as its restricted ability to customize graphical output and its inability to model spatial variation. It is suggested that these limitation could be resolved with the coupling of other program such as Microsoft Excel and ArcGIS. These limitations and their suggested alleviations will be discussed further in section 6 .

\subsection{Research Objectives}

The objective of this research is to develop a system dynamics model that reflects the interactions between the natural hydrologic cycle and the human management of freshwater resources. The presented project aims to establish a formal and comprehensive understanding of the human and natural water system relationships as to build knowledge of the specific causes and effects of various hypothetical management strategies. The coupled natural-human system approach of examining such complexities can give rise to novel scientific discoveries and is crucial to establishing effective policies for environmental and socioeconomic sustainability (Lui, et al., 2007). It is hoped that the model formulation can become the basis for an Integrated Water Resource Management (IWRM) tool to alleviate some of the hardship plaguing many waterscarce regions around the world.

It is hypothesized that through a series of thought experiments, a more detailed understanding of the effects of certain human actions on the natural-human water system can be achieved. Water management agencies whom are fully informed of the expected behaviors within the system should be able to enhance preparations for forecasted extremes, e.g., droughts and floods, and by doing so, will be able to plan for a more sustainable future. Additionally, questions regarding policy effectiveness can be answered with regards to water recycling, long-term and short-term water reserves, technological advances, transport efficiency, and reservoir capacity.

Further, it is hypothesized that with the application of the model toward both developed and undeveloped regions, noticeably different behaviors should be produced by the same variable under the varying conditions. We hypothesized that the developed regions will show a higher 
sensitivity toward water resource regulation policy, while, the undeveloped regions will show a higher sensitivity toward infrastructure and technological improvements.

\section{BACKGROUND}

The origin of System Dynamics modeling is rooted in industrial systems, first introduced by Jay Forrester, "the father of System Dynamics". The SD approach arose with Forrester's Industrial Dynamics in 1961, explaining the integrated relationship between management action and development of an organization. The application of the field later spread to Urban Dynamics (Forrester J. W., 1969), analyzing the evolution of cities in the United States and further applied to the first "World" model (Forrester J. , 1971) leading to the World3 model, introduced in the renowned Limits to Growth publication (Meadows, Meadows, Randers, \& Gehrens, 1972) which jump-started a concerned interest in global sustainability among growing population, food production, industrial production, pollution and non-renewable natural resource consumption subsystems of the world.

The Meadows et al. World3 model simulations indicated a collapse in the system under a 'business-as-usual' scenario, reinforcing the widely-accepted Tragedy of the Commons phenomena (Hardin, 1968). Some of the simulated scenarios of the World3 model suggest that, if the global population proceeds to grow at its current rate and non-renewable natural resources, e.g., groundwater and fossil fuels, maintain current consumption rates, global supply will be unable to meet demand, the system will no longer sustain itself and the social-economicenvironmental system will eventually collapse. Since natural resources, especially freshwater resources, are more often than not treated as a 'commons', proactive and sustainable management of freshwater resources is a justified growing interest. The possibility of reaching the humannatural freshwater resource supply system's collapse is potentially devastating and fatal. Any living system lacking renewable and sustainable freshwater quickly deteriorates and certainly does not progress. 
It has been predicted that freshwater availability will decline by $26 \%$ in North America and 56\% in Africa by 2025 (Stockholm Environmental Institute, 1997).With increasing awareness of the potential for a global 'water-crisis', politicians, managers and conservationists agree that an interdisciplinary approach to freshwater resource management is currently the best approach. Integrated Water Resource Management (IWRM) was formally developed in 1992 at the International Conference on Water and Environment, known then as the Dublin Principles, see Table 2 , and was later defined by the Global Water Partnership (GWP) as "a process which promotes the coordinated development and management of water, land and related resources, in order to maximize the resultant economic and social welfare in an equitable manner without compromising the sustainability of vital ecosystems."

\begin{tabular}{|c|l|}
\hline \multicolumn{2}{|c|}{ The Guiding Principles for the Dublin Statement } \\
\hline Principle 1 & $\begin{array}{l}\text { Fresh water is a finite and vulnerable resource, essential to sustain life, } \\
\text { development and the environment }\end{array}$ \\
\hline Principle 2 & $\begin{array}{l}\text { Water development and management should be based on a participatory } \\
\text { approach, involving users, planners and policy-makers at all levels. }\end{array}$ \\
\hline Principle 3 & $\begin{array}{l}\text { Women play a central part in the provision, management and } \\
\text { safeguarding of water }\end{array}$ \\
\hline
\end{tabular}

Table 2: The Dublin Principles (Moriarty, Butterworth, \& Batchelor, 2004)

It is suggested that the natural-human water SD model developed from the research presented in the following sections and other research like it should be utilized as a tool for the IWRM process. Increased integration of disciplines will achieve better water resource management and general resource management (Lui, et al., 2007). The proposed SD model and its potential for expanding into subsectors, i.e., economy and energy, facilitates the integration by relying on interdisciplinary data to drive the model. Not only will the use of COWA facilitate interdisciplinary efforts but additionally the increased interdisciplinary research will mutually facilitate the further development of COWA as data become more available and reliable. 


\subsection{Literature Review}

As previously mentioned, the application of SD modeling for the natural-human systems initiated and grew with the creation of the World3 model. Today, several SD models exist to assist in the management of natural resources including agriculture, land, energy, food and, of course, water. There have been several similar coupled natural-human freshwater resource supply models, see Table 3; though varying in temporal and spatial scales, all are developed to better assess the freshwater resource situation to their applied case studies and in some cases even analyze hypothetical policy changes.

\begin{tabular}{|c|c|c|c|}
\hline Model Name & Description (spatial scale) & $\begin{array}{c}\text { Time } \\
\text { Scale }\end{array}$ & Source \\
\hline ANEMI & $\begin{array}{c}\text { "reproduces the main characteristics of eight } \\
\text { sectors of the society-biosphere-climate system -- } \\
\text { climate, carbon cycle, land use, population, } \\
\text { surface water flow, water use, water quality and } \\
\text { the economy"; global scale }\end{array}$ & yearly & $\begin{array}{c}\text { Simonovic, } \\
\text { (Davis \& }\end{array}$ \\
WaterSim & $\begin{array}{c}\text { "investigates how alternative climate conditions, } \\
\text { rates of population growth and policy choices } \\
\text { interact to affect future water supply and demand } \\
\text { conditions in Phoenix, AZ" }\end{array}$ & yearly & $\begin{array}{c}\text { Lant, Tschudi, \& } \\
\text { Kirkwood, } \\
\text { 2011) }\end{array}$ \\
\hline WaterGAP2 & $\begin{array}{c}\text { a coupled Global Water Use model and a Global } \\
\text { Hydrology model; "used to compute water use } \\
\text { and availability at a river basin level"; "provides } \\
\text { a consistent method to fill in many of the existing } \\
\text { gaps in water resources data in many parts of the } \\
\text { world" }\end{array}$ & yearly & $\begin{array}{c}\text { Alcamo, et al., } \\
\text { 2010) }\end{array}$ \\
\hline $\begin{array}{c}\text { South Florida } \\
\text { Municipal } \\
\text { Water Model }\end{array}$ & $\begin{array}{c}\text { a system dynamics model developed for South } \\
\text { Florida municipal water use and evaluating water } \\
\text { conservation policies }\end{array}$ & monthly & $\begin{array}{c}\text { (Ahmad \& } \\
\text { Prashar, 2010) }\end{array}$ \\
\hline
\end{tabular}

Table 3: Comparable Natural-Human Water Resource SD Models

The four above mentioned models will be discussed briefly in the following sections. The purpose of each model as well as some important defined behaviors and their temporal and spatial resolutions will be compared to COWA.

\subsubsection{WaterSim}

The motivation behind the WaterSim model was a climate change alteration of the regional hydrology (Gober, Wents, Lant, Tschudi, \& Kirkwood, 2011). More rain and less snow 
in winter months was altering river flow regimes and decreasing freshwater availability for human use. It is argued that the deep uncertainty characterized by climate change disagreements has proven traditional use of historical climate and risk probability as inadequate (Gober, Wents, Lant, Tschudi, \& Kirkwood, 2011). In that context, the term deep uncertainty is addressed as a fundamental disagreement about driving forces that will shape the future (Lempert, Popper, \& Bankes, 2003). Therefore, it is suggested by Gober et al. that since it is unlikely that the deep uncertainties will be resolved before decisions need to be made, attention should not be focused on finding a single solution for projected conditions but rather looking for robust policy decisions that will effectively address a range of possible future climate scenarios (Gober, Wents, Lant, Tschudi, \& Kirkwood, 2011). Developers of the WaterSim and COWA models hold the opinion that SD modeling is the key to addressing the scientific roadblock of deep uncertainty.

The WaterSim model provides a case for the distinction between consolidative modeling versus exploratory modeling. Where consolidative modeling is built using the known facts of a complex system, exploratory modeling, the type of modeling used in WaterSim and COWA, is used to investigate the consequences of varying assumptions and hypotheses about a system and its future dynamics (Bankes, 1993). The uniqueness of exploratory modeling is that it openly acknowledges deep uncertainty of key variables and relationships which makes it especially appropriate for systems with high levels of complexity (Gober, Wents, Lant, Tschudi, \& Kirkwood, 2011) such as the natural-human freshwater system modeled in the COWA research. Both WaterSim and COWA developers agree, that when discussing the attainment of sustainable freshwater resource management, the human dimension must not be overlooked. The traditional process of decision making in this field is in need of innovation and change from inflexible technological solutions to flexible, adaptive solutions (Pahl-Wostl, 2002). When searching for such solutions, models are important scientific tools and can be used as communication devices that facilitate social learning about future conditions. 
WaterSim uses an 'XLRM” framework (Lempert, Popper, \& Bankes, 2003) very similar to the framework of COWA. The XLRM structure is defined by four components; (1) exogenous uncertainties (X) - factors that cannot be controlled by decision makers, (2) policy level (L) represents potential action decision makers could take, (3) relationships (R) - describe the mathematical associations between variables and (4) outcome measures (M) - summarize model outcomes for decision-making purposes. All of the 'XLRM' components can be found in the COWA research, some examples being net river inflow and outflow, recycling capacity, the fourth stage of model development, and the scenario results, respectively.

\subsubsection{Florida Municipal Water Conservation Policy Model}

The SD Florida municipal water conservation policy (FMWCP) model created by Ahmad and Prashar specifically targets the impacts of three particular policy changes to the south-central region of Florida surrounding Lake Okeechobee. While considering the municipal, agricultural and environmental water demands, Ahmad and Prashar also use population, land use, surface water and groundwater to simulate performance evaluations for implementation of (1) low flow appliances, (2) xeriscaping and (3) pricing policies.

The FMWCP model and the COWA model hold several similarities. First, they share a similar objective for evaluation of policy options to aid in the future freshwater situations for both anthropogenic and environmental uses. Also both models couple the natural and human components acting on the freshwater cycle.

However, the COWA model and the FWMCP model differ a great deal as well. The COWA population stock is directly linked to the natural system through the death rate, where the fatalities increases if basic human demands cannot be met. The FWMCP model does not apply this dynamic through population or anything similar. Ignoring the assumption that lack of water supply to meet demands will result in population decline is sufficient for developed regions, e.g., south-central Florida, which have means to either import water or by some other way avoid 
catastrophe. However, for models, like COWA, that are intended to be used in both developed and undeveloped regions, such an assumption must be held, as it is a genuine possibility for thirdworld populations. Additionally the FMWCP model looks at individual demands by sector, while in the COWA model all water demands from all sectors are combined into a singular flow called consumption. Dividing the demands by sector undoubtedly provides further insight into the dynamic of the system. Nevertheless, for the current purpose of COWA such extended insight is unnecessary though desired for future application and development of the model. Additionally, the FMWCP model considers the role of land use in the system which is a component COWA lacks. Though certain land use properties are indirectly incorporated (e.g., infiltration rate), the dynamic relationships between the land and the hydrologic cycle are not explicitly simulated in the COWA model. The decision to not include the dynamics of land use was made for the sake of simplicity. In this initial stage of COWA's development, the researcher's first priority was to create a generalized natural-human water model that would successfully simulate various scenarios concerning the freshwater system. Incorporating the intricate role of the land is a desired step for COWA's future development.

\subsubsection{WaterGAP2}

The WaterGAP2 model is also a representation of the natural-human water system. Similar to COWA, the WaterGAP2 model uses water balancing equations for both surface and groundwater sources. However, the purpose of WaterGAP2 is very different to that of COWA. Whereas COWA aims to evaluate potential policy solutions to the growing problem of freshwater management sustainability, WaterGAP2 aims to provide missing data for regions with insufficient ability to gather the data itself. The purpose of supplying missing data requires a very high degree of accuracy for the individual quantitative components within the WaterGAP2 model and, therefore, entails statistical validation of the simulated model output with empirical data. The function of the WaterGAP2 model differs from COWA's function, which expects a larger 
picture approach that focuses on the system structure instead. However, WaterGAP2 provided necessary insight into the contributions of technology and impacts of transfer efficiency, recycling and rooftop collection, which are expressed as "technological change" and "structural change", respectively. Additionally, the differentiation of water use by sector is a component of the system that WaterGAP2 applied and COWA has not, yet. However, this distinction is a planned expansion for COWA's future development, as previously mentioned.

\subsubsection{ANEMI}

The ANEMI (an ancient Greek term for the four winds) model is a fully comprehensive system dynamics model that couples the climate, hydrological, carbon and socio-economic systems to study their behaviors with change. The ANEMI model is a good example of what is to be expected from COWA in the final stages of future model development. The inclusion of carbon and economic systems in addition to expansion of the hydrological, climate and social systems are anticipated expectations of COWA's improvement. The ANEMI model is also one of few models, including COWA, which endogenously links population and water scarcity. However, ANEMI was developed to include water quality as a function of availability and COWA was not. It is acknowledged that water quality is a major factor affecting the potability and therefore availability of freshwater supply, however, at this stage in development, COWA is not structured for such a purpose.

Although ANEMI's comprehensiveness provides extensive insight into the dynamics of these systems and their interrelationships, the inclusiveness also requires widespread knowledge of these systems, and, therefore, time and energy. The attractiveness of COWA, as compared to ANEMI, is its relative generalization of the system which allows for sufficiently extensive insight into the natural-human water system without the delays from examination of the other involved systems that ANEMI includes. The COWA model also provides a higher temporal resolution at monthly intervals to provide seasonality modeling, while ANEMI models at an annual scale 
which prevents insight into seasonality. In other words, COWA would provide a good alternative to ANEMI for applications primarily interested in the natural-human water system or for timesensitive applications for local water management planning.

\subsubsection{Review Summary}

The major contrasting factors that separates COWA from the above mentioned models is its application flexibility and its endogenous coupling of population and the water system. The COWA model, being a generalized version of the system, is not overly specified to fit only one region (as seen with WaterSim) and not so general that it models at global or annual scales (as seen with ANEMI). Though it requires some initial input data for forcing the model, once these are obtained for the desired region, the model can be applied to any given watershed and produce site-specific results. Also the coupling of the population stock and the water-system through relationships between the death rate, the net immigration rate and the consumption threshold produces important bidirectional feedbacks. The linkage between water availability and population growth generates results that would otherwise be impossible to obtain when population is considered an exogenous variable.

\subsection{COWA: A Coupled Natural-Human Water Model}

The COWA (COupled WAter) model is a simple, exploratory SD model for the naturalhuman water system. The COWA model is coupled to a Global Climate Model (GCM) and a River Routing Module (RRM) via the links between precipitation and evapotranspiration, and, river inflow and river outflow, respectively. Using the GCM and RRM to drive the natural freshwater system (i.e., precipitation, evaporation, and river flows) and observed statistical data to initiate the human system (e.g., birth rate, death rate, immigration, and demand), COWA can establish the behaviors of available freshwater supply verses required demand along with the impacts of this relationship on individual components. 
The modeled system is composed of four stocks; (1) Population, (2) Groundwater Sources, (3) Surface Water Sources, and (4) Stored Freshwater Supply. Flows in and out of these stocks are driven by dynamic relationships between and among several other components defining the system, including withdrawal, effective demand, transfer efficiency, and various policy and climate components, among many others. For simplicity, water use by different sectors (i.e., domestic, agriculture, industry, and energy) is combined into a single flow in the model, termed, consumption. However, once the validation for the structure of the system is exhausted, expanding consumption flows by sector is an intended model improvement, as will be further discussed in Section 6. The main feature of COWA is the endogenous coupling of Population to the water system through bidirectional feedbacks, which allows for results that would otherwise be impossible to attain when population is defined as an exogenous driver.

The intention of the COWA model is to allow users to run thought experiments on the behaviors of freshwater resources and freshwater supply for consumption under various climatic and political conditions, as a function of time. Several parameters in the model are determined through policy variables which generate results indicating the effects of various policy scenarios. Therefore, COWA also allows for the user to study the impacts of different political decisions, regarding water resource management, under changing climatic scenarios, thus, providing necessary insight towards the system's reactions before the decisions are implemented.

\subsection{Case Studies}

There were three total regions used to apply COWA; the contiguous United States, the country of Somalia and the Phoenix Active Management Area. The US case study will only be discussed briefly, and only as it pertains to the advancement towards the model's final version. Additionally, an extended introduction of the Somalia and Phoenix AMA case studies will be provided, including a detailed description of the sites' natural hydrological and hydropolitical characteristics. 
The first case study considered for COWA simulation was the contiguous United States. However, the result quickly showed that the model was not yet sensitive enough to detect any spatial differentiation in water availability. The model results for the U.S. case study helped to expose the spatial distribution limitation of the model. The simulation results implied that as long as some freshwater was available to any part of the U.S., the entirety of the U.S. would not have a water-scarcity problem, which, in itself, was a serious shortcoming. It is known from history and experience that despite Michigan's ample supply of freshwater from The Great Lakes, the MidWestern States can still struggle with severe droughts, thus proving COWA's spatial limitations. To fix the problem and dismiss the limitation, it was decided to apply the model only to smaller regions, where local climate and policy will show local impacts.

The next choice for a case study site was Somalia. At the time of this decision, Somalia was undergoing an extremely severe drought and, eventually, consequential famine. The Somalia famine in the summer of 2011 was a worst-case scenario for every water-scarce region. Tens of thousands of lives were lost as a result of the severe water scarcity and poor governmental action. Additionally, the majority of those whom survived the famine remained internally displaced as they sought water. The population displacement toward (relatively) water-rich urban areas further exasperated the problem as cities quickly reached carrying capacities. However, the extreme event provided an opportunity to run a case study that could be properly hindcasted and remained relevant to current issues.

With initial hindcasting success from the Somalia case study, this investigation moved forward with a naturally similar but socially different case study in order to further examine the model's flexibility and ability to simulate reality. Additionally, after analyzing the Somalia simulation results, a watershed boundary was accepted as the most appropriate spatial delineation. Since political complications would be unavoidable, except in uninhabited areas, it was decided to reduce the natural hydrological complications as much as possible by choosing a case study 
within watershed boundaries. The Phoenix Active Management Area was chosen on the basis of its similar precipitation and evapotranspiration rates (i.e., the natural-system) but drastically different political influences (i.e., the human-system) than seen in Somalia.

\subsubsection{Somalia}

Somalia is an undeveloped, rain-dependent country located on the Horn of Africa at the northern end of the continent's eastern coast, see Figure 4. The country borders Ethiopia to the north and Kenya to the south. Somalia's surface area is $637,657 \mathrm{~km}^{2}$, slightly smaller than the state of Texas, and it is inhabited by approximately 10 million people (Central Intelligence Agency, 2013), many of whom are nomadic farmers. Unfortunately, there has been a long history of civil unrest in Somalia. The instability of Somalia's central government exacerbates the nation's water scarcity issues. Without appropriate water resource management or protection from water supply terrorism tactics by rebel forces, the Somali population is in constant struggle maintaining the required water supply to meet basic needs (i.e., food, drink and hygiene). 


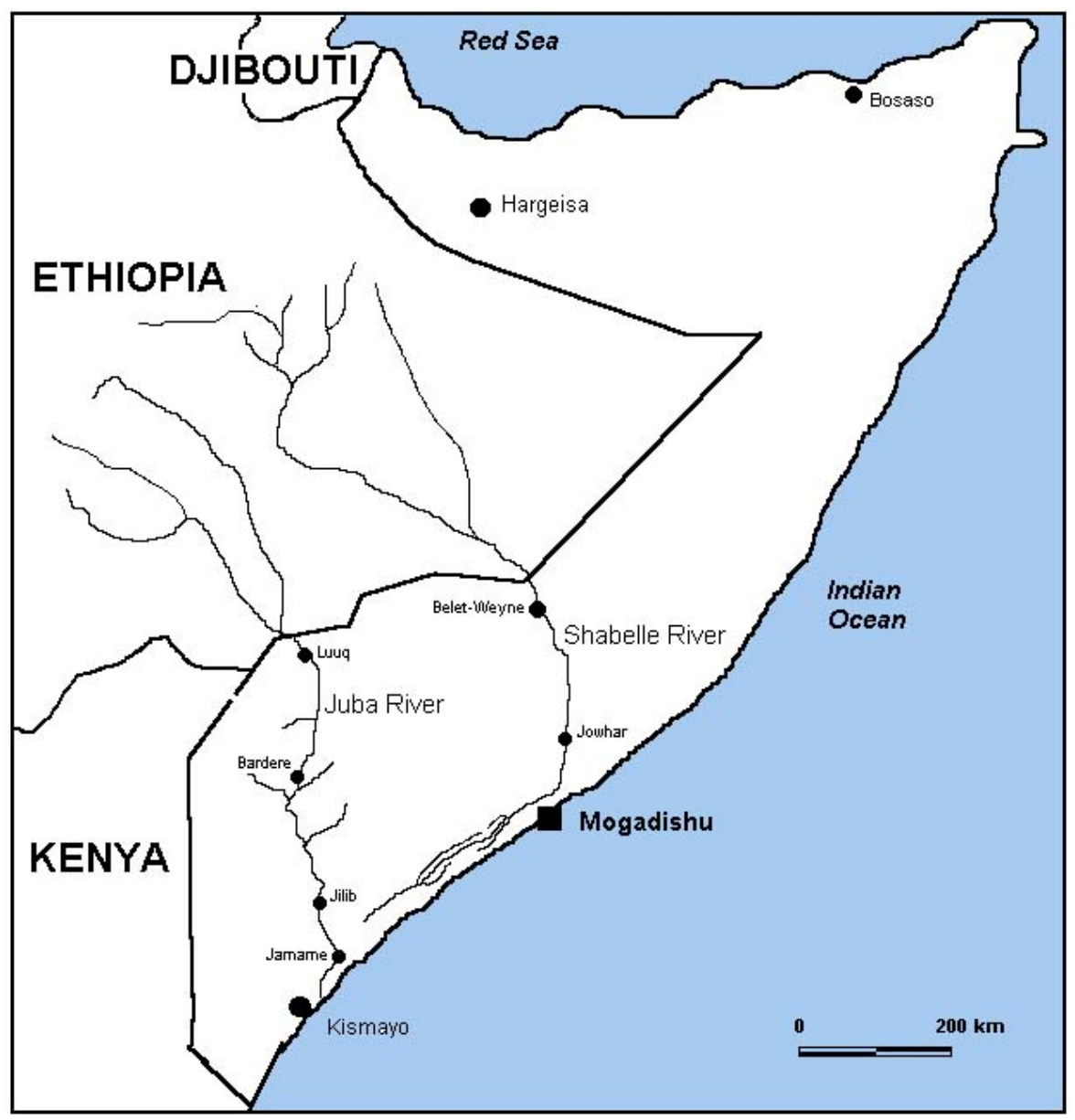

Figure 4: Location of Somalia (Source: Somali Center for Water and Environment)

The climatic conditions are dry and semi-arid. In most locations within Somalia, the 
potential evapotranspiration (PET) exceeds rainfall throughout the entire year, see Tables 4 for a summary of case study hydrologic factors. Somalia is considered to be rain-dependent as a result of the few natural freshwater bodies within the nation's borders and the lack of water resource infrastructure required to sufficiently distribute water supply to where it is demanded. Therefore, all water intensive sectors (e.g., agriculture and livestock farming) are highly dependent on natural water inputs, primarily rainfall. Additionally, Somalia has very distinct wet and dry seasons, see Table 5. Typically, in the best-case scenario, Somalia would only receive rain for 5 months out of the year.

\begin{tabular}{|c|c|c|c|c|}
\hline Case Study: & $\begin{array}{c}\text { Precipitation } \\
\text { (rainfall) }\end{array}$ & $\begin{array}{c}\text { Potential } \\
\text { Evapotranspiration }\end{array}$ & Relative Humidity & $\begin{array}{c}\text { Net River } \\
\text { Inflow }\end{array}$ \\
\hline Somalia & $200-500 \mathrm{~mm}$ & $1700 \mathrm{~mm}$ & $70-80 \%$ & $5.5 \mathrm{~km}^{3}$ \\
\hline Phoenix AMA & $170-630 \mathrm{~mm}$ & $2200 \mathrm{~mm}$ & $30-40 \%$ & $130 \mathrm{~km}^{3}$ \\
\hline
\end{tabular}

Table 4: Summary of hydrologic factors in Somalia and the PAMA

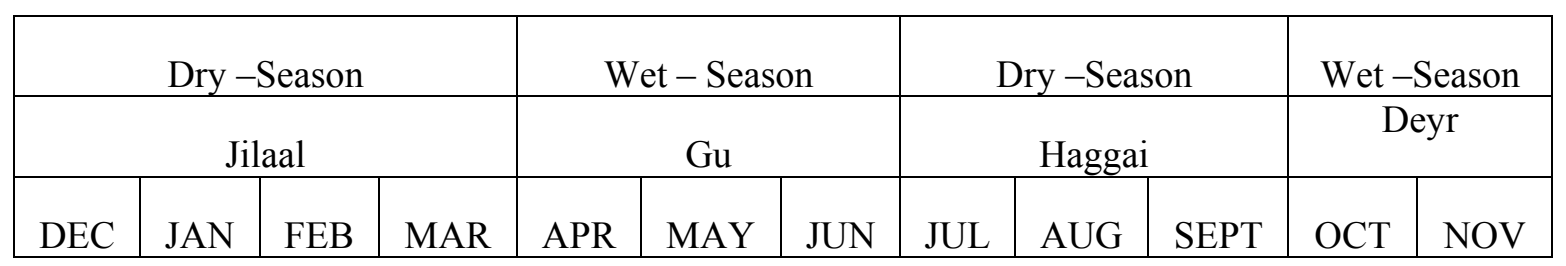

Table 5: Wet - and Dry - Seasons calendar in Somalia

Somalia's political instability in combination with its dry climate and limited freshwater resources, has left the nation with a grossly undeveloped water management system which, when exposed to periods of drought, results in enormous stress on the citizen's water consumption, food production, livelihoods and general well-being. Sadly, the struggles associated with water scarcity and undeveloped resource management is not a foreign situation to the Somali people. In 1974-75 a severe drought had devastating effects on crop production and widespread starvation soon followed. Then again, most recently, in July 2011 another famine was formally declared by the United Nations (UN) after a combination of drought, poverty and government conflicts. Tens of thousands of Somali lives were lost from starvation and dehydration at the end of two years of 
less than average or, at times, negligible rainfall during the Gu and Deyr wet seasons, see Appendix A for rainfall maps of Gu and Deyr seasons preceding the Somalia famine of 2011 . For several wet seasons prior to the UN-declared famine in June 2011, rainfall was, at most, half of what is normally expected in this region and in some months, i.e., October 2010, November 2010, April 2011, virtually negligible. Such an extreme and extended drought in heavily raindependent regions can quickly lead to food insecurity and freshwater resource depletion. If conditions do not improve or aid is not provided from surrounding regions fast enough, famine is likely to result, as was seen in Somalia.

Despite enormous effort from select organizations, extensive information gaps exist in the Somalian databases. In Somalia, information gaps tend to be the result of not only the lack of funding, personnel and equipment but also the serious threats of civil war and other security concerns. To further complicate data acquisition and resource management, the two major rivers supplying Somalia's water demands when precipitation cannot, are both transboundary water bodies. Both the Juba and Shabelle Rivers originate in Ethiopia and flow downstream to Somalia. With Ethiopia in direct control of downstream flows into Somalia and a long history of animosity, mistrust and border disputes between the two governments, proper water resource management is left with much to be desired. The hydropolitics surrounding these rivers is plagued with conflict resulting in two wars in 1964 and 1977.

It is suggested that with the use of the COWA model by groups, such as Food Security and Nutrition Analysis Unit (FSNAU) and Somalia Water and Land Information Management (SWALIM), at the first signs of drought, political action can be made to avoid famine. Although, first, a stable government may be needed before productive political actions can be made, the COWA model may provide a platform for government members to pull together and begin the important discussion of water resource sustainability. Through the appropriate combination of regulations, incentives and proactive conservation of resources for the region, it is suggested that 
comprehensively insightful planning can help circumvent the tragic consequences of extreme climates.

\subsubsection{Phoenix Active Management Area (PAMA), Arizona}

Preceding the Somalia hindcasting simulations, it was decided that in order to test the model's flexibility, a naturally similar, yet socially and politically different third case study was necessary. South-central Arizona was chosen for three reasons. First, like Somalia, precipitation is very low and evapotranspiration is very high in this portion of Arizona, relative to each other, as can be seen in Table 4, above. Second, unlike Somalia, Arizona has a long history of strict water resource regulations and a strong, unified government that is concerned and involved with its freshwater resources. Additionally, extensive cataloguing has decreased the amount of information gaps considerably, compared to those found in the Somalia case study. Since water has always been a limiting factor for development in Arizona, the U.S. government has been collecting hydrological data in Arizona since early development in the mid-1800s. 
The Phoenix Active Management Area (PAMA) is not a watershed itself, as defined by the United States Geological Survey (USGS), but rather a collection of seven sub-watersheds that

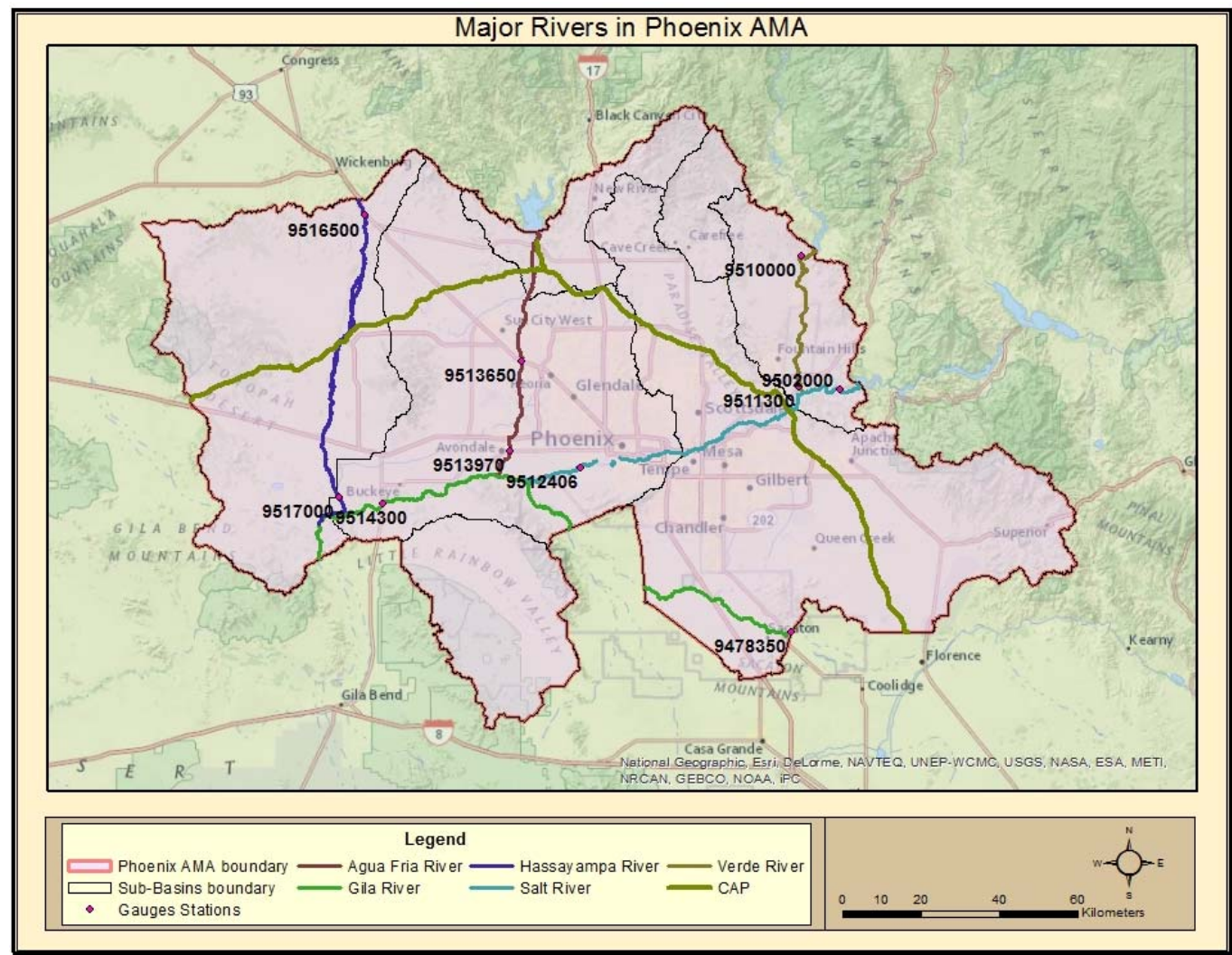

Figure 5: Map of Phoenix Active Management Area, sub-basins, major river networks and selected river gauge stations 
gather around the greater Phoenix area, see Figure 5. Located in south-central Arizona in the Southwest U.S., the PAMA surface area is $14,623 \mathrm{~km}^{2}$ and home to nearly 3.1 million people

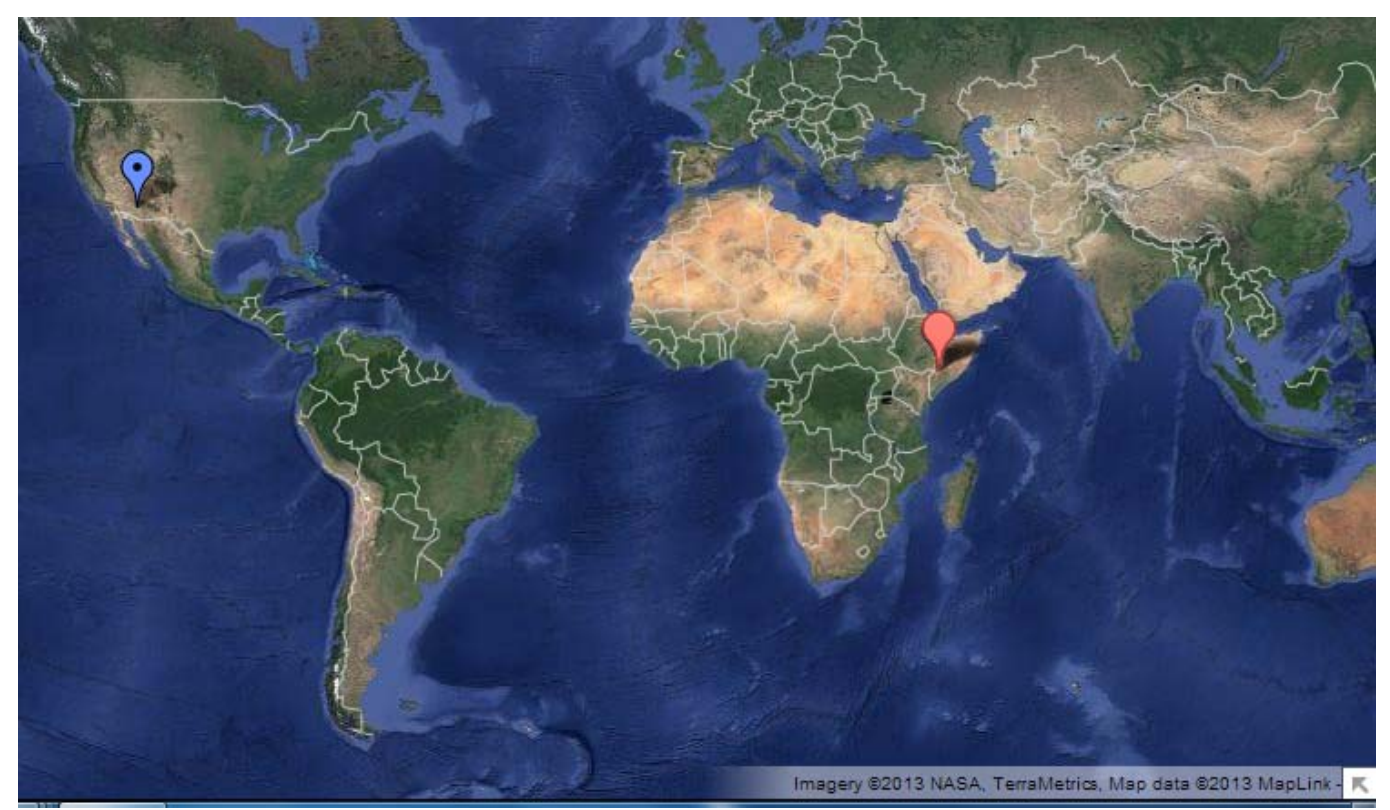

Figure 6: Location of Somalia (red) and PAMA (blue) (Google Earth, 2014)

(ADWR, 2000). As can be seen in Table 4, evapotranspiration is, generally, at least double the precipitation, similar to the proportions seen in Somalia. However, the net river inflow in the PAMA (the sum of 6 major rivers) is about 24 times greater than the net river inflow from Somalia (the sum of 2 major rivers). In terms of relative humidity, the Arizona case study is considerably more arid than Somalia, which can be attributed to differences in latitude, see Figure 6. Being much closer to the equator, Somalia's climate is significantly more humid than Arizona's.

The principal aquifer in the PAMA region is called the Basin \& Range (B\&R) aquifer. Prior to the widespread groundwater development in Arizona that occurred during WWII, groundwater storage was estimated at $1,110 \mathrm{~km}^{3}$ in the top 1,200 feet of the basin (Robson \& Banta, 1995). However, very little is known concerning the subsurface extent, thickness and 
water-yielding characteristics in many areas of the aquifer and therefore, groundwater storage values are, at best, only approximations.

The primary source of recharge for the $\mathrm{B} \& \mathrm{R}$ aquifer comes from precipitation in the mountainous surrounding areas. Recharge via interbasin flow is only considered a significant contributor in areas of the basin containing solution-altered carbonate rocks, which does not include the Phoenix AMA, (Robson \& Banta, 1995) and therefore is not treated as a significant inflow or outflow for the simulation runs.

The primary source of discharge for this aquifer is groundwater withdrawals; however, the largest natural component of discharge is evapotranspiration. In south central Arizona, the average rate of groundwater water-level decline exceeds $20 \mathrm{ft}$. /year (Robson \& Banta, 1995), particularly in rapidly expanding metropolitan areas such as Phoenix. In these areas the groundwater withdrawal rate can reach values approximately 200 times greater than the recharge rate. From 1915-1980, groundwater withdrawal from this aquifer was approximately $227 \mathrm{~km}^{3}$ in the case study region (Robson \& Banta, 1995). Nevertheless, progress has been seen since the 1970's, in recovering water-levels through withdrawal reduction efforts. Withdrawal rate reduction could have occurred as a result of a combination of factors including less irrigation acreage, more efficient irrigation practices, conversion to less water-intensive crops, larger precipitation amounts, increased surface water availability for irrigation, or stricter withdrawal policies.

\section{METHOD}

The following sections will discuss the methods used in the development process for creating the COWA model. The discussion will include the steps required to produce an SD model, an overview of the COWA model's structure and a detailed explanation of all the variables and parameters used to simulate the natural-human freshwater system. 


\subsection{Model Development}

The development process of any SD model must follow a series of five basic steps; 1.) Dynamically define the system, 2.) Identify all relevant components, 3.) Create a schematic of proposed system, 4.) Develop a graphical model with an accredited system dynamics program, and 5.) Define each variable or parameter in mathematical terms. However, as a result of the evolving nature of the validation process, discussed in section 4, many of these steps are revisited as the model developer builds confidence in the model's ability to simulate the real system (Figure 7). The dynamic definition of this coupled natural-human freshwater system has already been discussed in previous sections, therefore, further explanation of model development will begin with variable identification.

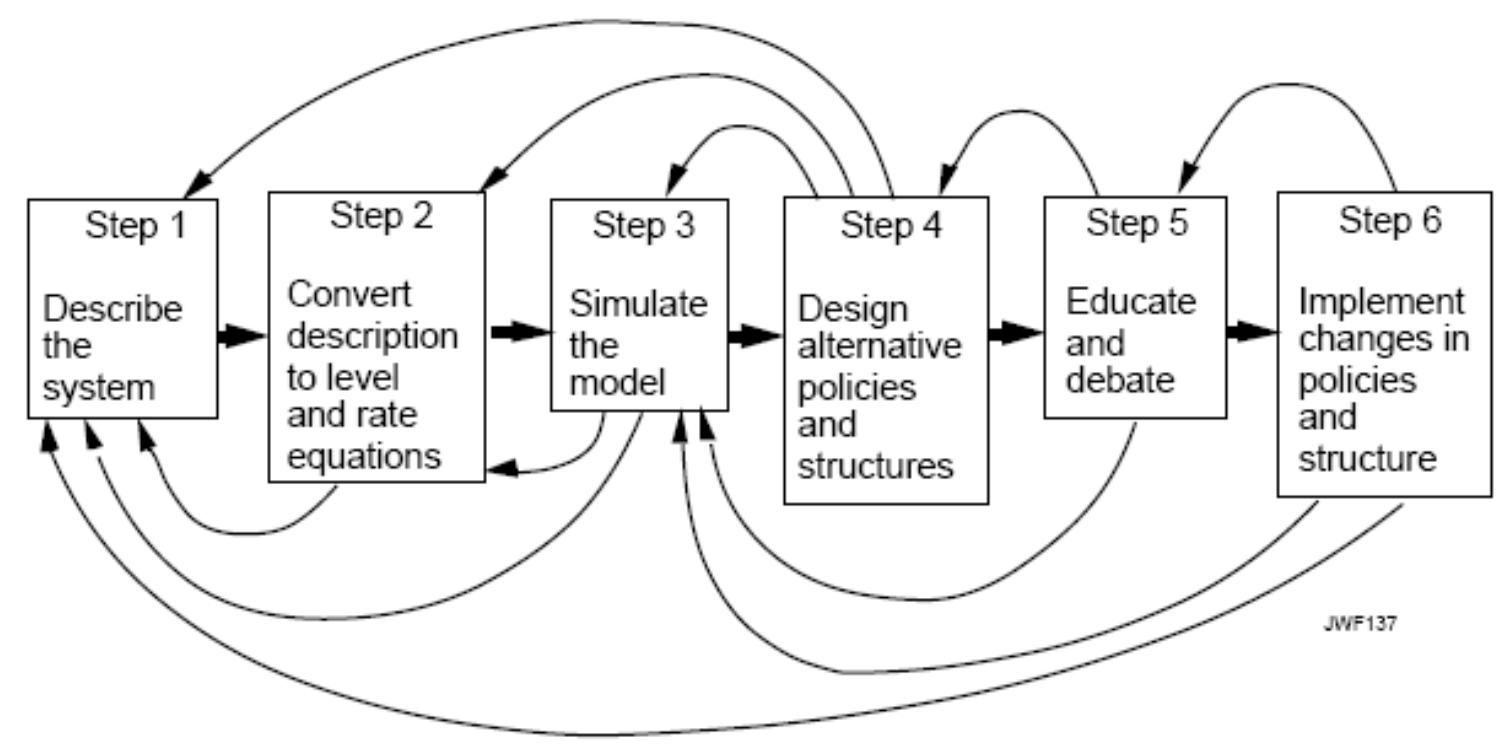

Figure 7: SD Model Development Process (Forrester J. , 1994)

\subsubsection{Variable Identification}

After the system had been dynamically defined, the first step to creating any systems dynamic model is identifying all involved factors. The initiation of the development process began with identifying all fundamental variables within the natural freshwater system, followed by the identification of all fundamental variables within the human freshwater system. The 
resulting collections of involved factors for the natural and human freshwater systems are listed in Table 6 and Table 7 respectively.

\begin{tabular}{|c|c|c|}
\hline & \multicolumn{2}{|l|}{ Natural System } \\
\hline & Variable & Units \\
\hline 1 & Surface Water Sources & $\mathrm{km}^{3}$ \\
\hline 2 & Groundwater Sources & $\mathrm{km}^{3}$ \\
\hline 3 & Precipitation rate & $\mathrm{km}^{3} / \mathrm{mo}$ \\
\hline 4 & Evapotranspiration rate & $\mathrm{km}^{3} / \mathrm{mo}$ \\
\hline 5 & Net river outflow & $\mathrm{km}^{3} / \mathrm{mo}$ \\
\hline 6 & Net river inflow & $\mathrm{km}^{3} / \mathrm{mo}$ \\
\hline 7 & Groundwater recharge rate & $\mathrm{km}^{3} / \mathrm{mo}$ \\
\hline 8 & Runoff to sources rate & $\mathrm{km}^{3} / \mathrm{mo}$ \\
\hline 9 & Infiltration rate & $\mathrm{km}^{3} / \mathrm{mo}$ \\
\hline 10 & Runoff to sources ratio & dmls $[0,1]$ \\
\hline
\end{tabular}

Table 6: List of Natural water system components

\begin{tabular}{|c|c|c|}
\hline & Human System & \\
\hline & Variable & Units \\
\hline 1 & Population & ppl \\
\hline 2 & Freshwater supply & $\mathrm{km}^{3}$ \\
\hline 3 & Immigration rate & $\mathrm{ppl} / \mathrm{mo} / \mathrm{ppl}=1 / \mathrm{mo}$ \\
\hline 4 & Rooftop collection rate & $\mathrm{km}^{3} / \mathrm{mo}$ \\
\hline 5 & Surface water withdrawal rate & $\mathrm{km}^{3} / \mathrm{mo}$ \\
\hline 6 & Groundwater withdrawal rates & $\mathrm{km}^{3} / \mathrm{mo}$ \\
\hline 7 & Supply collection rate & $\mathrm{km}^{3} / \mathrm{mo}$ \\
\hline 8 & Leakage rate & $\mathrm{km}^{3} / \mathrm{mo}$ \\
\hline 9 & Recycled water rate & $\mathrm{km}^{3} / \mathrm{mo}$ \\
\hline 10 & Total demand & $\mathrm{km}^{3} / \mathrm{mo}$ \\
\hline 11 & Effective demand & $\mathrm{km}^{3} / \mathrm{mo}$ \\
\hline 12 & Consumption per capita & $\mathrm{km}^{3} /(\mathrm{mo} * \mathrm{ppl})$ \\
\hline 13 & Threshold consumption per capita & $\mathrm{km}^{3} /(\mathrm{mo} * \mathrm{ppl})$ \\
\hline 14 & Death rate & $\mathrm{ppl} / \mathrm{mo}$ \\
\hline 15 & Leak to sources & $\mathrm{km}^{3} / \mathrm{mo}$ \\
\hline 16 & Nonrecycled to sources rate & $\mathrm{km}^{3} / \mathrm{mo}$ \\
\hline 17 & Consumptive to sewer rate & $\mathrm{km}^{3} / \mathrm{mo}$ \\
\hline 18 & Normal (minimum) death rate & $\mathrm{ppl} / \mathrm{mo} / \mathrm{ppl}=1 / \mathrm{mo}$ \\
\hline 19 & Famine (maximum) death rate & $\mathrm{ppl} / \mathrm{mo} / \mathrm{ppl}=1 / \mathrm{mo}$ \\
\hline 20 & Birth rate & $\mathrm{ppl} / \mathrm{mo} / \mathrm{ppl}=1 / \mathrm{mo}$ \\
\hline 21 & Demand per capita & $\mathrm{km}^{3} /(\mathrm{mo} * \mathrm{ppl})$ \\
\hline 22 & Transfer efficiency & $\mathrm{dmls}$ \\
\hline
\end{tabular}




\begin{tabular}{|l|c|c|}
\hline 23 & Technology factor & $\mathrm{dmls}$ \\
\hline 24 & Maximum capacity of freshwater supply & $\mathrm{km}^{3}$ \\
\hline 25 & Maximum withdrawal rate & $\mathrm{dmls}$ \\
\hline 26 & Maximum groundwater withdrawal rate & $\mathrm{km}^{3} / \mathrm{mo}$ \\
\hline 27 & Maximum recycling capacity & $\mathrm{km}^{3}$ \\
\hline 28 & Number of reserve months & $\mathrm{mo}$ \\
\hline 29 & Assurance factor & $\mathrm{dmls}$ \\
\hline 30 & Leak to sources time delay & $\mathrm{mo}$ \\
\hline 31 & Nonrecycled to sources ratio & $\mathrm{dmls}$ \\
\hline 32 & Consumptive to sewer ratio & $\mathrm{dmls}$ \\
\hline
\end{tabular}

Table 7: List of Human water system components

\subsubsection{Create a Schematic}

The next step involves the development of a schematic of the listed factors showing the relations among one another. The schematic evolved over a series of drafts, however, began as a simplified schematic of the natural system, Figure 8. Human factors were then added until all research team members were satisfied with the representation of the system. The resulting schematic, shown in Figure 9, served as a roadmap for the digital creation of the COWA model

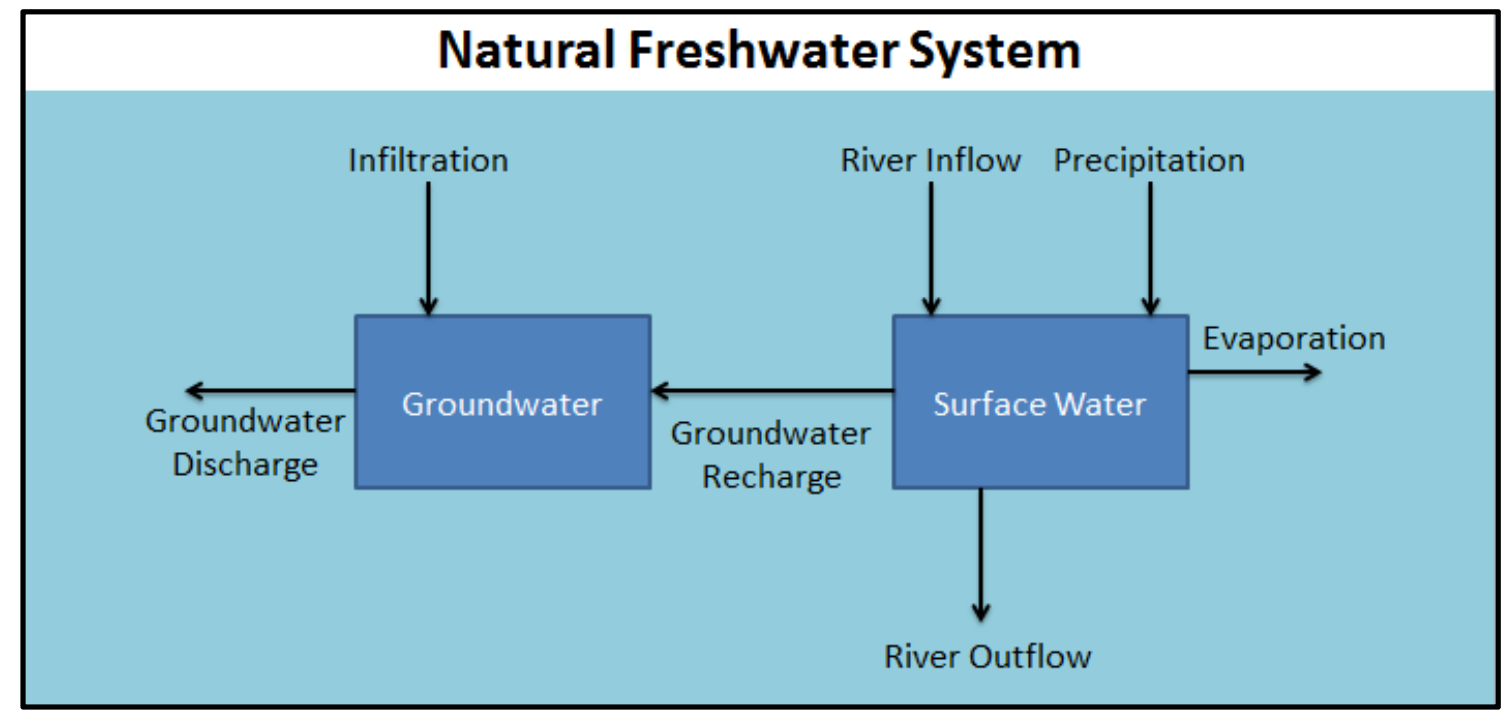

Figure 8: Initial schematic of natural water system

within the Vensim graphical user interface. 
Below, in Figure 9, is the product of several months of collaborative efforts between model developers. The left-most panel of the schematic portrays the natural system, including the primary inflows, precipitation and river inflows, and outflows, evaporation and river outflows. The top of the natural panel indicates the coupling of the UMD/ITCP's SPEEDY GCM and RRM as drivers of the natural system's variable input data. In the bottom left corner of the schematic, sea surface temperatures of the oceans is mentioned as part of the system, as is it a major driving force to the comprehensive hydrologic cycle, however, ultimately, it was not included in the development of COWA, as it was outside the scope of the model's purpose, at this time.

The larger panel on the right side of the schematic portrays the human system. As freshwater sources (i.e., lakes, rivers and aquifers) are fed by the natural system, the human system collects the needed quantity for supply, or possibly surpasses supply storage by collecting rooftop rainwater for direct consumption. The stored freshwater supply is then distributed to the

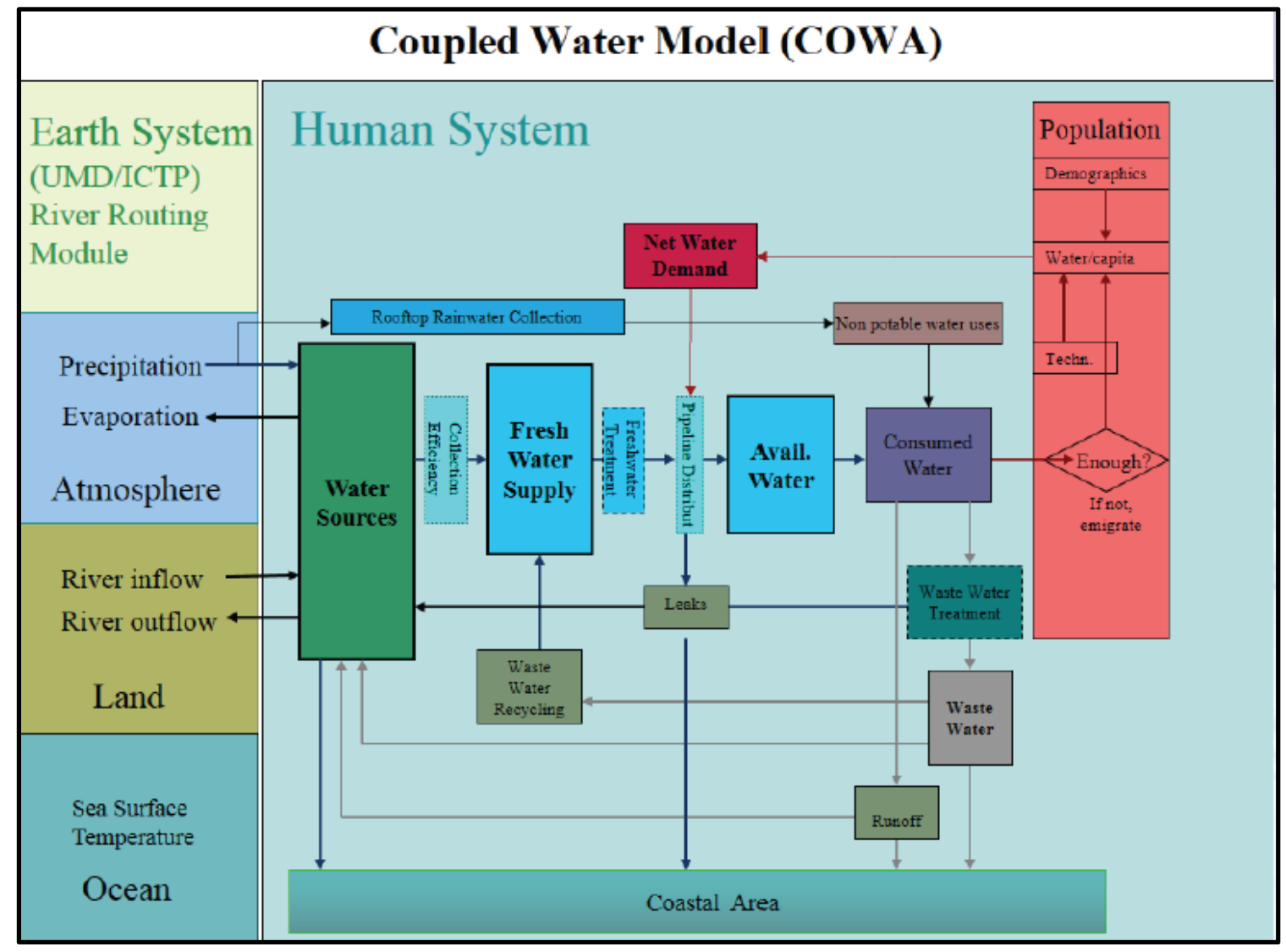

Figure 9: Final version of the COWA model schematic 
population based upon the demand, which is dependent on per/capita demand for basic needs and technological advancement or regression. Water distribution is subject to loss as a result of leakages. When leaks are considered as a loss before consumption that flow back to sources, the actual volume of water available for consumption can then be computed. Finally, consumed water is either treated and returned to sources, returned to sources without treatment or possibly recycled for addition use in supply. The structure of the final COWA schematic assisted in the graphical development of the model in the Vensim program but was not considered a strict blueprint of the system, as the system's refinement was an open process that continued throughout its development.

\subsubsection{Graphical Model Development}

Once these first steps are completed, the process of graphical model development begins. Vensim, the SD modeling software chosen for this research, provides a selection of factor types to begin the GUI drawing process. The options include Stocks (or box variables), Auxiliary variables, Rates (black arrows) and Flows (blue arrows). The natural model was drawn first because of its familiarity to the team members, making it a simpler model to conceptualized, see

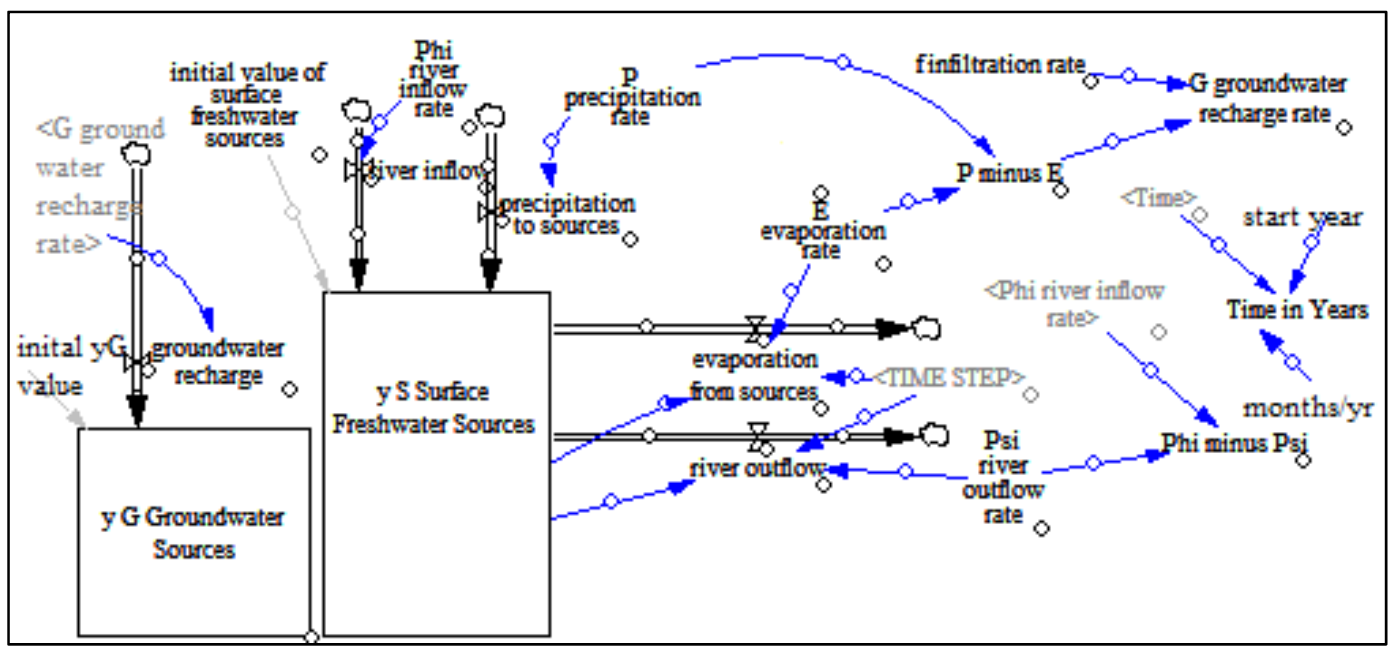

Figure 10: Graphical structure of the natural system in the Vensim program 
Figure 10.

The natural system developed for COWA was composed of two stocks, groundwater and surface water sources. The groundwater sources are fed by recharge flows, which is a function of infiltration, and the surface water sources are fed by river inflow and precipitation. Water flows out of the natural system via evapotranspiration and river outflow of the region.

The human system was less understood and thus required thorough research and deliberation amongst the team before all members were satisfied with its representation of the real system. It was agreed that the human system is fueled by population; therefore a simple population model was a starting point for the human system. From there, the human system was developed further to include technological factors, infrastructure integrity, demand per capita, and all other listed human factors in Table 7. As the human factors began to overlap with the natural factors, the two sides became increasingly integrated until both the natural and human sides of the freshwater system were fully coupled with one another. The model went through several drafts in a two year period until it was finalized in June 2013, as is shown in Figure 11.

From the final diagram of the natural-human water system, notice the natural system located in the top left corner of Figure 11. Freshwater is withdrawn from the two natural stocks, i.e., groundwater and surface water sources, via withdrawal rates. The withdrawal from source stocks feeds the stored freshwater supply stock and is a function of the population stock, both of which are human system stock (box) variables. Various other auxiliary variables are used to help define the other components that govern the stocks and the system as a whole. For example, the population stock is controlled by its relation with birth rate, death rate, net immigration and water availability. However, water availability is controlled by natural inputs (i.e., precipitation, river inflow and recharge), maximum withdrawal capacity, maximum storage capacity, and transfer efficiency, in addition to a few other factors. The structure of the model will be discussed in detail in section 3.2 Model Structure. 


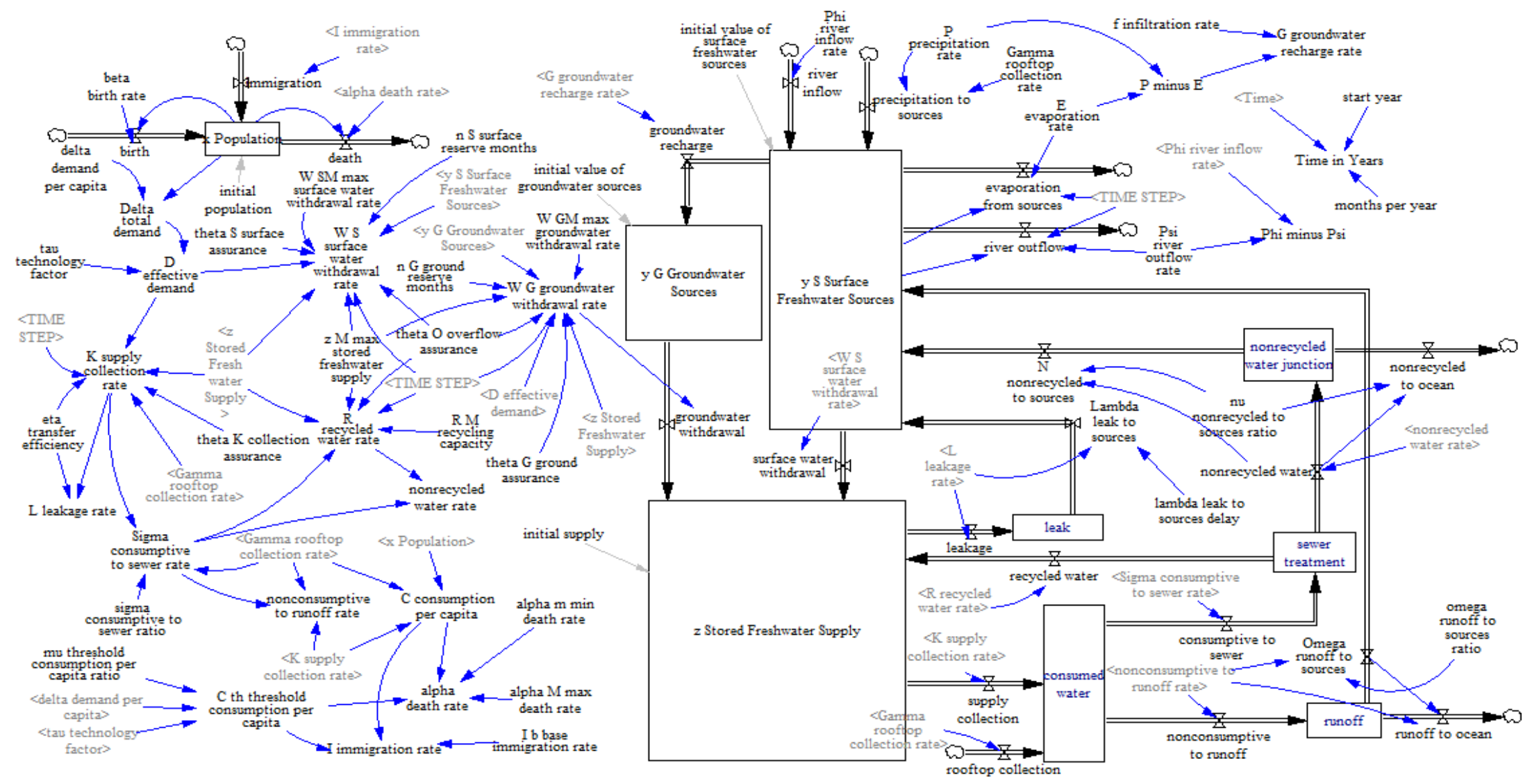

Figure 11: The SD model structure of a Coupled Natural-Human Freshwater Resource Supply system in the Vensim Program 


\subsubsection{Mathematical Definitions}

Following the drawing stages, the model must be mathematically defined in terms of its relations with all interacting components. At the definition stage, all factors represented in the graphical model diagram must be selected and individually defined by an equation or constant value that explains its role in the system. For example, the Population stock is a function of the inflow of births, the outflow of deaths and addition of net immigration (i.e., immigration minus emigration), therefore, population could be defined by the following equation,

$$
\text { Population }=\text { initial population }+(\text { births }- \text { deaths }+ \text { net immigration })
$$

Conversion of the conceptual description to a mathematical definition must be done with all involved variables and rates without any miscalculation of units or illogical formulations, otherwise the Vensim program will not allow the model programmer to continue. Not all factors require an equation, but, nevertheless, will need a mathematical formulation. For example, some variables or rates can be constants, such as any initial values used for the first time step in the system, in which case they will only need a starting value rather than an equation relating them to other influencing factors. Others may require a lookup function where the value is predetermined by a table or graph, previously created by the developer. Below, in Tables 8 and 9 , is a summary of the definitions for the state variables (stocks) and auxiliary variable functions in the model, respectively. Table 10 provides a summarized description of the function parameters. The complete list of model components with mathematical definition, explanations, symbols, units and sources is located in Appendix B. A detailed explanation of these listed relations will be provided in the following section for Model Structure.

\begin{tabular}{|l|l|c|}
\hline Variable Symbol & Variable Name & Governing Equation \\
\hline$X$ & Population & $\dot{x}=\beta x-\alpha x+I$ \\
\hline$y_{S}$ & Surface Water Sources & $\dot{y}_{S}=P-E+\Phi-\Psi-W_{S}+\Lambda+\Omega+N$ \\
\hline
\end{tabular}




\begin{tabular}{|l|l|c|}
\hline$y_{G}$ & Groundwater Sources & $\dot{y}_{G}=G-W_{G}$ \\
\hline$Z$ & Freshwater Supply & $\dot{z}=W_{S}+W_{G}+R-C-L$ \\
\hline
\end{tabular}

Table 8: State Variables (Stocks) used in COWA model

\begin{tabular}{|c|c|c|}
\hline $\begin{array}{l}\text { Function } \\
\text { Symbol }\end{array}$ & Function name & Defining Equation \\
\hline I & Immigration rate & Exogenous \\
\hline $\mathrm{P}$ & Precipitation rate & Exogenous \\
\hline $\mathrm{E}$ & Evapotranspiration rate & Exogenous \\
\hline$\Phi$ & Net river Inflow rate & Exogenous \\
\hline$\Psi$ & Net river Outflow rate & Exogenous \\
\hline$\Gamma$ & Rooftop collection & Exogenous \\
\hline G & Groundwater recharge rate & $=\max (0, f(P-E))$ \\
\hline $\mathrm{W}_{\mathrm{S}}$ & Surface water withdrawal rate & $\begin{array}{r}=\min \left(\theta \frac{y_{s}}{\Delta t}, \theta \frac{z_{M-z}}{\Delta t}, W_{M}-W_{G M}\right) \\
* \min \left(1, \frac{y_{G}+y_{s}}{n D}\right)\end{array}$ \\
\hline $\mathrm{W}_{\mathrm{G}}$ & Groundwater withdrawal rate & $\begin{aligned} &=\min \left(\theta \frac{y_{G}}{\Delta t}, \theta \frac{z_{M}-z}{\Delta t}, W_{G M}\right) \\
& * \min \left(1, \frac{y_{G}+y_{s}}{n D}\right)\end{aligned}$ \\
\hline $\mathrm{K}$ & Supply collection rate & $=\max \left(0, \min \left(D, \theta \eta \frac{Z}{\Delta t}\right)-\Gamma\right)$ \\
\hline $\mathrm{L}$ & Leakage rate & $=\frac{1-\eta}{\eta} K$ \\
\hline $\mathrm{R}$ & Recycled water rate & $=\min \left(\theta \frac{Z_{M}-Z}{\Delta t}, \Sigma, R_{M}\right)$ \\
\hline$\Delta$ & Total demand & $=\delta x$ \\
\hline $\mathrm{D}$ & Effective demand & $=\frac{\Delta}{\tau}$ \\
\hline $\mathrm{C}$ & Consumption per capita & $=(K+\Gamma) / x$ \\
\hline $\mathrm{C}_{\mathrm{th}}$ & Threshold consumption per capita & $=\mu \delta$ \\
\hline A & Death rate & $=\max \left(\alpha_{M}-\left(\alpha_{M-} \alpha_{m}\right)\left(\frac{C}{C_{t h}}\right), \alpha_{M}\right)$ \\
\hline$\Lambda$ & Leak to sources & $=L(t-\lambda)$ \\
\hline$\Omega$ & Runoff to sources rate & $=\omega(1-\sigma)(K+\Gamma)$ \\
\hline $\mathrm{N}$ & Nonrecycled to sources rate & $=v(\Sigma-R)$ \\
\hline$\Sigma$ & Consumptive to sewer rate & $=\sigma(K+\Gamma)$ \\
\hline
\end{tabular}

Table 9: Definition of Auxiliary Variable Functions used in model equations

\begin{tabular}{|l|l|}
\hline Parameter Symbol & Parameter name \\
\hline$\alpha_{\mathrm{m}}$ & Normal (minimum) death rate \\
\hline$\alpha_{\mathrm{M}}$ & Famine (maximum) death rate \\
\hline
\end{tabular}




\begin{tabular}{|l|l|}
\hline$\beta$ & Birth rate \\
\hline$\delta$ & Demand per capita \\
\hline$\eta$ & Transfer efficiency \\
\hline$\tau$ & Technology factor \\
\hline $\mathrm{Z}_{\mathrm{M}}$ & Maximum capacity of freshwater supply \\
\hline $\mathrm{W}_{\mathrm{M}}$ & Maximum withdrawal rate \\
\hline $\mathrm{W}_{\mathrm{GM}}$ & Maximum groundwater withdrawal rate \\
\hline $\mathrm{R}_{\mathrm{M}}$ & Maximum recycling capacity \\
\hline $\mathrm{n}$ & Number of reserve month \\
\hline $\mathrm{f}$ & Infiltration rate \\
\hline$\theta$ & Assurance factor \\
\hline$\lambda$ & Leak to sources time delay \\
\hline$\omega$ & Runoff to sources ratio \\
\hline$\nu$ & Nonrecycled to sources ratio \\
\hline$\sigma$ & Consumptive to sewer ratio \\
\hline
\end{tabular}

Table 10: Description of parameter used in COWA model

\subsection{Model Structure}

The following section discusses the specific structure of the COWA model. The section will begin with a detailed explanation of the four stock variables. Then, the components concerning freshwater demand by the population are identified and their definitions explained. Next, consumption and its link with the efficiency of transfer in the system is discussed, followed by the examination of components concerning the stored freshwater supply. Finally, section 3.2 concludes with an examination of the avenues in which consumed water returns to sources.

\subsubsection{Stocks}

When explaining the model's dynamic structure it is best to first examine the stocks. As previously mentioned, COWA has four state variable, or stocks, including Population $(x)$, Surface 
Water Sources $\left(y_{S}\right)$, Groundwater Sources $\left(y_{G}\right)$, and Stored Freshwater Supply (z). Surface water Sources and Groundwater Sources stocks are considered part of the natural system, while Population and Stored Freshwater Supply stocks are considered part of the human system, yet continuously impacting each other, and therefore, best defined as all part of the coupled humannatural system. However, it is the Stored Freshwater supply stock which serves as the connector between the two systems. The supply stock is where freshwater is extracted from the natural system to feed the human system. All four stocks are defined as differential balancing equations where their stock levels flux with changes in inflow and outflows through time. Below, the governing equations for the four stocks in COWA are defined:

$$
\begin{aligned}
& \dot{x}=\beta x-\alpha x+I(t) \\
& \dot{y}_{S}=\Phi(t)+P(t)-\Psi(t)-E(t)-W_{S}(t)+\Omega(t)+\Lambda(t)+N(t) \\
& \dot{y}_{G}=G(t)-W_{G}(t) \\
& \dot{z}=W_{S}(t)+W_{G}(t)+R(t)-K(t)-L(t)
\end{aligned}
$$

Population (x) is a function of the birth rate $(\beta)$, death rate $(\alpha)$ and net immigration rate (I). The stock grows with the addition of births and positive net immigration and shrinks with

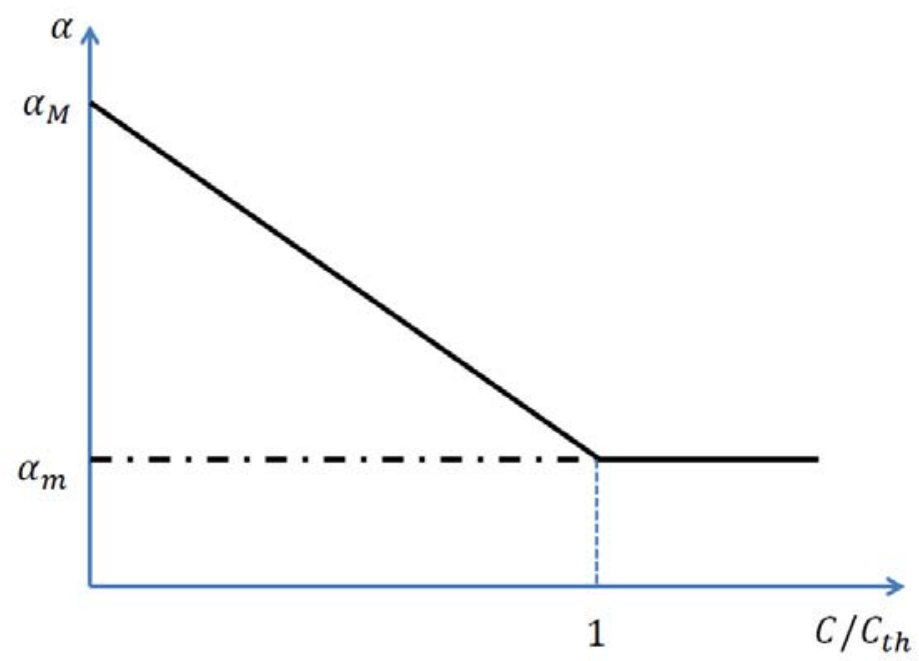

Figure 12: Death rate $(\alpha)$ relation to consumption $(C)$ 
subtraction of death and negative net immigration. While birth rate $(\beta)$ is defined as a constant long term average value, both the death rate and net immigration rate are defined as a function of consumption. Death rate $(\alpha)$ increases when consumption per capita falls below a given threshold value. The consumption threshold is representative of the quantity of freshwater required to meet basic needs. Therefore, the death rate and consumption relation is establishing a dynamic indicating a rise in fatalities when the basic water needs cannot be met, see Figure 12 .

Net immigration rate decreases when consumption falls below a given threshold value. When consumption continues to decrease, net immigration rate becomes negative indicating a shift from immigration to emigration from the region when basic water needs cannot be met, see Figure 13.

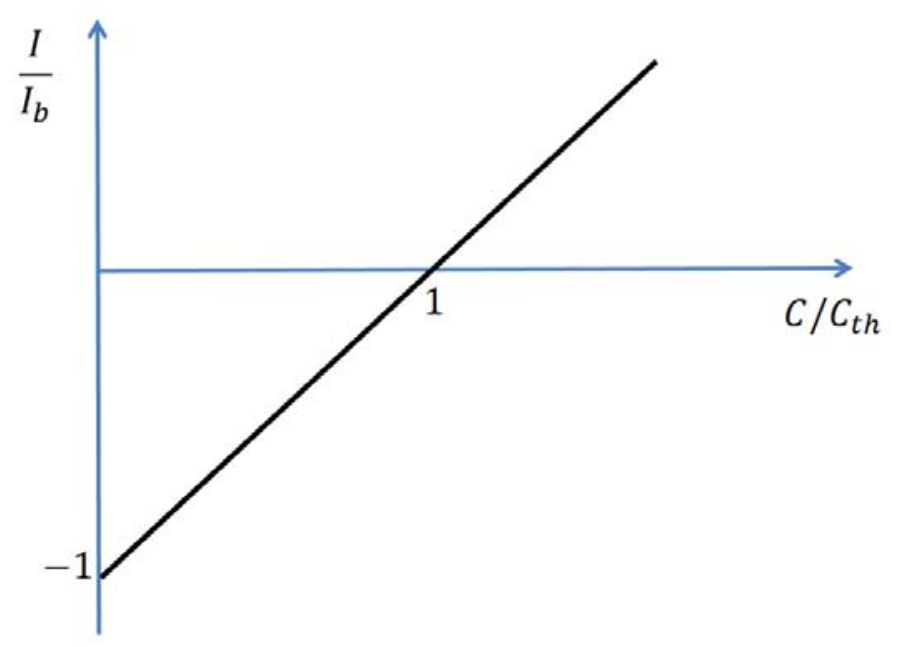

Figure 13: Net immigration (I) relation to consumption (C)

The surface water sources stock, being an open component of the water system, is a function of the inflow and outflow of several variables. Inflow variables include river inflow $(\Phi)$, precipitation $(\mathrm{P})$, leak to sources $(\Lambda)$, flow of non-recycled water back to sources $(\mathrm{N})$, and runoff 
to sources $(\Omega)$. Outflow variables include river outflow $(\Psi)$, evapotranspiration $(E)$, surface water withdrawal to supply $\left(\mathrm{W}_{\mathrm{S}}\right)$, and groundwater recharge $(\mathrm{G})$. The groundwater sources stock, being a more isolated, or closed, component of the water system, is a function of only the incoming groundwater recharge $(\mathrm{G})$ and the outgoing groundwater withdrawal to supply $\left(\mathrm{W}_{\mathrm{G}}\right)$.

The stored freshwater supply stock is driven by three inflows and two outflows; surface water withdrawal $\left(\mathrm{W}_{\mathrm{S}}\right)$, groundwater withdrawal $\left(\mathrm{W}_{\mathrm{G}}\right)$, recycling, $(\mathrm{R})$, supply collection $(\mathrm{K})$ and leakage (L), respectively. Withdrawal from both sources has been defined as a function of maximum withdrawal capacity and the sources' ability to meet demand for a given amount of future reserves, see Figure 14. Demand of future reserves $(\mathrm{nD})$ is defined by the number of desired reserve months (n), which is essentially the number of months reserved will last, and the effective demand (D), which is the total demand of the population given technological influences, this will be discussed further in following sections. The behavior of withdrawal is defined to continuously increase, so long as the source stocks (i.e., $\mathrm{y}_{\mathrm{S}}$ and $\mathrm{y}_{\mathrm{G}}$ ) are less than the desired

\section{Figure 14: Withdrawal relation with maximum capacity of withdrawal, sources and demand of reserves}

amount of water to meet demand stored for future reserves $(\mathrm{nD})$. Withdrawal will increase until it reaches maximum withdrawal capacity $\left(\mathrm{W}_{\mathrm{M}}\right)$ of pumping equipment and infrastructure.

Withdrawal rates are capped by the maximum capacity to withdrawal regardless of level of source stocks or desired reserves. Additionally, added freshwater for human consumption may come from the rooftop collection rate $(\Gamma)$, representative of any rainwater harvesting occurring in the region. However, since this portion of supply is assumed to be directly available for consumption once collected, instead of being withdrawn from sources to feed supply, it bypasses this supply storage part of the system and is deducted from total precipitation when calculating net inflow of water to sources. 


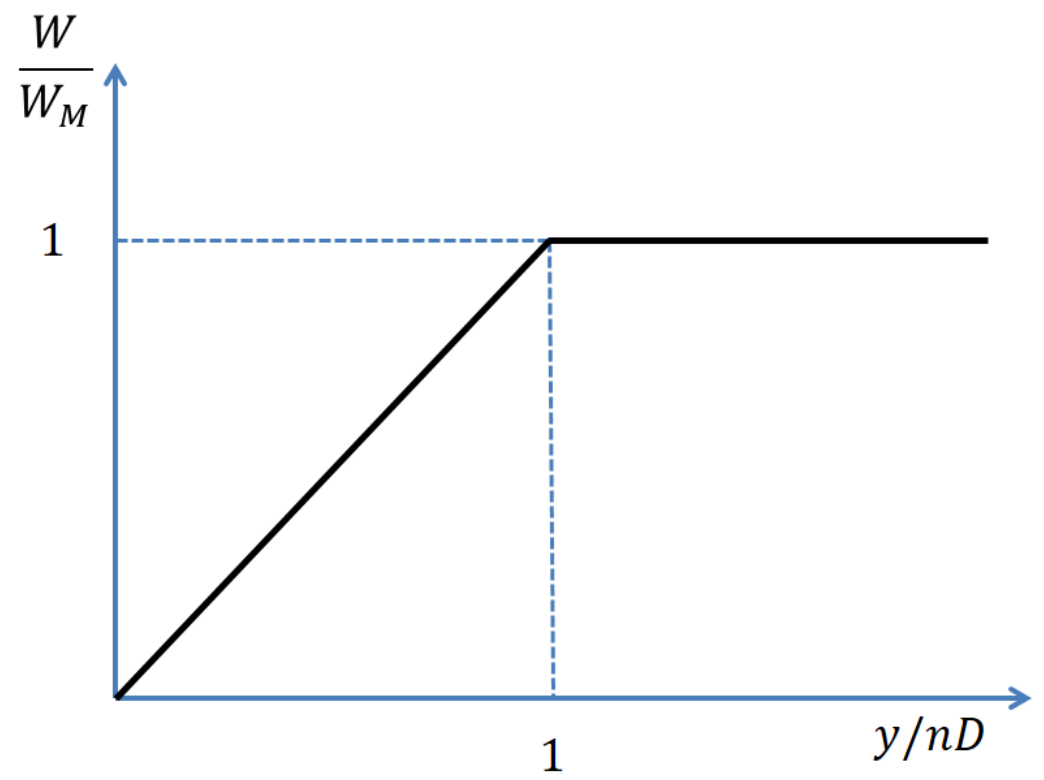


Now that the stocks have been examined, the key assumptions surrounding the model's structure will be addressed here briefly. Coupled to a GCM and RRM, the P, E, $\Psi$, and $\Phi$ variables are exogenous variables which are responsible for forcing the model. However, variables $\mathrm{W}_{\mathrm{G}}, \mathrm{W}_{\mathrm{S}}, \mathrm{K}, \mathrm{R}, \mathrm{L}, \Lambda, \Omega, \mathrm{N}$, and $\Sigma$ are all endogenous, mathematically defined as functions of other parameters and variables within the model. Model parameters include demand per capita $(\delta)$, technology factor $(\tau)$, transfer efficiency $(\eta)$, assurance factor $(\theta)$, maximum withdrawal capacity $\left(\mathrm{W}_{\mathrm{M}}\right)$, maximum groundwater withdrawal rate $\left(\mathrm{W}_{\mathrm{GM}}\right)$, maximum recycling capacity $\left(R_{M}\right)$, and maximum supply capacity $\left(\mathrm{z}_{\mathrm{M}}\right)$. The intertwining and interaction of all these

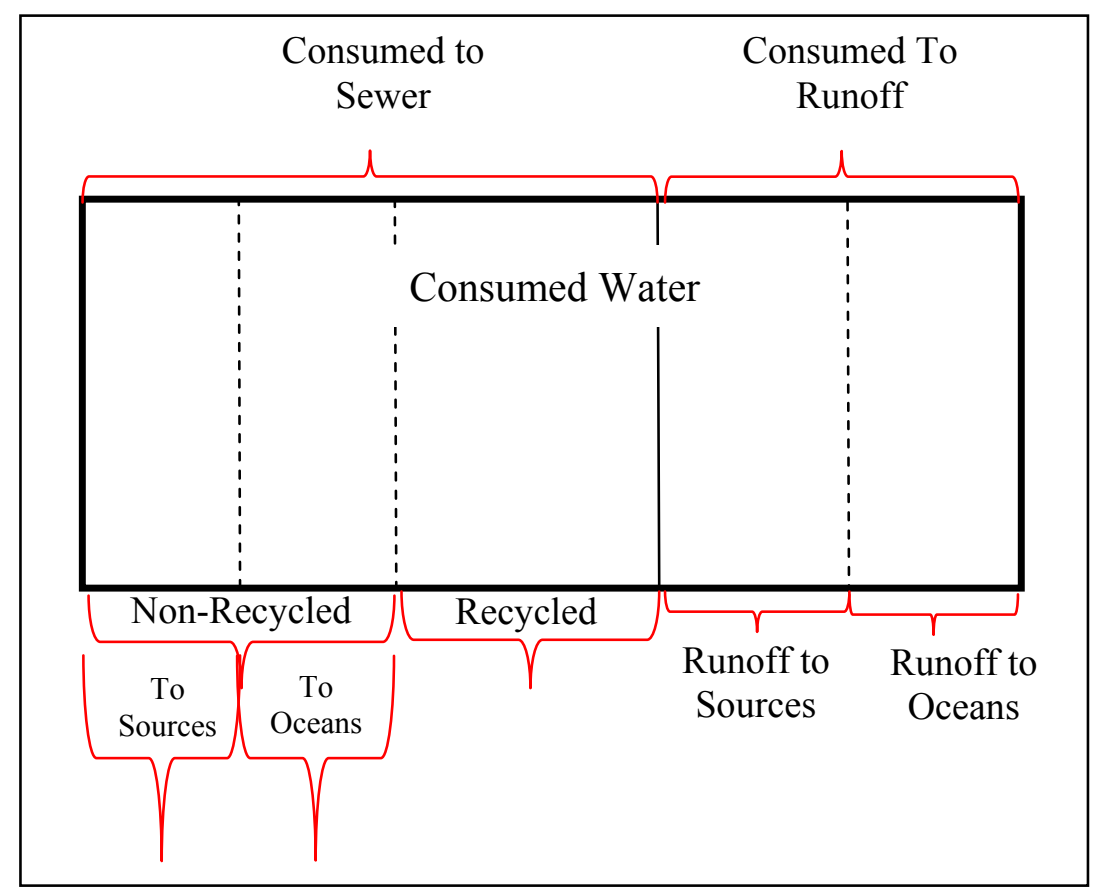

Figure 15: Conceptualization of portioning ratios of consumed water

parameters and variables with each other generate some interesting dynamics. Additionally, the model incorporates three ratios, consumptive to sewer $(\sigma)$, runoff to sources $(\omega)$, and nonrecycled to sources $(v)$ that serve as partitioning fractions. As is shown in Figure 15, consumed water can be portioned out into several avenues. 
Once water is consumed it will flow to and collect in the sewers or it is not collected and it will simply flow as runoff. Consumed water that flows as runoff is assumed to either flow back to ground or surface water sources or flow to oceans. Consumed water flowing to sewers will either become recycled water for reuse into supply or it is not recycled. Non-recycled consumedto-sewer water is assumed to be treated and released back into sources or released into oceans. Finally, COWA operates under the assumption that water diverted from the system because of leakage returns back to groundwater sources after a given time delay $(\lambda)$.

\subsubsection{Demand by Population}

Next, the COWA dynamics surrounding water demand by population will be addressed.

The human system connects to the natural system through the withdrawal process as a function of demand. Total demand, $\Delta(\mathrm{t})$, is given by:

$$
\Delta(t)=\delta x(t)
$$

Where total demand $(\Delta)$ at time $(\mathrm{t})$, is equal to the demand per capita $(\delta)$ multiplied by the population $(\mathrm{x})$ at time $(\mathrm{t})$. However, because different locations around the world may have the same demand per capita but different capabilities of using water because they have better or worse technologies, depending on the situation, the technology factor, $\tau$, is introduced to obtain the effective demand, D. Therefore, effective demand is a reflection of not only the total demand, $\Delta$, but also the technological abilities of system. Effective demand is given by the total demand divided by the technology factor:

$$
D(t)=\frac{\Delta(t)}{\tau}=\frac{\delta x(t)}{\tau}
$$

Technology factor, $\tau$, accounts for water efficient or water intensive appliances, irrigation methodologies, etc. When $\tau=1$, the technology factor represents a base line technology, meaning a standard water use for the current time. For values where $\tau>1$ it represents utilization of water efficient (or water saving) technologies (e.g., drip irrigation and dual flush toilets) 
because for the same number of people and the same demand per capita you would actually have a lesser effective demand when $\tau$ is greater than one. Further, when $\tau<1$ it represents the utilization of water intensive (or water wasting) technologies (e.g., flood irrigation and single stream faucets) because for the same amount of people and demand per capita you would have a greater effective demand when $\tau$ is less than one.

\subsubsection{Collection and Transfer Efficiency}

Water collection and its relation with transfer efficiency of water distribution networks will now addressed. Transfer efficiency $(\eta)$ is essentially a measure of how efficiently water is transported from stored supply to the population for use. In developed region transfer efficiency could represent the structural integrity of the water distribution systems, most often pipelines, and is an indication of water loss as a result of leakages. In undeveloped region transfer efficiency could represent the efficiency of manual transport via physical human labor.

When considering the amount of water consumed by a population as a fraction of the water that is actually collected, it is realized that because there is leakage, there is going to be an efficiency of transfer for what actually gets collected for consumption, K. The leakage dynamic immediately defines the transfer efficiency, $\eta$. Therefore, transfer efficiency is defined through the relation it shares with the supply collection rate in the defining equation of leakages.

$$
L(t)=\frac{1-\eta}{\eta} K(t)
$$

In the above equation, leakages (L) is defined, whereby, if there is a known or estimated efficiency of transfer, then there can be an immediate estimate of how much leakage is occurring and vice versa. 


\subsubsection{Freshwater Supply}

In the following section, the structure of the supply components of the model will now be discussed. There are five flows that drive the supply level including two withdrawals, collection, leakages and recycling, all of which we will examine individually below. The behaviors of these five supply components within the system are defined as:

$$
\begin{aligned}
& W_{S}(t)=\min \left(\theta \frac{y_{s}}{\Delta t}, \theta \frac{z_{M}-z}{\Delta t}, W_{M}-W_{G M}\right) * \min \left(1, \frac{y_{s}+y_{G}}{n D}\right) \\
& W_{G}(t)=\min \left(\theta \frac{y_{G}}{\Delta t}, \theta \frac{z_{M}-z}{\Delta t}, W_{G M}\right) * \min \left(1, \frac{y_{s}+y_{G}}{n D}\right) \\
& K(t)=\max \left(0, \min \left(D(t), \theta \eta \frac{z(t)}{\Delta t}\right)-\Gamma\right) \\
& L(t)=\frac{1-\eta}{\eta} K(t) \\
& R(t)=\min \left(\theta \frac{z_{M}-z}{\Delta t}, \Sigma(t), R_{M}\right)
\end{aligned}
$$

The two withdrawal flows, surface water withdrawal $\left(\mathrm{W}_{\mathrm{S}}\right)$ and groundwater withdrawal $\left(\mathrm{W}_{\mathrm{G}}\right)$, reflect the water that is withdrawn from the respective source and converted into available supply. The withdrawal behaviors have been formulated by defining them in term of the

minimum value of one of three quantities; (1) an assured portion of water in sources $\left(\theta \frac{y_{x}}{\Delta t}\right)$

an assured portion of available supply storage space $\left(\theta \frac{z_{M}-z}{\Delta t}\right)$, and (3) the physical pumping capacity limitation $\left(W_{M}\right)$. The assured portion of water in sources is the amount of water in that source, $\mathrm{y}_{\mathrm{x}}$, at any given month (each time step, $\Delta \mathrm{t}$, is equal to one month), multiplied by the assurance factor, $\theta$. The general idea of the assurance factor is that, $\theta$ is a fractional value, ranging between zero and one, being used as a type of protection parameter. Since it is difficult to know exactly how much water there is in the source at any given time, it is assumed that even with the best estimations, withdrawal will only be a fraction of this approximation. 
The second way to approach withdrawal is from the supply side by considering the assured portion of available storage space for supply. For any given month (one time step), the maximum capacity for supply, $\mathrm{z}_{\mathrm{M}}$, is calculated, minus what is currently already stored, $\mathrm{z}$. The difference will provide the storage space available to take in more water from sources for supply. Additionally the assurance factor is again multiplied by this value to remain consistent with the comparison with the sources.

Lastly, the maximum withdrawal capacity of the system is considered. Imagine water is being extracted from the sources through pipes, pumps and wells. The infrastructure has a maximum capacity that cannot be exceeded. Therefore, maximum withdrawal capacity is a required consideration for the defined behavior of withdrawal. When these three components (i.e., source availability, supply storage availability, and withdrawal ability) are compared, the one with the smallest value is chosen, being the limiting factor of the withdrawal dynamic. The Limiting factor is then multiplied by 1 or, the value of total water in all sources, $\mathrm{y}_{\mathrm{S}}+\mathrm{y}_{\mathrm{G}}$, divided by required reserves, $\mathrm{nD}$, if this value is less than one. The purpose of multiplying by 1 or $\frac{y_{S}+y_{G}}{n D}$ is to avoid over-withdrawals. The required reserves allows for a policy parameter, $\mathrm{n}$, representing a given number of months of stored water reserves. For example, if $n=12$, then the system should have a years' worth of water demands stored in reserves in case of emergency. By dividing the total water in all sources by this required reserved quantity, we are preventing the over-withdrawal from sources. For example, if total water in sources is less than required reserves, then only that fraction of the withdrawal rate will be collected as to not exhaust the resource. However, if total water in sources is greater than required reserves, this fraction will be greater than one and therefore not chosen. Instead, the withdrawal rate will remain the chosen minimum value of the three previously compared components.

Collection, $K$, is driven by the maximum of two values: (1) demand and (2) zero. First, collection is driven by demand. Considering, at any point in time, if water is available for 
demand, then this quantity will be collected as needed, which is what the system defines as effective demand, D. In other words, when water is plentiful in sources, it may be collected at will. Additionally, the potential for a physical limitation to the supply must also be considered. To formulate physical limitation consideration, the effective demand, D, must be compared to the supply available for consumption in any given month, z $(\mathrm{t})$, given an applied transfer efficiency, $\eta$, to account for leaks, and assurance factor, $\theta$, to account for the uncertainty of these

parameters. If the value for the available supply, $\theta_{k} \eta \frac{z(t)}{\Delta t}$, is less than effective demand it must be the chosen value because the system is limited by availability. After choosing the minimum of effective demand or available supply, the rooftop collection, $\Gamma$, from rainwater harvesting is then subtracted because it is being used to alleviate a portion of the demand. The resulting value is then used for the collection rate as long as it is positive. However, if this value is negative, it creates a scenario where the system may not collect water, or $\mathrm{K}=0$. The zero value option is included as a logical rationing component to ensure that if the situation arises where the system is void of water, collection will not ensue.

The leakage component of supply and its linkage with consumption has already been discussed in the above paragraphs. However, in summary, once consumption is determined, leakage can be estimated through the use of approximated transfer efficiency, $\eta$.

Finally, the recycling component of supply follows logic similar to that seen in the withdrawal definitions. The quantity of water potentially available for recycling is the sum of the consumption to sewer rate $(\Sigma)$ however, it is limited by both maximum recycling capacity $\left(\mathrm{R}_{\mathrm{M}}\right)$ and available stored freshwater supply (z).

The amount of water at any given month that can be recycled is the least of three components; (1) an assured portion of available supply storage space $\left(\theta \frac{z_{M}-z}{\Delta t}\right)$, (2) the amount of total consumed water that flows to the sewer $(\Sigma(\mathrm{t}))$, and (3) the maximum recycling capacity 
$\left(R_{M}\right)$. The assured portion of available supply storage space, as defined in withdrawal, is the maximum storage space available minus the current space already in use from supply, for any given month, multiplied by the assurance factor to account for uncertainties. The amount of total consumed water that flows to sewers, $\Sigma$, is formulated by the total collected water, $\mathrm{K}+\Gamma$, multiplied by the consumed to sewer ratio, $\sigma$. The maximum recycling capacity is the maximum possible rate of recycling for the equipment and infrastructure used for wastewater recycling which cannot be exceeded. Finally, all three components are compared and whichever of these has the smallest value will act as the limiting factor, restricting the amount of recycling in that given month to the chosen value.

\subsubsection{Consumed Water Returned to Sources}

The components concerning wastewater returning to sources after consumption will be described in the following section. When water is consumed, a portion of it flows to sewers $(\sigma)$. Once a portion of consumed water flows to sewers, the water could get treated, then recycled if such practices are exercised, and fed back into supply (R), or it could get treated and returned to sources $(\mathrm{N})$, without being recycled for additional supply use. Additionally, the portion of consumed water that does not go to sewer is formulated to be the sum of water collected from sources for supply $(\mathrm{K})$ and rooftop collection from rain harvesting $(\Gamma)$ multiplied by the inverse ratio of what does go to sewer (1- $\sigma)$. The portion which does not go to sewer, instead, flows as runoff and a fraction, $(\Omega)$, feeds back to sources. These above mentioned flows are thereby defined as:

$$
\begin{aligned}
& \Lambda(t)=L(t-\lambda) \\
& \Omega(t)=\omega(1-\sigma)(K(t)+\Gamma(t)) \\
& N(t)=v(\Sigma(t)-R(t))
\end{aligned}
$$




$$
\Sigma(t)=\sigma(K(t)+\Gamma(t))
$$

The water lost through leakages that returns to sources in any given month is effectively the total leakages, $L$, delayed by a time factor, $\lambda$, as mentioned previously in the key assumptions. In other words, the total leakages will return to sources $\lambda$-times later, where $\lambda$ is in units of months.

Of the total consumed water, a portion of it flows to sewers and the remainder is considered to be runoff as it was consumed (typically for irrigation or other outdoor uses) but not rerouted into a sewer network, and, instead, remaining in the environment. Once in the sewer network, the wastewater is either recycled or it is not recycled. In developed regions, nonrecycled wastewater is typically treated and returned to sources. In many undeveloped regions, the treatment process is sometimes not implemented and wastewater is returned directly into the natural resources. However, a portion is also considered to flow to oceans.

The nonrecycled-to-sources ratio, $\mathrm{N}(\mathrm{t})$, is formulated by finding the difference between the amount of consumed water flowing to sewers, $\Sigma(\mathrm{t})$, and recycled water, $\mathrm{R}(\mathrm{t})$, then multiplying this difference by the proportion of nonrecycled water returning to sources, $v$.

The runoff-to-sources ratio, $\Omega(\mathrm{t})$, is formulated as follows. As mentioned before, the total water consumed at any given time is the sum of supply collection and rooftop collection, $\mathrm{K}$ $(t)+\Gamma(t)$. When multiplying by the inverse of the consumed-to-sewer ratio, $(1-\sigma)$, the resulting value reflects the total consumed water that does not flow to sewers, i.e., runoff. Further, only a portion of runoff will return to sources, reflected by the runoff-to-sources ratio, $\omega$, the remainder is considered to flow to oceans. 


\subsection{Data Sources}

Before experimental simulation can begin, several parameters within the model must be researched and estimated to obtain the necessary input data specific to the case study site.

Observations of historical time series data were used to quantify the variables through statistical long-term averages. If data was not available at a monthly temporal resolution, data at lower temporal resolutions, e.g., annual or biannual, were divided by the number of months represented by the data to provide an average monthly value. Additionally, all volumetric quantities are represented in units of cubic kilometers $\left(\mathrm{km}^{3}\right)$ and, therefore, required appropriate conversions for most of the data from various US standard and metric units (e.g., acre-feet or mm). Several variables are defined by long term averages, such as birth rate $(\beta)$, normal (minimum) death rate $\left(\alpha_{\mathrm{m}}\right)$ and net immigration rate $(I)$. Others components are exogenous variables that are coupled to climate and river routing models for better representation, which include precipitation rate $(P)$, evapotranspiration rate $(E)$, net river inflow rate $(\Phi)$, net river outflow rate ( $\Psi)$. Further, many variables are educated estimations based on literature research and knowledge of the system, such as rooftop collection rate $(\Gamma)$, demand per capita $(\delta)$, maximum capacity of freshwater supply $\left(\mathrm{z}_{\mathrm{M}}\right)$, groundwater $\left(\mathrm{W}_{\mathrm{GM}}\right)$ and surface water withdrawal rates $\left(\mathrm{W}_{\mathrm{SM}}\right)$, maximum recycling capacity $\left(\mathrm{R}_{\mathrm{M}}\right)$, and infiltration rate $(f)$.

For the Somalia case study, the majority of the data came from the United Nations (UN) Food and Agriculture Organization (FAO). Under the FAO authority, two Somalia-specific programs have proven most helpful in data acquisition; (1) Somalia Water and Land Information Management (SWALIM) and (2) Food Security and Nutrition Analysis Unit (FSNAU) in Somalia. The primary source of information regarding demography and other social aspects of the model was UNdata, an online data access system for UN databases. The primary source of water management data and environmental information was SWALIM. 
The majority of the data required in the PAMA case study came from United States Census Bureau (USCB), the Arizona Department of Water Resources (ADWR), Arizona Department of Health Services (ADHS), the National Oceanic and Atmospheric Administration (NOAA), Arizona State University (ASU), the United States Geological Survey (USGS) and the National Archives and Records Administration (NARA).

\subsection{Parameters and Exogenous Variable Definitions}

The following section examines the parameters used to define the model's variables as well as the input data for the exogenous variables coupled to the GCM and RRM. A detailed explanation of the mathematical definitions, identification of the data sources, and a catalogue of datasets used in estimations is provided. Following the entirety of section 3.4 is a summary of all parameters and their values used in the baserun of each case study, see Table 16. The baserun simulations generated for this research are representative of base or standard conditions. Further discussion of the baserun simulations is found in Section 5.

\subsubsection{Birth rate $(\beta)$}

The birth rate is defined in this research as a long term average of a series of observed birth rates. The available time series observations were provided as average annual birth rates. Monthly rates were approximated from the annual rates, assuming equal distribution, and the average of this temporal series was then used as the constant birth rate value, in units of deaths per month per population (i.e., $\mathrm{ppl} / \mathrm{mo} / \mathrm{ppl}=1 / \mathrm{mo}$ ), for the model. Limitations and benefits to this method are discussed in Section 4.

Collecting data for the Somalia case study proved relatively difficult as a result of large information gaps existing in most data sources. Therefore, birth rate data were collected for all available years between 1950 and 2013 (United Nations, 2013). The Somalia case study made use 
of 12 data values, for the years with in 1950-2010 because the available information only provided approximate birth rates at 5-year intervals. An additional 18 data values were collected from projected values for years 2015-2100, at 5-year intervals, assuming medium variant (United Nations, 2013).

The PAMA case study made use of 96 data values, one for every year within 1915 2011. The majority of the data came from the Center of Disease Control and Prevention's (CDC) and the United States Census Bureau (USCB). All estimated birth rates for 1915-1925 are averages for registered births in the United States at the given time because Arizona was not admitted to the birth-registration system until 1925. From 1925-1950 data were available for Arizona specifically and from 1950-2011 data were available for the approximated PAMA area, specifically Maricopa and Pinal counties. All estimated population data were provided by the CDC's National Vital Statistics Division (NVSD) and USBC.

The data collected for estimated and projected values of annual birth rates in Arizona from 1915-2011 and in Somalia from 1950-2010 (including projected birth rates through 2100), with their respective sources, can be found in Appendix C.

Since the model runs on a monthly time step, the units for birth rate are represented as people/month*people or $1 /$ month. Therefore, it is assumed that there is even distribution of births throughout the year and each annual average birth rate is divided by 12 months to return the value in the units desired. These mean monthly values are then averaged again to find the long term monthly average for birth rates in the region. The following equation was used to compute the long term average birth rate for this model's input data.

$$
\beta=\frac{\sum_{i=1}^{n} \frac{\beta_{1}}{12}+\cdots \frac{\beta_{n}}{12}}{n}
$$




\subsubsection{Death rate, Minimum and Maximum $\left(\alpha_{m}\right.$ and $\left.\alpha_{M}\right)$}

The death rate $(\alpha)$ defines part of the outflow from the population stock $(\mathrm{x})$. In the COWA model, death rate is defined as a function of three parameters; consumption per capita (C), minimum (normal) death rate $\left(\alpha_{m}\right)$ and maximum (famine) death rate $\left(\alpha_{M}\right)$. When consumption reaches levels below the consumption threshold $\left(\mathrm{C}_{\mathrm{th}}\right)$ value for basic needs, the death rate will increase toward the value of maximum death rate. However, while consumption remains larger than the consumption threshold, the death rate will be held at the minimum death rate. The minimum death rate is considered the normal death rate and is defined in the model as equivalent to the long term average death rate for the region. It was defined in comparison to the maximum death rate which is considered to be the rate of death in times of famine, or when consumption for basic needs cannot be met. The maximum death rate is given by level 3 of a developed famine intensity scale (Howe \& Devereux, 2004), see Figure 16. 
Intensity scale

\begin{tabular}{|c|c|c|c|}
\hline Levels & $\begin{array}{l}\text { Phrase } \\
\text { designa- } \\
\text { tion }\end{array}$ & $\begin{array}{l}\text { 'Lives': malnutrition } \\
\text { and mortality } \\
\text { indicators }\end{array}$ & $\begin{array}{l}\text { 'Livelihoods': food- } \\
\text { security descriptors }\end{array}$ \\
\hline 0 & $\begin{array}{l}\text { Food- } \\
\text { security } \\
\text { conditions }\end{array}$ & $\begin{array}{l}\text { CMR }< \\
0.2 / 10,000 / \text { day and } \\
\text { Wasting }<2.3 \%\end{array}$ & $\begin{array}{l}\text { Social system is cohesive; prices are } \\
\text { stable; negligible adoption of coping } \\
\text { strategies. }\end{array}$ \\
\hline 1 & $\begin{array}{l}\text { Food- } \\
\text { insecurity } \\
\text { conditions }\end{array}$ & $\begin{array}{l}\text { CMR }>=0.2 \text { but } \\
<.5 / 10,000 / \text { day } \\
\text { and } / \text { or } \\
\text { Wasting }>=2.3 \text { but } \\
<10 \%\end{array}$ & $\begin{array}{l}\text { Social system remains cohesive; } \\
\text { price instability, and seasonal } \\
\text { shortage of key items; reversible } \\
\text { 'adaptive strategies' are employed. }\end{array}$ \\
\hline 2 & $\begin{array}{l}\text { Food } \\
\text { crisis } \\
\text { conditions }\end{array}$ & $\begin{array}{l}\text { CMR }>=.5 \text { but } \\
<1 / 10,000 / \text { day } \\
\text { and/or Wasting } \\
>=10 \text { but }<20 \% \\
\text { and/or prevalence } \\
\text { of Oedema }\end{array}$ & $\begin{array}{l}\text { Social system significantly stressed } \\
\text { but remains largely cohesive; } \\
\text { dramatic rise in price of food and } \\
\text { other basic items; adaptive } \\
\text { mechanisms start to fail; increase in } \\
\text { irreversible coping strategies. }\end{array}$ \\
\hline 3 & $\begin{array}{l}\text { Famine } \\
\text { conditions }\end{array}$ & $\begin{array}{l}\text { CMR }>=1 \text { but } \\
<5 / 10,000 / \text { day } \\
\text { and/or_Wasting } \\
>=20 \% \text { but }<40 \% \\
\text { and/or prevalence } \\
\text { of Oedema }\end{array}$ & $\begin{array}{l}\text { Clear signs of social breakdown } \\
\text { appear; markets begin to close or } \\
\text { collapse; coping strategies are } \\
\text { exhausted and survival strategies are } \\
\text { adopted; affected population identify } \\
\text { food as the dominant problem in the } \\
\text { onset of the crisis. }\end{array}$ \\
\hline 4 & $\begin{array}{l}\text { Severe } \\
\text { famine } \\
\text { conditions }\end{array}$ & $\begin{array}{l}\text { CMR }>5=\text { but } \\
<15 / 10,000 / \text { day } \\
\text { and/or_Wasting } \\
>=40 \% \text { and/or pre- } \\
\text { valence of Oedema }\end{array}$ & $\begin{array}{l}\text { Widespread social breakdown; } \\
\text { markets are closed or inaccessible to } \\
\text { affected population; survival } \\
\text { strategies are widespread; affected } \\
\text { population identify food as the } \\
\text { dominant problem in the onset of this } \\
\text { crisis. }\end{array}$ \\
\hline 5 & $\begin{array}{l}\text { Extreme } \\
\text { famine } \\
\text { conditions }\end{array}$ & $\begin{array}{l}\text { CMR > } \\
=15 / 10,000 / \text { day }\end{array}$ & $\begin{array}{l}\text { Complete social breakdown; } \\
\text { widespread mortality; affected } \\
\text { population identify food as the } \\
\text { dominant problem in the onset of the } \\
\text { crisis. }\end{array}$ \\
\hline
\end{tabular}

C.MR: crude mortality rate.

Table 11: Famine Intensity Scale (Howe \& Devereux, 2004)

The Somalia case study made use of 12 data values of average annual death rates for the years within 1950-2010, because the limited available information only provided approximate birth rates at 5-year intervals. An additional 18 data values were collected of projected values (of medium variant) for years 2015-2100, at 5-year intervals. The primary data source for these values was UNdata (United Nations, 2013).

The PAMA case study made use of 211 data values of average annual death rate between years 1900-2011. The data collected for determining the minimum death rate in the Phoenix 
AMA were obtained from the ADHS, CDC and USBC. Data collected from 1900-1925 are national US averages because the state of Arizona was not admitted to the death-registration system until 1926. Then, from 1926-1960 collected data are state-wide averages for Arizona and from 1960-2011 collected data are representative of the PAMA area, specifically Maricopa and Pinal counties. The observed data used to estimate the long term averaged minimum (normal) death rate for both case studies, with their respective sources, are collected in Appendix D.

The minimum death rate is estimated similarly to the birth rate, explained above. Using a long term average, several years of historical, observed annual death rates are collected and their mean is calculated. The observed collected death rate data are assumed to be evenly distributed temporally. Therefore, the annual long term death rate averages were divided by 12 to receive a monthly long term average in units of people/month*people, or $1 /$ month.

$$
\alpha_{m}=\frac{\sum_{i=1}^{n} \frac{\alpha_{m_{1}}}{12}+\cdots \frac{\alpha_{m_{n}}}{12}}{n}
$$

\subsubsection{Base Net Immigration rate $\left(I_{b}\right)$}

The base net immigration rate is defined as the net non-birth population inflow at the initial time step, $\mathrm{t}=0$. The model calculates net immigration rate as a function of the base immigration rate and the availability of consumable freshwater. The net immigration rate is defined as:

$$
I=I_{b} * \frac{C-C_{t h}}{C_{t h}}
$$

In this formulation, net immigration (I) is equal to the base net immigration ( $\mathrm{I}_{\mathrm{b}}$ ) multiplied by a

proportion, $\frac{c-c_{t h}}{c_{t h}}$, representing available consumption. When the consumption is just enough to meet basic needs and there is no difference between consumed water $(\mathrm{C})$ and the consumption threshold $\left(\mathrm{C}_{\mathrm{th}}\right)$, (i.e., $\left.\mathrm{C}=\mathrm{C}_{\mathrm{th}}\right)$, the proportion is equal to zero, thereby equating net immigration to zero as well (i.e., no one is entering or exiting the region). When consumption is double the value 
of the consumption threshold, (i.e., $\mathrm{C}=2 \mathrm{C}_{\mathrm{th}}$ ), the proportion is equal to 1 , thereby, equating net immigration to base net immigration. Likewise, when $C$ is $4 x$ greater than $C t h$, (i.e., $C=4 C_{t h}$ ), the proportion is equal to 2, and the net immigration is double the base immigration. However, when the consumption is more than enough, but not quite double the value required to meet basic needs and there is a positive $(+)$ difference between consumed water and the consumption and the consumption threshold, (i.e., $2 \mathrm{C}_{\mathrm{th}}>\mathrm{C}>\mathrm{C}_{\mathrm{th}}$ ), the proportion is greater than zero but less than 1 , thereby equating net immigration to a fraction of base immigration. Further, the consumption could also be less than enough to meet basic needs, resulting in a negative (-) difference between consumed water and the consumption threshold, (i.e., $\mathrm{C}<\mathrm{C}_{\mathrm{th}}$ ). When consumption falls below the threshold, the consumption proportion falls below 1 and the immigration proportion falls below zero, equating the net immigration to a negative value, indicating a shift from immigration into the region to emigration out of the region.

Base immigration rate is estimated as the long term average of net immigration, as birth rate and minimum death rate were explained previously. This value will almost always be positive as a result of rapid and, generally, steady population growth.

The Somalia case study made use of 11 data values from selective years between years 1962-2012. Projected values of future rates were also collected, assuming a medium variant, at 5year intervals for years 2015-2100. All the data collected were obtained from the UNdata databank.

The PAMA case study made use of 29 data values for annual average net immigration between the years 1981-2010. The collected data are annual averages of net immigration within the PAMA area, specifically Maricopa and Pinal counties. All data values were collected from Internal Revenue Service (IRS) and the U.S. Census Bureau (USCB). All collected data for the Somalia and PAMA case studies, and their respective sources, can be found in Appendix E. 
Data were collected either as net immigration already computed by the source, or as a combination of immigration and emigration information, requiring initial computing to obtain net immigration. For the latter, the outflows (e.g., emigration) were then subtracted from the inflows (e.g., immigration) for every year collected, which gave annual net immigration rates. Since it is assumed that, similar to birth rate and minimum death rate, net immigration rates are evenly distributed throughout the year, the annual net immigrate rates were then averaged over time and divided by 12 to give a base net immigration rate in units of people/month, see equation below.

$$
I_{b}=\frac{\sum_{i=1}^{n} \frac{I_{b_{1}}}{12}+\cdots \frac{I_{b_{n}}}{12}}{n}
$$

\subsubsection{Precipitation rate $(P)$}

The formulation of Precipitation rate (P) evolved over the course of model development. The original definition of precipitation rate was a constant long term monthly average value for every time step. In the Somalia case study, precipitation was defined by a customized lookup graph of 12 long term monthly values, representative of each month of the year (i.e., Jan.-Dec.). Defining precipitation using a lookup graph allowed for simulation of the important impacts of seasonality as the 12 monthly averages cycled through each year. In the PAMA case study, precipitation rate was defined by the forced input data from the coupled GCM, allowing for better representation of the temporal variation from month to month and throughout the years. For benefits and limitations of these methods see Section 4

Precipitation data needed for the Somalia case study were collected from the SWALIM Somalia Climate Technical Report No. W-01. The long-term monthly averages, for each month, from several selective rain gauge stations throughout the region were used to find a national long term average for each month. The estimation was done by first calculating the average monthly rainfall in the first month (i.e., January) from selected station, and so on for the remainder of the months of the year. These values of national long term monthly rainfall averages, by month, 
were then each multiplied by total area of the region to produce a volumetric quantity of monthly rainfall, to receive the desired units, $\mathrm{km}^{3} / \mathrm{mo}$. Using the months of January and December as examples (i.e., Jan and Dec) as an example, the Somalia precipitation rate is defined by the following equations,

$$
\begin{aligned}
P_{J a n}=\frac{\sum_{i=1}^{n} P_{J a n, 1}+\cdots P_{J a n, n}}{n} & P_{1}=P_{J a n} * \bar{A} \\
P_{D e c}=\frac{\sum_{i=1}^{n} P_{D e c, 1}+\cdots P_{D e c, n}}{n} & P_{12}=P_{D e c} * \bar{A}
\end{aligned}
$$

Where, $\mathrm{n}=$ rain gauge station number and values must be found for $\mathrm{P}_{1}-\mathrm{P}_{12}$. The customized lookup graph was then created based off these values. The $12(\mathrm{x}, \mathrm{y})$ points included $\mathrm{P}_{1}-\mathrm{P}_{12}$ as values for $\mathrm{y}$ and the number of the corresponding month of the year as $\mathrm{x}$. The resulting graph defined the value of precipitation rate specifically for each monthly time step, see Figure 17 below. The data used to estimate these values were obtained through SWALIM and provided in Appendix F. Additionally, in the PAMA case study, input data were generated for precipitation rate values by the coupled GCM (Molteni, 2003).

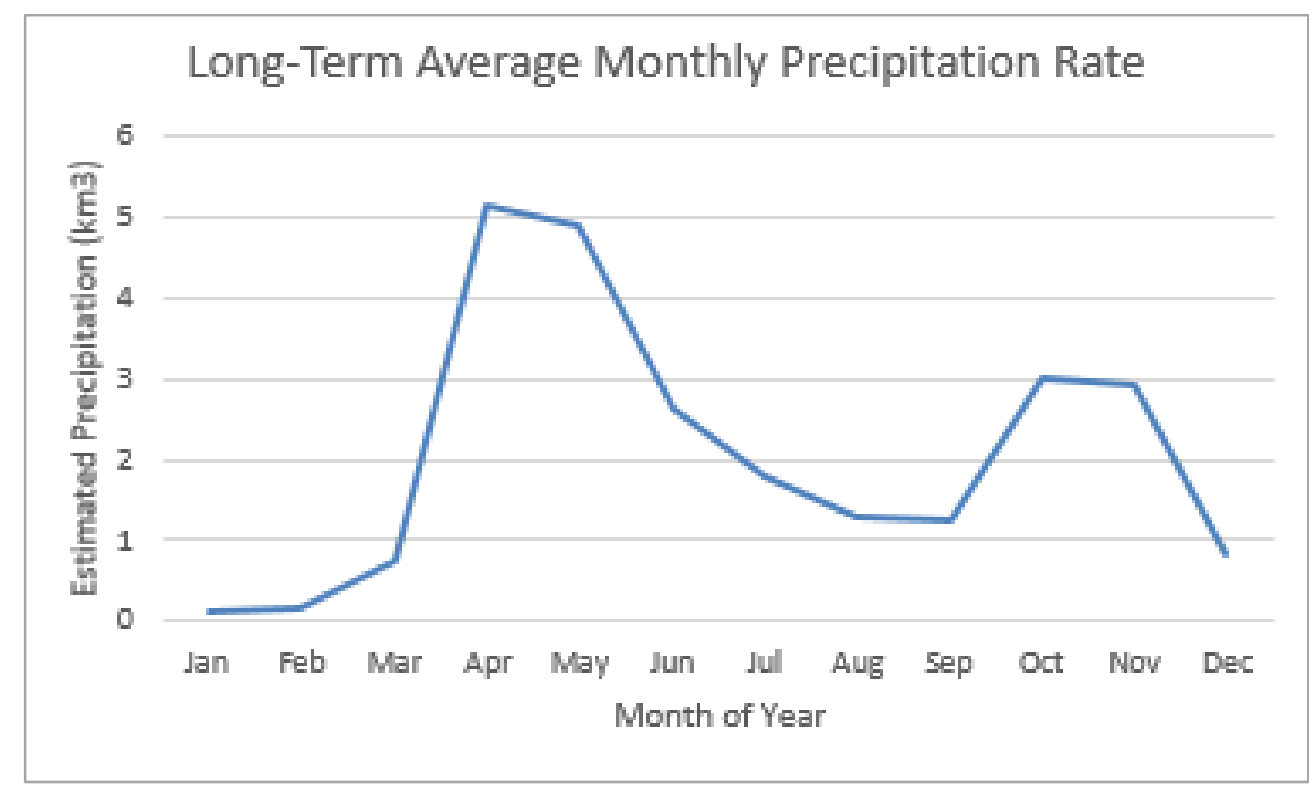

Figure 16: Customized lookup graph for COWA precipitation rate formulation in Somalia case study 


\subsubsection{Evapotranspiration rate (E)}

For the purpose of this model, the evapotranspiration rate $(\mathrm{E})$ is considered an estimation of potential evapotranspiration (PET). The formulation of evapotranspiration rate evolved similarly to the precipitation rate, previously mentioned. The original formulation was a constant value of an estimated long-term average of monthly PET. For the Somalia case study, the evapotranspiration rate was defined by a customized lookup graph of $12(\mathrm{x}, \mathrm{y})$ coordinates. The lookup graph allows for the model to simulate seasonal variation in the variable as the given 12 monthly averages cycle through every 12 time steps. For the PAMA case study, evapotranspiration rate was forced by input data from a coupled GCM.

All evapotranspiration data used in the Somalia case study were obtained from SWALIM Somalia Climate Technical Report No. W-01. Making use of the lookup graph function, E was estimated similarly to $\mathrm{P}$, mentioned in the previous section. Long term monthly averages for several selective rain gauge stations around the region were collected. The national $\mathrm{E}$ was defined with 12 values, estimated by the average of the PET observations from all stations for each month. Using January (i.e., Jan) and December (i.e., Dec) as an example, the following equations were used for the estimations,

$$
\begin{array}{ll}
E_{J a n}=\frac{\sum_{i=1}^{n} P E T_{J a n, 1} \ldots+P E T_{J a n, n}}{n} & E_{1}=E_{J a n} * A \\
E_{D e c}=\frac{\sum_{i=1}^{n} P E T_{D e c, 1} \ldots+P E T_{D e c, n}}{n} & E_{12}=E_{D e c} * A
\end{array}
$$

Where $\mathrm{n}=$ the number of selected PET stations and the long term monthly average (i.e., $\left.\mathrm{E}_{\mathrm{Jan}}\right)$ is multiplied by the area of the region (A) to provide average volumetric PET into the system (i.e., $\left.E_{1}\right)$. The $(x, y)$ coordinates were formulated by the 12 values estimated as $E_{1}-E_{12}$ which are used as the $y$ values, while, the $x$ value is the number (1-12) of the month of the year, see Figure 18 below. 


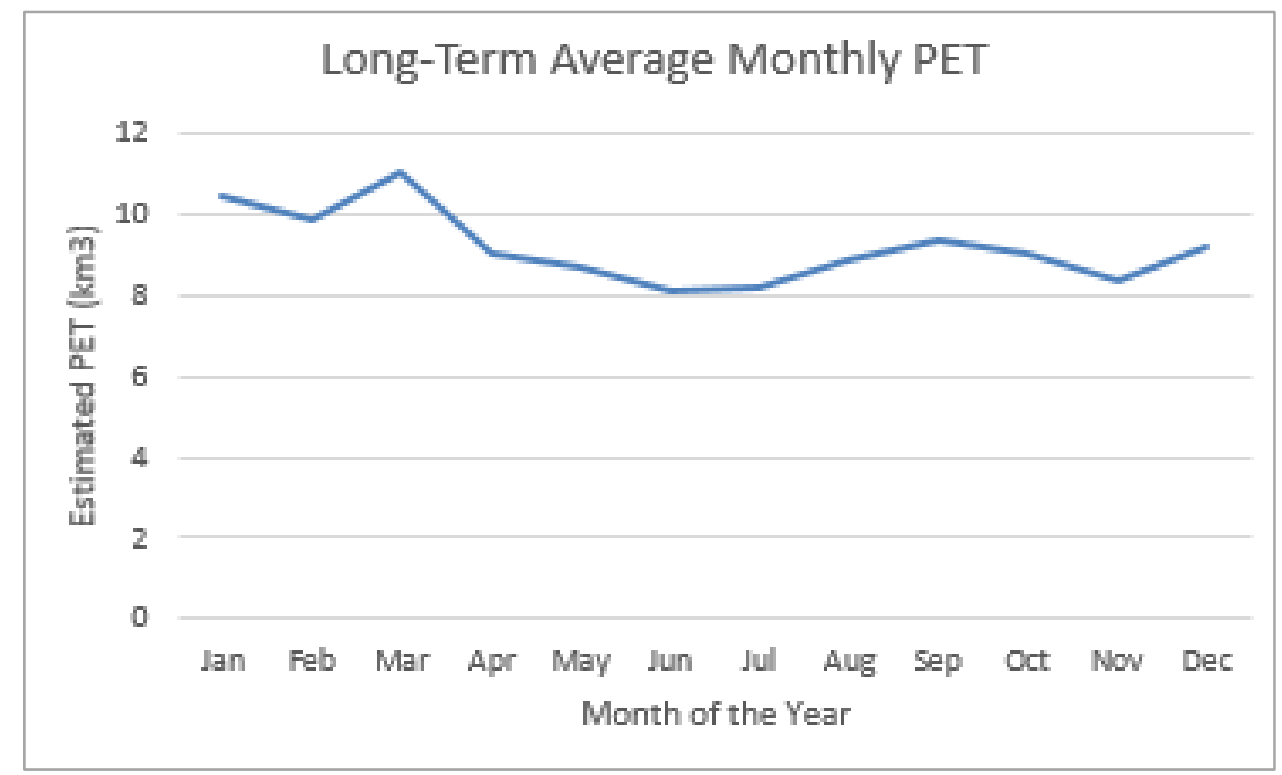

Figure 17: Customized lookup graph for COWA evapotranspiration rate formulation in Somalia case study

Alternatively, for the PAMA case study, in order to capture the seasonal variability of evapotranspiration rates from month to month and between years, the UMD/ICTP SPEEDY model was used to simulate changing E values throughout the year (Molteni, 2003). All evapotranspiration data collected for the PAMA case study were obtained through NOAA and can be found in Appendix G.

\subsubsection{Net river inflow rate $(\Phi)$ and outflow rate $(\Psi)$}

The net river inflow as defined in this model is the sum of all major river discharge flowing into the case study boundaries. Conversely, the net river outflow rate is defined as the sum of all major river discharge flowing out from the case study boundaries. Similar to the other exogenous variables (i.e., Precipitation and Evapotranspiration rates), river inflow and river outflow both evolved from different behavior formulations. The original mathematical formulation, which was used in the Somalia case study, for river inflow and river outflow was a constant value representing the sum of long term average river discharge, from all major river 
networks, into and out of the regions boundaries. In the PAMA case study, the river inflow and river outflow variables are forced by the input data generated by the coupled RRM.

For the Somalia case study, a long term average of total annual river discharge was calculated from historical observations obtained through the SWALIM Project Report No. W-11. Somalia only has two perennial rivers, the Juba River and the Shabelle River, therefore, these are the only inflows and outflows considered in the estimation. Both the Juba and Shabelle rivers enter Somalia in the southern part of the country stemming from Ethiopia, flowing from north to south at Luuq and Belet Weyne, respectively. The river discharge stations closest to the border with Ethiopia are considered the inflow point and the station furthest downstream, closest to the mouth of the rivers expelling into the ocean, is considered the outflow point, see Figure 19. Below, in Table 11, the inflow and outflow values are listed by river and station. The net river inflow and outflow values were then divided by 12 to obtain a monthly estimation. The limitations and benefits of this method are discussed further in Section 4.

With the PAMA case study, a river routing module (RRM) was utilized to more accurately model the net river inflow and outflow temporal variability. The RRM used in the COWA model research was created by Miller, et al. (1994). The Miller, et al. RRM makes use of topographic gradient and runoff factors in addition to being coupled with the GCM mentioned above, in sections 3.2.4 and 3.2.5, in order to simulate more accurate temporal variability of river discharge. There were six major river networks consider for the PAMA case study, one of which is man-made: (1) Gila River, (2) Salt River, (3) Verde River, (4) Agua Fria River, (5) Hassayampa River and (6) Central Arizona Project (CAP). The RMM required input data consisting of historical discharge rates observation at several stations along all considered rivers, which can be found in Appendix H. 


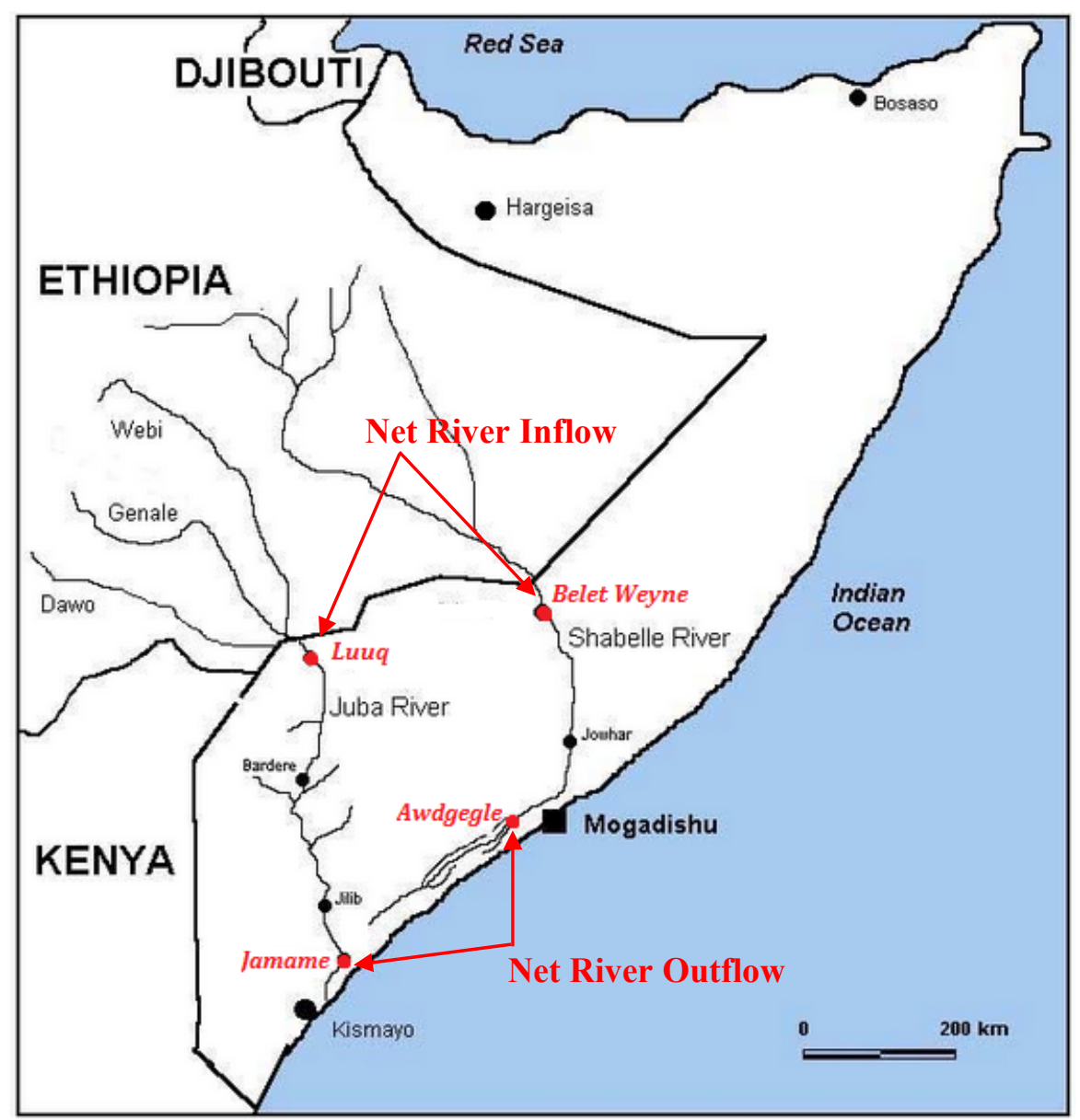

Figure 18: Location of river gauge stations used for data to estimate Net River Inflow and Net River Outflow in Somalia

\begin{tabular}{|l|l|l|l|l|}
\hline \multirow{2}{*}{ River: } & \multicolumn{2}{|c|}{ Inflow } & \multicolumn{2}{c|}{ Outflow } \\
\cline { 2 - 5 } & \multicolumn{1}{|c|}{ Station } & $\begin{array}{c}\text { Discharge } \\
\left(\mathrm{km}^{3} / \mathrm{yr}\right)\end{array}$ & \multicolumn{1}{c|}{ Station } & $\begin{array}{c}\text { Discharge } \\
\left(\mathrm{km}^{3} / \mathrm{yr}\right)\end{array}$ \\
\hline Juba & Luuq & 5.9 & Jamame & 5.4 \\
\hline Shabelle & Belet Weyne & 2.4 & Awdgegle & 1.4 \\
\hline Net: & & $\mathbf{8 . 3}$ & & $\mathbf{6 . 8}$ \\
\hline
\end{tabular}

Table 12: River Inflow and Outflow in Somalia

\subsubsection{Rooftop collection rate $(\Gamma)$}

The rooftop collection rate is defined as the estimated volumetric collection of rainwater from rooftop harvesting efforts to be used for direct consumption. The rooftop collection variable 
is considered to be one of the adjustable human policy factors used to modify the thought experiments. High, low and intermediate estimation for the rooftop collection rate are representative of the community's willingness to adapt to changing freshwater conditions. The value of rooftop collection is a constant monthly value. The following equation was used for the estimation of the value used for rooftop collection rate:

$$
\Gamma(\text { gal. })=P(\text { in. }) * 0.623 * A\left(f t^{2}\right) * R_{\text {coeff }},
$$

where $\Gamma$ (gal.) is the volumetric rooftop collection in gallons, $\mathrm{P}$ (in.) is monthly rainfall in inches, 0.623 is the conversion factor, $\mathrm{A}\left(\mathrm{ft}^{2}\right)$ is the catchment area or in this case the rooftop area, and $\mathrm{R}_{\text {coeff }}$ is the runoff coefficient (Waterfall, 2004). However, further conversions will be needed to receive $\Gamma$ in units of $\mathrm{km}^{3} / \mathrm{mo}$.

Assumptions made for this variable include the amount of participatory community member and the average sized rooftop area. Variable $\mathrm{P}$ is known from the precipitation rate data and $\mathrm{R}_{\text {coeff }}$ is known to be about 0.9 for rooftops (Waterfall, 2004). The catchment area, A, is assumed to be the sum of participatory rooftop areas. For the Somalia case study, it is assumed that the average roof area is about $500 \mathrm{ft}^{2}$, while in the PAMA case study it is assumed to be $2,000 \mathrm{ft}^{2}$. The low estimation assumes none of the community participates in rainwater harvesting, the high estimation assumes $50 \%$ of the population will participate in rainwater harvesting.

\subsubsection{Demand per capita $(\delta)$}

Demand per capita is defined as the average amount of water required to sustain the livelihood of a single individual. Since this variable considers all aspects of livelihood, not just what is required for basic needs (approximately 20 liters per capita per day), the water demands from all sectors, (e.g., domestic, commercial, agriculture, industry), are summed and divided by the population to produce this value. The data used for estimates of freshwater demands by sector for the Somalia and PAMA case studies were obtain from SWALIM and ADWR, respectively. 
For a summary of the freshwater demands by sector for PAMA and Somalia case studies see Tables 12 and 13, respectively, below.

\begin{tabular}{|c|c|c|c|c|c|c|c|}
\hline \multirow{3}{*}{$\begin{array}{c}\text { Yea } \\
\mathbf{r}\end{array}$} & \multirow{3}{*}{$\begin{array}{c}\text { Estimated } \\
\text { and } \\
\text { Projected } \\
\text { Populatio } \\
\text { n }\end{array}$} & \multicolumn{6}{|c|}{ Average Annual Demand (in $\mathbf{k m}^{3}$ ) } \\
\hline & & \multicolumn{3}{|c|}{ Well Pumpage } & \multicolumn{3}{|c|}{ Non-Groundwater ${ }^{3}$} \\
\hline & & Municipal & Industrial & Agricultural & Muni. & Ind. & Agri. \\
\hline $\begin{array}{c}197 \\
1\end{array}$ & & \multirow{5}{*}{\multicolumn{3}{|c|}{2.202}} & \multirow{5}{*}{\multicolumn{3}{|c|}{1.179}} \\
\hline $\begin{array}{c}197 \\
2\end{array}$ & & & & & & & \\
\hline $\begin{array}{c}197 \\
3\end{array}$ & & & & & & & \\
\hline $\begin{array}{c}197 \\
4\end{array}$ & & & & & & & \\
\hline $\begin{array}{c}197 \\
5 \\
\end{array}$ & & & & & & & \\
\hline $\begin{array}{c}197 \\
6\end{array}$ & & \multirow{5}{*}{\multicolumn{3}{|c|}{1.817}} & \multirow{5}{*}{\multicolumn{3}{|c|}{1.324}} \\
\hline $\begin{array}{c}197 \\
7\end{array}$ & & & & & & & \\
\hline $\begin{array}{c}197 \\
8\end{array}$ & & & & & & & \\
\hline $\begin{array}{c}197 \\
9\end{array}$ & & & & & & & \\
\hline $\begin{array}{c}198 \\
0\end{array}$ & $1,471,074$ & & & & & & \\
\hline $\begin{array}{c}198 \\
1\end{array}$ & $1,548,026$ & \multirow{5}{*}{\multicolumn{3}{|c|}{1.576}} & \multirow{5}{*}{\multicolumn{3}{|c|}{1.209}} \\
\hline $\begin{array}{c}198 \\
2 \\
\end{array}$ & $1,624,991$ & & & & & & \\
\hline $\begin{array}{c}198 \\
3\end{array}$ & $1,701,968$ & & & & & & \\
\hline $\begin{array}{c}198 \\
4\end{array}$ & $1,778,957$ & & & & & & \\
\hline $\begin{array}{c}198 \\
5\end{array}$ & $1,855,960$ & & & & & & \\
\hline $\begin{array}{c}198 \\
6\end{array}$ & $1,930,480$ & \multirow{4}{*}{\multicolumn{3}{|c|}{1.570}} & \multirow{4}{*}{\multicolumn{3}{|c|}{1.459}} \\
\hline $\begin{array}{c}198 \\
7\end{array}$ & $2,009,280$ & & & & & & \\
\hline $\begin{array}{c}198 \\
8\end{array}$ & $2,057,140$ & & & & & & \\
\hline $\begin{array}{c}198 \\
9\end{array}$ & $2,135,901$ & & & & & & \\
\hline
\end{tabular}




\begin{tabular}{|c|c|c|c|c|c|c|c|}
\hline $\begin{array}{l}199 \\
0\end{array}$ & $2,150,726$ & & & & & & \\
\hline $\begin{array}{c}199 \\
1\end{array}$ & $2,199,760$ & \multirow[t]{5}{*}{0.277} & \multirow[t]{5}{*}{0.083} & \multirow[t]{5}{*}{0.635} & \multirow[t]{5}{*}{0.644} & \multirow[t]{5}{*}{0.068} & \multirow[t]{5}{*}{0.955} \\
\hline $\begin{array}{c}199 \\
2\end{array}$ & $2,288,101$ & & & & & & \\
\hline $\begin{array}{c}199 \\
3\end{array}$ & $2,350,317$ & & & & & & \\
\hline $\begin{array}{c}199 \\
4\end{array}$ & $2,404,332$ & & & & & & \\
\hline $\begin{array}{c}199 \\
5\end{array}$ & $2,571,732$ & & & & & & \\
\hline $\begin{array}{c}199 \\
6\end{array}$ & $2,675,544$ & \multirow[t]{5}{*}{0.314} & \multirow[t]{5}{*}{0.097} & \multirow[t]{5}{*}{0.641} & \multirow[t]{5}{*}{0.845} & \multirow[t]{5}{*}{0.083} & \multirow[t]{5}{*}{0.920} \\
\hline $\begin{array}{c}199 \\
7\end{array}$ & $2,768,160$ & & & & & & \\
\hline $\begin{array}{c}199 \\
8\end{array}$ & $2,847,060$ & & & & & & \\
\hline $\begin{array}{c}199 \\
9\end{array}$ & $2,948,434$ & & & & & & \\
\hline $\begin{array}{c}200 \\
0\end{array}$ & $3,118,049$ & & & & & & \\
\hline $\begin{array}{c}200 \\
1\end{array}$ & $3,213,086$ & \multirow[t]{5}{*}{0.365} & \multirow[t]{5}{*}{0.110} & \multirow[t]{5}{*}{0.530} & \multirow[t]{5}{*}{0.916} & \multirow[t]{5}{*}{0.091} & \multirow[t]{5}{*}{0.768} \\
\hline $\begin{array}{c}200 \\
2\end{array}$ & $3,307,260$ & & & & & & \\
\hline $\begin{array}{c}200 \\
3\end{array}$ & $3,405,497$ & & & & & & \\
\hline $\begin{array}{c}200 \\
4\end{array}$ & $3,513,969$ & & & & & & \\
\hline $\begin{array}{c}200 \\
5\end{array}$ & $3,650,464$ & & & & & & \\
\hline
\end{tabular}

Table 13: Surface and Groundwater demand in PAMA (ADWR, 2010)

\begin{tabular}{|c|l|l|c|c|}
\hline Somalia & Population & Domestic & Livestock & Agriculture \\
\hline 2007 & $7,500,000$ & 0.087 & 0.084 & 1.333 \\
\hline
\end{tabular}

Table 14: Estimated Surface and Groundwater demand in Somalia (SWALIM, 2007)

\subsubsection{Maximum Capacity of stored freshwater supply $\left(\mathrm{z}_{M}\right)$}


The maximum capacity of stored freshwater supply is defined as maximum potential storage space for freshwater supply, measured in units of cubic kilometers $\left(\mathrm{km}^{3}\right)$. This may include the total volumetric capacity of reservoirs, water towers, tanks, dams or other storage units.

In the Somalia case study, the main supply storage infrastructures include wars and berkads. Regional water storage data are provided by SWALIM Project Report No. W-07 and No. W-11. Estimations are made by multiplying the number of wars or berkads (i.e., count) by the estimated storage capacity to give maximum potential storage capacity for each region of Somalia. Maximum capacity of stored freshwater supply is given by the sum of total storage capacity from each region. The data used from SWALIM literature for these estimations are summarized below, in Table 14.

\begin{tabular}{|c|c|c|c|}
\hline \multirow[t]{3}{*}{ Somaliland } & Type & Count & Estimated Storage Capacity $\left(\mathrm{m}_{3}\right)$ \\
\hline & Wars & 3 & 450,000 \\
\hline & Berkads & 9080 & $2,724,000$ \\
\hline \multirow{3}{*}{$\begin{array}{l}\text { Puntland - } \\
\text { North }\end{array}$} & Type & Count & Storage capacity $\left(\mathrm{m}^{3}\right)$ \\
\hline & Wars & 0 & 0 \\
\hline & Berkads & 51 & 32,640 \\
\hline \multirow[t]{3}{*}{ Central-North } & Type & Count & Storage capacity $\left(\mathrm{m}^{3}\right)$ \\
\hline & Wars & 3755 & $1.13 \mathrm{E}+09$ \\
\hline & Berkads & 53 & 15,900 \\
\hline \multirow{3}{*}{ South-Central } & Type & Count & Storage capacity $\left(\mathrm{m}^{3}\right)$ \\
\hline & Wars & 4 & 92,000 \\
\hline & Berkads & 22110 & $1,216,050$ \\
\hline
\end{tabular}

Table 15: Estimated freshwater supply storage capacity in Somalia, by region and storage type (SWALIM, 2007) (SWALIM, 2007)

In the PAMA case study, several reservoirs and storage ponds are considered the primary supply storage infrastructure. The sum of their combined storage capacities will be the estimated maximum capacity of stored freshwater supply for the region. The data used to estimate this value 
were obtained from ADWR Water Atlas - 8.1 Phoenix AMA and the Salt River Project (SRP) and is summarized below in Table 15 .

\begin{tabular}{|c|c|c|}
\hline \multicolumn{3}{|c|}{ Large Reservoirs (50 acre-feet capacity and greater) } \\
\hline $\begin{array}{l}\text { Reservoir/ Lake Name } \\
\text { (Name of dam, if different) }\end{array}$ & $\begin{array}{l}\text { Maximum } \\
\text { storage }\left(\mathrm{km}^{3}\right)\end{array}$ & $\mathrm{Use}^{1}$ \\
\hline $\begin{array}{l}\text { Lake Pleasant } \\
\text { (New Waddell Dam) }\end{array}$ & 1.367 & $\mathrm{C}, \mathrm{H}, \mathrm{R}, \mathrm{S}$ \\
\hline Theodore Roosevelt Lake & 3.590 & $\mathrm{R}, \mathrm{C}$ \\
\hline $\begin{array}{l}\text { Apache Lake } \\
\text { (Horse Mesa Dam) }\end{array}$ & 0.313 & $\mathrm{R}, \mathrm{C}, \mathrm{H}$ \\
\hline $\begin{array}{l}\text { Canyon Lake } \\
\text { (Mormon Flat Dam) }\end{array}$ & 0.071 & $\mathrm{R}, \mathrm{C}, \mathrm{H}$ \\
\hline $\begin{array}{l}\text { Seguaro Lake } \\
\text { (Stewart Mountain Dam) }\end{array}$ & 0.086 & $\mathrm{R}, \mathrm{C}, \mathrm{H}$ \\
\hline Bartlett Lake & 0.220 & $\mathrm{R}, \mathrm{C}$ \\
\hline Horseshoe Lake & 0.162 & $\mathrm{R}, \mathrm{C}, \mathrm{S}$ \\
\hline C.C. Cragin Reservoir & 0.019 & $\mathrm{~S}$ \\
\hline Tempe Town Lake & $3.510 \mathrm{E}-3$ & $\mathrm{R}$ \\
\hline White Tanks \#4 & $2.775 \mathrm{E}-3$ & $\mathrm{R}, \mathrm{C}$ \\
\hline $\begin{array}{l}\text { Camp Dyer Diversion } \\
\text { (Lower Lake Pleasant) }\end{array}$ & $8.511 \mathrm{E}-4$ & I \\
\hline Fire Bird & $1.628 \mathrm{E}-4$ & $\mathrm{R}$ \\
\hline $\begin{array}{l}\text { Other Smaller Reservoirs } \\
\text { (41 count) }\end{array}$ & 0.001 & --- \\
\hline Stockponds $^{2}$ (711 count) & $8.63 \mathrm{E}-4-0.012^{3}$ & \\
\hline \multicolumn{3}{|c|}{$\begin{array}{l}{ }^{1} \mathrm{C}=\text { Flood Control; } \mathrm{H}=\text { Hydroelectric; } \mathrm{I}=\text { Irrigation; } \mathrm{R}=\text { Recreation; } \mathrm{S}=\text { Water } \\
\text { Supply; “---“" = no data } \\
{ }^{2} \text { all stockponds have } 15 \mathrm{AF} \text { capacity or less } \\
{ }^{3} \text { estimation from approximate minimum and maximum potential storage, data of actual } \\
\text { storage are unknown in source }\end{array}$} \\
\hline
\end{tabular}

Table 16: Freshwater supply storage capacity in PAMA (ADWR, 2010)

\subsubsection{Maximum Groundwater Withdrawal rate $\left(\mathbf{W}_{\mathrm{GM}}\right)$}

The groundwater withdrawal rate is defined as the potential maximum volume of water withdrawn from groundwater sources per month. This variable, $\mathrm{W}_{\mathrm{GM}}$, is an approximated value 
obtained through research of current observed actual withdrawal and pumping capacities of regional wells.

In the Somalia case study, there are two primary types of groundwater pumping infrastructure; boreholes and dug wells. Based on data provided by SWALIM, the maximum groundwater withdrawal capacity was estimated by calculating the total number of boreholes and dug wells and multiplying the count by their respective pumping capacities. The estimated pumping capacity from the information provided in SWALIM was approximately $0.02 \mathrm{~km}^{3} / \mathrm{mo}$. However, according to the FAO Aquastat's Somalia Fact sheet, the total groundwater withdrawn in 2003 was $0.01 \mathrm{~km}^{3} / \mathrm{mo}$. Therefore, the approximated maximum groundwater withdrawal is the average of these two values, $0.015 \mathrm{~km}^{3} / \mathrm{mo}$. The SWALIM data used in the first estimation can be found in Appendix I.

In the PAMA case study, according to local Arizona water law, all users pumping water from the ground must have permitted wells. The required pumping permits have created a large database for registered wells and their pumping capacities. Using data from the ADWR well registry, the total pumping capacity of all registered wells was calculated and converted into units of cubic kilometers per month, $\mathrm{km}^{3} / \mathrm{mo}$. The entirety of the list consisted of 40,712 registered wells and respective capacities. From this data, the total pumping capacities of all registered wells and the estimated maximum groundwater withdrawal rate is $0.73 \mathrm{~km}^{3} / \mathrm{mo}$., rounding to the nearest whole number, the $\mathrm{W}_{\mathrm{GM}}$ variable is approximate $1 \mathrm{~km}^{3} / \mathrm{mo}$. The data used for this estimation can be found in the ADWR's Well registry filtered for the Phoenix AMA Basin, however, a sample of these data is also provided in Appendix I.

\subsubsection{Maximum Surface water Withdrawal rate $\left(\mathrm{W}_{\mathrm{SM}}\right)$}

The maximum surface water withdrawal rate is similar to $\mathrm{W}_{\mathrm{GM}}$ except instead of considering withdrawal from groundwater sources, $\mathrm{W}_{\mathrm{SM}}$ considers withdrawal from surface 
water, i.e., from rivers and lakes. This variable is defined as the potential maximum volume of water withdrawn from surface water sources per month. Surface water withdrawal rate is estimated by the sum of all monthly surface water pumping capacities in the region.

In the Somalia case study, for simplicity and as a result of extensive information gaps, the maximum surface water withdrawal rate is approximately equal to the total surface water withdrawn. The approximate total annual surface water withdrawal for 2003 (FAO, 2014) was divided by 12 months. Therefore, the estimated maximum surface water withdrawal rate is 0.263 $\mathrm{km}^{3} / \mathrm{mo}$.

In the PAMA case study, for simplicity the maximum surface water withdrawal rate is estimated to be equivalent to maximum groundwater withdrawal rate, therefore approximately 1 $\mathrm{km}^{3} / \mathrm{mo}$. This is likely to be a generous estimate however for the sake of time it was considered sufficient to allow maximum groundwater withdrawal capacity to be a reflection of maximum surface water withdrawal capacity. Benefits and limitations to this method are discussed further in Section 4.

\subsubsection{Recycling capacity $\left(R_{M}\right)$}

Recycling capacity is defined as the maximum potential volume of water that can be treated and reused per month. This variable will be limited by the case study's development of water recycling infrastructure, which, in turn is limited by the government's prioritization of water sustainability. The recycling capacity is another adjustable human policy variable used to generate the thought experiments examining both proactive (i.e., relatively large $R_{M}$ ) and indifferent governments (i.e., relatively small or nonexistent $\mathrm{R}_{\mathrm{M}}$ ).

In the Somalia case study, $\mathrm{R}_{\mathrm{M}}$ was estimated to be negligible, thereby equal to zero. This variable is considered approximately zero because very little data were available on water reuse practices in Somalia and it is assumed that as a result of poor financial and political stability recycling infrastructure is very limited. 
In the PAMA case study, $\mathrm{R}_{\mathrm{M}}$ is also considered to be a negligible amount, however, not for the same reasons. Although PAMA is currently very active in water recycling and reuse efforts, these practices are still very new to this region. Since the recycling capacity for present day is only representative of a small portion of time in the total simulation duration, this value is not used in the PAMA baserun simulation. Rather, a value of zero is used to properly represent real system conditions for the majority of the simulation duration time. However, estimated recycled water generation capacity of present day is incorporated into the other thought experiment simulations. The adjusted value for an increased recycling scenario was

approximately $1 \mathrm{~km}^{3}$. The value was estimated by computing the total recycled volume generated in the region and doubling it in order to represent anticipated capacity growth. The data used to adjust this value were obtained through the ADWR and can be found in Appendix J. Benefits and limitations of this method will be discussed further in Section 4.

\subsubsection{Infiltration rate $(f)$}

The groundwater sources stock is fed by groundwater recharge inflow. Groundwater recharge is defined in this model as a function of the infiltration rate. The infiltration rate as defined in this model is a portion of rainfall that is not lost as a result of evapotranspiration. The benefits and limitations of this method are discussed in Section 4. For both case studies, it was assumed that the majority of rainfall not lost through evapotranspiration would infiltrate the ground to eventually become groundwater recharge.

In the PAMA case study, a conservative estimate was used to reflect this parameter. The baserun scenario defines infiltration as only half of the rainfall volume not lost through evapotranspiration. Although it is assumed that the majority (i.e., greater than half) of rainfall not evapotranspired infiltrates the ground to become recharge, equating infiltration to $0.5 *(\mathrm{P}-\mathrm{E})$ we can provide the conservative estimate. 
As a result of Arizona's relatively low natural infiltration rates and highly developed water resource management, artificial recharge efforts have been made to subsidize groundwater supply in the form of Underground Storage Facilities (USFs) and Groundwater Saving Facilities (GSFs), see Figure 20. Underground Storage Facilities are a form of direct artificial recharge by physically pumping or facilitating the infiltration of excess surface CAP water into aquifers. GSFs are a form of indirect artificial recharge which will set aside excess surface CAP water for use towards demands usually met by groundwater. For this model, all USF and GSF recharge rates are not added to the PAMA infiltration rate. The addition of artificial recharge to natural recharge in PAMA gives an additional infiltration rate of $0.144 \mathrm{~km}^{3} / \mathrm{mo}$. See Appendix K for all

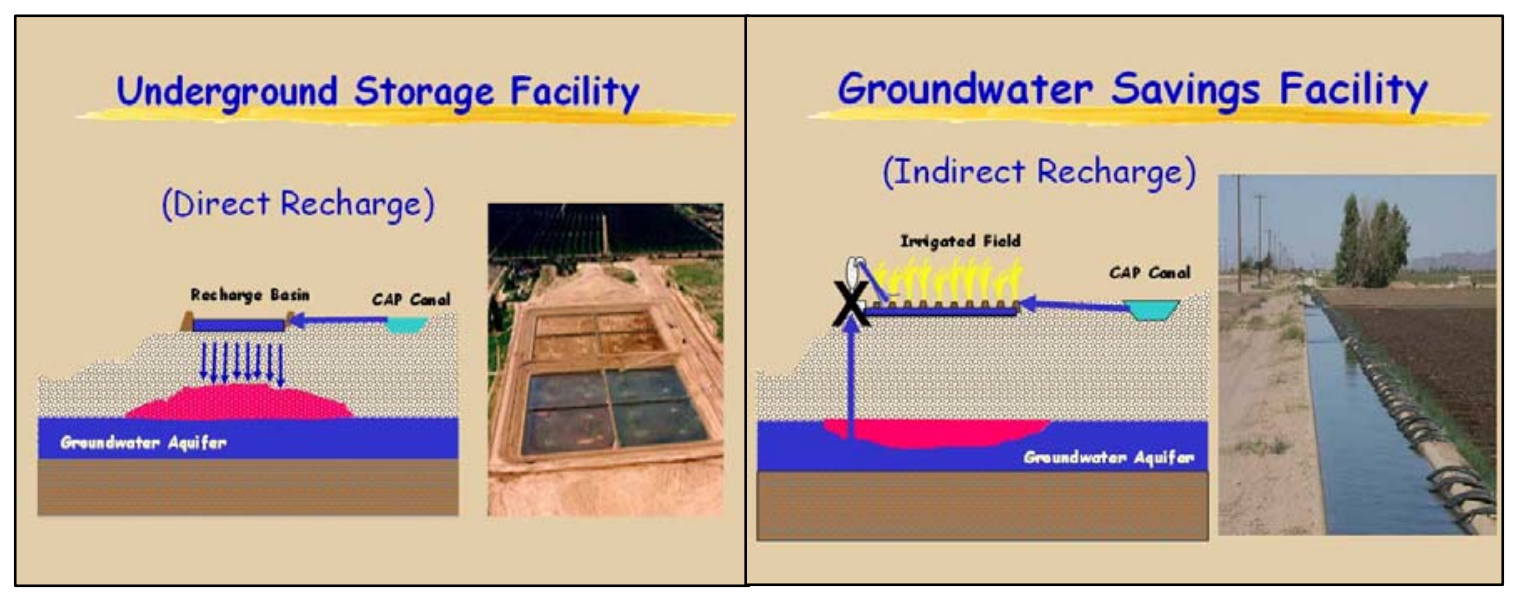

Figure 19: Artificial Groundwater Recharge (AWBA, 2014)

USF and GSF data obtain through ADWR.

Below, in Table 16, is a comprehensive list of all parameter constants used to force the baseruns for both the Somalia and PAMA case studies.

\begin{tabular}{|l|c|l|l|}
\hline Parameter & Symbol & Somalia & Phoenix AMA \\
\hline Birth rate & $\beta$ & 0.0039 & 0.0016 \\
\hline
\end{tabular}




\begin{tabular}{|c|c|c|c|}
\hline $\begin{array}{l}\text { Minimum (normal) death } \\
\text { rate }\end{array}$ & $\alpha_{\mathrm{m}}$ & 0.0012 & 0.0006 \\
\hline $\begin{array}{l}\text { Maximum(famine) death } \\
\text { rate }\end{array}$ & $\alpha_{M}$ & 0.0035 & 0.0035 \\
\hline Base Immigration & $\mathrm{I}_{\mathrm{b}}$ & 0.03 & 3000 \\
\hline Initial Population (year) & $\mathrm{x}_{\mathrm{i}}$ & $1.712 \times 10^{6}(2009)$ & $27,000(1900)$ \\
\hline Rooftop Collection rate & $\Gamma$ & 0.000516 & 0 \\
\hline Demand per capita & $\delta$ & $1.394 \times 10^{-8}$ & $8.3 \times 10^{-8}$ \\
\hline $\begin{array}{l}\text { Stored Freshwater Supply } \\
\text { Maximum Capacity }\end{array}$ & $\mathrm{Z}_{\mathrm{M}}$ & 0.200363 & 5 \\
\hline $\begin{array}{l}\text { Groundwater withdrawal } \\
\text { Maximum Capacity }\end{array}$ & $\mathrm{W}_{\mathrm{GM}}$ & 0.015 & 1 \\
\hline $\begin{array}{l}\text { Surface Water Withdrawal } \\
\text { Maximum Capacity }\end{array}$ & $\mathrm{W}_{\mathrm{SM}}$ & 3.286 & 1 \\
\hline $\begin{array}{l}\text { Recycling maximum } \\
\text { capacity }\end{array}$ & $\mathrm{R}_{\mathrm{M}}$ & 0 & 0 \\
\hline Infiltration rate & $\mathrm{f}$ & 0.85 & 0.50 \\
\hline \multicolumn{4}{|l|}{ Number of reserve months } \\
\hline Groundwater & $\mathrm{n}_{\mathrm{g}}$ & 1 & 60 \\
\hline Surface water & $\mathrm{n}_{\mathrm{s}}$ & 1 & 60 \\
\hline Technology factor & $\tau$ & 1 & 1 \\
\hline \multicolumn{4}{|l|}{ Assurance Factors } \\
\hline Groundwater & $\theta_{\mathrm{G}}$ & 0.2 & 1 \\
\hline Surface water & $\theta_{\mathrm{S}}$ & 0.2 & 1 \\
\hline Collection & $\theta_{\mathrm{K}}$ & 0.2 & 0.1 \\
\hline Overflow & $\theta_{\mathrm{O}}$ & 1 & 1 \\
\hline Transfer efficiency & $\eta$ & 0.63 & 0.85 \\
\hline Initial supply & $\mathrm{z}_{\mathrm{i}}$ & 0.1 & 3 \\
\hline $\begin{array}{l}\text { Initial groundwater } \\
\text { sources }\end{array}$ & $\mathrm{y}_{\mathrm{Gi}}$ & 12300 & 660 \\
\hline $\begin{array}{l}\text { Initial surface water } \\
\text { sources }\end{array}$ & $\mathrm{y}_{\mathrm{Si}}$ & 1.5 & 30 \\
\hline $\begin{array}{l}\text { Consumption threshold } \\
\text { ratio }\end{array}$ & $\mu$ & 0.2 & 0.5 \\
\hline Consumption-to-sewer & $\sigma$ & 0.63 & 0.85 \\
\hline
\end{tabular}




\begin{tabular}{|l|l|l|l|}
\hline ratio & & & \\
\hline Runoff-to-source ratio & $\omega$ & 0.8 & 0.8 \\
\hline $\begin{array}{l}\text { Nonrecycled -to-source } \\
\text { ratio }\end{array}$ & $v$ & 0.9 & 0.5 \\
\hline Leak-to-sources delay & $\lambda$ & 1 & 1 \\
\hline
\end{tabular}

Table 17: Input data for Somali and PAMA case studies

\section{VALIDATION}

The validation of a SD model differs from other types of validation in that it is a continuous and evolutionary process. The general procedure for validating an SD model will be discussed in this section as well as the specific steps taken to validate the COWA model. Further, in order to examine the validation of the COWA model, the initial stages of model development must be revisited to provide a comprehensive view of the validation process, which begins immediately preceding model development.

\subsection{Procedure}

Before the validity of the COWA model is discussed specifically, the validation process of a system dynamics model must be explained, as it is unique to the traditional, more established approaches of model validation used in many other modeling techniques. When most students are taught model validation, it typically involves a reductionist philosophy where the validity of a model is a measure of how accurately the model's output matches empirical observations of the real system (Barlas, 1994). This type of validation generally makes use of standard statistical tests, such as hypothesis testing, to give a numerical value of accuracy, thereby quantifying its validity. However, this traditional statistical validation method is not the procedure when judging the validity of a system dynamics model. As a result of the nature of SD models, such testing is either only supplementary or sometimes inappropriate for SD validation (Forrester \& Senge, 1980). To completely understand the contrasting processes some important concepts must be defined first. 
First, the validation of a model can be defined as "establishing confidence in the usefulness of a model with respect to its purpose" (Barlas, 1994). Such confidence building comes as a result of much testing. In this context, testing is meant as "the comparison of a model to empirical reality for the purpose of corroborating or refuting the model" (Forrester \& Senge, 1980). Further, "empirical" should be understood as "derived from or guided by experience or experiment" (Random House Unabridged Dictionary, 1994), thereby, acknowledging that empirical information used for testing may take forms other than numerical statistics (Forrester \& Senge, 1980).

Where as many traditional numerical models aim to predict or forecast, a SD model is intended to teach the user about the system's internal and external relationships, (i.e., the system's dynamics). Therefore, confidence in an SD model's validation can be accumulated through the testing of the model's structure, behaviors and policy implications (Forrester \& Senge, 1980). As a result of the potential possibility that a simulation could generate results that match

observations, yet the structure may still be falsely representing the real system, structural validity must be priority over behavior validity.

The SD validation is a cumulative process that extends throughout the development of the model, beginning with system conceptualization and ending in policy change simulations. However, the majority of what is considered 'formal' SD validation occurs between the construction of the model and proposals of policy experiments. A diagram demonstrating the overall nature of formal validation if provided in Figure 21, below.

\subsubsection{Formal SD Validation}

In this section, the focus will be only on the 'formal' validation process. Formal SD structural validation includes theoretical validation and empirical validation. Empirical validation involves comparing the model's structure to knowledge of the real system. Theoretical validation involves comparing the model's structure to generalized knowledge produced from research of published 
literature. Further, structural validity can be tested directly and indirectly. The direct structure tests involve analysis of the individual equations while structure-oriented behaviors tests involve the indirect analysis of structure through assessment of the model's behavior.

In this research, direct theoretical testing and direct empirical testing were completed using

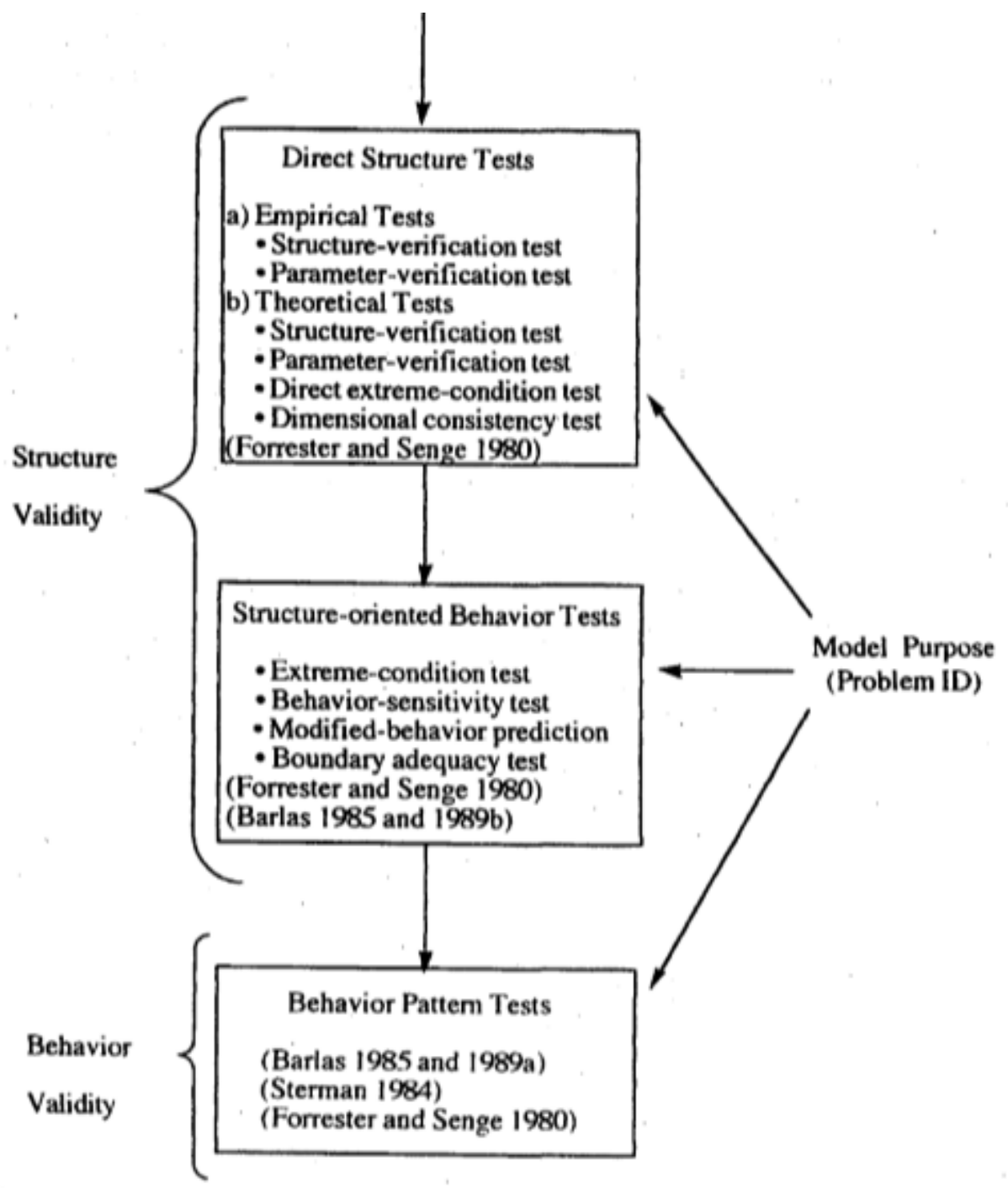

Figure 20: Structure of formal validation process for SD models (Barlas, 1994)

structure-verification and parameter-verification tests. The model developer initiates the direct theoretical validation process by establishing confidence in the model's structure through the comparison of their well-researched knowledge of the system. Once the model developer is 
sufficiently confident in the model's structure, it is necessary for an expert, outside of the model developer(s), to judge how appropriately the model represents the real system. This dualjudgment of the model facilitates a communication process that is essential to the SD validation process. The model developer must be able to successfully transfer their confidence to a target audience, otherwise the model's potential to enhance understanding and aid in more effective decision-making will be ineffective.

In this stage of the COWA research development, we will be focusing on the structure and parameter validation. Formal behavior validation is anticipated to be completed as part of the next stage of continued COWA research. However, an initial behavior analysis of the 9 experimental simulations will be discussed in Section 5 of this thesis.

\subsection{Initial Testing}

As mentioned previously, the validation process begins immediately after model development. Therefore, revisiting the initial development of the COWA model is necessary to fully discuss the validation process.

When COWA was first developed in the summer of 2011, it began as a much simpler version of what it is today. The surface water and groundwater sources stocks were combined into a singular Freshwater Sources stock. Rooftop Collection was not a consideration. Assurance Factors were not implemented. The coupling of precipitation and evapotranspiration to the GCM and the coupling of river inflows and outflows to the RRM was not yet applied. The relations between death rate and immigration rate to a consumption threshold were not established, in fact, the consumption threshold was not even considered in the system. Further, many of the mathematical definitions were not as they are defined today. Below, in Figure 22, is a screen shot of the initial COWA model presented as a comparison to the final product shown earlier in Figure 11 from section 3.1.3 Graphical Model Development. 

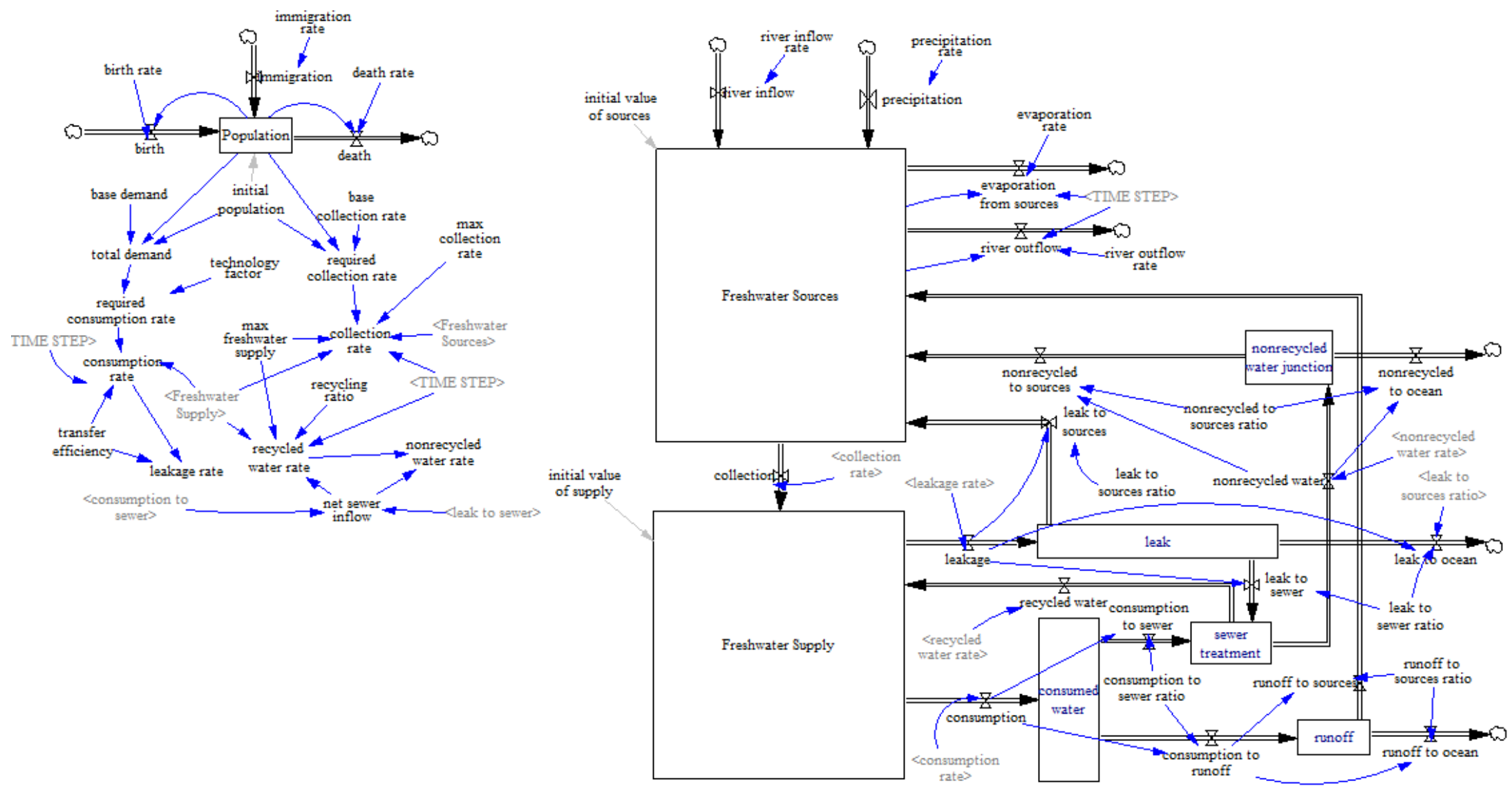

Figure 21: Original version of COWA in Vensim, compared with final version 
As can be seen in the above image, the model began as a generalized version of the current COWA model. However, all research must start somewhere. The initial simulation runs left much to be desired. Most scenarios reflecting water-scarce conditions resulted in a collapse of the system. At the time, the system was defined without the protection of assurance factors nor any rationing logic and therefore most simulated runs produced a "saw-toothed" behavior pattern for sources. In times of water scarcity the system was allowed to completely use up all water present in sources at any given time. In the next time step sources were partially and temporarily replenished before immediately being used by the population in the following time step. This repeating pattern produced the "saw-tooth" behavior seen below in Figure 23, and was considered

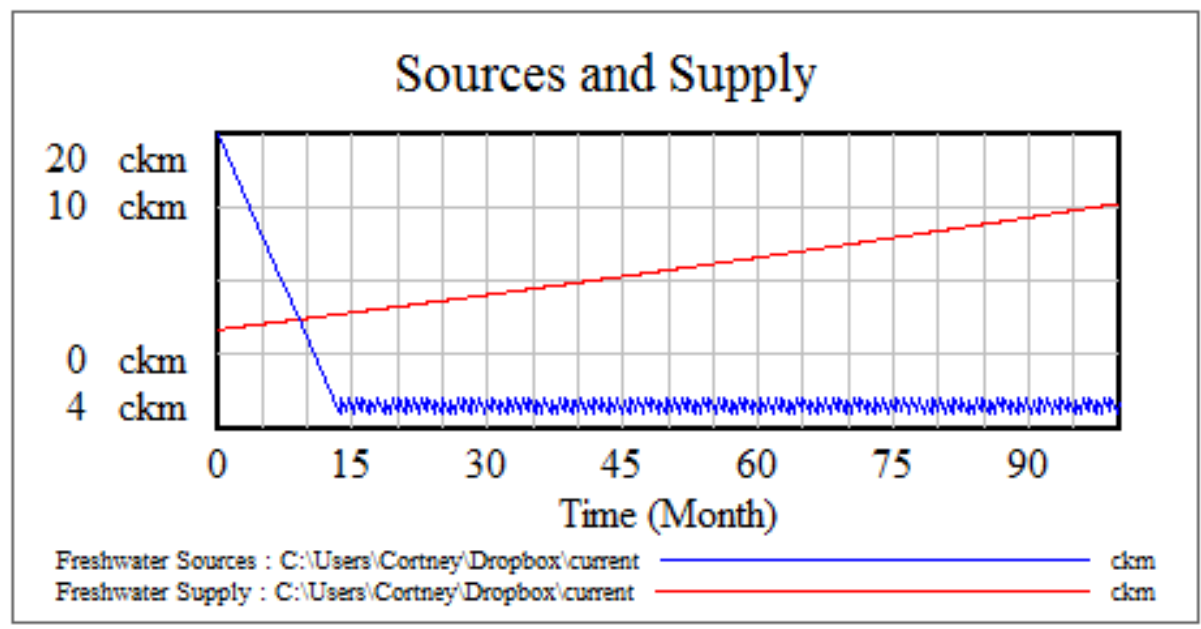

Figure 22: Saw-toothed behavior of sources

to be a collapse of the system, as it remained unstable until the end of the simulation.

An initial case study considering the contiguous United States was completed in the beginning stages of model development prior to any other case studies. The simulations generated for the US case study proved to show serious errors in the model, yet, were considerably enlightening toward the model's spatial resolution capacity. Despite extreme manipulation of the system's natural freshwater inflows, (e.g., precipitation and river inflow), 
impacts on supply collections were negligible. Such observations of the system's behavior led to the hypothesis that the system was not sensitive enough to identify special differences in water supply at a continental spatial scale. Surely some parts of the United States will not feel impacts of water scarcity as much as others (i.e., Great Lakes regions vs. Midwest regions). An example of the resulting output from the US case study is shown in Figure 24. The results portrayed in Figure 24 were generated from a scenario where there was no rainfall inflow, $\mathrm{P}=0$. The results from this case study supported a watershed or regional approach, where local causes will have effects, rather than simulating at a continental extent.

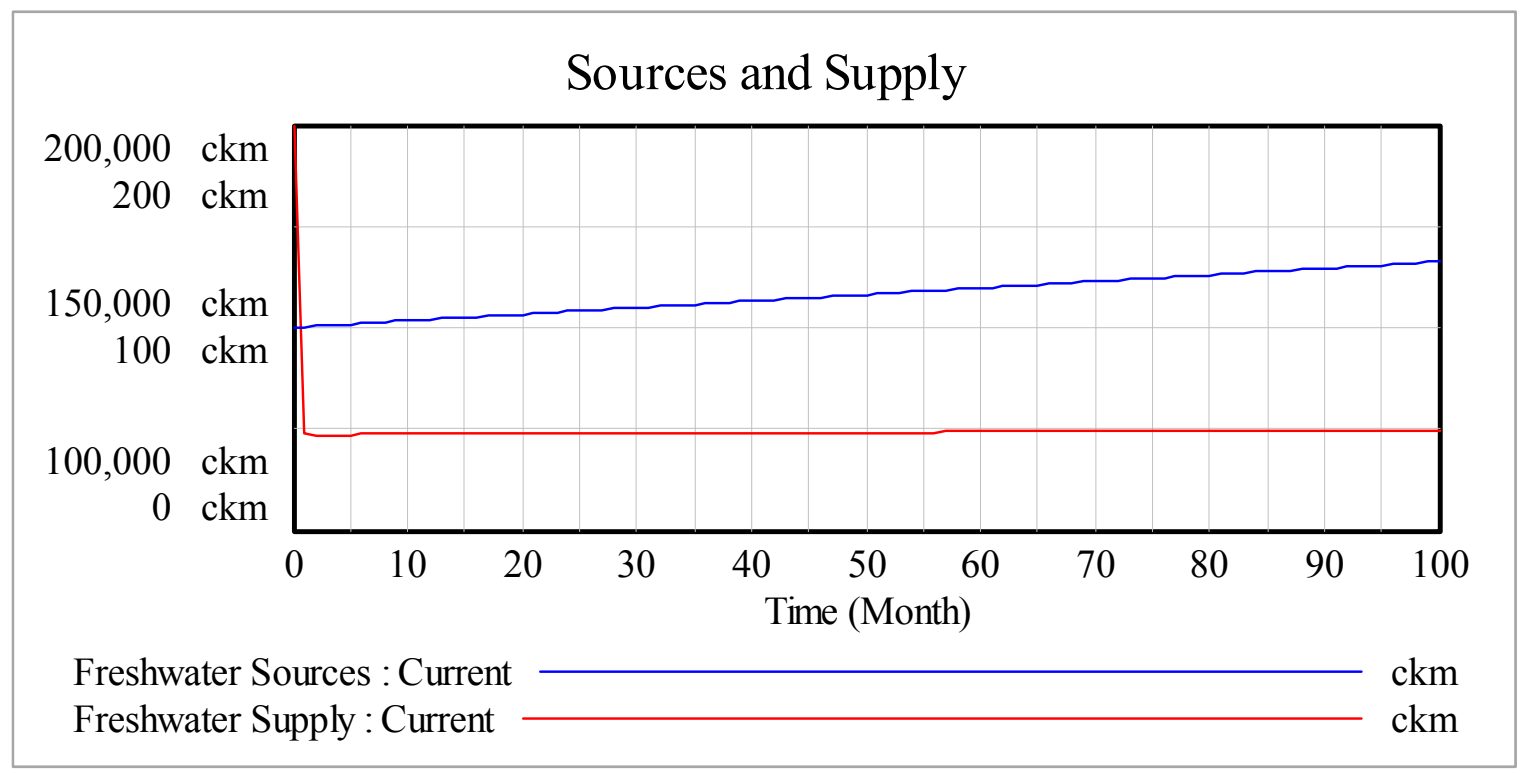

Figure 23: The US case study simulated output of sources vs. supply stocks

Additionally, the original US case study simulation results lacked temporal variation in the exogenous variables precipitation, evapotranspiration, and net river inflow and outflow. As previously mentioned, $\mathrm{P}, \mathrm{E}, \Phi$, and $\Psi$ were all originally defined by a constant long term average value. Allowing these components to be defined by a constant value was eliminating the model's ability to simulate seasonality. The temporal variation and seasonality of these variables was recognized as an important dynamic that needed revaluation of its structural role in the system. For the purpose of the COWA model, a constant value was an insufficient definition. Therefore, 
model developers designed a new definition using a lookup function, then further coupling these to the RRM and GCM.

\subsection{Final Testing}

In this section, the theoretical and empirical, direct and indirect, structure- and parameterverification tests will be discussed as they are applied to the final version of the COWA model, used to simulate the PAMA case study scenarios.

\subsubsection{Structure-verification test}

To perform a structure-verification test, the model's structure must be compared to the real system's structure. First, the assumptions and relationships defined in the equations defining the system variables must be identified because these will be the subjects of comparison. For a list of all structural components, their defined equations and equation explanations, please see Appendix L. Once these assumptions and relations have been identified, the model builder must use knowledge gained from literature of the real system to compare and validate the structure. To begin this testing we will first look at the four state variables, population, groundwater sources, surface water sources and stored freshwater supply.

\subsubsection{Population}

The population stock is structured to assume two inflows, births and net immigration, and one outflow, deaths. Net immigration, as explained previously, includes the net value of domestic and international immigration and emigration. However, both net immigration and deaths are assumed to be tied to consumption per capita. Working under the understanding that when freshwater demands for basic needs cannot be met, those whom can leave the region will leave and those whom cannot leave the region will die. Validation for this understanding came from the empirical evidence seen in Somalia as well as published literature.

Validation for the first structural assumption comes from the population balancing equation which stands as the most basic approach for determining population change through 
time (Population Reference Bureau, 2011). Validation for the second assumption, that population decline will occur through migration and deaths as a result of insufficient water supply, comes from empirical evidence seen in various case studies including Somalia (1992 \& 2011) and the widely adopted theory of the animal response to fight or flight, first suggested by Walker Bradford Cannon. By this theory, when faced by a threat it is animal nature to stay and fight or leave and flee. This is the rational used for this second assumption. When people are faced with conditions where basic water needs are not met, they will either migrate to water rich regions (flight) or they will stay (fight) in hopes of better conditions. However, staying is risky. If water

supply is not increased and continues to fall short of the basic need minimum, deaths will begin to increase as a result of the average human body's ability to last only 3-5 days without any water.

\subsubsection{Ground water sources}

The Groundwater source stock is defined by only one inflow, recharge, and one outflow, groundwater withdrawal. Further, the recharge flow is defined by infiltration rates, precipitation and evapotranspiration; therefore, these are also included in groundwater source stock definition indirectly. The version of Vensim used in the model's development unfortunately lacks the ability to model spatial differentiations. Therefore, an average infiltration rate for the entire region is used. It is acknowledge that this is an oversimplification of the groundwater system, however, at this stage of model development and for the purpose of this model it is consider appropriate. Given the B\&R aquifer description, provided above in section 2.3.2, is was deemed appropriated to reduce inflows and outflows to a function of net precipitation (removing loss from evapotranspiration), and groundwater withdrawal, respectively. The recharge for this aquifer is primarily derived from precipitation in the mountainous surrounding regions, interbasin flow is not a significant component and withdrawal and evapotranspiration are the primary discharge components (Robson \& Banta, 1995). It is also acknowledged that changes in land use, land cover and soil types across the region will cause for infiltration rate changes, however, these 
infiltration rate dynamics will not be able to be modeled at this time but is expected to be done in newer versions of Vensim, as GIS coupling becomes an improved feature to the software in the future.

\subsubsection{Surface water sources}

The surface water source stock is also defined in the form of a budgeting equation. The change in the stock value is equivalent to the difference between the inflows and outflows through time. The inflow components for the surface water source stock include precipitation, river inflow, leaks to source, runoff to sources, and non-recycled water to sources. The outflow components include evapotranspiration, river outflow and surface water withdrawals. Surface runoff values are also accounted for within the RRM and included as part of the total river inflows and outflows. Although it is acknowledged that a component to account for base flow is missing, it was decided to keep this component from the equation for two reasons. First, the Arizona aquifer is very deep and base flow in this region is very small. Second, base flow represents the exchange of water between the ground and surface resources. Groundwater and surface water exchange dynamics is considered an important but complex relation that requires further development in the current model. Therefore, incorporating the subsurface - surface interrelationships is planned for the second stage of this model's development once this stage of development and validation has been completed.

\subsubsection{Stored Freshwater Supply}

The Stored Freshwater supply stock is also defined as a budget of inflows and outflows. The inflow components include recycling and withdrawals from ground and surface water sources. The outflow components include leaks and supply collections. The following two sections explain the rationale for the major inflow and outflow components, withdrawal and supply collection, respectively. 


\section{Withdrawal}

In the COWA model, water withdrawal is pumped from both surface and ground water resources to meet human demands. The surface water and groundwater withdrawals are defined as a function of the maximum collection rate, available space in freshwater storage and the available water volume in sources to withdrawal from. Collection from both sources is capped by the maximum collection rate which represents the regional infrastructure's capacity to pump. Collection is also capped by the available space in storage facilities since it is illogical to pump more than what can be held. Withdrawal from both sources is also controlled by the water supply left available in the ground and surface sources. Withdrawal is defined to allow collection for what is required by demand only if it is available in the source, thereby rejecting the possibility of pumping water from empty sources.

It is acknowledged that, particularly in proactive, water conscious region such as the Phoenix AMA, withdrawal is also controlled by policy. The policy impacts are seen when either, technology factor increases or decreases effective demand, transfer efficiency increases or decreases water available for collection, number of reserve months increases or decreases total requirement of collection, recycling increases or decreases supply, or when rooftop collection increases or decreases supply collection.

\section{Supply Collection Rate}

The supply collection rate is defined as a function of the effective demand, transfer efficiency, stored freshwater supply and any rainwater harvesting from rooftops that can be applied. If the supply can provide for the full required consumption, then it is collected. Otherwise, whatever water that is available is collected. Transfer efficiency enters the equation because only that portion of the withdrawal from supply goes to consumption, 1- transfer efficiency of the total withdrawal is lost through leaks. Collection is capped at the lower end by zero as to prevent a negative collection. Collection assurance factor is also applied to prevent a 
complete depletion of supply and account for any uncertainty. The assurance factor guarantees a portion of supply always available for storage if estimates are correct and also works as a buffer for estimate uncertainty. Finally, the rainwater harvesting efforts are included as to deduct this value from the amount of water required for collection to meet demands Rooftop collection functions as its own collection that is done outside of withdrawal from sources.

\subsubsection{Parameter Verification test}

Parameter verification testing entails examination of the system parameters (constants) and their comparison to knowledge the real system. For this portion of the validations process, all parameters will be evaluated by their representation of the real parameter values. To view the complete list of parameters of the COWA system, refer to Table 10 in section 3.1 .

\section{Birth and Death rate}

Birth rates and minimum (normal) death rates were taken as a long term average of the regions observed annual values from 1915-2012. The long term averages were then converted into units of monthly rates, under the assumption that birth and death rates do not operate with seasonal patterns. It is acknowledged that birth rates and death rates change in time, particularly in rapidly growing metropolises such as Phoenix, AZ. A long term average of these rates for such a long period of time is not as representative of the lower and upper bounds as they are of the middle years. However, at this stage in model development and for the purpose of the model, it is considered adequate. In future stages of model development, it is expected to define both minimum death rate and birth rate with a lookup graph that will represent average observed rates of ten year intervals to provide more appropriate values with change in time.

The maximum (famine) death rate is based from the famine scale developed by Paul Howe and Stephen Devereux in 2004. Based on this scale there are five levels of famine, all of which have a corresponding crude mortality rate. For the purpose of this model and this parameter, it was decided to define the maximum death rate in accordance to this scale. Levels 2 
and 3 of the famine scale are representing food crisis conditions and famine condition, respectively. It was decided that the maximum death rate would fall between these two levels, at the higher end of level 2 and the lower end of level 3. This representation of maximum death rate was chosen as to assume that although environmental and societal condition can, in some regions, easily generate famine conditions, efforts from organizations, such as the United Nations, and increasingly water concerned populations should hopefully take action to deter from severe or extreme famine conditions, level 4 and 5 respectively.

\section{Demand per capita}

The demand per capita parameter is a representation of all water use by every sector in the region divided by the total population. By representing demand per capita by a measure of total water use in every sector, the assumption is made that all production from this total water use is going back to the local community. It is understood that this is true as local population is expected to benefit directly or indirectly through the generation of jobs and consumption of locally produced goods, e.g., food and energy. Therefore, demand per capita is represented by a long term average of annual total water use divided by annual populations. Observed values of water use by sector and population, between years 1970-2005, were taken from the ADWR Water Atlas. Similar to the birth rate and death rate, it is acknowledged that this parameter does change with time but at this stage of model development and for the purpose of the model the above mentioned method of estimating the demand per capita parameter is considered adequate.

\section{Transfer Efficiency}

As mention previously the transfer efficiency of the system is a representation of the water distribution system's effectiveness of transporting stored freshwater supply to the population. Since most water distribution infrastructure is not perfect, there is some loss of water to leaks. Data for this parameter is difficult to measure and for many regions in the world documented observations are nonexistent. Therefore, an estimated value for developed and 
undeveloped regions is used. In 2005, Lee \& Schwab summarized the available data from around the world concerning the deficiencies in water distribution systems. It was their educated opinion that the average distribution deficiency in the United States was about $15 \%(\eta=0.85)$ and the average distribution deficiency in the developing world was between $37 \%-41 \%(\eta=0.61)$ (Lee $\&$ Schwab, 2005). From the literature, these seem to be the most adequate estimations for such a parameter.

\section{Technology Factor}

The technology factor is the parameter representing the impacts of water-efficient technology and practices. For a technology factor value of 1, devices and practices are considered 'standard' in regards to water intensity, for today's standards in developed regions. For a technology factor value less than 1, water-delivering devices and practices are considered "substandard" in regards to water intensity, as compared to today's standards. For technology factor value greater than 1, water-delivery devices and practices are considered "water-efficient" in regards to water intensity, as compared to today's standards. By using this scaling for technology factor, the model is able to simulate impacts of the increased use of water-efficient technologies. By increasing the technology factor, the model is effectively decreasing the effective demand by the reciprocal of the factor value. For example, in an undeveloped region where appliances and practices are behind the times as a result of lack of development, the technology factor could be 0.5 , in which case effective demand would double, appropriately representing the relatively wasteful practices. Conversely, in a highly developed region where appliances and practices are ahead of the times as a result of extensive development, the technology factor could be 2 in which case the effective demand would be halved, appropriately representing the relatively efficient practices

For the case studies presented in this research, approximated values were used for the technology factor. For the Phoenix AMA base run, it was assumed that $\tau=1$ as a result of the 
degree of development in the region. It is understood that in the PAMA area, strict building code regulation requires the installment of appliances and equipment that meet standard requirements. For the Somalia case study, is was assumed that $\tau$ would be less than 1 , estimated at $\tau=0.7$, approximately $1 / 3$ less water efficient than practices found in the Phoenix AMA.

This scaling requires a more strict definition which is intended to be done with respect to the United States Department of Energy's (DOE) Building Technologies Office (BTO). The BTO has developed appliance and equipment standards which are intended to represent a technology factor equaled to 1 , for the purpose of this model. These established standard will be used to compare against other appliances and equipment to develop a better defined scaling system, however, approximations are considered sufficient at this point in model development.

\section{Maximum Withdrawal Rates}

The groundwater and surface water withdrawal rates are defined by an upper bound of maximum capacity of withdrawal rates. For maximum groundwater withdrawal rates, this is controlled by the pumping capacity of groundwater wells. Since water can only be withdrawn as fast as the pumping equipment physically permits, it would be illogical to allow withdrawal to exceed the physically pumping capacity. In developed areas such as the PAMA case study, this data is easily available as groundwater wells are strictly monitored. Therefore, an average monthly value based on total annual capacity is an adequate estimation of maximum groundwater withdrawal.

Alternatively, data provided for maximum surface water pumping capacities was not as well documented. Therefore, maximum surface water withdrawal was to be defined in comparison to groundwater withdrawal. As a result of, US water laws protecting natural resource through the enforcement of policy to ensure critical environmental flows and the large volume discrepancy between groundwater and surface water, the pumping capacity for groundwater was considered a sufficient marker of surface water pumping capacity. This value is acknowledged as 
an overestimation from comparison with data concerning the total surface water withdrawn (ADWR, 2011). However, the comparable data was sparse and in need of further research. Therefore, for the sake of time and continuation of the research, maximum groundwater withdrawal rate was considered to be a sufficient estimate of maximum surface water withdrawal rate.

\section{Recycling Capacity}

Similar to the maximum withdrawal rates, the recycling capacity is defined as the upper bound of the recycling rate and is a function of the physical limitations of infrastructure. This definition came with the understanding that it would be illogical to produce more recycled water than can be generated from implemented infrastructure. As it is currently defined, this value of recycling capacity is a constant long term average of total generated recycled water. However, similar to birth rate, in the real system, this value changes in time and should not remain constant in an area of rapid development concerned with sustainability, in order to account for growth in reuse of recycled water. Although it is acknowledge that in the real system this parameter changes with time and development, in general the practice of water recycling is relatively new and any recycling capacity estimates from generation capacity data will only be representative of the very small portion of the simulation duration. For a large majority of the time simulated, recycling practices was non-existent and therefore, in the baserun scenarios, this parameter is considered to be negligible, a value of zero.

\section{Infiltration rate}

Infiltration, as defined by the COWA model, is a portion of rainfall not lost as a result of evapotranspiration. This definition of infiltration is acknowledged as a simplification of the dynamics involved with infiltration within the real system. Typically, infiltration is estimated as a function of soil type, land use and land over (LULC). Different soil particle sizes (i.e., finer or courser) impacts percolation of rainfall into the ground and different soil materials (i.e., clay or 
gravel) impact effects of loss due to soil moisture. Further, different types of land use and land cover (e.g., agriculture or commercial and asphalt or grass, respectively) impact permeability and runoff. However, for this purpose of the model, the infiltration aspect of interest is only how much it contributes to inflow of the groundwater source stock via recharge. Therefore, the more complex dynamics of the infiltration are omitted and instead, infiltration is defined only by a portion of total rainfall.

Infiltration is a result of rainfall penetrating the ground's surface and percolating through the soil until it becomes part of the water table or remains as suspended in the ground as soil moisture. The ground's surface serves as a partitioning agent of rainfall between infiltration and runoff (FAO, 2004). Simultaneously, other forces, such as evaporation and transpiration, are consuming the rainfall volume, consequently, this quantity is taken from the available volume for infiltration. Additional partitioning occurs through the interception of vegetation canopies (FAO, 2004). Therefore, defining infiltration as a portion of total rainfall after removing estimated loss from evapotranspiration is sufficient for the purpose of this model.

Estimating the infiltration portion at 0.85 is admittedly an overestimation but considered sufficient at this point in the COWA research. Approximately, 40 percent of rainfall is lost to runoff and 30 percent of rainfall is lost to canopy interception (FAO, 2004). However, a significant portion of the 40 percent lost to runoff flowing to rivers is assumed to make its way back to infiltration via the interflow between the bottom lining of a surface water body and groundwater sources. Additionally, much of the canopy interception is assumed to be accounted for with the removal of loss from evapotranspiration. Therefore, an educated approximation of 0.85 was considered sufficient for this stage of COWA research.

\subsubsection{Behavior-Oriented Structure testing}

Behavior-oriented structure testing evaluates the model's ability to reproduce behavior patterns observed in the real system. For this portion of the validation process, model developers 
made use of analysis of several thought experiments in addition to simulated versus observed graphs, created for chosen system components. Unfortunately, the simulated verses observed graphs could only be produced for a few components of this system, limited by the available observed data to conduct such testing. Nevertheless, at this stage in the model validation, developers are only interested in general behavior patterns which is best discussed as an analysis of thought experiments. The thought experiments and their behavioral analysis will be discussed in section 5 .

Observed population in the Juba basin of Somalia was graphed with COWA's simulated population for the Somalia case study. Simulated values are expected to be higher than observed since observations are only of a portion of the total country (i.e., Juba Basin). However, because it is a densely populated region the average birth rates and minimum death rate applied to the simulation are considered representative of the Juba basin. Furthermore, the discrepancy between values is not of concern in this validation. Rather, only the behavior patterns, or trends, are of interest. In Figure 25, below, is a graphical illustration of the observed verses simulated analysis for population in the Somalia case study. The visual analysis of this comparison provides further confidence in the validation of the population stock structure. The simulated population seems to be increasing at the appropriate rate to properly represent the real system, for a 15 years duration roughly.

Additionally, observed population estimates and projections of the PAMA area were graphed with the simulated population from the PAMA baserun simulation. In Figure 26, below, is a graphical illustration of the observed verses simulated analysis for the PAMA case study. 


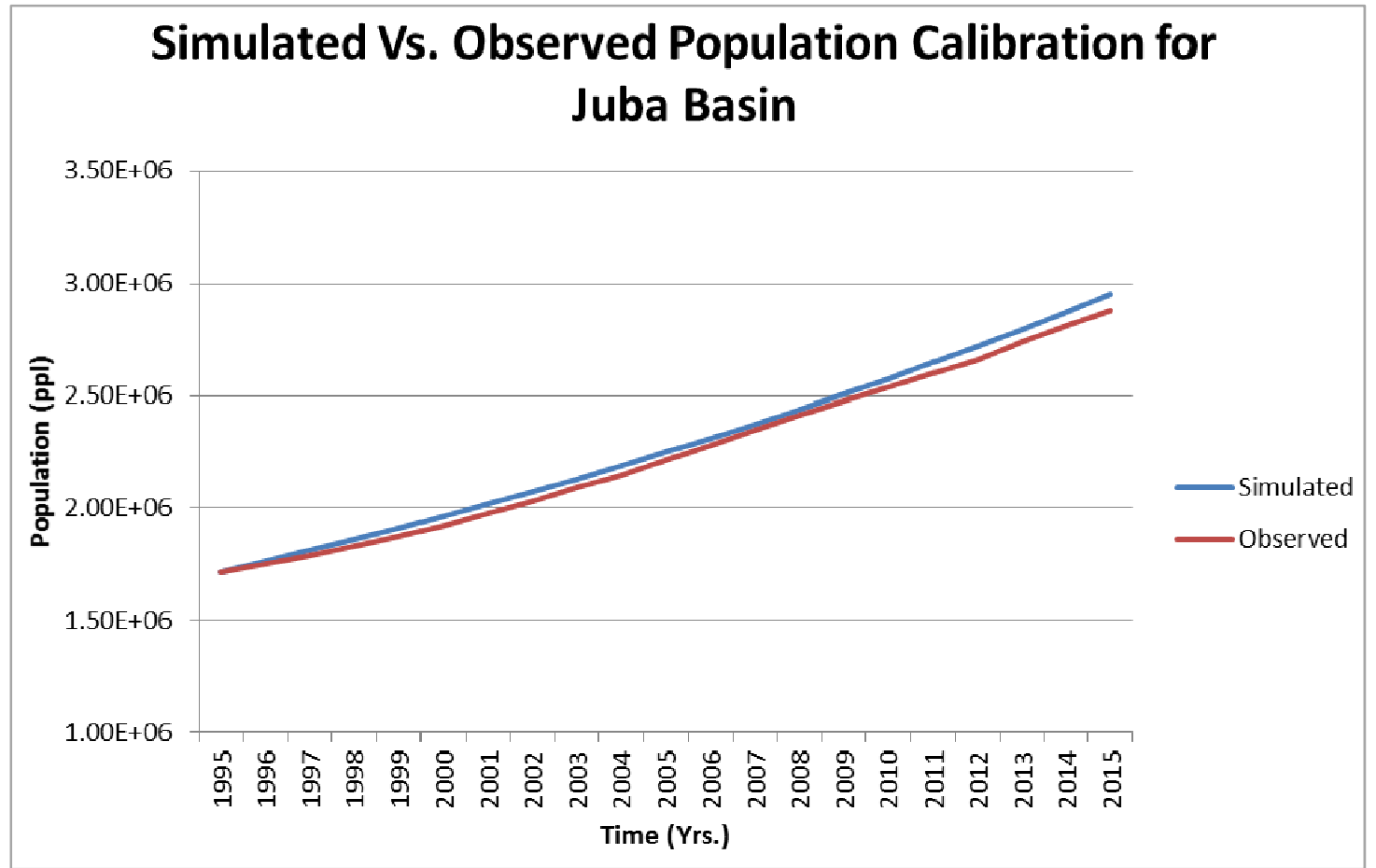

Figure 24: Observed population in Juba Basin as compared to simulation COWA population

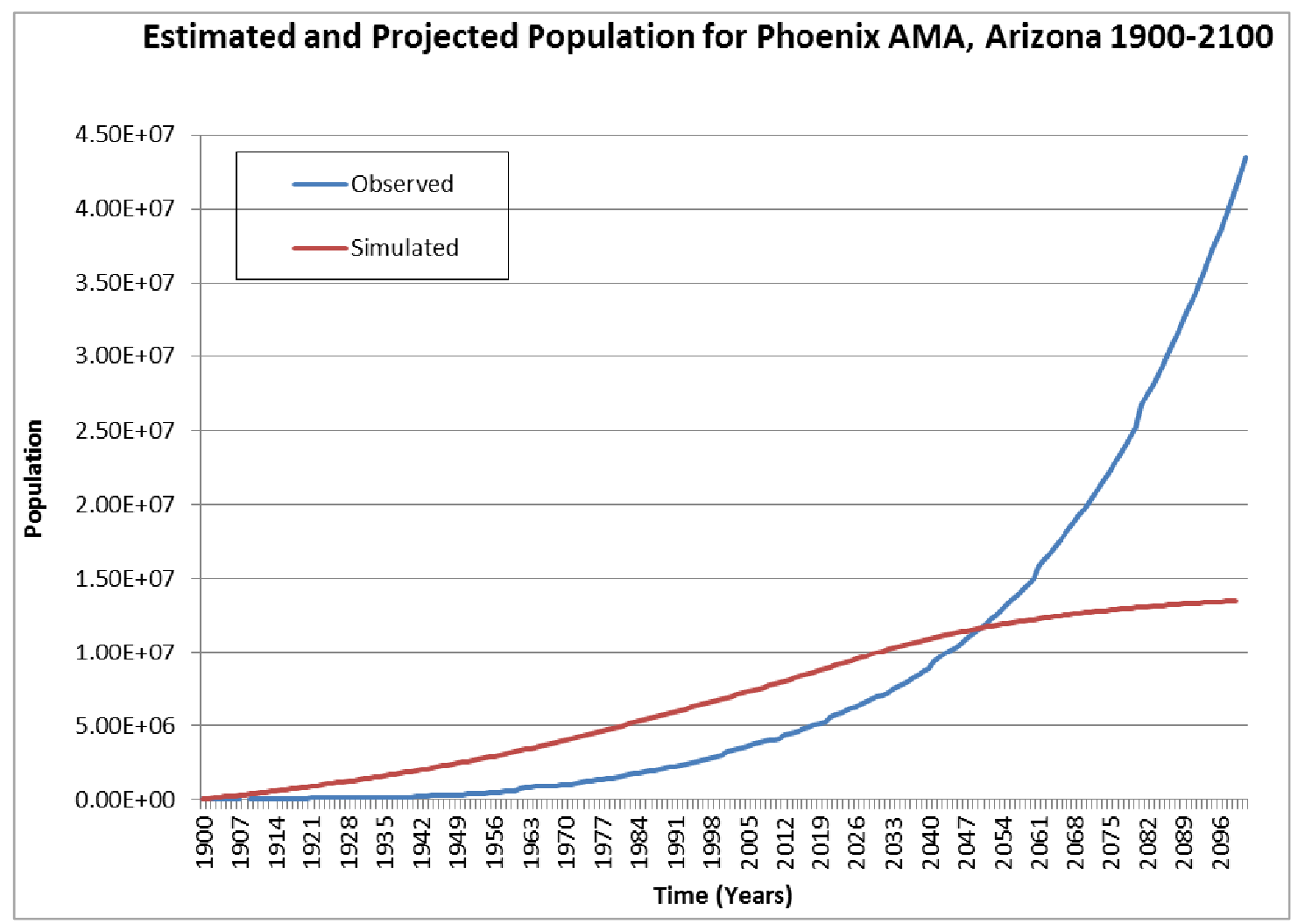

Figure 25: Observed and projected population in PAMA as compared to simulated population of PAMA baserun 
The results from the visual analysis of the behavior patterns were not as immediately apparent as was for the Somalia analysis. There is a clear discrepancy not just in the values but in the behaviors of these data sets. However, upon further analysis it was discovered that this was an anticipated result. As mentioned in section 4, birth rate is currently held at a constant long-term average and death rate is a function of consumable water availability. As a result of a rapidly and steadily growing population, a long term average birth rate left constant over time will ultimately be an over estimation for the first half of the simulation. Further, the link between death rate and consumption limits population growth in a matter that is not considered in the projected observed values. In other words, the observed values of projected population (i.e., beyond 2013), do not take into account natural resource restriction on population growth, whereas the COWA simulated population restricted by freshwater resources.

The graphical depiction of simulated population behavior sufficiently represents the real system given the over estimation of inflow by way of a long term average birth rate, until about 2030. At this point in the simulation data, population begins to level off, depicting the impacts of insufficient water supply to meet basic needs. Although the behavior of the simulation does not match observed projected values exactly, the reasons for the discrepancy are understood and explainable. It is expected, that with the structural adjustment to birth rate suggested in section 4 , the simulated population behavior will better match observed behavior.

\section{RESULTS}

In this section, the results from COWA simulations will be discussed. The Somalia case study discussion includes only the hindcasting simulation used to build confidence in the model's overall structure and continue research. A suite of simulations were run for the PAMA case study. Model developers considered 9 scenarios for the PAMA area. The thought experiments were examined individually by model developers and system experts by way of structure-oriented 
behavior validation. The analysis performed by the model developers followed a simple process illustrated by a flow chart in Figure 27, below. Once the 9 thought experiments were simulated, the behaviors of the four stock variables and consumption per capita were graphs together. These five behaviors were then analyzed individually by way of the process in Figure 27. This initial structure-oriented behavior validation is discussed for all simulated scenarios in the sections below.

\subsection{Somalia Case Study}

The Somalia case study simulation results executed and discussed in this section were generated using the initial version of COWA. Results from this case study were used for the structure-oriented behavior validation process of the model. The analysis of the simulation results includes variable sensitivity testing, extreme-conditioning testing and modified behavior testing. By examining the simulated behavior patterns and comparing them to knowledge of the real system's behavior, or expected behavior, the model developers were able to further refine the mathematically defined relationships to better fit the causes and effects observed of the real system. Effectively, this comparison and refinement are the first steps of the SD validation process, as mentioned in section 4 .

Below are the results of the Somalia case study simulation runs. The duration of the entire simulation runs was 8.3 years, or 100 months, using monthly time steps, with the start year as 2009. The portion of the run used for hindcasting was the first two years, roughly, representing the beginning of the drought conditions that drove the 2011 famine in Somalia. It was agreed that if the model could reflect the famine via a collapse in the system in the correct time frame, then the developers would have sufficient evidence to further explore the ability of the model to represent other real systems. 


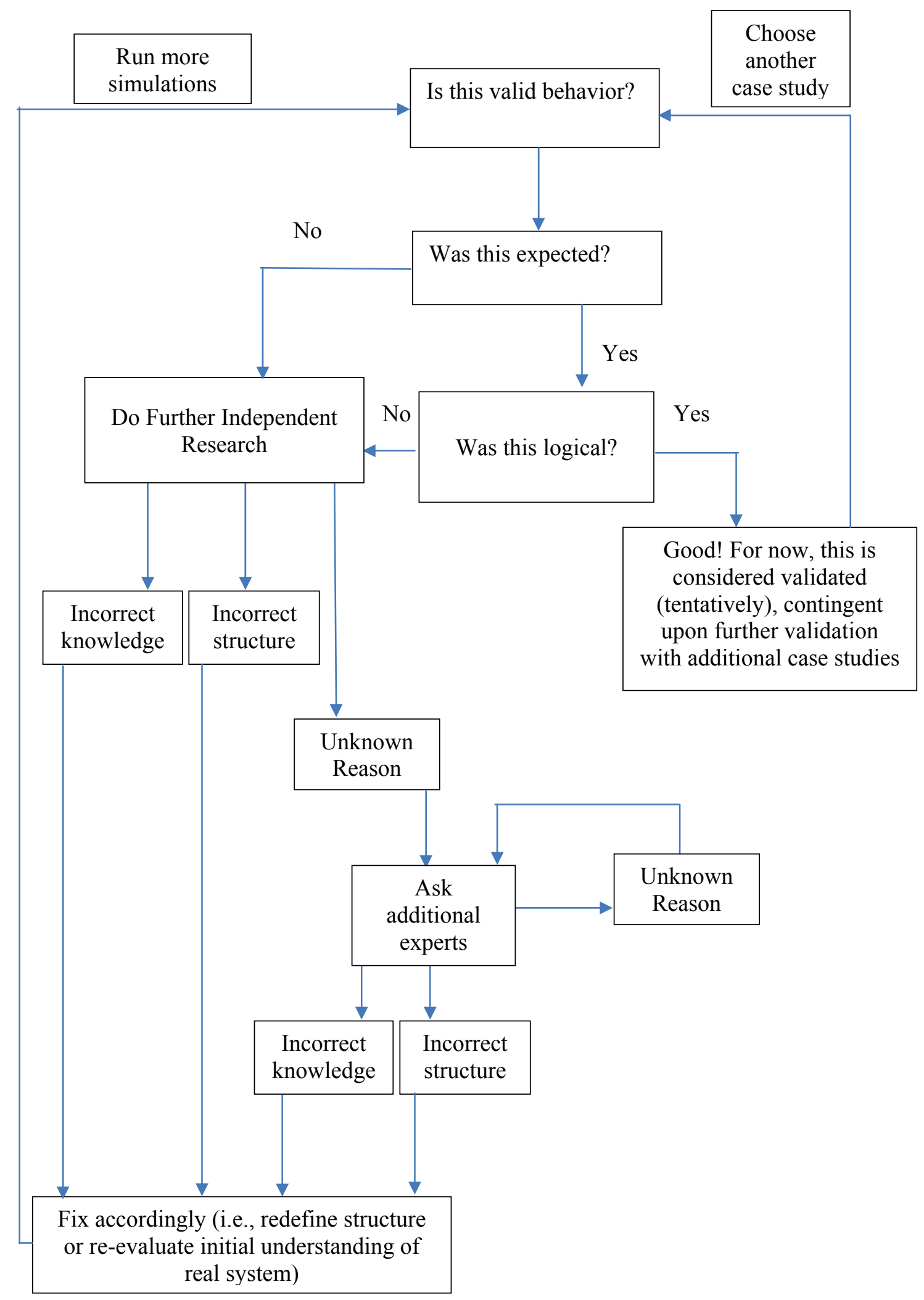

Figure 26: Analysis process for theoretical validation of thought experiments 


\subsubsection{Summer 2011 Famine Hindcast}

The hindcasting completed for this case study was intended to reflect the behavior of certain components under famine conditions. At this point in model development, Somalia was experiencing severe consequences from extended drought conditions. This unfortunate scenario of the real system provided the opportunity to apply COWA to empirically known causes and effects of water resource mismanagement. The start time $(t=0)$ was defined as January 2009 to identify the beginning of the drought event that eventually led to famine conditions, therefore the initial input data was representative of this period. A summarized list of input data for the hindcasting simulation is provided above in Table 16.

Birth rate is the long-term average of the annual crude birth rates between years 1970-2010 obtained from the United Nations databank, UNdata. Minimum (normal) death rate is the longterm average of the annual crude birth rates between years 1985-2010 also obtained from the United Nations databank, UNdata. Net Immigration rate is the number of immigrants minus the number of emigrants over a period, divided by the person-years lived by the population of the receiving country over that period. The final value is a long-term average of Net immigration for select years between years 1962-2012. The exogenous variables, Precipitation and Evapotranspiration, are defined by lookup values given by a customized graph. The (x, y) coordinates are defined by the average monthly P or E experienced at several weather stations across the region (y), and the number of month of the year the y value represents $(\mathrm{x})$. The average seasonal behavior of $\mathrm{P}$ and $\mathrm{E}$ and individual station data are as defined in Figures 28 and 29, respectively. 


\section{Long Term Mean Monthly Rainfall (mm)}

and Selective Somalia Weather Stations

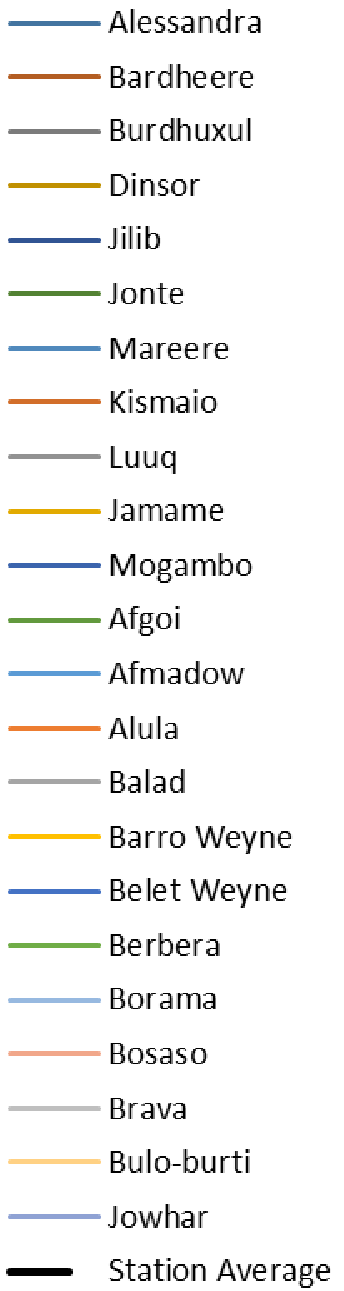

Figure 27: Long-term Average Precipitation in Somalia and Selected Stations 


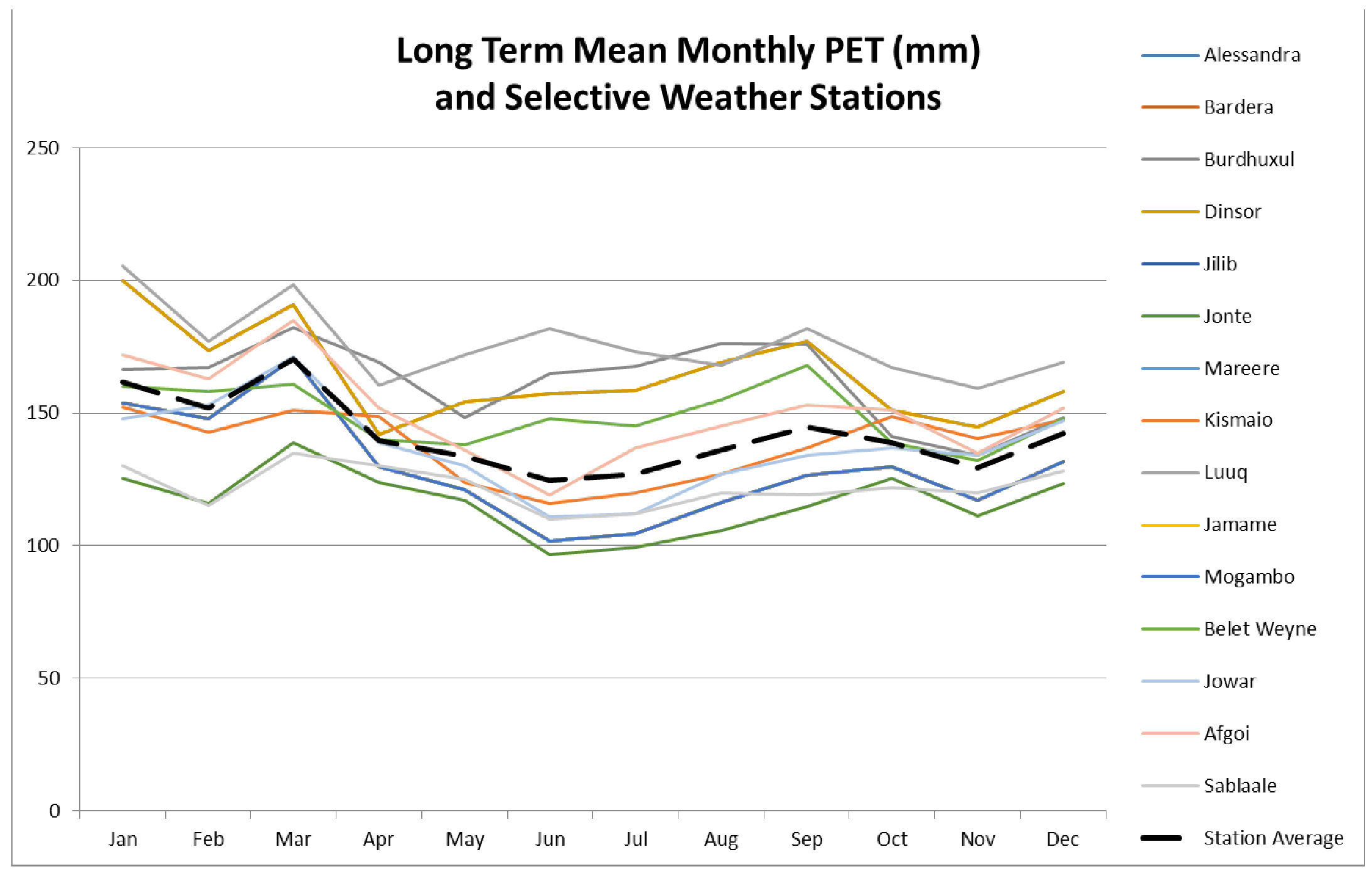

Figure 28: Long-term Average PET in Somalia and Selected Stations 
To test the COWA-Somalia results, the model developers began the hindcasting of the 2011 famine from the start of the drought conditions which fueled the event. In this case, the hindcasting can be thought of as a form of an extreme condition test. Extreme condition testing involves setting select parameters to an extreme, but plausible, value and comparing the simulation output to known or expected behavior of the real system (Forrester \& Senge, 1980). Since Somalia experienced extreme drought conditions for an extended period of time, nearly negligible rainfall for approximately 2 years, the modeled system assigned precipitation rate to a value of zero and launched the simulation.

The model simulation, under the above mentioned conditions for Somalia, was expected to show an inability for the coupled natural-human water system to sustainably function, in the presence of extended drought conditions. Specifically, in order to tentatively validate the COWA's structure, the simulations were expected to depict a system in which the natural source stocks would be unable to provide the needed supply to meet demands. Additionally, the natural source stock would also have to deplete at a rate sufficient to completely deplete sources within an approximate 2 year duration of the start date.

The resulting behavior patterns of the source and supply stocks are illustrated below in Figure 30 . The behavior patterns of both the sources stock and the supply stock are stacked in the line graph. The y-axis is also stacked with the stock's respective volumetric ranges. The y-axis is meant to be read as, sources (blue) ranging from 0-20 cubic kilometers (ckm) and supply (red) ranging from 4-8 ckm.

As was expected, with time, the freshwater source stock steadily depletes below the freshwater supply stock needed to meet demands. More importantly, the simulation was able to successfully model the approximate 2 year, or $\sim 24$ month, period it took before famine conditions were officially recognized by the UN in the real system. At, approximately, time $(x)=22$ months, 


\section{Sources and Supply}

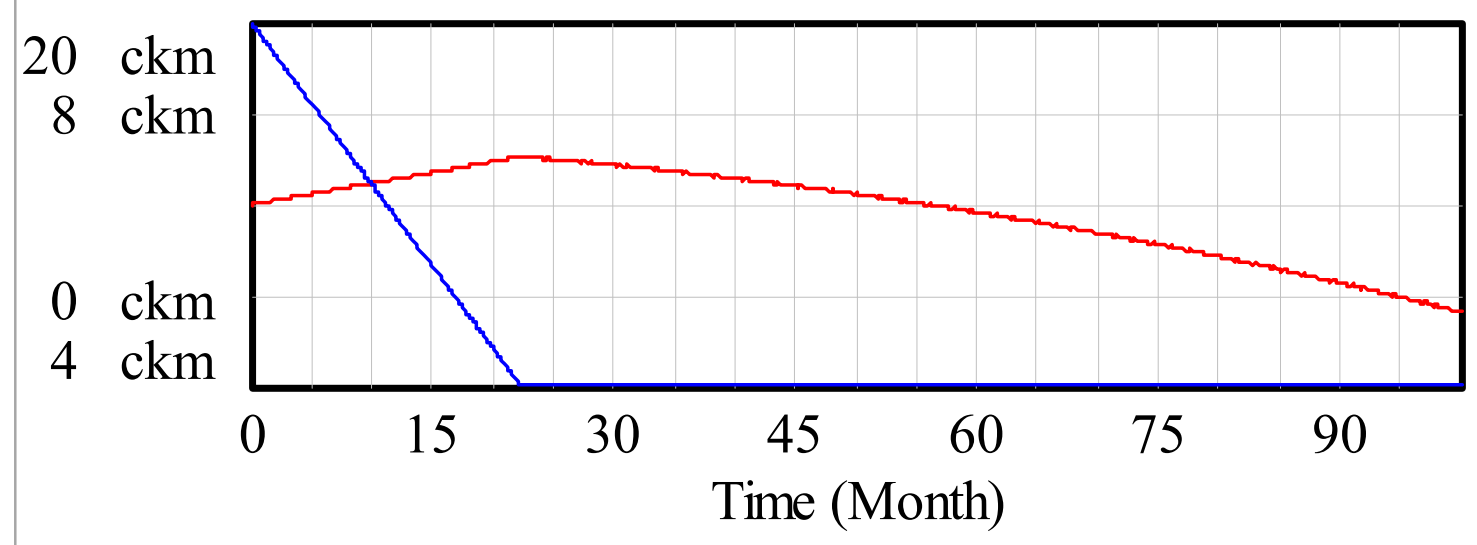

Freshwater Sources : test 2

Freshwater Supply : test2

Figure 29: Somalia Hindcasting Results for Freshwater Sources and Freshwater Supply stocks

the freshwater sources flat line at a zero value. In the context of the model, this is representative of drought conditions in which natural resources are not being replenished at a competitive rate with human demand, which has no restrictions other than the accessibility and availability of the resource. Further, freshwater supply stock slowly but steadily increases until the source stock reaches zero. Then, at approximately 22 months, the supply stock begins to decrease. The behavior pattern of the supply stock built confidence in the model's ability to represent the model developer's understanding of the real system. It was logical and expected to see a decline in the supply stock once the source stock reached zero because the supply stock withdrawals from the source stock even when sources are low. Withdrawals from sources cannot be completely prevented until they become physically unavailable and negative withdrawals cannot be made in the real system. Therefore, the simulated behavior of served as additional tentative validation of the model's structure

Variable sensitivity tests were also conducted with the Somalia case study simulations. Sensitivity testing involves determining the parameters which the system is most sensitive to, 
then determining whether or not this sensitivity is representative in the real system as well (Forrester \& Senge, 1980). The result of the sensitivity analysis proved $\tau$, technology factor, and $\eta$, transfer efficiency, to be most sensitive to the system, see Figures 31 and 32, respectively. Identifying both technology and transfer efficiency as the two most sensitive parameters in the system is a logical and expected scenario for the real system, as defined in COWA.

The real system is partially driven by the supply and demand between the natural and human systems. If technological advancements could half the effective demand, or conversely, if technological repression could double the effective demand, the source and supply stocks should behave accordingly. For example, in the real system, older, sub-standard technologies such as those found in dishwashers, showerheads and toilets typically required about 40, 20, and 23 liters of water per use, respectively, while newer, above-standard technologies in dishwashers showerheads and toilets require about 18, 4 and 4.5 liters of water per use, respectively (McGinnis \& McGinnis, 2014). Water conservation technologies can significantly impact the quantity of required water to meet demands and thereby, indirectly slowing the depletion time of natural resources. 
The sensitivity analysis of $\tau$, the technology factor, is depicted in Figure 31 . Not much

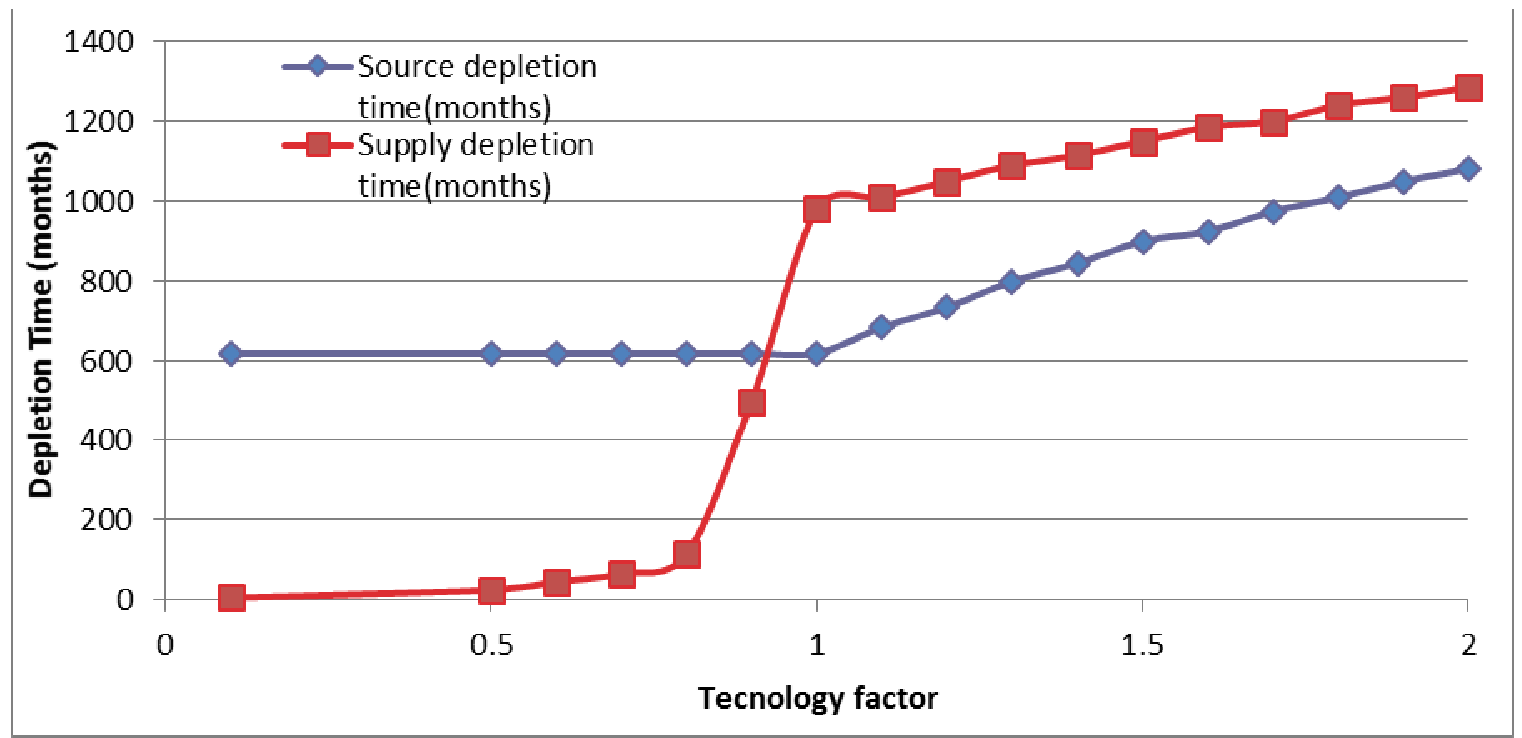

Figure 30: Technology factor sensitivity analysis results

change is seen in supply (red) and source (blue) depletion times when the technology factor is below 1, or technologies are sub-standard. However, as $\tau$ approaches and increases from 1, there is a jump up in supply depletion time and a gradual incline of source depletion time. As is expected in the real system, when demand is depressed by water conservation technologies, the supply stock will feel the impacts immediately as withdrawals from sources remains the same but collection from supply drops. The impact on source stocks is more gradual because although withdrawals stop growing, the natural replenishment of sources is a slower process than humanfacilitated supply replenishment.

It is also expected that transfer efficiency would be a highly sensitive component in the real system as implied by the sensitivity results, Figure 32. Losing potential water supply in transit from supply storage to the user is a hidden but serious concern for sustainable management. Losing potential supply to leaks or spillage is a relatively significant loss to the real system. Of total water withdrawn from sources and stored for supply, approximately $15 \%$ in developed regions and 37\% in undeveloped regions (Lee \& Schwab, 2005) is lost as a result of 
inefficiencies in the transport of the water from storage to user. This deficiency in the system is expected to have a significant impact of the supply and source depletion time because human system will be over-withdrawing relative to the actual need, as a result of accounting for the loss to leaks.

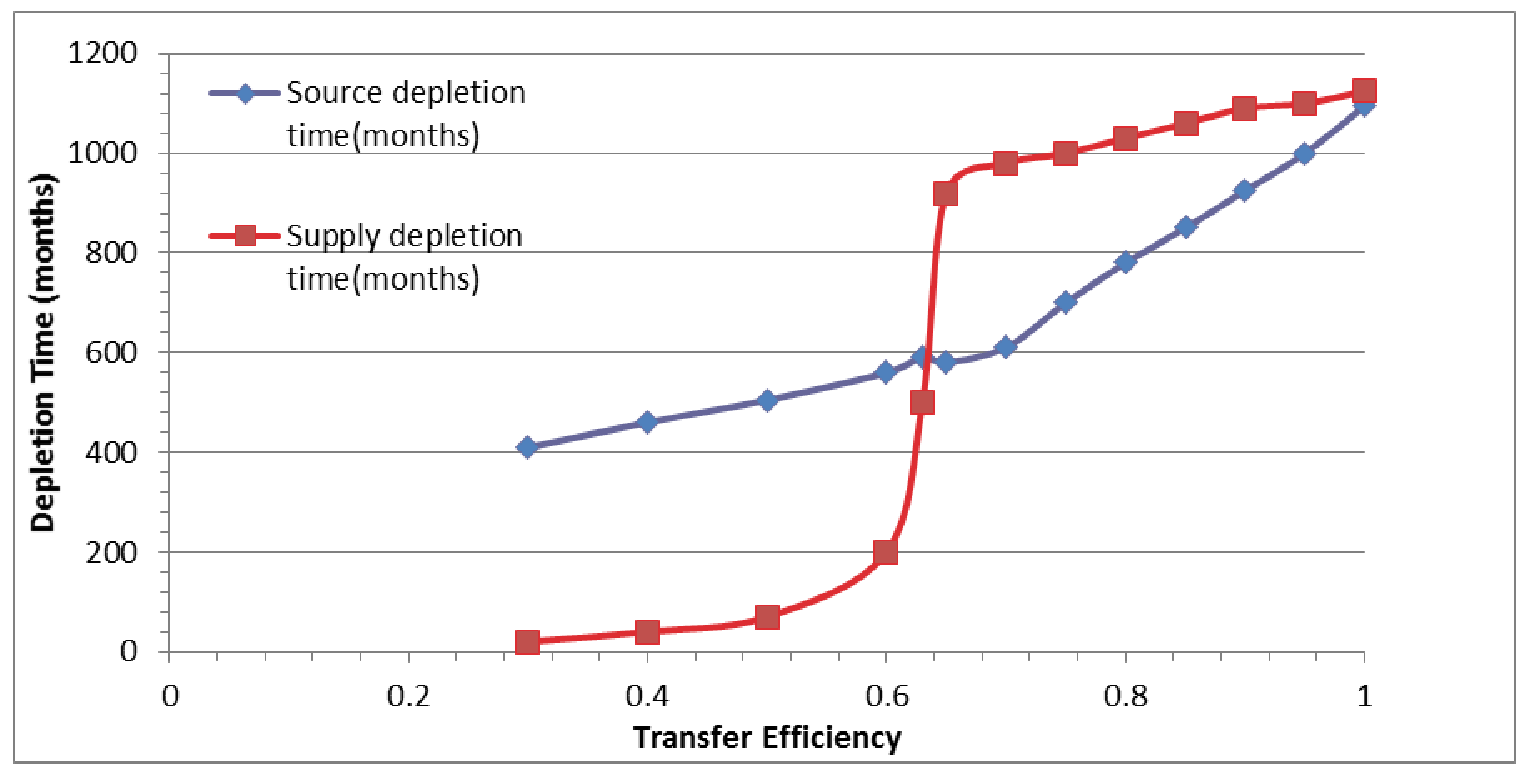

Figure 31: Transfer efficiency sensitivity analysis results

Depicted in Figure 32, when $\eta<0.6$, or the loss to leaks is more than, approximately, $40 \%$ of total supply collected for demand both the source and supply depletion time remain relatively short, i.e., fast depletion rates. However, the supply depletion time (red) spikes as transfer efficiency approaches and surpassed 0.6 , or less than $40 \%$ loss to leaks. Likewise, source depletion time (blue) also steepens at this point. This is an expected behavior of the real system because the loss to leaks occurs after water in withdrawn from sources to replenish supply. Leakages is directly impacting supply and indirectly impacting sources. If the loss to leaks steadily reduces, effectively increasing transfer efficiency, there should be an immediate and significant impact on supply depletion time. As transfer efficiency increases, wasted supply decreases resulting in a larger depletion time, i.e., slower depletion rate. The same behavior is expected from the source depletion time but not as intense because of the degree of separation 
between leaks in collection and withdrawal from sources, in addition to the slow nature of natural replenishment.

The evidence provided from the hindcasting results and the sensitivity analysis were considered to be tentative validation of the model's structure. This initial validation proved to be sufficient enough to continue the research with another case study. However, before addition simulations commenced model developers reformulated selective variables as to better match the real system's behavior. Some of the major reformulations included the coupling of precipitation and evapotranspiration variables to a GCM, coupling the river inflow and outflow variables to a RMM and redefining the dynamic between population and consumption through the relations between death rate and immigration rate with consumption per capita. Once the most current version of COWA was finalized, 9 thought experiments were simulated using a new case study with fewer information gaps.

\subsection{Phoenix Active Management Area Case Study}

In this section, the 9 thought experiments applied to the PAMA case study will be discussed. The analysis of these scenarios is intended to serve as modified behavior testing for continuation of the structure-oriented behavior validation process. Modified behavior testing consists of comparing the results from a modified version of the simulated system with known or expected behaviors of the real system under the same modifications (Forrester \& Senge, 1980).

The first scenario reflects no change to the current ways of management, a business as usual scenario that maintains the current status quo, called the 'baserun'. The second scenario considers the adoption of stricter water recycling, or water reuse, policy. The third scenario assumes efforts have been made in the technological field to increase the water conservation of appliances and devices, e.g., dual-flush toilets or drip irrigation. The fourth scenario represents the inevitable aging of water delivery pipelines if infrastructure is not built to last or maintained. The fifth scenario expresses the opposite case, in which the water delivery pipelines and 
infrastructure is improved to maximize transfer efficiency. The sixth scenario experiments with an increase of reservoir capacity and, thus, increasing potential freshwater supply storage. The seventh scenario keeps the higher reservoir capacity and adds stricter groundwater withdrawal policies. The eighth scenario examines the uncertainty in the initial groundwater source stock estimation by modeling both high and low estimation extremes. The ninth and final scenario simulates the lowest bound of initial ground water estimations in combination with influence from stricter groundwater withdrawal policies. Below, the scenarios from both case studies are listed and summarized in Table 17.

\begin{tabular}{|l|l|l|}
\hline Case Study: & Scenario \# & \multicolumn{1}{c|}{ Description } \\
\hline Somalia & & Hind casting 2011 Famine \\
\hline PAMA & 1 & \\
\hline & 1 & Baserun \\
\hline & 2 & Increased Recycling \\
\hline & 3 & Improved Technology Factor \\
\hline & 4 & Deteriorated Transfer Efficiency \\
\hline & 5 & Improved Transfer Efficiency \\
\hline & 6 & Increased Reservoir Capacity \\
\hline & 7 & $\begin{array}{l}\text { Increased Reservoir Capacity, } \\
\text { Strict GW Withdrawal Policy }\end{array}$ \\
\hline & 8 & Low and High GW Estimates \\
\hline & 9 & $\begin{array}{l}\text { Low GW Estimate, } \\
\text { Strict GW Withdrawal Policy }\end{array}$ \\
\hline & $18:$ List of simulations, by case study \\
\hline & & \\
& &
\end{tabular}

Table 18: List of simulations, by case study

\subsubsection{Scenario 1 - Baserun}

The first scenario, titled 'baserun', is a simulation to serve as a model of what is currently experienced in the real system. The baserun simulation will be used as a standard of comparison 
for the other simulated scenarios. Behaviors patterns from these results are expected to match typical conditions of the real system in the PAMA case study. The results from this simulation do not reflect modified behavior but, rather, serve as the 'control' for analysis.

The following parameter values and initial conditions are used for the base run: minimum death rate $\alpha_{\mathrm{m}}=0.0006$, normal birth rate $\beta=0.0016$, initial population $\mathrm{x}_{\mathrm{i}}=27,000$, initial groundwater $\mathrm{y}_{\mathrm{G}, \mathrm{i}}=660$, initial surface water $\mathrm{y}_{\mathrm{s}, \mathrm{i}}=30$, initial supply $\mathrm{z}_{\mathrm{i}}=3$, total reservouir capacity $\mathrm{Z}_{\mathrm{M}}=5$, surface water withdrawal capacity $\mathrm{W}_{\mathrm{SM}}=1$, groundwater withdrawal capacity $\mathrm{W}_{\mathrm{GM}}=1$, surface water reserve months $\mathrm{n}_{\mathrm{S}}=60$, groundwater reserve months $\mathrm{n}_{\mathrm{G}}=60$, recycling capacity $R_{M}=0$, transfer efficiency $\eta=0.85$, technology factor $\tau=1$, base immigration $I_{b}=3,000$, demand per capita $\delta=8.3 \times 10^{-8}$. The time step is 1 month (mo); Unit of volume is cubic kilometer $\left(\mathrm{km}^{3}\right)$; Unit of population is people (ppl). Freshwater Supply z is shown dimentionless (Dmnl) and normalized to $\mathrm{z}_{\mathrm{M}}$ in all the Figures for PAMA simulation results. Units for all other quantities are chosen to conform with the basic units, mo,ppl and $\mathrm{km}^{3}$. These values are used in combination with the coupled GCM and RRM to force the model to run a simulation of the baserun, scenario 1 .

The results for the behavior patterns of the four stock variables and consumption per capita are graphed below in Figure 33. The purpose of this scenario is to function as a control condition of which all other scenarios will be compared to, it is the 'base' condition. When reading the graph in Figure 33, notice the vertical y-axis labeling. The minimum and maximum values of all unit of measure used in the graphed behaviors are stacked at the bottom and top of the axis, respectively. Therefore, the $y$ - axis should be read as; the Population values, in units of people (ppl), ranges from $0-40$ million $(\mathrm{M})$; the Normalized Stored Freshwater Supply in dimensionless units (Dmls), ranges from 0 - 1; Surface Water Source and Groundwater Source values, in units of cubic kilometers (ckm), ranges from $0-800 \mathrm{ckm} ;$; and the Consumption per 
Capita and Threshold Consumption per Capita values, in units of cubic kilometers per person per month (ckm/mo*ppl), ranges from $0-1 \mathrm{e}-007 \mathrm{ckm} /(\mathrm{mo} * \mathrm{ppl})$.

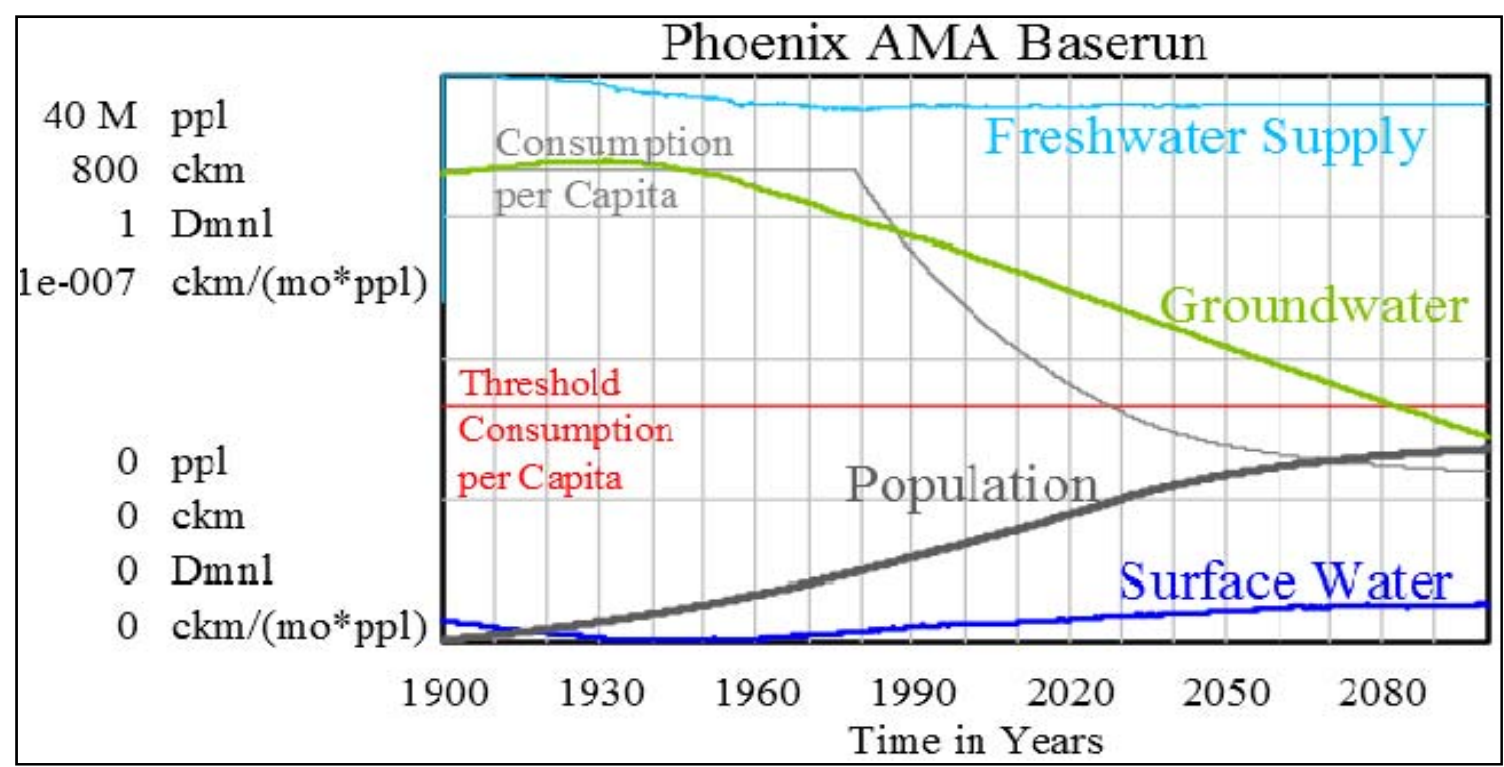

Figure 32: Scenario 1 -Simulated behavior patterns of selected system components

The baserun graph, Figure 33, provides some insight into the behavior of the consumption per capita and the four stock variables; Population, Groundwater Sources, Surface Water Sources and Stored Freshwater supply. Initially, as population steadily grows, the surface water sources drops, while groundwater maintains its relative level. Within the first 50 years of simulation (1900-1950), population continues to grow, surface water reaches its lowest levels and groundwater begins to plummet. Within another 50 years (1950-2000), around present day, surface water begins to replenish its stocks and groundwater continues to fall as population maintains a steady growth and normalized freshwater supply begins to level out at a value just below 1 . Additionally, the consumption per capita takes a sharp dive and its value quickly decreases shortly before this time, approximately 80 years into the simulation. Further, 50 years into the future, population starts to level off once the consumption per capita drops below the threshold value for consumption per capita required for basic needs. The surface water has recovered a sustained, healthy flow and the groundwater levels have severely depleted. The 
Stored Freshwater supply initially maintains its level for a short period ( $\sim 30$ years) then gradually drops for a short period and continues to maintain a relatively constant level through the end of the simulation.

The above mentioned behaviors are considered to be sufficiently representative of the real system's behaviors. Historically, the original primary source of freshwater for the PAMA population was surface water sources as a result of its accessible nature. In time, with the onset of rapid development and growing populations, the PAMA region switched its primary freshwater source from surface water to groundwater as a result of its large stock volume and the introduction of pumping technologies. Significant population growth and, therefore, significant increases in demands for freshwater supply stresses on both ground and surface water sources limiting allowable withdrawal from sources to feed supply. However, in a highly-developed area such as PAMA, these stresses will not deplete supply but simply lower it from full capacity. Finally, it is also expected from the real system that, if, in the future, groundwater sources eventually deplete past a level which can support the consumption per capita threshold, population growth will be negatively impacted and slow, or possibly decline, as basic need cannot be met. The resulting behavior patterns of the five considered components were additional evidence of the model's ability to appropriately simulate real system behavior and further build developers' confidence in the COWA 


\subsubsection{Scenario 2 - Increased Recycling}

The second scenario is a representation of modified base conditions, with a raise in the

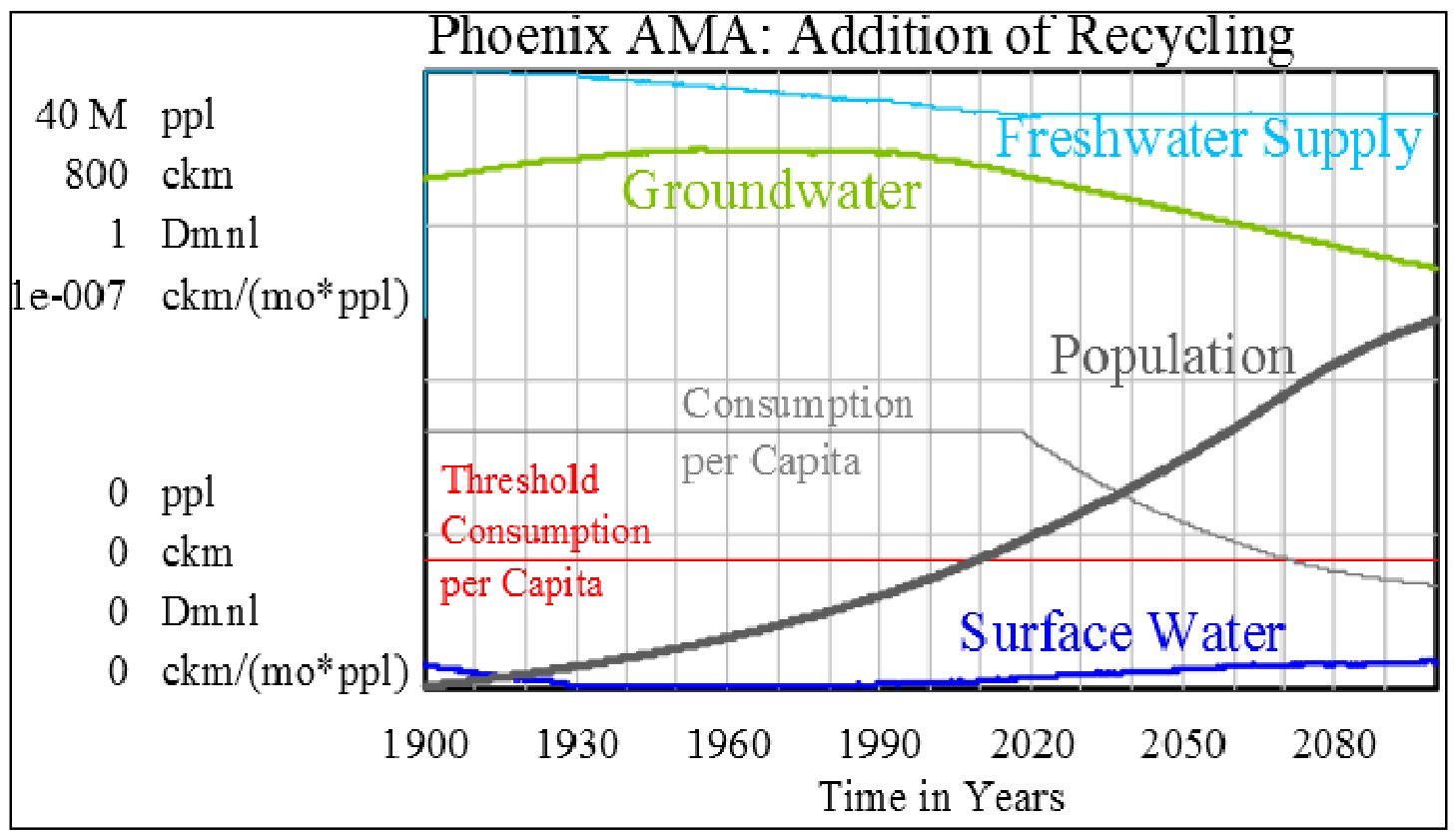

Figure 33: Scenario 2 - simulated behavior patterns of selected system components

amount of recycled water produced by increasing the recycling rate then launching the simulationn. By increasing the recycling variable, we are theoretically creating a situation in which water recycling and reuse becomes a more popular practice within the population, which could be accomplished through increased wiliness or increased means. It is expected that this additional inflow into the stored water supply will lessen pressures on withdrawal from sources by relieving this duty from the sole responsibility of the natural freshwater sources and, instead, sharing it with grey water sources.

The behaviors of the individual five variables are graphed in Figure 34, below. Compared to the baserun, the increased recycling modification resulted in slower decreasing stored freshwater supply, groundwater levels begin to deplete later in time and at a slower rate 
i.e., less steep slope, slower replenishing of Surface Water, population increases faster, and consumption per capita maintains a constant level before quickly dipping below the threshold value for basic needs.

By adding a recycling capacity $\mathrm{R}_{\mathrm{M}}$ of $1 \mathrm{~km}^{3} / \mathrm{mo}$, final population can grow to a maximum of $23 \mathrm{M}$, compared to $14 \mathrm{M}$ without recycling. More importantly, groundwater ends up at a level of $550 \mathrm{~km}^{3}$, compared to $300 \mathrm{~km}^{3}$, which is a significant improvement. Several behavior patterns depicted above in Figure 34, are sufficiently representative of the expectations of the real system under a modified scenario simulation increased generation of recycled water. It was expected that the modified system would show a significant increase of population growth because the population growth is indicative of positive progress in the society. Population as defined by the model is dependent on the system's ability to meet basic consumption needs and the sustainable nature of recycling would ensure those needs to be met. The more gradual depletion of groundwater sources was also an anticipated behavior of the real system because recycled water would relieve withdrawal pressures from this source. Additionally, the slower decrease of normalized freshwater supply was also expected as water reuse should delay any depletion of supply because over time this volume of supply is never lost, only cycled back to the supply stock. However, the slower replenishment of surface water source stocks the downward shift of consumption per capita were both unexpected behaviors and require further analysis.

\subsubsection{Scenario 3 - Improved Technology}

The third scenario is a representation of a modified base scenario with the addition of improved technology. It is assumed that with the advancement of improved technology aimed at providing progressively more water-efficient appliances and devices, freshwater resource conservation will result. Through the mass application of technological solutions such as low flow or motion-sensor faucets and showerheads, dual flush toilets, and drip irrigation, it is expected that the effective demand for freshwater will decrease significantly enough to subside 
some of the withdrawal stresses from freshwater resources while maintaining the major waterconsuming aspects of the population's current lifestyle.

As compared to the baserun, the simulated behavior of the five analyzed components were very different, see Figure 35. Stored freshwater supply decreases slower, then maintains a relatively constant level after about 100 years, a similar behavior to that of scenario 2. Actually, almost all of the components, graphed below in Figure 35, behave similarly as they did in Scenario 2. The only noticeable difference is seen in the behavior of the Groundwater sources stock. In Scenario 3, groundwater levels begin to dip around the same time as they did in the baserun which is slightly earlier than they did in Scenario 2. However, the decline in groundwater

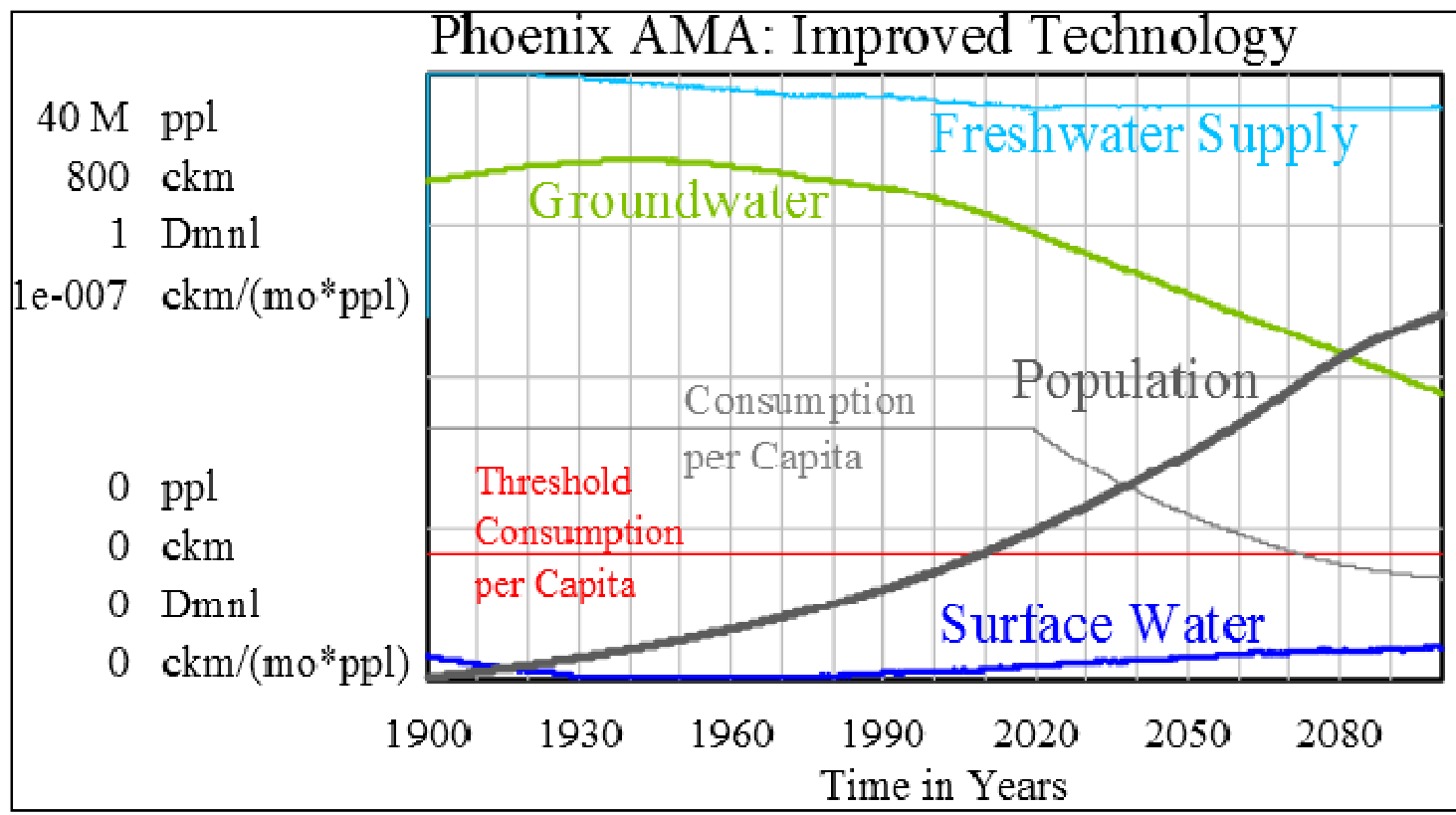

Figure 34: Scenario 3 - Simulated behavior patterns of selected system components sources is more gradual than the baserun, yet more intense than it was in Scenario 2.

By increasing the technology factor to $\tau=2$ (equivalent to reducing effective demand by half), population can grow to a maximum of $24 \mathrm{M}$, compared to $14 \mathrm{M}$ with no technological improvements. More importantly, groundwater ends up at a level of $490 \mathrm{~km}^{3}$, compared to 300 $\mathrm{km}^{3}$ seen in the baserun. Since an improved technology factor of 2 effectively halves the effective 
demand, a slower depletion of groundwater source stocks is expected behavior of the real system because it is understood that less demand creates less withdrawal and therefore, a more gradual rate of decline in groundwater sources. Further, using technology to effectively stretch water supply to last a longer time allows for larger societal growth (i.e., population increase) and slower supply depletions in the same amount of time.

\subsubsection{Scenario 4 - Aging Pipeline}

For the fourth scenario, developers introduced the assumed effects of aging pipelines by decreasing the transfer efficiency and effectively worsening the leakage amounts as freshwater is transported from supply to consumption. When the transfer efficiency is decreased, more freshwater withdrawn from both groundwater and surface water sources or recycled back into supply is a temporary loss of supply as it is taken through leakages then rerouted back in the system. Instead of transferring from supply to consumption, this water loss through leakages, is avoiding consumption and feeding back into groundwater sources where, after a short delay for infiltration into the water table, it is subject to withdrawal for supply, again, as the system cycles. 
The resulting behaviors of the four stock variables and consumption per capita are

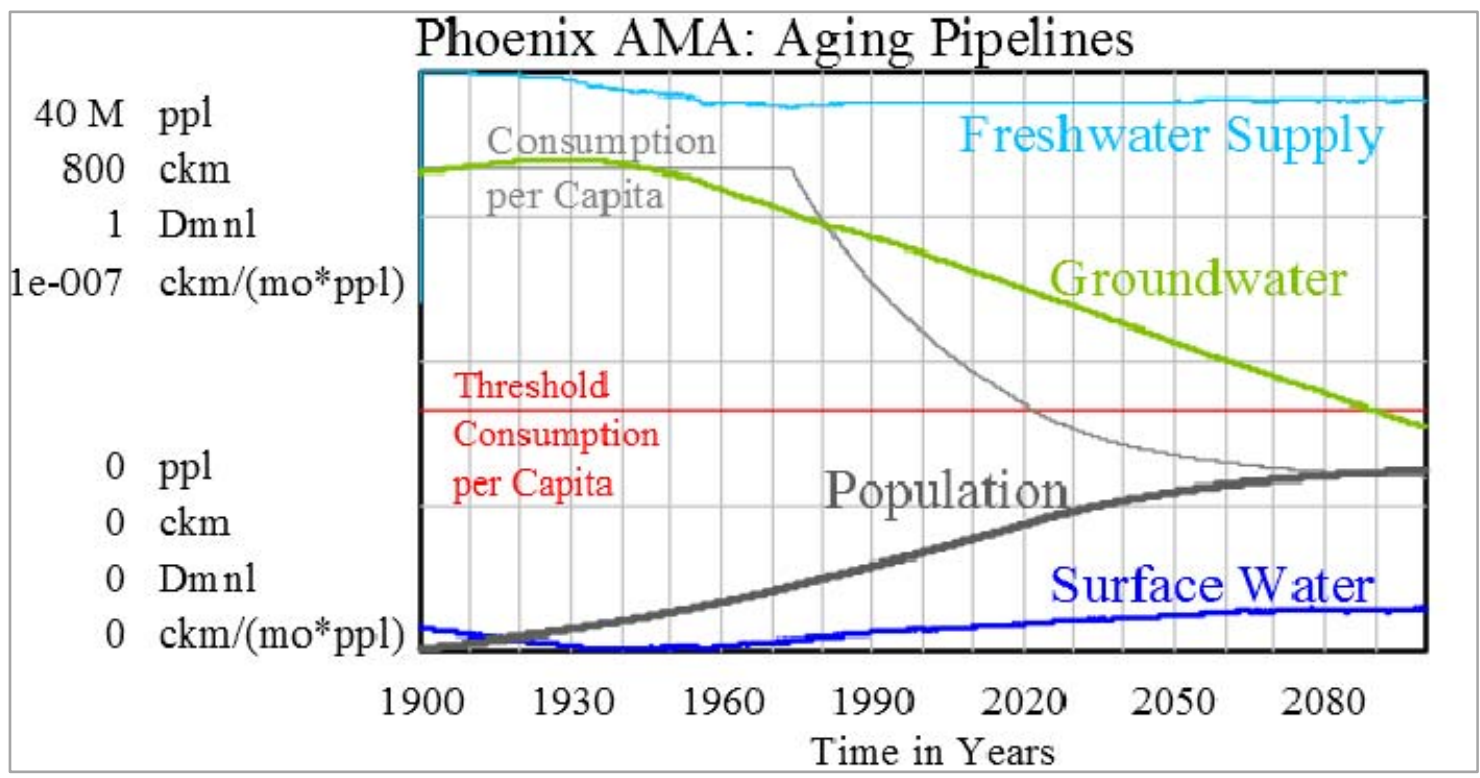

Figure 35: Scenario 4 - Simulated behavior patterns of selected system components

graphed below, in Figure 36. When considering this scenario for the PAMA, it was expected that the results would be mildly worse (i.e., smaller final levels) than the baserun. Since aging the pipelines would assumingly make the system less effective by decreasing the efficiency of transporting freshwater from the sources to human consumption, a negative impact was anticipated. However, because the case study was a developed area where transfer efficiency was already very high, only a drastic impairment of the pipelines would have a significant effect. Since, the transfer efficiency was only diminished by $8 \%$, only a very mild decline was expected to be seen in population levels as compared to the baserun. All other variables were expected to behave similarly to their behaviors in the baserun.

By increasing the net leakage only $8 \%(\eta=0.85$ to $\eta=0.77)$, final population reduces to $12 \mathrm{M}$, compared to $14 \mathrm{M}$ in the baserun. Further, the impact on groundwater is small and essentially unnoticeable, compared to behavior patterns from scenario 1. As anticipated, the wasteful consequences of aging pipelines stunted population growth but only slightly as a result 
relatively small modification to transfer efficiency. Since transfer efficiency directly impacts only the collection flow from supply to consumption, it was appropriate for the other behavior patterns to remain similar to the baserun behaviors.

\subsubsection{Scenario 5 - Improved Pipelines}

Scenario 5 was designed to serve as the contrasting conditions of scenario 4 , where the pipeline distribution portion of the system is improved as opposed to impaired. By increasing the transfer efficiency, we are effectively decreasing leakages and enhancing the effectiveness of the pipeline distribution from supply to consumption. The behavior modifications were expected to be mildly positive. By lessening the losses due to leakage, it was understood that less pressure would be applied on source withdrawal and human demands would be satisfied more efficiently, thereby allowing for more productive conditions, i.e., population increase.

The resulting behaviors of the five analyzed variables for scenario 5 are graphed below in Figure 37. The modified-condition behavior seem to reflect those of the baserun scenario for the most part. However, as expected from the real system, by reducing the leaks $10 \%(\eta=0.85$ to $\eta$ $=0.95$ ), the final population increases to $15 \mathrm{M}$, compared to $14 \mathrm{M}$ (i.e., a mild positive impact). Additionally, as was seen in the previous scenario 4, the impact on groundwater is small and essentially unnoticeable. 


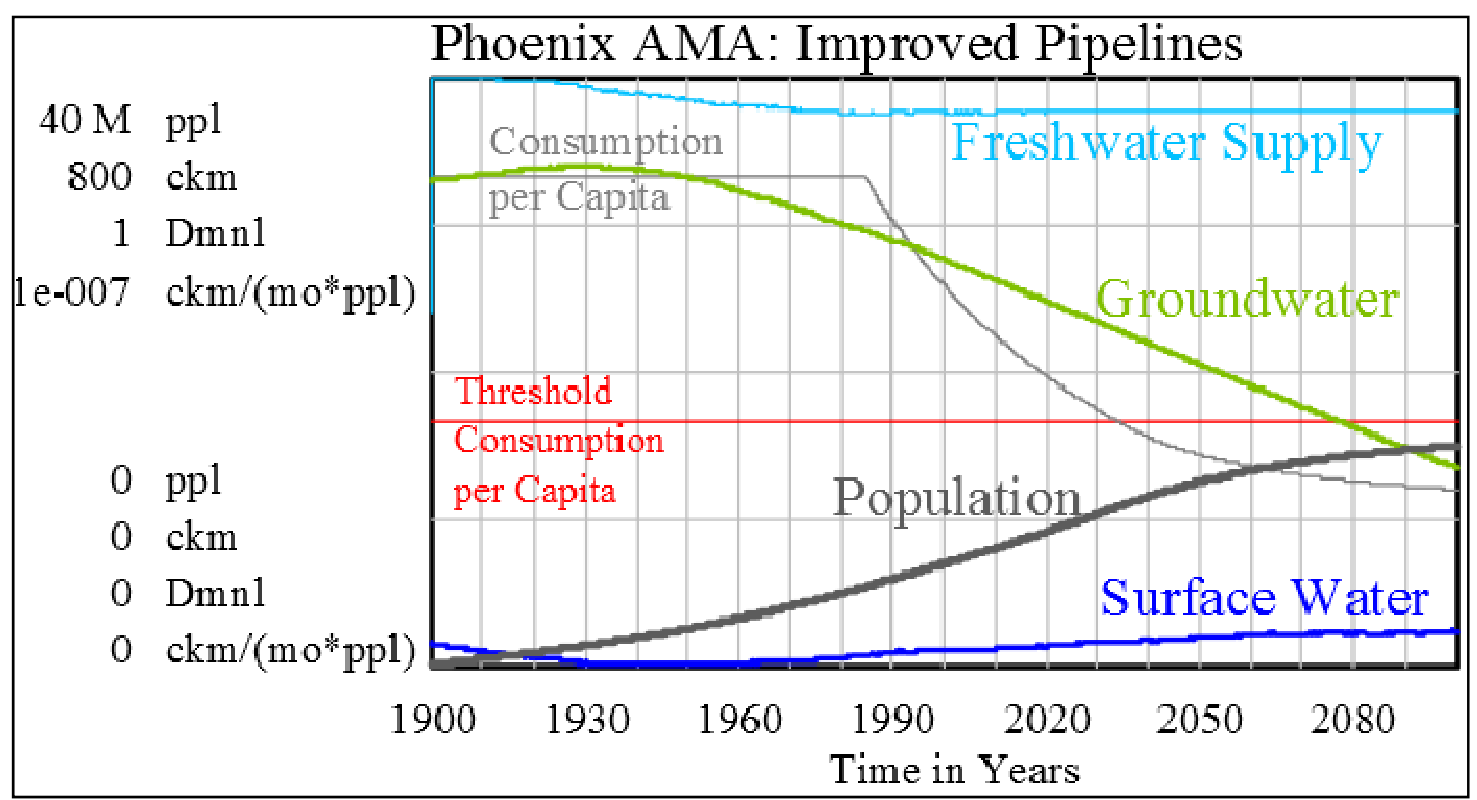

Figure 36: Scenario 5 - Simulated behavior patterns of selected system components 5.2.6 Scenario 6 - Higher Reservoir Capacity 
In Scenario 6, the modified conditions reflect the doubling of the maximum reservoir capacity for retaining stored freshwater, i.e., increasing $\mathrm{z}_{\mathrm{M}}$. This simulation looks at the advantages or disadvantages of increasing the storage capacity of freshwater supply stock through actions such as expanding current reservoir infrastructure or, more likely, building new infrastructure or storage facilities for freshwater supply storage. It was expected that such a

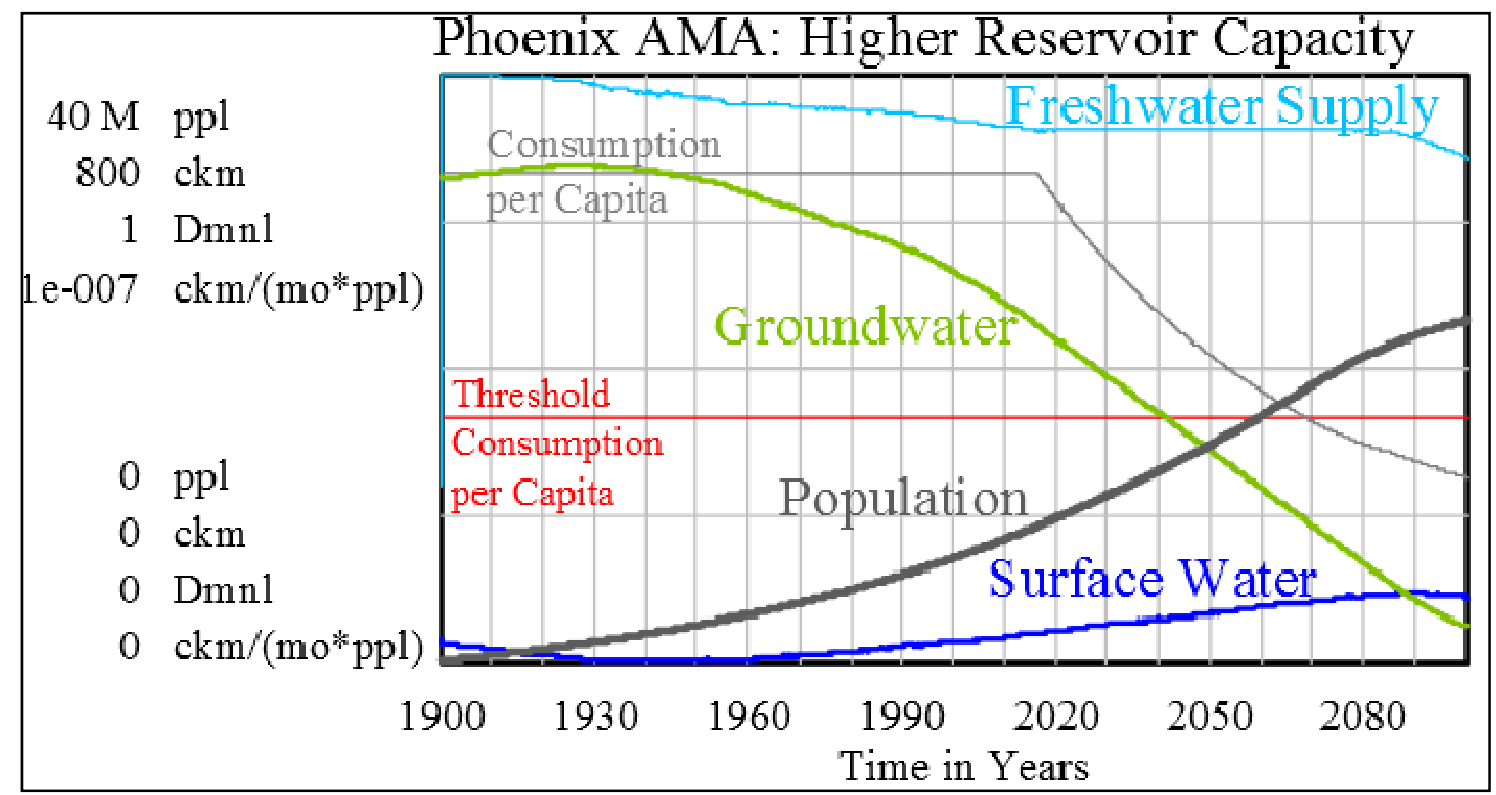

Figure 37: Scenario 6 - Simulated behavior patterns of selected system components

modification in the storage capacity would result in larger withdrawals from sources as a result of the human tendency to abuse use of resources, especially when the resource is considered a 'common'. However, the expectation of significant population growth was also anticipated through the understanding that larger storage and, therefore, larger potentially available supply facilitates progress, so long as sources are not empty. The resulting behavior patterns of the four stocks and consumption per capita are graphed below in Figure 38.

By doubling the reservoir capacity to $\mathrm{z}_{\mathrm{M}}=10$, population can grow to a maximum of $23 \mathrm{M}$, compared to $14 \mathrm{M}$. However, groundwater levels deplete to a low of $50 \mathrm{~km}^{3}$. It is suggested that stricter groundwater withdrawal policies can prevent this unacceptably low depletion. 
Once the behaviors under a 'higher reservoirs capacity' scenario were simulated, results showed that population is given a high potential for growth but at the cost of groundwater resource depletion. From the developers' understand of the real system, this behavior is expected under such conditions but unsustainable and therefore, unacceptable. In the next scenario, developers explored the possibility of a stricter groundwater withdrawal policy in addition to this 'higher reservoir capacity' scenario as an attempt to correct the groundwater depletion while still maintain the population growth.

\subsubsection{Scenario 7 - Higher Reservoir Capacity, Stricter GW Withdrawal Policy}

In Scenario 7, the reservoir capacity is doubled, as was done in the previous scenario, however, it also modifies the number of reserve months, $n$, to reflect implementing stricter groundwater withdrawal policy in the real system. In order to apply a stricter groundwater policy to this scenario, the number of groundwater reserve months $\left(\mathrm{n}_{\mathrm{G}}\right)$ was increased from 60 to 300 months. A large $\mathrm{n}_{\mathrm{G}}$, number of groundwater reserve months, means the effective demand could be met for a longer amount of time with a reserved amount of water guaranteed to be left in groundwater sources. As a result of the growing $\mathrm{n}_{\mathrm{G}}$, the withdrawal from groundwater sources is restricted to maintain the guaranteed quantity.

By increasing the reservoir capacity and increasing the quantity of required groundwater reserves, effectively constricting groundwater withdrawal, the system will be reflecting larger freshwater storage potential and more conservative groundwater use practices. It was expected that the majority of population growth will be maintained, though anticipated to slightly decrease and a function of the limitation on withdrawal, while the groundwater source stock levels are expected to be larger and healthier as compared to Scenario 6 .

The behaviors of the four stocks and consumption per capita under the above mentioned conditions are graphed above in Figure 39. The reservoir capacity is doubled to $z_{M}=10$, but simultaneously, groundwater reserve months is increased from $\mathrm{n}_{\mathrm{G}}=60$ ( 5 years $)$ to $\mathrm{n}_{\mathrm{G}}=300(25$ 
years). As compare to Scenario 6, Population grows to a final level of 21M instead of 23M.

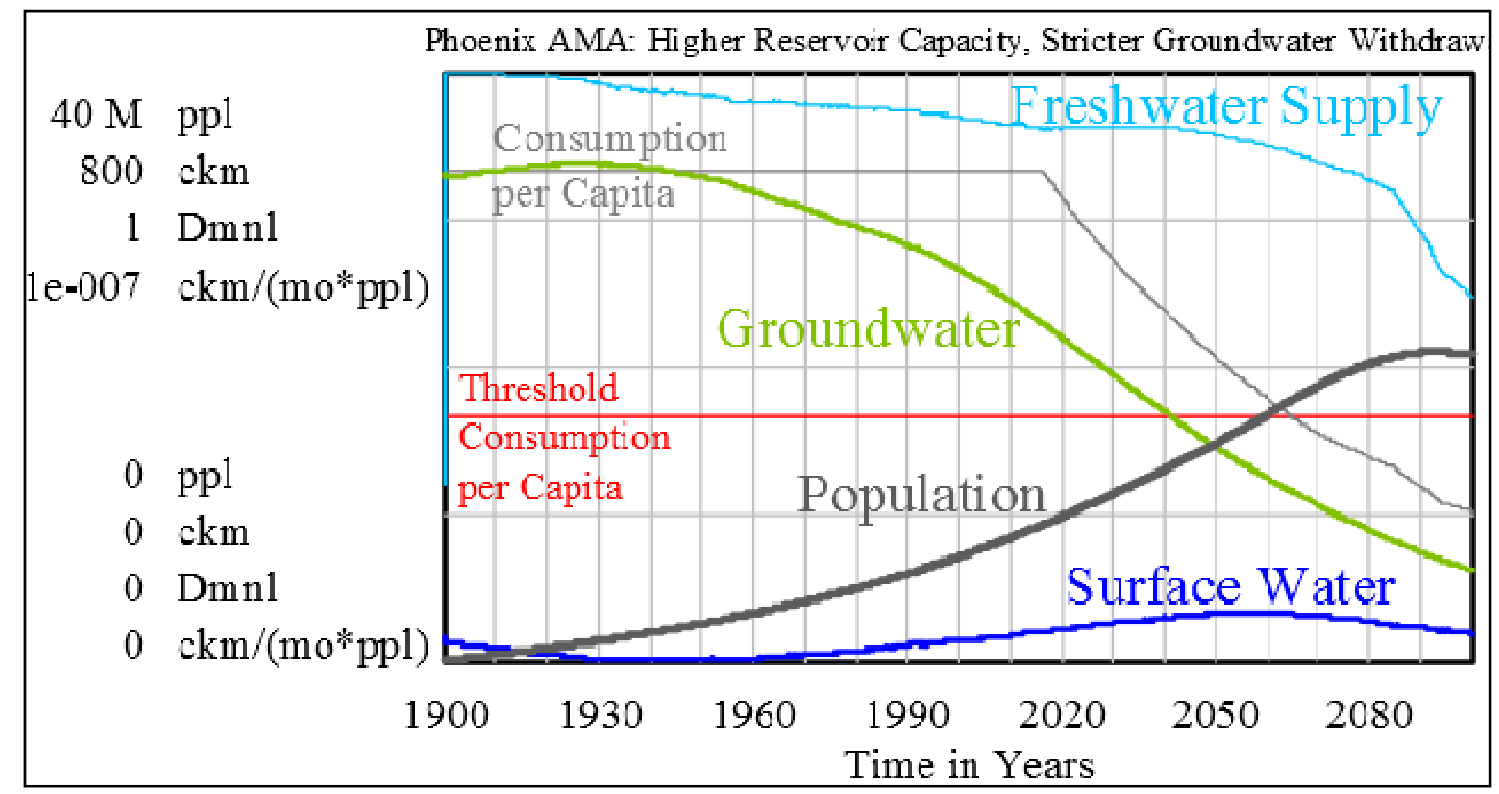

Figure 38: Scenario 7 - Simulated behavior patterns of selected system components

However, groundwater ends up at a level of $140 \mathrm{~km}^{3}$, which is much healthier than the $50 \mathrm{~km}^{3}$ reached when no changes in groundwater withdrawal policy are implemented.

\subsubsection{Scenario 8 - Lower GW Estimates}

Volumetric groundwater estimations are known to be very difficult to approximate with certainty. Therefore, this scenario represents conditions in which the initial estimation of groundwater sources, in the baserun, was too high and instead the system began with lower than originally expected groundwater estimates. To simulate this modification of groundwater sources, the initial value was decreased by half and the simulation was launched.

It was expected that a lower initial value would undoubtedly result in a lower final value of groundwater source stock levels. However, this scenario sets the stage to investigate the impact of a stricter groundwater withdrawal policy as was done with higher reservoir capacity in scenarios 6 and 7. The behaviors of the five analyzed components under the modified conditions of scenario 8 are graphed in Figure 40, below. 


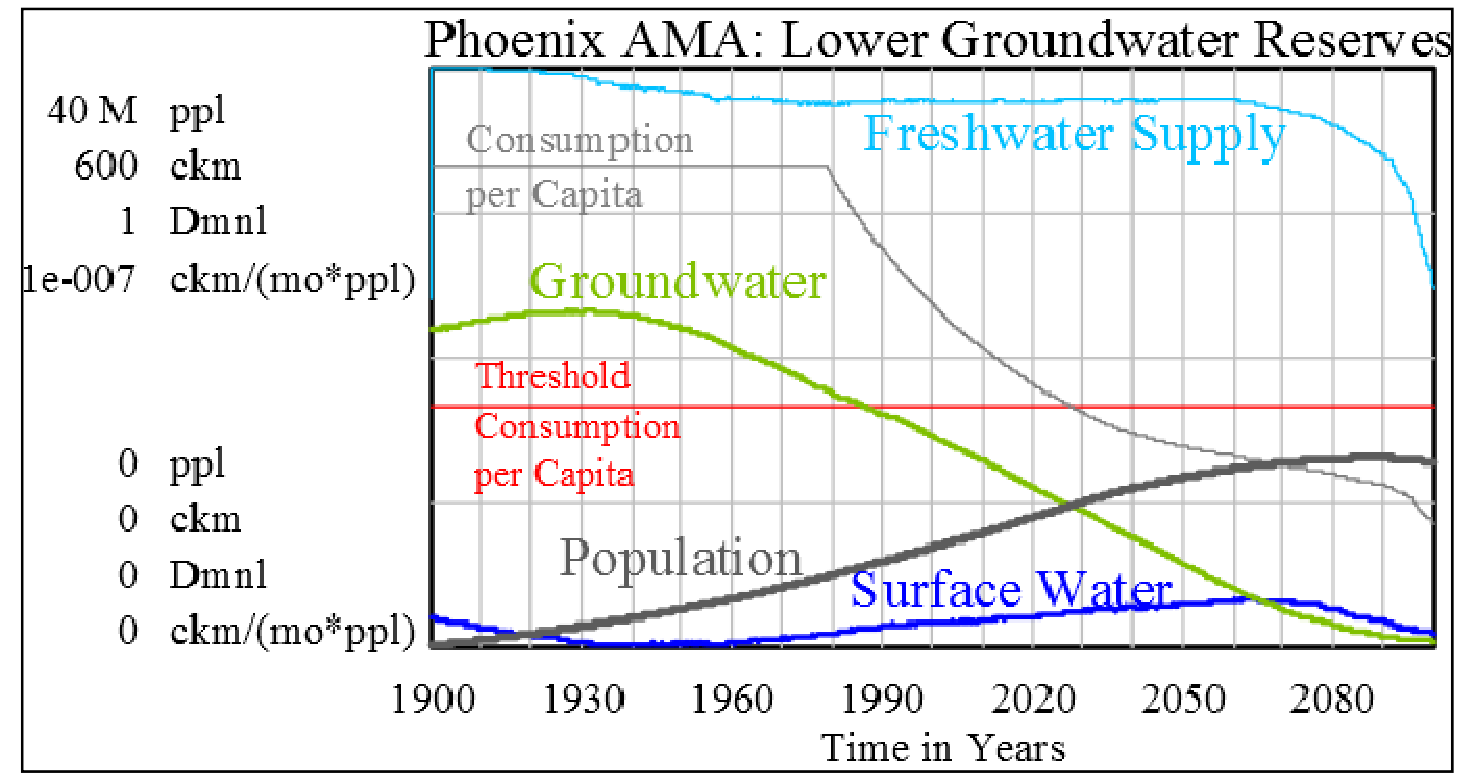

Figure 39: Scenario 8 - Simulated behavior patterns of selected system components

With a $50 \%$ error in the original estimate of the initial groundwater, population growth is stunted, only growing to a maximum of $13 \mathrm{M}$, compared to $14 \mathrm{M}$ seen in the baserun. However, groundwater ends up at a much lower level of $5 \mathrm{~km}^{3}$, which is unacceptable for a sustainable system. Lower initial estimates of groundwater source stock levels is expected to lower to have a significant negative impact on all stock levels in the real system. If the PAMA region had half of the groundwater stock of what was originally estimated, not only would both ground and surface water source level eventually deplete completely but population growth would also be negatively affected as basic water need are not met.

As seen from scenarios $6 \& 7$, implementing stricter groundwater withdrawal policies could resolve this drawback. In the following scenario 9, the resulting modified behaviors from lower groundwater estimates and simultaneous stricter groundwater withdrawal policy are examined.

\subsubsection{Scenario 9 - Lower GW Estimate, Stricter Withdrawal Policy}

As the final scenario, the system operates under modified conditions where the initial groundwater estimates are half of what was originally simulated in the baserun and stricter 
groundwater withdrawal policy is applied. Groundwater source stock levels are dropped to account for estimation uncertainties and stricter policy was included to analyze its impact on the groundwater source final level. It is expected that the addition of policy changes will result in a higher final level of groundwater sources as compared to behavior from scenario 8 . However, impacts on population are expected to be a greater restriction of growth. The behaviors of the stock variables and consumption per capita under the modified conditions of scenario 9 are graphed in Figure 41 below.

The initial groundwater is reduced to $\mathrm{y}_{\mathrm{G}, \mathrm{I}}=330$, but at the same time, groundwater reserve months is increased from $\mathrm{n}_{\mathrm{G}}=60$ to $\mathrm{n}_{\mathrm{G}}=300$. Population grows to a final level of $10 \mathrm{M}$ instead of $13 \mathrm{M}$, as seen in scenario 8 . However, groundwater ends up at a level of $40 \mathrm{~km}^{3}$, which is much more acceptable than the $5 \mathrm{~km}^{3}$ final level reached when no changes in groundwater withdrawal policy are simulated. The addition of a stricter groundwater withdrawal policy in the presence of lower estimated initial groundwater levels serves to conserve groundwater source stocks yet, restrain population growth as expected. By limiting withdrawals, replenishing sources stocks is becomes easier but population is becomes more difficult

\subsubsection{Simulation Summary}

In this section, the final levels of Population and groundwater source stock from the nine scenarios are summarized. The baserun scenario is used as a foundation for comparison with all other scenarios. The eight other thought experiments investigate the behavioral changes within the system as a result of modified conditions. The suite of experimental simulations are used to serve as a comparative tool, providing insight toward potential actions concerning sustainable freshwater resource management, including, recycling, technology, upgrading/degrading piping, storage capacity, groundwater uncertainty and withdrawal policy. The final levels of population and groundwater source stocks, from all nine simulations, are graphed below, in Figure 42. 
Final Population (Millions of People)

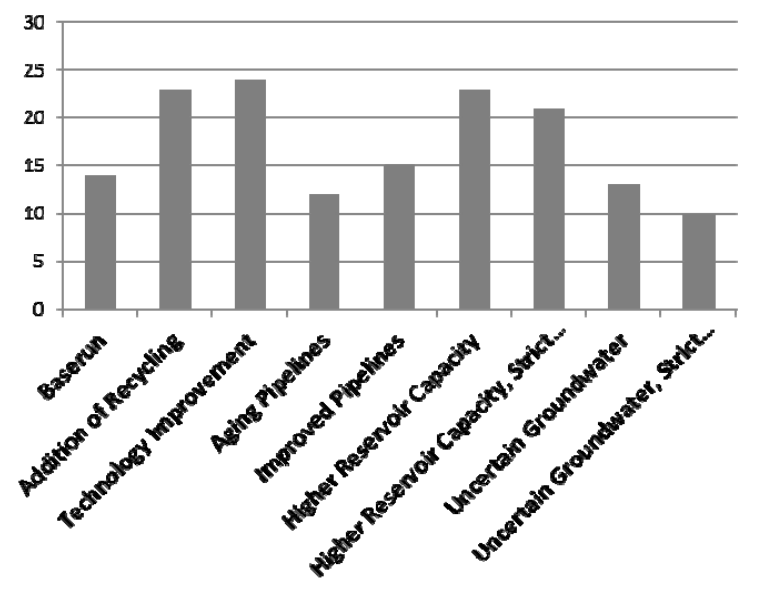

Final Groundwater (ckm)

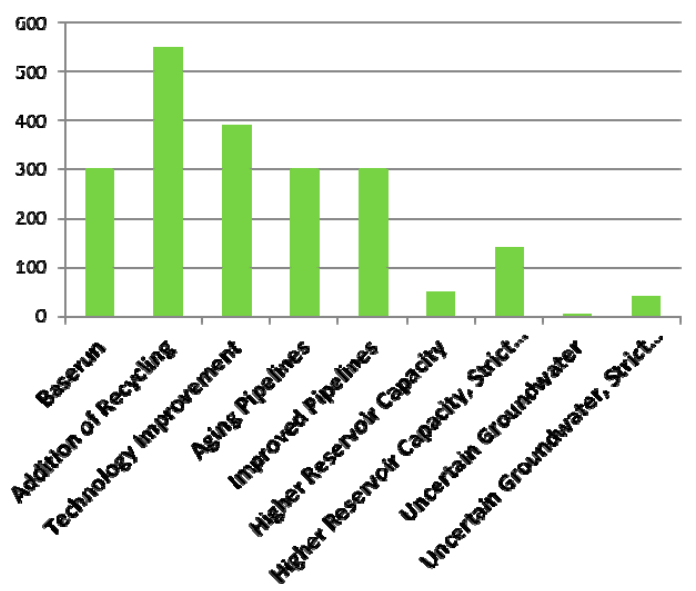

Figure 40: Final Population and Final Groundwater Source levels for nine simulations

As can be seen in the charts above, Figure 42, some simulations performed better (i.e., higher final levels) and some perform worse (i.e., lower final levels) than the base scenario, in terms of population and ground water source stocks. Final population levels were able to grow the highest under improved technology conditions, which also produced the second largest final groundwater source level. Final groundwater levels were able to grow the most under increased recycling condition, which also produced the second largest final population level. These results suggest that increased recycling and technological improvements would be the most effective political strategies toward achieving sustainability within the real system.

\section{DISCUSSION}

This section provides a review of the accumulated tentative validation provided by the extreme condition and sensitivity tests performed on the Somalia case study, in addition to the analysis of the baserun and 8 modified scenarios simulated for the PAMA case study, serving as a modified behavior test. The discussion will begin with the analysis of the PAMA thought experiment scenarios. 
The majority of the modified behaviors, particularly of the stock variables, were relatively predictable from knowledge of the real system and were expected. Such results provide sufficient evidence for building further confidence in the model's representation of the real system. The only real unexpected behavior pattern was seen in the consumption per capita simulations. Still, it was only partially unexpected. The behavior patterns of consumption per capita is considered partially unexpected because the expectation of the real system would involve a sharp decline in the presents of slower population growth, or decline from baserun, and a more mild decline in the presence of faster population growth. This expectation was noticed in the behavior patterns of the simulations. For example, both, scenarios 2 and 3 saw more gentle declines in consumption per capita in the presence of their significant population growths, while scenarios 4 and 9 experienced much steep declines in consumption per capita in the presence population decline (in comparison to the baserun). However, the unexpected immediate sharp drop after a considerable period of a constant, sustained level is a behavior pattern deserving of further analysis.

The results for the Somalia case study simulation and sensitivity testing served as valuable evidence toward the initial validation of the COWA model. The general behavior patterns of the source stock and supply stock of the real system were simulated in the appropriately time frame and the system's sensitivity to both the technology factor and transfer efficiency was expected of this undeveloped region. The simulation results provided the necessary evidence to justify continuation of model validation using modified behavior test for another case study with fewer information gaps, as to provide better knowledge of expected real system behavior under the modified conditions.

COWA needs further improvement, however this could be said about all models at any stage of development. Modeling is generally considered, both, an art and a science. With improved development and increased availability of data, there will always be room for improvement in 
regards to representing reality through models. Nevertheless, it is important to understand the general behaviors of the different systems that impact our livelihoods, if sustainability is to be achieved. This research argues that modeling these systems using a SD approach will provide the necessary insight for obtaining a sustainable future.

There are several specific improvements intended to be adopted in the next version of COWA; (1) The coupling of a GIS component will provide COWA with the much desired spatial differentiation; (2) Redefining the birth rate and minimum death rates as changing in time, rather than a constant value throughout the entire 200 year simulation; (3) Revaluating structure of consumption per capita.

It is important to note that if the simulation was for a shorter time duration a constant average value for birth rate and minimum death rate may be sufficient, however, there is considerable change in birth and minimum death rates in 200 years, thereby proving a long term average constant value to be insufficiently representative of the upper and lower temporal bounds. It is intended to fix this through the use of the 'lookup value' function which allows for behavior of a variable to be defined by given ( $\mathrm{x}, \mathrm{y})$ points specifically indicated by a customizable graph. This solution would allow the time-specific variables to hold a short term (approximately 10-20 years) average value and change accordingly in the next time step, another 10-20 years later.

The GIS coupling will be relatively more difficult to apply but possible nevertheless. The proposed approach to this improvements is a new software tool called SimArc (Mazzoleni, Hiannino, Colandrea, Nicolazzo, \& di Agaria, 2003). The SimArc software was recently developed to interface the SD software Similie and the GIS platform ArcView. This integration allows for the SD model to be driven by GIS data input. The SimArc tool essentially runs the SD model and produces output for each individual pixel in the GIS layer, using that pixel's layered data as input for the model, shown in Figure 43, below. 


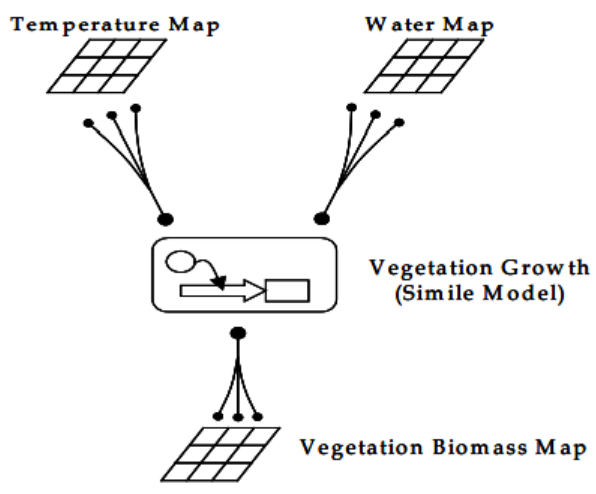

Figure 41: SimArc - A schematic of an application from Similie and ArcView

The SimArc approach to integrating the spatial variation of GIS data with the temporal simulation of SD modeling is planned to be executed for the doctoral dissertation of this continued research. However, before this integration can be made, the COWA model requires further behavioral validation and is hoped to be expanded into the socio-economic model proposed in Figure 44, below.

A team of scientists at the University of Maryland have developed a Socio-Economic Model (SEM) and intend to couple it with a Global Agro-Ecological Zones Model (GAEZ) through the linkage between available land to consume and the productivity of that land. This coupling has allowed for the study of mutual interaction of land use and land cover changes (LULCC) with various socio-economic drivers. This SEM-GAEZ model is represented by the left hand side of the diagram below in Figure 44. Since water is a major factor of natural and manufactured production, it is essential to couple the right hand side and left hand side models represented in the diagram below and thereby allowing the study of the fully integrated socioeconomic water system which includes water, climate, agriculture, energy and human system components. We propose to develop a more detailed version of COWA that includes consumption in various sectors of economy and couple it to the other three systems shown below. 


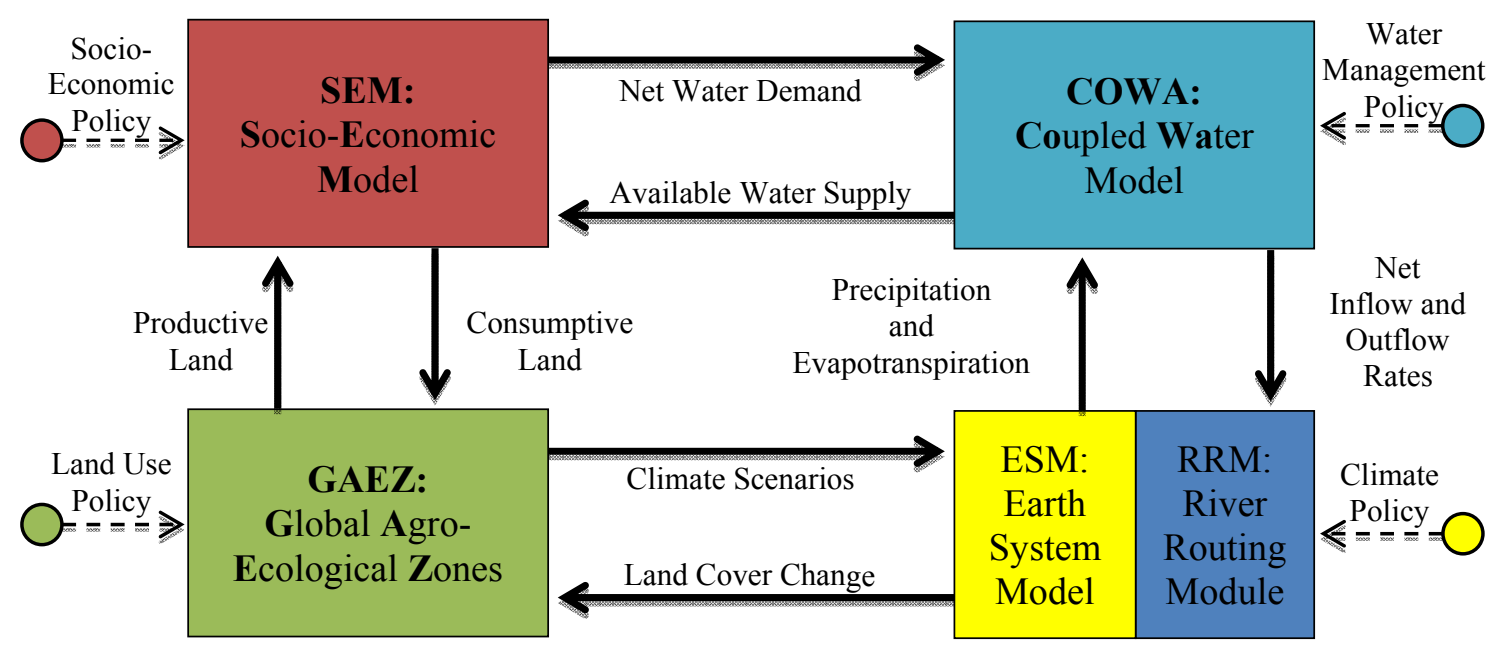

Figure 42: Future expectations of COWA, coupling among four models

By using public policy to drive the four sub-systems within the larger fully-coupled socio-economic water model, politicians, economists, and environmentalists will have a universal tool to help achieve sustainability through better decision making. Creating a model representing a system such as the one depicted from the schematic in Figure 44, will provide a platform for needed communication between several different but connected disciplines (e.g., politics, economy, hydrology, agriculture, climatology, and demography).

\section{CONCLUSION}

Thoroughly understood behaviors are easiest to anticipate and progressing into the future can only be accomplished if our basic needs are met. Mastering the management of freshwater resources, the life source of all living organism, for today and future generations, can only be done through the comprehension of the natural-human system and all its parts. System Dynamics modeling provides an approach for obtaining such comprehensive knowledge.

The model created in this research was applied to two case studies, similar in their natural system, yet, completely opposite in their human system. The Somalia and PAMA case studies served to show the models' ability to simulate the behavior of the same natural-human freshwater system variables under contrasting conditions. The results from both direct structure validation 
testing and structure-oriented behavior validation testing provided sufficient evidence for building initial confidence and established tentative validation in COWA's structure. However, further refinement of the structure is planned as part of the additional coupling of the SEM and GAEZ models.

The research in this thesis is the first step toward a larger goal for the COWA model. The final product is meant to serve as a comprehensive management tool used to create a sustainable environment, in all capacities, both in nature and society. It is argued that static management aimed at controlling and manipulating natural flows to fit anthropogenic demands is an outdated and naïve approach to systems management. Instead, it is suggested, that a more flexible management aimed at an implicit understanding of the natural flows to, rather, control and manipulate anthropogenic demands to adjust to current or potential conditions is a more appropriate approach to system management. The adaptive nature of the suggested approach helps build social resilience toward the uncertainties of the future. After all, it seems illogical to expect a single solution to fit every problem. As conditions in the natural system remain in a state of constant flux, it is argued that the most appropriate management strategies will be those catered toward change. It is expected that through SD modeling a comprehensive insight into the system's dynamics and alternative outcomes become possible. By establishing a basis for understanding the system from the inside out, it is hoped a more rationally based and accountable relationship will evolve between decision makers and their decisions. 


\section{LIST OF REFERENCES}

ADHS. (2013, December). Arizona Vital Statistics Trends-Deaths. Retrieved from Populatoin Health and Vital Statistics: www.azdhs.gov/plan/menu/info/trend/vstrendsdeaths.htm

ADHS. (2013, December). Birth Statistics. Retrieved from Population Health and Vital Statistics: www.azdhs.gov/plan/menu/for/births.htm

ADWR. (2010). Arizona Water Atlas Volume 8.1: Phoenix Active Management Area. ADWR.

ADWR. (2011). Phoenix Active Management Area Water Demand and Supply Assessment: 19852025. Phoenix, AZ: ADWR.

Ahmad, S., \& Prashar, D. (2010). Evaluating Municipal Water Conservation Policies Using a Dynamic Simulation Model . Water Resource Management, 3371-3395.

Alcamo, J., Doll, P., Henrichs, T., Kaspar, F., Lehner, B., Rosch, T., \& Siebert, S. (2010). Development and testing of WaterGAP 2 global model of water use and avilability. Hydrological Science Journal, 317-337.

AWBA. (2014). Arizona Water Banking Authority. Retrieved from Water Storage: http://www.azwaterbank.gov/Water_Storage/Recharge_and_Facilities.htm

Bankes, S. (1993). Exploritory modeling for policy analysis. Operations Research, 439-449.

Barlas, Y. (1994). Model Validation in System Dynamics. 1994 International System Dynamics Conference, (pp. 1-10). Sterling, Scotland.

Central Intelligence Agency. (2013). The World Factbook. Retrieved from Somalia: www.cia.gov/library/publications/the-world-factbook/geos/so.html

Davis, E., \& Simonovic, S. (2010). ANEMI: a new model of integrated assessment of global change. Interdisciplinary Environmental Review, 127-161.

FAO. (2004). Drought-resistant soils Optimization of soil moisture for sustainable plant production. FAO Land and Water Bulletin (p. Discussion Papers). Rome: FAO.

FAO. (2014, May). Somalia Country Fact Sheet. Retrieved from Aquastat: http://www.fao.org/nr/aquastat/

Forrester, J. (1971). World Dynamics. Wright-Allen Press.

Forrester, J. (1994). System Dynamics, Systems Thinking and Soft OR. System Dynamics Review, pp. 1-13.

Forrester, J. W. (1969). Urban Dynamics. Cambridge, MA: M.I.T. Press.

Forrester, J. W., \& Senge, P. (1980). Tests for Building Confidence in System Dynamics Models. TIMS Studies in the Management Sciences, 209-228. 
Forrester, J., \& Senge, P. (1980). Test for Building Confidence in System Dynamics Models. TIMS Studies in the Management Sciences, 14, 209-228.

Gober, P., Wents, E., Lant, T., Tschudi, M., \& Kirkwood, C. (2011). WaterSim: a simulation model for urban water planning in Phoenix, Arizona, USA. Environment and Planning B: Planning and Design, 197-215.

Google Earth. (2014). Somalia and Phoenix Active Management Area.

Grove, R., \& Hetzel, A. (1968). Vital Statistics Rates in the United States 1940-1960. Washington, D.C.: National Center for Health Statistics.

Hardin, G. (1968). The Tragedy of the Commons. Science, 162, 1243-1248, dio: 10.1126/science.162.2859.1243.

Howe, P., \& Devereux, S. (2004). Famine Intensity and Magnitude Scales: A Proposal for an Instrumental Definition of Famine. Disasters, 353-372.

Internal Revenue Service. (2014, April). SOI Tax Stats - County-to-County Migration Flow Data Files. Retrieved from IRS.gov: www.irs.gov/uac/SOI-Tax-Stats-County-to-CountyMigration-Data-Files

Lee, E., \& Schwab, K. (2005). DeficienciesIn DrinkWaterDistributionSystemsinDevelopingCountries. Journal of Water and Health, 109-127.

Lempert, R., Popper, S., \& Bankes, S. (2003). Shaping the Next One Hundred Years: New Methods for Quantitative Long-Term POlicy Analysis. Santa Monica, CA: RAND.

Linder, F., \& Grove, R. (1947). Vital Statistics Rates in the United States 1900-1940. Washington, D.C.: UNited States Public Health Service.

Lui, J., Dietz, T., Carpenter, S., Folke, C., Alberti, M., Redman, C., . . Provencher, W. (2007). Coupled Human and Natural Systems. AMBIO: A Journal of the Human Environment, 639-649.

Mazzoleni, S., Hiannino, F., Colandrea, M., Nicolazzo, M., \& di Agaria, F. (2003). Integration of System Dynamics Models and Geographic Information Systems. Modeling and Simulation, 304-306.

McGinnis, M., \& McGinnis, K. (2014). Water Conservation Technology. Retrieved from Benefits of Recycling: http://www.benefits-of-recycling.com/waterconservationtechnology/

Meadows, D., Meadows, D., Randers, J., \& Gehrens, W. (1972). The Limits to Growth. New York: New American Library. 
Molteni, F. (2003). Atmospheric simulation using a GCM with simplified physical parameterization. I:model climatology and variability in multi-decadal experiments. Climate Dynamics, 175-191.

Moriarty, P., Butterworth, J., \& Batchelor, C. (2004). Integrated Water Resource Management: And the domestic water and sanitation sub-sector. The Netherlands: IRC International Water d Sanitation Centre.

Pahl-Wostl, C. (2002). Towards sustainability in the water sector: the importance of human actors and processes of social learning. Aquatic Science, 394-411.

Population Reference Bureau. (2011, August). Population Handbook 6th Edition. Population Change. Washington, D.C.

Random House Unabridged Dictionary. (1994). Random House Reference.

Robson, S., \& Banta, E. (1995). Groundwater Atlas of the United States, HA 730-C. Retrieved from United States Geological Survey: http://pubs.usgs.gov/ha/ha730/ch_c/index.html

Stockholm Environmental Institute. (1997). Comprehenssive Assessment of Freshwater Resources of the World. Stockholm, Sweden: Stockholm Environemntal Institute.

SWALIM. (2007). Rural Water Supply Assessment Project Report W-8. Nairobi, Kenya: SWALIM.

SWALIM. (2007). Water Resources of Somalia Project Report W-11. Nairobi, Kenya: SWALIM.

Thirty-Thousandy.org. (2007, December). Hypothetical Annual Population Projection for the United States by state. Retrieved from Thirty-Thousand.org: http://www.thirtythousand.org/documents/QHA-01_2100.pdf

UN. (2013). World Propulation Prospects: The 2012 Revision. New York: Population Division of the Department of Economic and Social Affairs of the United Nations Secretariat.

United Nations. (2013). World Population Prospects: The 2012 Revision. New York: Department of Economic and Social Affairs Population DIvision.

USGS. (2014, March). The USGS Water Science School. Retrieved from The Summary of the Water Cycle: http://water.usgs.gov/edu/watercyclesummary.html

Waterfall, P. (2004). Harvesting Rainwater. Tuscan, AZ: University of Arizona. 
APPENDICES 


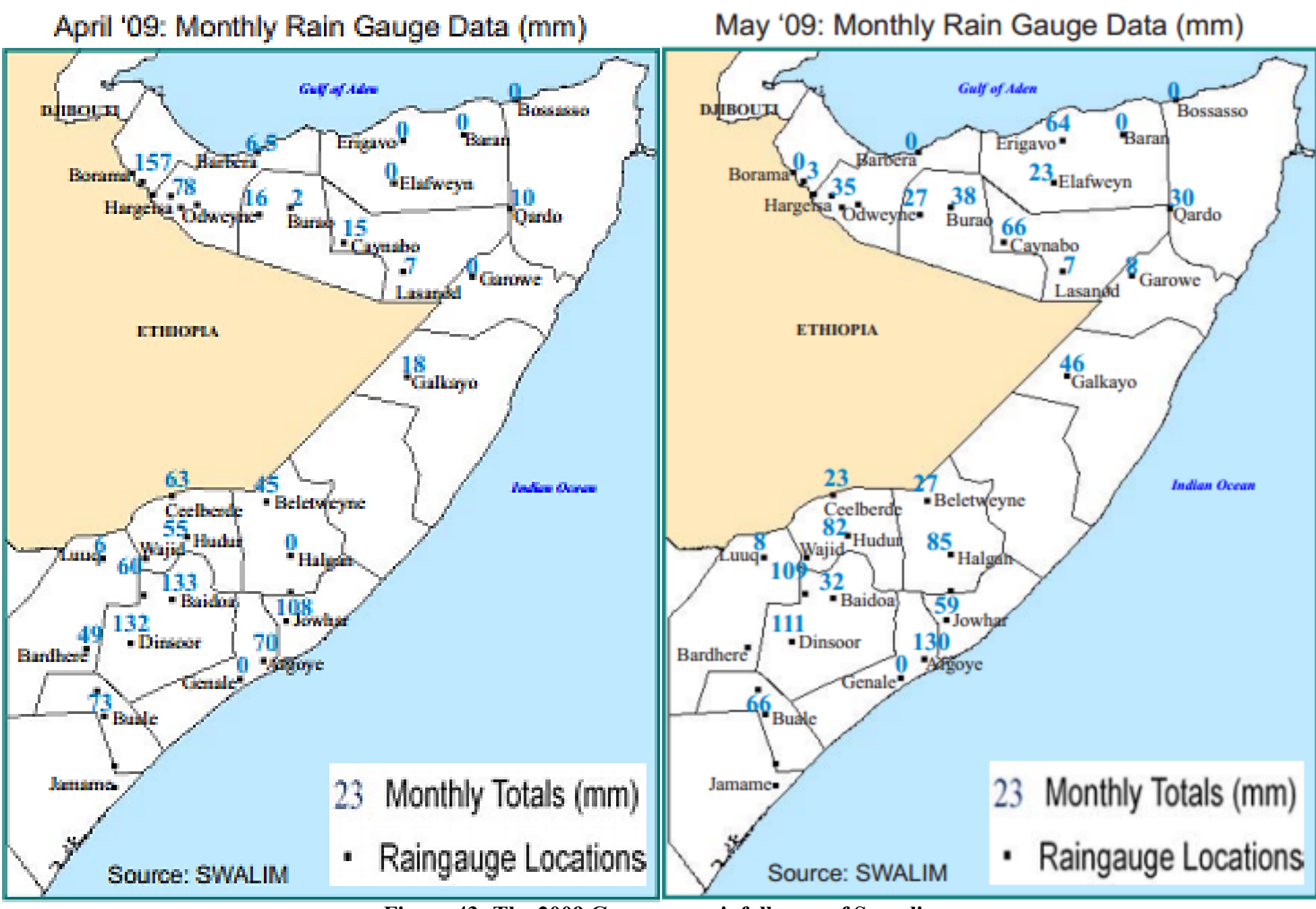

Figure 43: The 2009 Gu season rainfall map of Somalia

Appendix A. - Gu and Deyr seasons (2009 - 2011) rainfall maps in Somalia 
Appendix A. - cont.

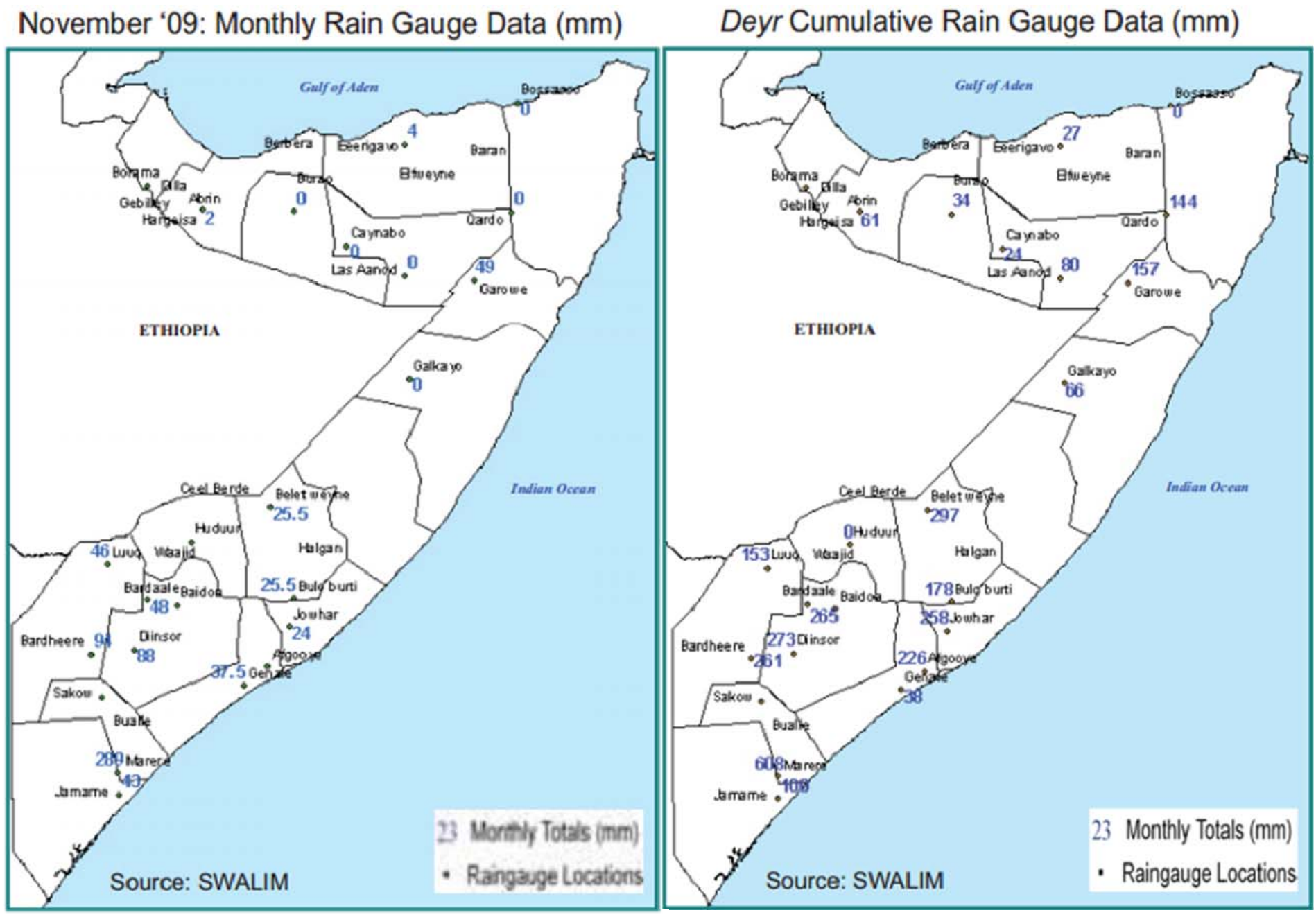

Figure 44: 2009 Deyr season rainfall map of Somalia 
Appendix A. - cont.

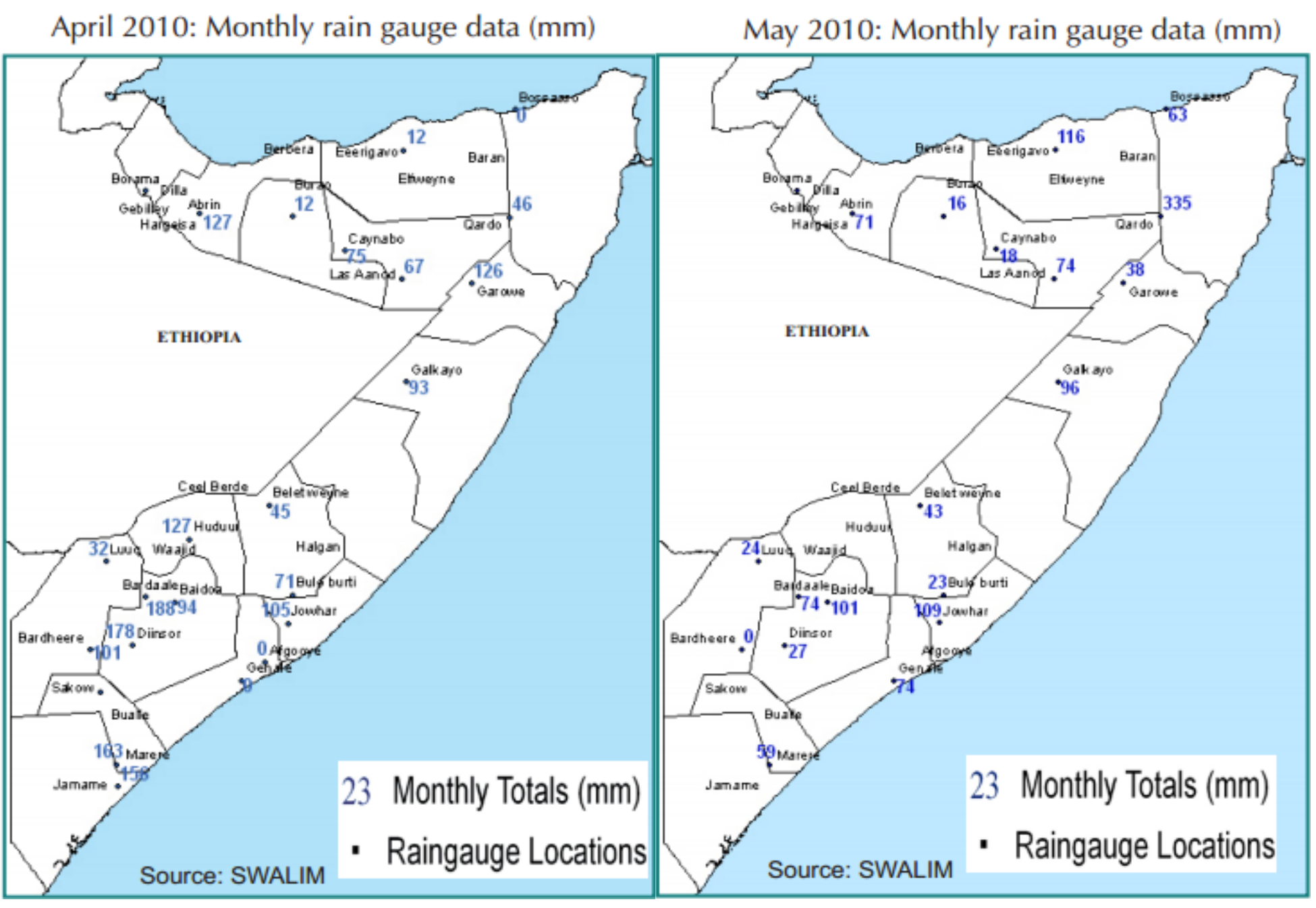

Figure 45: The 2010 Gu season rainfall map of Somalia 
Appendix A. - cont.

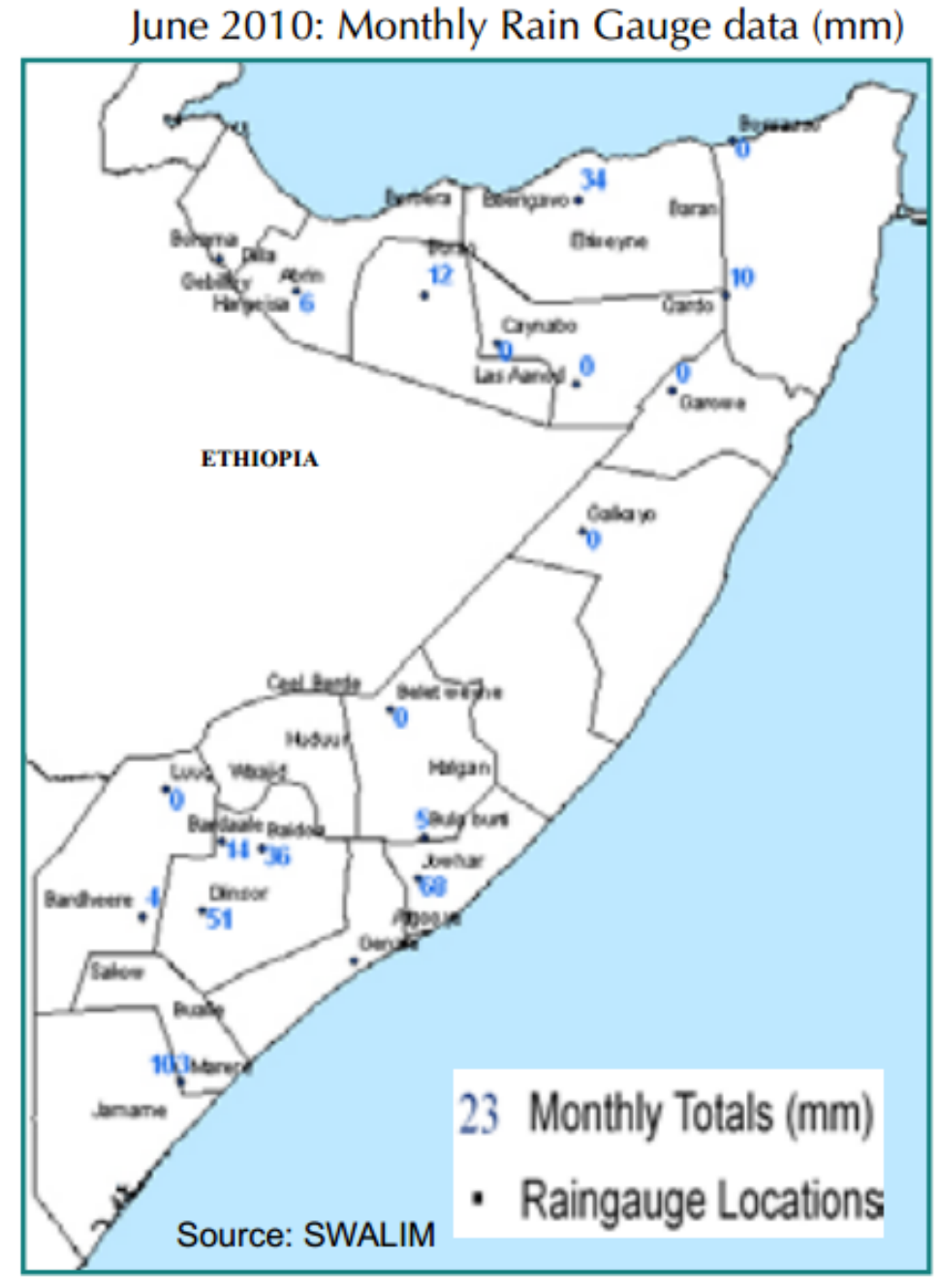

Figure 46: The 2010 Gu season rainfall map of Somalia (cont.) 
Appendix A. - cont.

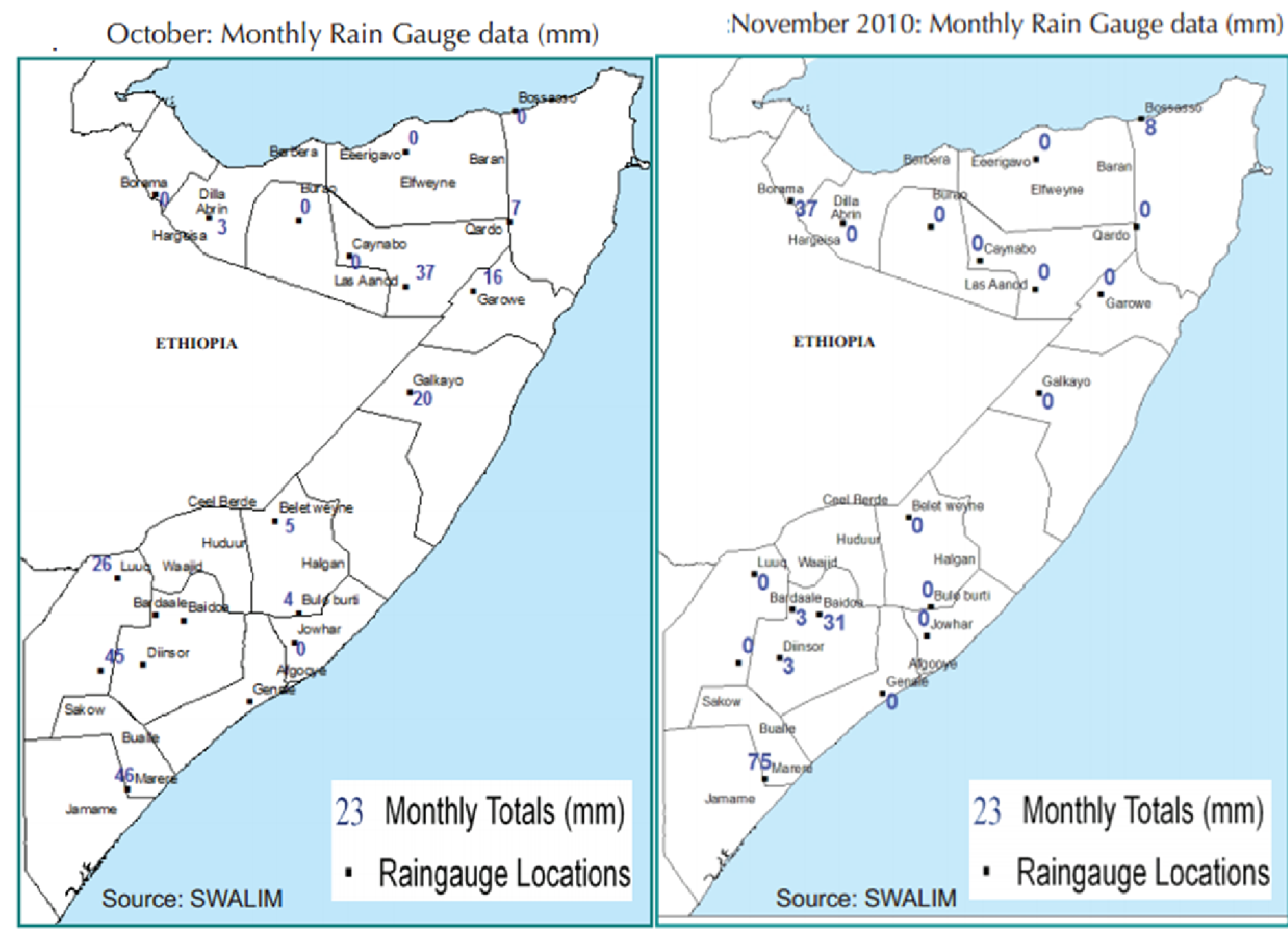

Figure 47: 2010 Deyr season rainfall map of Somalia 
Appendix A. - cont.

April 2011: Monthly Rain Gauge data (mm)

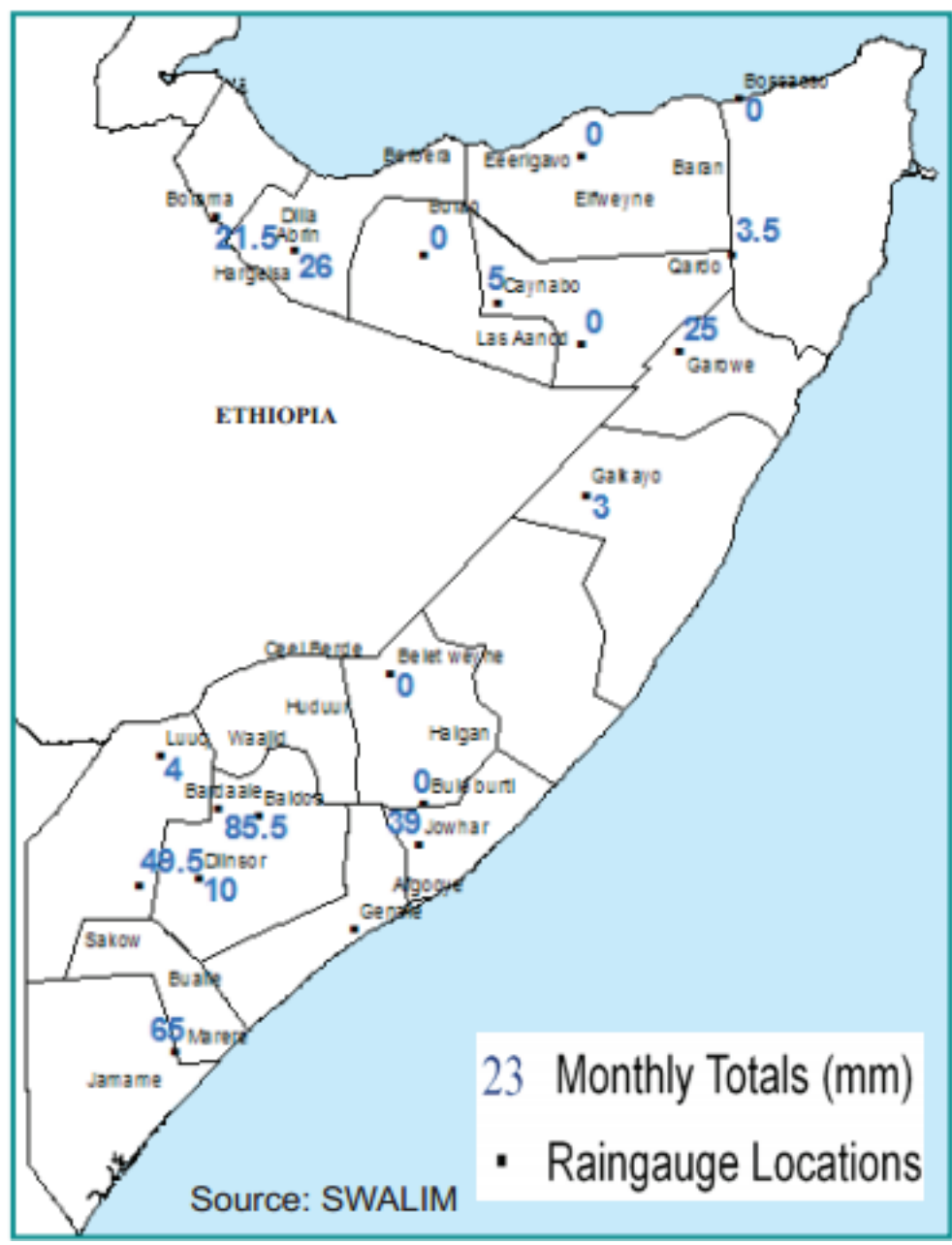

May 2011: Monthly Rain Gauge data (mm)

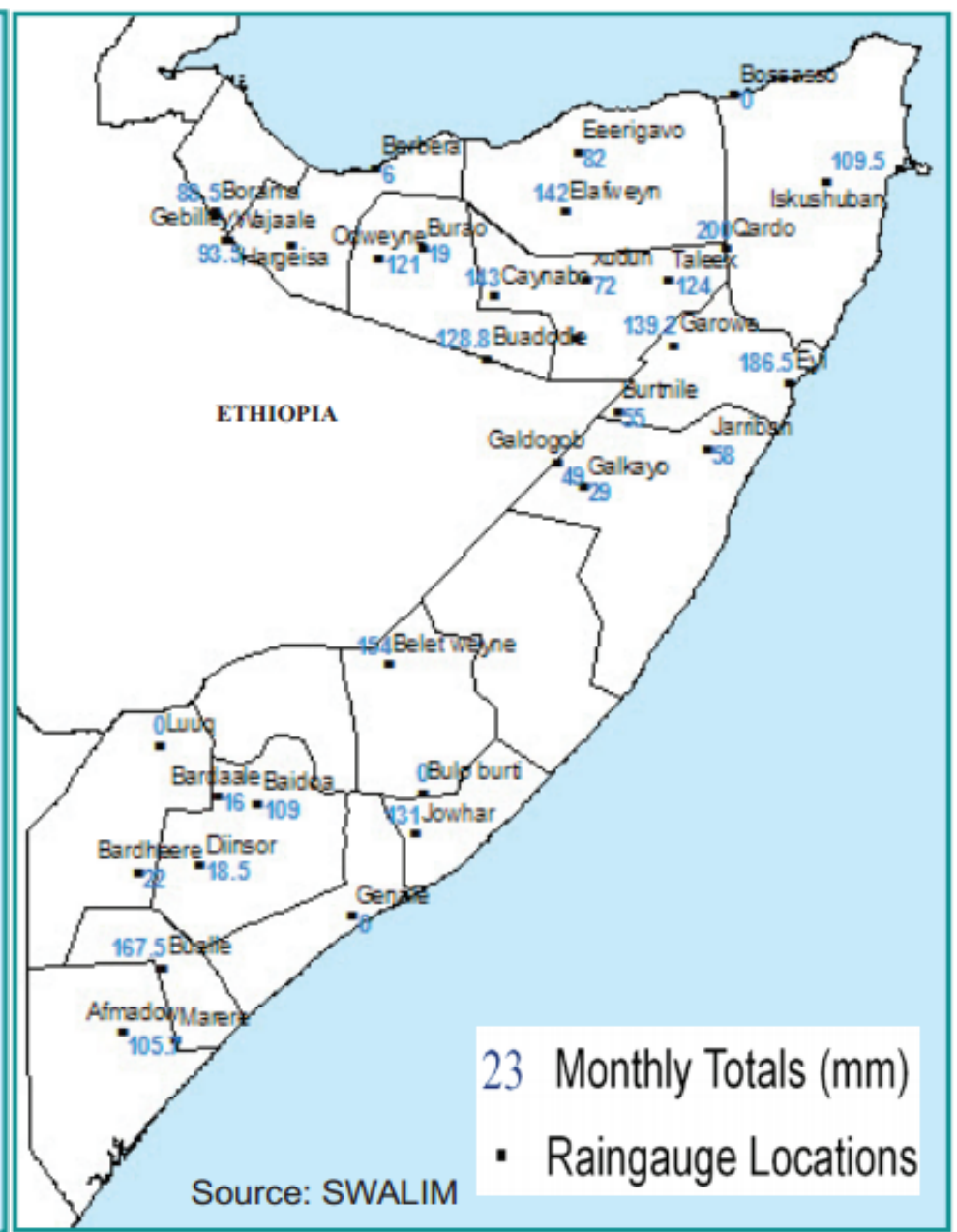

Source: SWALIM

Figure 48: The $2011 \mathrm{GU}$ season rainfall map of Somalia 
Appendix A. - cont.

June 2011: Monthly Rain Gauge data (mm)

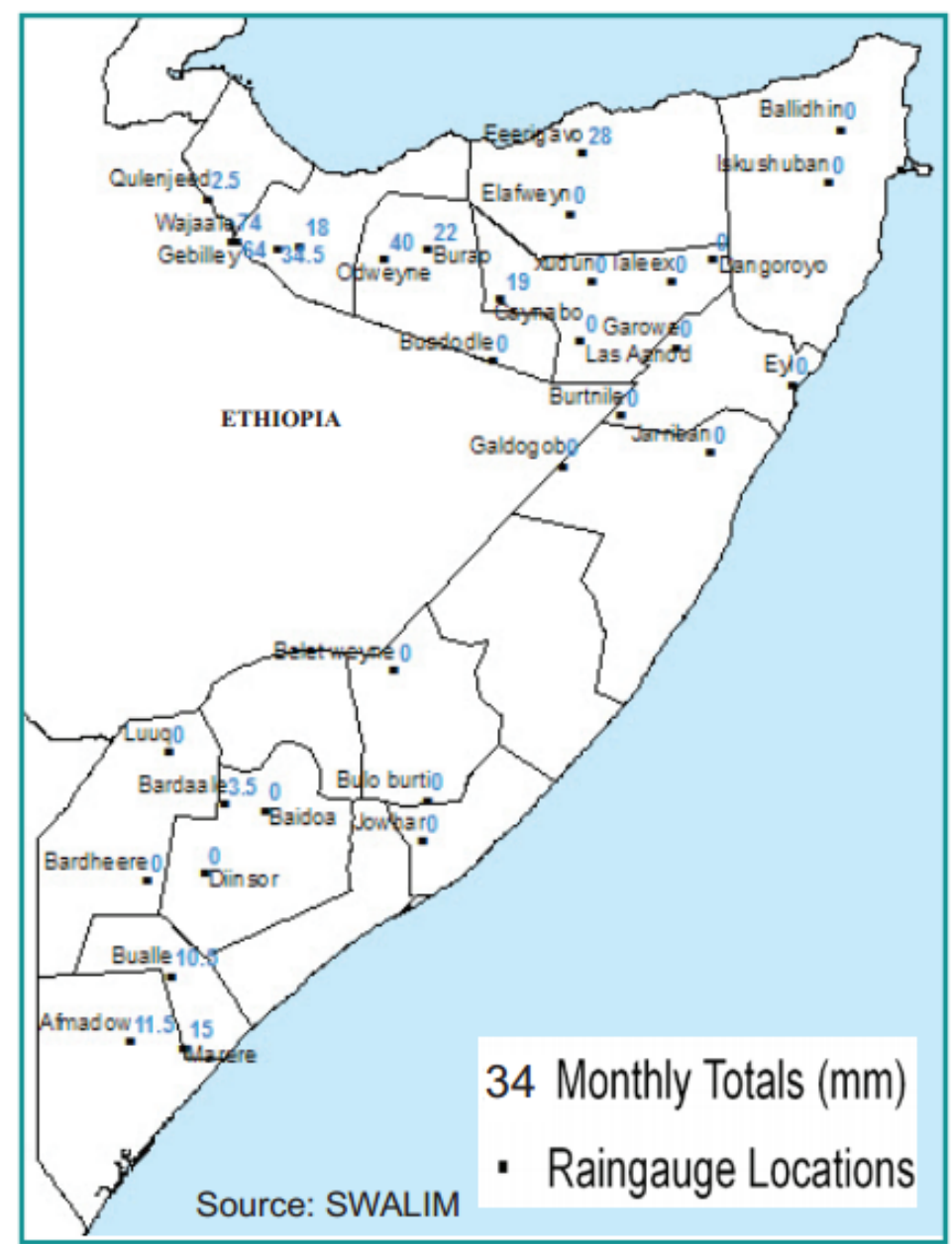

Figure 49: The 2011 Gu season rainfall map of Somalia (con't.) 
Appendix B. - Model Components 


\begin{tabular}{|c|c|c|c|c|c|}
\hline & \multicolumn{2}{|c|}{ Variable name (symbol) } & Explanation & Definition & Source \\
\hline 1 & assurance factor & $\theta$ & & & \\
\hline 2 & birth & - & Total births adding to population & birth rate*Population & $1,5^{*}$ \\
\hline 3 & birth rate & $\beta$ & The unit is in fact $(\mathrm{ppl} / \mathrm{mo}) / \mathrm{ppl}$. & Long-Term Average (LTA) & $1,5^{*}$ \\
\hline 4 & consumed water & - & $\begin{array}{l}\text { This parameter is the measure of all rainwater } \\
\text { harvesting from rooftops and water collected for supply } \\
\text { minus that which is consumed and passed to sewers or } \\
\text { passes through as runoff }\end{array}$ & $\begin{array}{l}\text { INTEG (supply collection }+ \text { rooftop } \\
\text { collection - consumptive to sewer- } \\
\text { nonconsumptive to runoff, } 0 \text { ) }\end{array}$ & \\
\hline 5 & $\begin{array}{l}\text { consumption per } \\
\text { capita }\end{array}$ & $\mathrm{C}$ & & $\begin{array}{c}\text { xidz (K supply collection rate } \\
+ \text { Gamma rooftop collection rate, } \mathrm{x} \\
\text { Population, } 0) \\
\end{array}$ & \\
\hline 6 & consumptive to sewer & - & $\begin{array}{l}\text { This flow entails all the water that flows into the sewer } \\
\text { system after consumption. Examples are domestic and } \\
\text { commercial consumptive water (i.e., grey water) which } \\
\text { goes into the sewer system of the cities to be treated. }\end{array}$ & consumptive to sewer rate & \\
\hline 7 & $\begin{array}{l}\text { consumption to sewer } \\
\text { rate }\end{array}$ & $\Sigma$ & & $\begin{array}{l}\text { sigma consumptive to sewer ratio } * \\
\text { (C supply collection rate }+ \text { Gamma } \\
\text { rooftop collection rate) }\end{array}$ & \\
\hline 8 & $\begin{array}{l}\text { consumptive to sewer } \\
\text { ratio }\end{array}$ & $\sigma$ & & estimated & \\
\hline 9 & death & - & $\begin{array}{l}\text { This is a measure of the total deaths per month as a } \\
\text { function of a dynamic death rate and initial population }\end{array}$ & alpha death rate*Population & \\
\hline
\end{tabular}




\begin{tabular}{|c|c|c|c|c|c|}
\hline 10 & death rate & $\alpha$ & $\begin{array}{l}\text { If the current consumption per capital is less than the } \\
\text { minimum consumption per capita then the death rate is } \\
\text { the difference between the maximum death rate and the } \\
\text { difference between max and min death rates times the } \\
\text { ratio of current consumption per capita/ minimum } \\
\text { consumption per capita. Otherwise the death rate will } \\
\text { be equal to the minimum death rate. }\end{array}$ & $\begin{array}{l}\text { if then else(Cconsumption per capita } \\
<\mathrm{C} \text { m min consumption per capita, } \\
\text { alpha } \mathrm{M} \text { max death rate -(alpha } \mathrm{M} \\
\text { max death rate-alpha m min death } \\
\text { rate)*(K consumption per capita } / \mathrm{K} \\
\mathrm{m} \text { min consumption per capita), } \\
\text { alpha m min death rate) }\end{array}$ & $1,5^{*}$ \\
\hline 11 & demand per capita & $\delta$ & & LTA & 2 \\
\hline 12 & effective demand & $\mathrm{D}$ & $\begin{array}{l}\text { This parameter is the measure of water demanded once } \\
\text { the impact of low flow technology is considered }\end{array}$ & $\begin{array}{l}\text { Delta total demand/ tau technology } \\
\text { factor }\end{array}$ & \\
\hline 13 & $\begin{array}{l}\text { evapotranspiration } \\
\text { from sources }\end{array}$ & - & $\begin{array}{l}\text { When the water sources are depleted, there is no water } \\
\text { available to be evaporated from them. }\end{array}$ & $\begin{array}{l}\text { if then else(evaporation rate*TIME } \\
\text { STEP }<\text { Freshwater Sources, } \\
\text { evaporation rate, } 0)\end{array}$ & \\
\hline 14 & $\begin{array}{l}\text { evapotranspiration } \\
\text { rate }\end{array}$ & $\mathrm{E}$ & about two-thirds of the normal precipitation rate & $0.6^{*}$ precipitation LTA & \\
\hline 15 & final time & - & The final time for the simulation. & \# of years desired for simulation $* 12$ & \\
\hline 16 & Freshwater Sources & $\mathrm{Y}$ & $\begin{array}{l}\text { Freshwater sources include freshwater lakes, rivers, } \\
\text { aquifers, etc. Freshwater is collected from such sources } \\
\text { to fill up the water reserves, i.e., the freshwater supply. }\end{array}$ & $\begin{array}{l}\text { INTEG (Lambda leak to sources }+\mathrm{N} \\
\text { nonrecycled to sources }+ \\
\text { precipitation to sources }+ \text { river inflow } \\
+ \text { Omega runoff to sources } \\
\text { withdrawal - evaporation from } \\
\text { sources-river outflow, initial value of } \\
\text { freshwater sources) }\end{array}$ & \\
\hline 17 & immigration & - & & equivalent to immigration rate & \\
\hline
\end{tabular}




\begin{tabular}{|c|c|c|c|c|c|}
\hline 18 & immigration rate & I & $\begin{array}{c}\text { This parameter represents a the combined values of } \\
\text { international immigration and national migration into } \\
\text { the region }\end{array}$ & LTA & 1 \\
\hline 19 & initial time & - & The initial time for the simulation & & \\
\hline 20 & initial population & - & Population at $\mathrm{t}=0$ & LTA & 2 \\
\hline 21 & $\begin{array}{l}\text { initial value of } \\
\text { freshwater sources }\end{array}$ & - & This is the total volume of the freshwater sources at $\mathrm{t}=0$. & LTA & 2 \\
\hline 22 & leak & - & $\begin{array}{c}\text { This parameter represents the water lost completely } \\
\text { due to leaks in water transfer systems }\end{array}$ & $\begin{array}{l}\text { INTEG (leakage-Lambda leak to } \\
\text { sources, 0) }\end{array}$ & \\
\hline 23 & leak to sources delay & $\lambda$ & & estimated & \\
\hline 24 & leak to sources & $\Lambda$ & & $\begin{array}{c}\text { DELAY FIXED (L leakage rate, } \\
\text { lambda leak to sources delay, } \\
\text { Leakage rate) }\end{array}$ & \\
\hline 25 & leakage & - & & equivalent to $\mathrm{L}$ leakage rate & \\
\hline 26 & leakage rate & $\mathrm{L}$ & $\begin{array}{l}\text { This is the leakage rate if the supply is not empty. } \\
\text { Transfer efficiency is always positive and cannot be } \\
\text { zero. Moreover, consumption rate takes a transfer } \\
\text { efficiency fraction of the supply when the supply is } \\
\text { almost empty, and the rest, which is equal to (1-transfer } \\
\text { efficiency)*Freshwater Supply/ TIME } \\
\text { STEP goes into leakage. Therefore, this equation is } \\
\text { always valid and we don't need to worry about the } \\
\text { supply becoming negative. }\end{array}$ & $\begin{array}{c}((1-\text { eta transfer efficiency }) / \text { eta } \\
\text { transfer efficiency }) * C \text { supply } \\
\text { collection rate }\end{array}$ & \\
\hline
\end{tabular}




\begin{tabular}{|c|c|c|c|c|c|}
\hline 27 & max death rate & $\alpha_{M}$ & $\begin{array}{c}\text { This parameter is a measure of the highest death rate } \\
\text { representative of a famine scenario }\end{array}$ & $\begin{array}{c}\text { See Famine Intensity Scale (Howe \& } \\
\text { Devereux, 2004) }\end{array}$ & \\
\hline 28 & $\begin{array}{l}\text { max stored freshwater } \\
\text { supply }\end{array}$ & $\mathrm{Z}_{\mathrm{M}}$ & $\begin{array}{l}\text { This parameter is a measure of the capacity of all the } \\
\text { dams, water towers, etc. in the region under study. }\end{array}$ & LTA & \\
\hline 29 & max withdrawal rate & $\mathrm{W}_{\mathrm{M}}$ & This parameter is a measure of the collection capacity. & & \\
\hline 30 & $\begin{array}{l}\text { min consumption per } \\
\text { capita }\end{array}$ & $\mathrm{C}_{\mathrm{m}}$ & & $\begin{array}{l}\text { mu min consumption per capita } \\
\text { ration*delta demand per capita }\end{array}$ & \\
\hline 31 & $\begin{array}{l}\text { min consumption per } \\
\text { capita ratio }\end{array}$ & $\mu$ & This parameter is of a value between $0-1$ & & \\
\hline 32 & min death rate & $\alpha_{\mathrm{m}}$ & $\begin{array}{l}\text { This parameter is a measure of the average death rate } \\
\text { between } 1915-2010 \text {. }\end{array}$ & LTA & $1,5^{* *}$ \\
\hline 33 & months per year & - & & & \\
\hline 34 & net source outflow & - & & $\begin{array}{c}\text { withdrawal }+ \text { E evaporation rate }+ \text { Psi } \\
\text { river outflow rate - P precipitation } \\
\text { rate - Phi river inflow rate - N } \\
\text { nonrecycled to sources }\end{array}$ & \\
\hline & & & & $\begin{array}{l}\text { Lambda leak to sources - Omega } \\
\text { runoff to sources }\end{array}$ & \\
\hline
\end{tabular}




\begin{tabular}{|c|c|c|c|c|}
\hline 35 & net supply outflow & - & Sum of all the flows out of the Freshwater supply & $\begin{array}{l}\text { supply collection + leakage - } \\
\text { withdrawal - recycled water }\end{array}$ \\
\hline 36 & $\begin{array}{l}\text { nonconsumptive to } \\
\text { runoff }\end{array}$ & - & $\begin{array}{l}\text { "Runoff" includes all water that is consumed and does } \\
\text { not go into the sewer system. Examples are water used } \\
\text { for irrigation and water for energy or mineral } \\
\text { production in certain plants. }\end{array}$ & nonconsumptive to runoff rate \\
\hline 37 & $\begin{array}{l}\text { nonconsumptive to } \\
\text { runoff rate }\end{array}$ & - & & $\begin{array}{l}\text { C Supply collection rate }+ \text { Gamma } \\
\text { rooftop collection rate - Sigma } \\
\text { consumptive to sewer rate }\end{array}$ \\
\hline 38 & nonrecycled to ocean & & $\begin{array}{l}\text { "Ocean" includes all sources of seawater or brackish } \\
\text { water. It excludes all sources of freshwater. Note that } \\
\text { we integrate "evaporation" into this flow. }\end{array}$ & $\begin{array}{c}\text { (1 - nu nonrecycled to sources ratio) } \\
* \text { nonrecycled water }\end{array}$ \\
\hline 39 & $\begin{array}{l}\text { nonrecycled to } \\
\text { sources }\end{array}$ & $\mathrm{N}$ & & $\begin{array}{c}\text { nu nonrecycled to sources ratio } * \\
\text { nonrecycled water }\end{array}$ \\
\hline 40 & $\begin{array}{l}\text { nonrecycled to } \\
\text { sources ratio }\end{array}$ & $v$ & & estimated \\
\hline 41 & nonrecycled water & - & & equivalent to nonrecycled water rate \\
\hline 42 & $\begin{array}{l}\text { nonrecycled water } \\
\text { junction }\end{array}$ & - & $\begin{array}{l}\text { All the water that is not treated in the sewer treatment } \\
\text { facilities, either because of the low capacity of the } \\
\text { facilities, or because of the costs of the treatment } \\
\text { process. }\end{array}$ & $\begin{array}{c}\text { INTEG (nonrecycled water - N } \\
\text { nonrecycled to sources - nonrecycled } \\
\text { to ocean, } 0 \text { ) }\end{array}$ \\
\hline 43 & nonrecycled water rate & - & $\begin{array}{l}\text { This is by definition all the water that has not been } \\
\text { recycled. }\end{array}$ & $\begin{array}{l}\text { Sigma consumptive to sewer ratio - } \mathrm{R} \\
\text { recycled water rate }\end{array}$ \\
\hline
\end{tabular}




\begin{tabular}{|c|c|c|c|c|c|}
\hline 44 & $\mathrm{P}$ minus $\mathrm{E}$ & - & & $\begin{array}{l}\text { P precipitation rat e - E evaporation } \\
\text { rate }\end{array}$ & \\
\hline 45 & Population & $\mathrm{X}$ & & $\begin{array}{l}\text { INTEG (birth+immigration-death, } \\
\text { initial population) }\end{array}$ & \\
\hline 46 & precipitation rate & $\mathrm{P}$ & $\begin{array}{l}\text { The rainwater that is collected from rooftops is } \\
\text { subtracted from precipitation. Rooftop collection does } \\
\text { not go into freshwater sources, but is directly consumed }\end{array}$ & LTA & \\
\hline 47 & $\begin{array}{l}\text { precipitation to } \\
\text { sources }\end{array}$ & - & $\begin{array}{l}\text { The rainwater that is collected from rooftops is } \\
\text { subtracted from precipitation. Rooftop collection does } \\
\text { not go into freshwater sources, but is directly consumed }\end{array}$ & $\begin{array}{l}\text { P precipitation rate - Gamma rooftop } \\
\text { collection rate }\end{array}$ & \\
\hline 48 & Phi minus Psi & - & & $\begin{array}{l}\text { Phi river inflow rate - Psi river } \\
\text { outflow rate }\end{array}$ & \\
\hline 49 & recycling capacity & $\mathrm{R}_{\mathrm{M}}$ & Maximum volumetric capacity of system to recycle & & \\
\hline 50 & recycled water & - & & equivalent to $\mathrm{R}$ recycled water rate & \\
\hline 51 & recycled water rate & $\mathrm{R}$ & $\begin{array}{l}\text { If the supply is almost full, we do not really need to } \\
\text { recycle. }\end{array}$ & $\begin{array}{l}\min \text { ( theta assurance factor*(ZM max } \\
\text { stored freshwater supply - Z stored } \\
\text { freshwater supply) / TIME STEP, } \\
\text { min( SIGMA consumptive to sewer } \\
\text { rate, RM recycling capacity) }\end{array}$ & \\
\hline 52 & river inflow & - & $\begin{array}{l}\text { This is the total incoming water into the region under } \\
\text { study by rivers. }\end{array}$ & equivalent to Phi river inflow rate & \\
\hline 53 & river inflow rate & $\Phi$ & & LTA & 2 \\
\hline
\end{tabular}




\begin{tabular}{|c|c|c|c|c|}
\hline 54 & river outflow & - & $\begin{array}{l}\text { If freshwater sources, which include rivers, are dried } \\
\text { out, there is no more water in rivers to flow out of the } \\
\text { region under study. }\end{array}$ & $\begin{array}{l}\text { if then else(Psi river outflow } \\
\text { rate*TIME STEP }<\text { y Freshwater } \\
\text { Sources, Psi river outflow rate, } 0 \text { ) }\end{array}$ \\
\hline
\end{tabular}




\begin{tabular}{|c|c|c|c|c|c|}
\hline 55 & river outflow rate & $\Psi$ & & LTA & 2 \\
\hline 56 & rooftop collection rate & - & & $\begin{array}{l}\text { equivalent to Gamma rooftop } \\
\text { collection rate }\end{array}$ & \\
\hline 57 & rooftop collection rate & $\Gamma$ & $\begin{array}{c}\text { This parameter allows for the effect of conservation } \\
\text { policy to impact the model }\end{array}$ & $\begin{array}{l}(2.9361 \mathrm{e}-09) * \text { population } / 3 * \text { percent } \\
\text { population participation }\end{array}$ & 3 \\
\hline 58 & runoff & - & & $\begin{array}{l}\text { INTEG nonconsumptive to runoff - } \\
\text { runoff to ocean - Omega runoff to } \\
\text { sources, } 0 \text { ) }\end{array}$ & \\
\hline 59 & runoff to ocean & - & $\begin{array}{l}\text { "Ocean" includes all sources of seawater or brackish } \\
\text { water. It excludes all sources of freshwater. Note that } \\
\text { we integrate "evaporation" into this flow. }\end{array}$ & $\begin{array}{l}\text { nonconsumptive to runoff rate - } \\
\text { Omega runoff to sources }\end{array}$ & \\
\hline 60 & runoff to sources & $\Omega$ & & $\begin{array}{l}\text { omega runoff to sources } \\
\text { ratio*nonconsumptive to runoff rate }\end{array}$ & \\
\hline 61 & runoff to sources ratio & $\omega$ & $\begin{array}{l}\text { This ratio is between } 0 \text { and } 1 . \text { It shows what fraction of } \\
\text { runoff water returns to sources. }\end{array}$ & LTA & \\
\hline 62 & SAVEPER & - & The frequency in which output is stored & TIME STEP & \\
\hline 63 & start year & - & & arbitrary & \\
\hline 64 & $\begin{array}{l}\text { stored freshwater } \\
\text { supply }\end{array}$ & $\mathrm{Z}_{\mathrm{M}}$ & & $\begin{array}{l}\text { INTEG (withdrawal+recycled water- } \\
\text { supply collection-leakage, ZM max } \\
\text { stored freshwater supply) }\end{array}$ & \\
\hline 65 & supply collection & - & & equivalent to $\mathrm{K}$ supply collection rate & \\
\hline
\end{tabular}




\begin{tabular}{|c|c|c|c|c|c|}
\hline 66 & supply collection rate & $\mathrm{K}$ & & $\begin{array}{l}\max (0, \min (\mathrm{D} \text { effective demand, eta } \\
\text { transfer efficiency * theta assurance } \\
\text { factor* } \mathrm{z} \text { stored Freshwater Supply/ } \\
\text { TIME STEP) - Gamma rooftop } \\
\text { collection rate }) \\
\end{array}$ & \\
\hline 67 & sewer treatment & - & & $\begin{array}{l}\text { INTEG (consumptive to sewer - } \\
\text { recycled water - nonrecycled water, } \\
0 \text { ) }\end{array}$ & \\
\hline 68 & technology factor & $\tau$ & $\begin{array}{l}\text { This factor shows how improved technology can reduce } \\
\text { the consumption. Normal technology corresponds to a } \\
\text { technology factor of } 1 \text {. Improved technology results in } \\
\text { increasing of this factor, and therefore, the required } \\
\text { consumption rate is reduced. Lack of normal } \\
\text { technology can result in increased consumption, }\end{array}$ & Estimated & \\
\hline 69 & time in years & - & & $($ Time/months per year $)+$ start year & \\
\hline 70 & TIME STEP & - & The time step for the simulation. & 1 month & \\
\hline 71 & total demand & $\Delta$ & & $\begin{array}{l}\text { delta demand per capita } * x \\
\text { Population }\end{array}$ & \\
\hline 72 & transfer efficiency & $\eta$ & $\begin{array}{l}\text { This parameter represents the condition and integrity of } \\
\text { the piping system or other water transport system in use }\end{array}$ & Estimated & 2,4 \\
\hline 73 & withdrawal & - & & equivalent to withdrawal rate & \\
\hline
\end{tabular}




\begin{tabular}{|c|c|c|c|c|}
\hline 74 & Withdrawal rate & W & $\begin{array}{l}\text { The conditions and constraints considered for writing } \\
\text { the above equation are as following: } 1) \text { collection rate is } \\
\text { capped by the max collection rate. That is why we have } \\
\text { min (max collection rate,...) in both then and else } \\
\text { statements. } 2 \text { ) Collection rate is also capped by the } \\
\text { available space in the Freshwater supply. That is why } \\
\text { we have min ((max freshwater supply - freshwater } \\
\text { supply)/ TIME STEP,...) in both statements. } 3 \text { ) If the } \\
\text { available water in the sources is less than the required } \\
\text { collection amount, we will collect whatever remains. }\end{array}$ & $\begin{array}{c}\min (\min (\text { theta assurance factor } \\
\text { *y Freshwater Sources/ TIME } \\
\text { STEP, theta assurance factor* } \\
\text { (ZM max stored freshwater supply } \\
\text { - Z stored Freshwater Supply)/ } \\
\text { TIME STEP), WM max withdrawal } \\
\text { rate) }\end{array}$ \\
\hline & 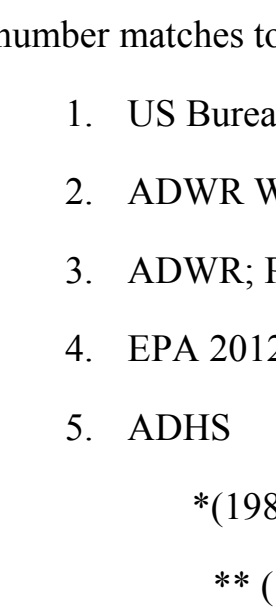 & $\begin{array}{l}\text { Cens } \\
\text { Atla } \\
\text { aix N }\end{array}$ & $\begin{array}{l}\text { elow } \\
\text { Vol. } \\
\text { arket Trends } \\
2012 \\
\text { ) }\end{array}$ & \\
\hline
\end{tabular}


Appendix C. - Birth rate data

\begin{tabular}{|c|c|c|c|}
\hline \multicolumn{4}{|c|}{ Crude birth Rates (births/1000 pop) } \\
\hline year & US average & Arizona & Source \\
\hline 1915 & 25 & & \multirow{24}{*}{$\begin{array}{c}\text { (Linder \& } \\
\text { Grove, 1947) }\end{array}$} \\
\hline 1916 & 24.9 & & \\
\hline 1917 & 24.5 & & \\
\hline 1918 & 24.7 & & \\
\hline 1919 & 22.4 & & \\
\hline 1920 & 23.7 & & \\
\hline 1921 & 24.2 & & \\
\hline 1922 & 22.3 & & \\
\hline 1923 & 22.1 & & \\
\hline 1924 & 22.2 & & \\
\hline 1925 & 21.3 & & \\
\hline 1926 & 20.5 & 20.8 & \\
\hline 1927 & 20.5 & 20 & \\
\hline 1928 & 19.7 & 21.2 & \\
\hline 1929 & 18.8 & 22.3 & \\
\hline 1930 & 18.9 & 23.7 & \\
\hline 1931 & 18 & 21.1 & \\
\hline 1932 & 17.4 & 18.9 & \\
\hline 1933 & 16.6 & 17.8 & \\
\hline 1934 & 17.2 & 18.4 & \\
\hline 1935 & 16.9 & 19.5 & \\
\hline 1936 & 16.7 & 20.1 & \\
\hline 1937 & 17.1 & 21.9 & \\
\hline 1938 & 17.6 & 22.4 & \\
\hline
\end{tabular}

\begin{tabular}{|r|r|r|r|}
\hline 1939 & 17.3 & 22.2 & \\
\hline 1940 & 17.9 & 23 & \\
\hline 1941 & 18.8 & 23.8 & (Grove \& \\
\cline { 1 - 3 } Hetzel, 1968) \\
\hline 1942 & 20.8 & 26 & \\
\hline 1943 & 21.5 & 26.1 & \\
\hline 1944 & 20.2 & 26 \\
\hline 1945 & 19.5 & 24.2 \\
\hline 1946 & 23.3 & 26.8 \\
\hline 1947 & 25.8 & 29.3 \\
\hline 1948 & 24.2 & 27.8 \\
\hline 1949 & 23.9 & 28.4 \\
\hline 1950 & 23.6 & 27.8 \\
\hline 1951 & 24.5 & 28.7 \\
\hline 1952 & 24.7 & 29.4 \\
\hline 1953 & 24.7 & 28.3 \\
\hline 1954 & 24.9 & 28.7 \\
\hline 1955 & 24.6 & 28.3 \\
\hline 1956 & 24.9 & 28.2 \\
\hline 1957 & 25 & 28.4 \\
\hline 1958 & 24.3 & 27.7 \\
\hline 1959 & 24 & 27.5 \\
\hline 1960 & 23.7 & 28.2 \\
\hline
\end{tabular}




\begin{tabular}{|c|c|c|c|c|}
\hline \multicolumn{5}{|c|}{ Crude Birth Rates (births/ 1000 ppl) } \\
\hline \multirow[t]{2}{*}{ Year } & \multicolumn{2}{|c|}{ County } & \multirow[t]{2}{*}{ Arizona } & \multirow[t]{2}{*}{ Source } \\
\hline & Maricopa & Pinal & & \\
\hline 1960 & 26.8 & 31.0 & 28.1 & \multirow{25}{*}{$\begin{array}{c}\text { (ADHS, } \\
2013)\end{array}$} \\
\hline 1961 & 24.9 & 31.0 & 26.6 & \\
\hline 1962 & 23.9 & 29.6 & 25.7 & \\
\hline 1963 & 22.5 & 27.1 & 24.3 & \\
\hline 1964 & 21.7 & 24.9 & 23.2 & \\
\hline 1965 & 19.6 & 24.7 & 21.2 & \\
\hline 1966 & 18.8 & 22.4 & 20.0 & \\
\hline 1967 & 18.5 & 19.7 & 19.6 & \\
\hline 1968 & 18.4 & 20.1 & 19.3 & \\
\hline 1969 & 18.9 & 21.1 & 19.7 & \\
\hline 1970 & 20.3 & 22.7 & 21.2 & \\
\hline 1971 & 19.4 & 22.5 & 20.6 & \\
\hline 1972 & 17.8 & 21.1 & 19.1 & \\
\hline 1973 & 17.3 & 20.3 & 18.3 & \\
\hline 1974 & 17.4 & 20.8 & 18.5 & \\
\hline 1975 & 16.4 & 19.5 & 17.8 & \\
\hline 1976 & 16.2 & 18.9 & 17.6 & \\
\hline 1977 & 16.5 & 18.3 & 17.8 & \\
\hline 1978 & 16.4 & 19.4 & 17.4 & \\
\hline 1979 & 17.2 & 18.1 & 17.7 & \\
\hline 1980 & 17.8 & 20.2 & 18.4 & \\
\hline 1981 & 17.9 & 20.3 & 18.4 & \\
\hline 1982 & 17.8 & 20.5 & 18.2 & \\
\hline 1983 & 17.6 & 19.3 & 18.0 & \\
\hline 1984 & 17.7 & 18.8 & 17.9 & \\
\hline
\end{tabular}

\begin{tabular}{|c|c|c|c|c|}
\hline 1985 & 18.8 & 20.5 & 17.6 & \multirow{2}{*}{ (ADHS, } \\
\hline 1986 & 18.5 & 19.8 & 18.1 & \\
\hline 1987 & 18.4 & 19.8 & 18.3 & \\
\hline 1988 & 18.4 & 19 & 18.2 & \\
\hline 1989 & 18.2 & 18.5 & 18.0 \\
\hline 1990 & 19.0 & 18.3 & 18.8 \\
\hline 1991 & 18.3 & 17.8 & 18.1 \\
\hline 1992 & 17.9 & 16.7 & 17.8 \\
\hline 1993 & 17.7 & 16.6 & 17.5 \\
\hline 1994 & 18.1 & 16.1 & 17.6 \\
\hline 1995 & 18.2 & 14.9 & 17.3 \\
\hline 1996 & 17.7 & 14.6 & 16.8 \\
\hline 1997 & 17.3 & 14.5 & 16.4 \\
\hline 1998 & 17.6 & 14.6 & 16.5 \\
\hline 1999 & 17.7 & 14.5 & 16.3 \\
\hline 2000 & 17.7 & 14.5 & 16.6 \\
\hline 2001 & 17.4 & 13.5 & 16.1 \\
\hline 2002 & 17.2 & 14.1 & 16.0 \\
\hline 2003 & 17.4 & 14.5 & 16.1 \\
\hline 2004 & 17.2 & 14.1 & 16.0 \\
\hline 2005 & 17.1 & 14.8 & 15.8 \\
\hline 2006 & 17.6 & 16.6 & 16.4 \\
\hline 2007 & 17.0 & 18.0 & 16.0 \\
\hline 2008 & 16.0 & 17.8 & 15.2 \\
\hline 2009 & 14.5 & 16.2 & 14.0 \\
\hline 2010 & 14.2 & 13.3 & 13.2 \\
\hline 2011 & 13.9 & 12.0 & 13.2 & \\
\hline & & & \\
\\
\hline 190 \\
\end{tabular}




\begin{tabular}{|c|c|c|}
\hline \multicolumn{3}{|c|}{ Crude Birth Rates (births/1000 pop.) } \\
\hline Year(s) & Somalia & Source \\
\hline $2095-2100$ & 16 & (United Nations, 2013) \\
\hline $2090-2095$ & 17 & \\
\hline $2085-2090$ & 18 & \\
\hline 20802085 & 19 & \\
\hline $2075-2080$ & 20 & \\
\hline $2070-2075$ & 21 & \\
\hline $2065-2070$ & 23 & \\
\hline $2060-2065$ & 24 & \\
\hline $2055-2060$ & 26 & \\
\hline $2050-2055$ & 28 & \\
\hline $2045-2050$ & 30 & \\
\hline $2040-2045$ & 31 & \\
\hline $2035-2040$ & 34 & \\
\hline $2030-2035$ & 36 & \\
\hline
\end{tabular}

\begin{tabular}{|c|c|}
\hline $2025-2030$ & 38 \\
\hline $2020-2025$ & 40 \\
\hline $2015-2020$ & 42 \\
\hline $2010-2015$ & 44 \\
\hline $2005-2010$ & 46.2 \\
\hline $2000-2005$ & 47.4 \\
\hline $1995-2000$ & 49.7 \\
\hline $1990-1995$ & 49.2 \\
\hline $1985-1990$ & 47.5 \\
\hline $1980-1985$ & 46.1 \\
\hline $1975-1980$ & 45.6 \\
\hline $1970-1975$ & 46 \\
\hline $1965-1970$ & 47 \\
\hline $1960-1965$ & 47.4 \\
\hline $1955-1960$ & 48 \\
\hline $1950-1955$ & 48.9 \\
\hline
\end{tabular}


Appendix D. - Death rate data

\begin{tabular}{|c|c|c|c|}
\hline \multicolumn{4}{|c|}{ Crude death rates (deaths/1000 pop) } \\
\hline Year & US & Arizona & Source \\
\hline 1900 & 17.2 & & \multirow{24}{*}{ (Linder \& Grove, 1947) } \\
\hline 1901 & 16.4 & & \\
\hline 1902 & 15.5 & & \\
\hline 1903 & 15.6 & & \\
\hline 1904 & 16.4 & & \\
\hline 1905 & 15.9 & & \\
\hline 1906 & 15.7 & & \\
\hline 1907 & 15.9 & & \\
\hline 1908 & 14.7 & & \\
\hline 1909 & 14.2 & & \\
\hline 1910 & 14.7 & & \\
\hline 1911 & 13 & & \\
\hline 1912 & 13.6 & & \\
\hline 1913 & 13.8 & & \\
\hline 1914 & 13.3 & & \\
\hline 1915 & 13.2 & & \\
\hline 1916 & 13.8 & & \\
\hline 1917 & 14 & & \\
\hline 1918 & 18.1 & & \\
\hline 1919 & 12.9 & & \\
\hline 1920 & 13 & & \\
\hline 1921 & 11.5 & & \\
\hline 1922 & 11.7 & & \\
\hline 1923 & 12.1 & & \\
\hline
\end{tabular}

\begin{tabular}{|c|c|c|c|}
\hline 1924 & 11.6 & & \\
\hline 1925 & 11.7 & & \multirow[t]{16}{*}{ (Linder \& Grove, 1947) } \\
\hline 1926 & 12.1 & 13.8 & \\
\hline 1927 & 11.3 & 14.2 & \\
\hline 1928 & 12 & 15.3 & \\
\hline 1929 & 11.9 & 15.8 & \\
\hline 1930 & 11.3 & 15.3 & \\
\hline 1931 & 11.1 & 13.7 & \\
\hline 1932 & 10.9 & 12 & \\
\hline 1933 & 10.7 & 12.2 & \\
\hline 1934 & 11.1 & 12.2 & \\
\hline 1935 & 10.9 & 13 & \\
\hline 1936 & 11.6 & 13.8 & \\
\hline 1937 & 11.3 & 14.4 & \\
\hline 1938 & 10.6 & 12.4 & \\
\hline 1939 & 10.6 & 11.9 & \\
\hline 1940 & 10.8 & 11.6 & \\
\hline 1941 & 10.5 & 12.2 & \multirow[t]{9}{*}{ (Grove \& Hetzel, 1968) } \\
\hline 1942 & 10.3 & 10.7 & \\
\hline 1943 & 10.9 & 8.2 & \\
\hline 1944 & 10.6 & 10.2 & \\
\hline 1945 & 10.6 & 10.3 & \\
\hline 1946 & 10 & 9.3 & \\
\hline 1947 & 10.1 & 9.2 & \\
\hline 1948 & 9.9 & 9.5 & \\
\hline 1949 & 9.7 & 8.9 & \\
\hline
\end{tabular}




\begin{tabular}{|c|c|c|c|}
\hline 1950 & 9.6 & 8.6 & \\
\hline 1951 & 9.7 & 9.1 & \\
\hline 1952 & 9.6 & 8.8 & \multirow{5}{*}{ (Grove \& Hetzel, 1968) } \\
\hline 1953 & 9.6 & 8.7 & \\
\hline 1954 & 9.2 & 7.7 & \\
\hline 1955 & 9.3 & 7.7 & \\
\hline 1956 & 9.4 & 7.5 & \\
\hline 1957 & 9.6 & 7.8 & \multirow[t]{4}{*}{ (Grove \& Hetzel, 1968) } \\
\hline 1958 & 9.5 & 7.6 & \\
\hline 1959 & 9.4 & 7.6 & \\
\hline 1960 & 9.5 & 7.8 & \\
\hline
\end{tabular}

\begin{tabular}{|c|c|c|c|c|}
\hline \multicolumn{5}{|c|}{ Death Rates (deaths/ 1000 ppl) } \\
\hline Year & $\begin{array}{l}\text { Maricopa } \\
\text { county }\end{array}$ & $\begin{array}{l}\text { Pinal } \\
\text { county }\end{array}$ & Arizona & Source \\
\hline 1960 & 7.6 & 7.6 & 7.7 & \multirow{21}{*}{$\begin{array}{c}\text { (ADHS, } \\
2013)\end{array}$} \\
\hline 1961 & 7.1 & 8.1 & 7.5 & \\
\hline 1962 & 7.1 & 8.0 & 7.6 & \\
\hline 1963 & 7.4 & 8.3 & 7.8 & \\
\hline 1964 & 7.4 & 8.4 & 7.7 & \\
\hline 1965 & 7.3 & 8.0 & 7.5 & \\
\hline 1966 & 7.6 & 8.4 & 7.9 & \\
\hline 1967 & 7.5 & 7.6 & 7.8 & \\
\hline 1968 & 7.8 & 7.7 & 8.1 & \\
\hline 1969 & 7.9 & 8.0 & 8.0 & \\
\hline 1970 & 8.1 & 8.0 & 8.4 & \\
\hline 1971 & 8.1 & 8.5 & 8.4 & \\
\hline 1972 & 7.8 & 8.3 & 8.1 & \\
\hline 1973 & 7.9 & 8.2 & 8.1 & \\
\hline 1974 & 7.8 & 7.2 & 7.9 & \\
\hline 1975 & 7.5 & 6.6 & 7.6 & \\
\hline 1976 & 7.6 & 7.2 & 7.6 & \\
\hline 1977 & 7.7 & 7.1 & 7.7 & \\
\hline 1978 & 7.8 & 7.9 & 7.7 & \\
\hline 1979 & 7.5 & 7.7 & 7.5 & \\
\hline 1980 & 7.8 & 8.0 & 7.8 & \\
\hline 1981 & 7.7 & 8.0 & 7.6 & \multirow{3}{*}{$\begin{array}{c}\text { (ADHS, } \\
2013)\end{array}$} \\
\hline 1982 & 7.6 & 7.8 & 7.6 & \\
\hline 1983 & 7.6 & 8.1 & 7.7 & \\
\hline
\end{tabular}




\begin{tabular}{|c|c|c|c|c|}
\hline 1984 & 7.7 & 8.3 & 7.7 & \\
\hline 1985 & 7.6 & 7.8 & 7.7 & \\
\hline 1986 & 7.4 & 9.1 & 7.6 & \\
\hline 1987 & 7.4 & 8.6 & 7.7 & \\
\hline 1988 & 7.4 & 9.2 & 7.7 & \\
\hline 1989 & 7.2 & 9.4 & 7.5 & \\
\hline 1990 & 7.4 & 8.6 & 7.8 & \\
\hline 1991 & 7.4 & 8.8 & 7.8 & \\
\hline 1992 & 7.6 & 8.6 & 8.0 & \\
\hline 1993 & 8.0 & 8.7 & 8.4 & \\
\hline 1994 & 8.1 & 9.6 & 8.5 & \\
\hline 1995 & 8.0 & 9.7 & 8.5 & \\
\hline 1996 & 7.7 & 8.8 & 8.2 & \\
\hline 1997 & 7.6 & 9.0 & 8.1 & \\
\hline 1998 & 7.5 & 9.5 & 8.1 & \\
\hline 1999 & 7.7 & 8.6 & 8.1 & \\
\hline 2000 & 7.4 & 8.6 & 7.8 & \\
\hline 2001 & 7.1 & 8.0 & 7.7 & \\
\hline 2002 & 7.1 & 8.7 & 7.7 & \\
\hline 2003 & 6.9 & 8.4 & 7.6 & \\
\hline 2004 & 6.7 & 7.7 & 7.3 & \\
\hline 2005 & 6.8 & 7.6 & 7.5 & \multirow{4}{*}{$\begin{array}{c}\text { (ADHS, } \\
2013)\end{array}$} \\
\hline 2006 & 6.7 & 7.2 & 7.3 & \\
\hline 2007 & 6.3 & 6.9 & 6.9 & \\
\hline 2008 & 6.2 & 6.3 & 6.9 & \\
\hline 2009 & 6.1 & 6.1 & 6.8 & \multirow{2}{*}{$\begin{array}{c}\text { (ADHS, } \\
2013)\end{array}$} \\
\hline 2010 & 6.4 & 6.0 & 7.2 & \\
\hline
\end{tabular}

\begin{tabular}{|l|l|l|l|l|}
\hline 2011 & 6.6 & 6.2 & 7.4 & \\
\hline
\end{tabular}




\begin{tabular}{|c|c|c|}
\hline \multicolumn{3}{|c|}{ Crude Dearth Rate (death/1000pop) } \\
\hline Year(s) & Somalia & Source \\
\hline $2095-2100$ & 8 & \multirow[t]{14}{*}{ (United Nations, 2013) } \\
\hline $2090-2095$ & 8 & \\
\hline $2085-2090$ & 7 & \\
\hline $2080-2085$ & 7 & \\
\hline $2075-2080$ & 7 & \\
\hline $2070-2075$ & 7 & \\
\hline $2065-2070$ & 6 & \\
\hline $2060-2065$ & 6 & \\
\hline $2055-2060$ & 6 & \\
\hline $2050-2055$ & 7 & \\
\hline $2045-2050$ & 7 & \\
\hline $2040-2045$ & 7 & \\
\hline $2035-2040$ & 8 & \\
\hline $2030-2035$ & 9 & \\
\hline $2025-2030$ & 9 & \multirow[t]{2}{*}{ (United Nations, 2013) } \\
\hline $2020-2025$ & 10 & \\
\hline
\end{tabular}

\begin{tabular}{|c|c|}
\hline $2015-2020$ & 11 \\
\hline $2010-2015$ & 12 \\
\hline $2005-2010$ & 13.7 \\
\hline $2000-2005$ & 15 \\
\hline $1995-2000$ & 16.5 \\
\hline $1990-1995$ & 20.2 \\
\hline $1985-1990$ & 19 \\
\hline $1980-1985$ & 19.4 \\
\hline $1975-1980$ & 20.7 \\
\hline $1970-1975$ & 22.2 \\
\hline $1965-1970$ & 24 \\
\hline $1960-1965$ & 25.8 \\
\hline $1955-1960$ & 27.7 \\
\hline $1950-1955$ & 29.8 \\
\hline
\end{tabular}


Appendix E. - Net immigration data

\begin{tabular}{|c|c|c|}
\hline \multicolumn{3}{|c|}{ Net immigration (migrants/ 1000 pop) } \\
\hline Year(s) & Somalia & Source \\
\hline $1950-1955$ & 0 & (United Nations, 2013) \\
\hline $1955-1960$ & 0 & \\
\hline $1960-1965$ & 0 & \\
\hline $1965-1970$ & 0 & \\
\hline $1970-1975$ & 0 & \\
\hline $1975-1980$ & 64 & \\
\hline 1980-1985 & -27 & \\
\hline $1985-1990$ & -20 & \\
\hline $1990-1995$ & -28 & \\
\hline $1995-2000$ & -3 & \\
\hline $2000-2005$ & -5 & \\
\hline 2005-2010 & -7 & \\
\hline $2010-2015$ & -3 & \\
\hline $2015-2020$ & -3 & \\
\hline $2020-2025$ & -2 & (United Nations, 2013) \\
\hline $2025-2030$ & -2 & \\
\hline $2030-2035$ & -2 & \\
\hline $2035-2040$ & -1 & \\
\hline $2040-2045$ & -1 & \\
\hline
\end{tabular}

\begin{tabular}{|c|c|}
\hline $2045-2050$ & -1 \\
\hline $2050-2055$ & -1 \\
\hline $2055-2060$ & -1 \\
\hline $2060-2065$ & -1 \\
\hline $2065-2070$ & 0 \\
\hline $2070-2075$ & 0 \\
\hline $2075-2080$ & 0 \\
\hline $2080-2085$ & 0 \\
\hline $2085-2090$ & 0 \\
\hline $2090-2095$ & 0 \\
\hline $2095-2100$ & 0 \\
\hline
\end{tabular}




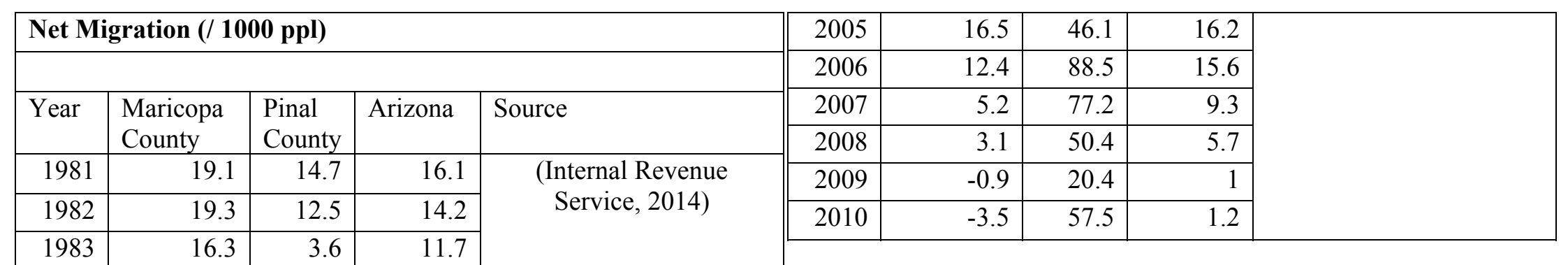


Appendix F. - Precipitation data

\section{Long term mean monthly and annual rainfall $(\mathrm{mm})$ at selective stations in Somalia}

\begin{tabular}{|c|c|c|c|c|c|c|c|c|c|c|c|c|c|c|c|}
\hline Station & Long $(\circ \mathbf{E})$ & Lat $(\circ \mathbf{N})$ & Elevation (m) & Jan & Feb & Mar & Apr & May & Jun & Jul & Aug & Sep & Oct & Nov & Dec \\
\hline Alessandra & 42.7 & 0.5 & 25 & 1 & 3 & 4 & 131 & 136 & 74 & 50 & 24 & 20 & 51 & 69 & 37 \\
\hline Bardera & 42.3 & 2.35 & 116 & 3 & 6 & 27 & 117 & 71 & 10 & 11 & 5 & 8 & 82 & 116 & 17 \\
\hline Burdhuxul & 43.3 & 4.1 & 400 & 0 & 0 & 26 & 215 & 67 & 0 & 0 & 0 & 1 & 102 & 24 & 3 \\
\hline Dinsor & 42.98 & 2.41 & 280 & 3 & 0 & 30 & 138 & 70 & 15 & 11 & 11 & 11 & 64 & 98 & 19 \\
\hline Jilib & 42.8 & 0.43 & 23 & 1 & 5 & 4 & 122 & 170 & 106 & 47 & 41 & 26 & 25 & 87 & 29 \\
\hline Jonte & 42.46 & -0.33 & 8 & 0 & 0 & 0 & 42 & 124 & 82 & 52 & 15 & 9 & 3 & 28 & 29 \\
\hline Mareere & 42.71 & 0.43 & 12 & 2 & 4 & 33 & 148 & 167 & 89 & 47 & 41 & 27 & 49 & 114 & 45 \\
\hline Kismaio & 42.43 & -0.36 & 8 & 0 & 1 & 6 & 45 & 80 & 117 & 70 & 34 & 28 & 11 & 24 & 3 \\
\hline Luuq & 42.45 & 3.58 & 165 & 1 & 1 & 18 & 82 & 52 & 2 & 1 & 1 & 3 & 48 & 48 & 12 \\
\hline Jamame & 42.73 & 0.05 & 10 & 2 & 3 & 5 & 60 & 99 & 78 & 68 & 24 & 32 & 27 & 19 & 18 \\
\hline Mogambo & 42.75 & 0.06 & 10 & 0 & 0 & 10 & 119 & 130 & 140 & 38 & 28 & 34 & 12 & 75 & 15 \\
\hline
\end{tabular}

\begin{tabular}{|l|l|l|l|l|l|l|l|l|}
\hline & Phoenix & Avondale & Glendale & Mesa & $\begin{array}{l}\text { Paradise } \\
\text { Valley }\end{array}$ & Peoria & Scottsdale & Sun City \\
\hline January & 0.91 & 1.04 & 1.04 & 0.91 & 1.26 & 1.04 & 0.91 & 1.04 \\
\hline
\end{tabular}




\begin{tabular}{|c|c|c|c|c|c|c|c|c|}
\hline Feb & 0.92 & 1.28 & 1.28 & 0.92 & 1.21 & 1.28 & 0.92 & 1.28 \\
\hline Mar & 0.99 & 1.07 & 1.07 & 0.99 & 1.23 & 1.07 & 0.99 & 1.07 \\
\hline April & 0.28 & 0.33 & 0.33 & 0.28 & 0.45 & 0.33 & 0.28 & 0.33 \\
\hline May & 0.11 & 0.1 & 0.1 & 0.11 & 0.19 & 0.1 & 0.11 & 0.1 \\
\hline June & 0.02 & 0.04 & 0.04 & 0.02 & 0.07 & 0.04 & 0.02 & 0.04 \\
\hline July & 1.05 & 0.92 & 0.92 & 1.05 & 1.04 & 0.92 & 1.05 & 0.92 \\
\hline August & 1.00 & 1.2 & 1.2 & 1.00 & 1.17 & 1.2 & 1.00 & 1.2 \\
\hline September & 0.64 & 0.82 & 0.82 & 0.64 & 0.9 & 0.82 & 0.64 & 0.82 \\
\hline October & 0.58 & 0.61 & 0.61 & 0.58 & 0.77 & 0.61 & 0.58 & 0.61 \\
\hline November & 0.65 & 0.68 & 0.68 & 0.65 & 0.85 & 0.68 & 0.65 & 0.68 \\
\hline December & 0.88 & 1.05 & 1.05 & 0.88 & 1.13 & 1.05 & 0.88 & 1.05 \\
\hline & Tempe & Tolleson & Chandler & El Mirage & $\begin{array}{l}\text { Fountain } \\
\text { Hills }\end{array}$ & Gilbert & Goodyear & Linchfeld \\
\hline
\end{tabular}




\begin{tabular}{|c|c|c|c|c|c|c|c|c|}
\hline January & 0.91 & 1.26 & 1.08 & 1.04 & 1.26 & 1.52 & 1.04 & 1.04 \\
\hline Feb & 0.92 & 1.21 & 1.16 & 1.28 & 1.21 & 1.32 & 1.28 & 1.28 \\
\hline Mar & 0.99 & 1.23 & 1.11 & 1.07 & 1.23 & 1.41 & 1.07 & 1.07 \\
\hline April & 0.28 & 0.45 & 0.28 & 0.33 & 0.45 & 0.48 & 0.33 & 0.33 \\
\hline May & 0.11 & 0.19 & 0.14 & 0.1 & 0.19 & 0.21 & 0.1 & 0.1 \\
\hline June & 0.02 & 0.07 & 0.03 & 0.04 & 0.07 & 0.07 & 0.04 & 0.04 \\
\hline July & 1.05 & 1.04 & 1.06 & 0.92 & 1.04 & 1.18 & 0.92 & 0.92 \\
\hline August & 1.00 & 1.17 & 1.36 & 1.2 & 1.17 & 1.53 & 1.2 & 1.2 \\
\hline September & 0.64 & 0.9 & 0.68 & 0.82 & 0.9 & 0.96 & 0.82 & 0.82 \\
\hline October & 0.58 & 0.77 & 0.64 & 0.61 & 0.77 & 0.76 & 0.61 & 0.61 \\
\hline November & 0.65 & 0.85 & 0.69 & 0.68 & 0.85 & 0.86 & 0.68 & 0.68 \\
\hline December & 0.88 & 1.13 & 1.1 & 1.05 & 1.13 & 1.35 & 1.05 & 1.05 \\
\hline
\end{tabular}


Appendix G. - Evapotranspiration data

Somalia Long term mean monthly PET 1963-1990 (mm)

\begin{tabular}{|c|c|c|c|c|c|c|c|c|c|c|c|c|}
\hline Station & Jan & Feb & Mar & Apr & May & Jun & Jul & Aug & Sep & Oct & Nov & Dec \\
\hline Alessandra & 153.6 & 148 & 170.7 & 129.7 & 121.1 & 101.9 & 104.4 & 116.3 & 126.6 & 129.9 & 117.1 & 131.6 \\
\hline Bardera & 199.9 & 173.6 & 190.7 & 141.9 & 154.1 & 157.4 & 158.5 & 169.1 & 177.2 & 151.2 & 144.7 & 158 \\
\hline Burdhuxul & 166.3 & 167 & 182.1 & 169.3 & 148.4 & 165 & 167.4 & 176.2 & 175.8 & 141.1 & 134.2 & 148.4 \\
\hline Dinsor & 199.9 & 173.6 & 190.7 & 141.9 & 154.1 & 157.4 & 158.5 & 169.1 & 177.2 & 151.2 & 144.7 & 158 \\
\hline Jilib & 153.6 & 148 & 170.7 & 129.7 & 121.1 & 101.9 & 104.4 & 116.3 & 126.6 & 129.9 & 117.1 & 131.6 \\
\hline Jonte & 125.5 & 116 & 138.7 & 124 & 117 & 96.8 & 99.5 & 105.7 & 114.9 & 125.3 & 111.1 & 123.4 \\
\hline Mareere & 153.6 & 148 & 170.7 & 129.7 & 121.1 & 101.9 & 104.4 & 116.3 & 126.6 & 129.9 & 117.1 & 131.6 \\
\hline Kismaio & 152.1 & 142.8 & 150.9 & 148.8 & 123.7 & 115.8 & 120 & 126.9 & 137 & 148.8 & 140.5 & 147.6 \\
\hline Luuq & 205.6 & 177.2 & 198.2 & 160.6 & 172 & 181.9 & 173.1 & 168.1 & 181.7 & 167 & 159.2 & 169.2 \\
\hline Jamame & 153.6 & 148 & 170.7 & 129.7 & 121.1 & 101.9 & 104.4 & 116.3 & 126.6 & 129.9 & 117.1 & 131.6 \\
\hline Mogambo & 153.6 & 148 & 170.7 & 129.7 & 121.1 & 101.9 & 104.4 & 116.3 & 126.6 & 129.9 & 117.1 & 131.6 \\
\hline
\end{tabular}




\begin{tabular}{|c|c|c|c|}
\hline Station Name & Elevation $(\mathrm{ft})$ & Period of Record Used for Averages & Average Annual PET (in) \\
\hline Bartlett Dam & 1,650 & 1939-2005 & 117.54 \\
\hline Mesa & 1,235 & $1896-2005$ & 94.38 \\
\hline Sacaton & 1,285 & $1908-2005$ & 107.42 \\
\hline Stewart Mountain & 1,422 & $1948-2005$ & 106.23 \\
\hline Tempe ASU & 1,170 & $1953-2005$ & 74.29 \\
\hline Buckeye & 1,000 & 1999 - current & 80.23 \\
\hline Desert Ridge & 1,700 & 2002 - current & 67.75 \\
\hline Laveen & 1,033 & 1999 - 2001 (inactive) & 68.91 \\
\hline Litchfield & 1,014 & 1999 - 2003 (inactive) & 80.59 \\
\hline Mesa & 1,202 & 2003 - current & 78.42 \\
\hline Phoenix Encanto & 1,099 & 1999 - current & 72.97 \\
\hline Phoenix Greenway & 1,316 & 1999 - current & 74.22 \\
\hline Queen Creek & 1,410 & 1999 - current & 76.65 \\
\hline Wadell & 1335 & 1999 - current & 75.71 \\
\hline
\end{tabular}


Appendix H. - River discharge data

\begin{tabular}{|c|c|c|c|c|c|c|c|c|c|c|c|c|c|c|}
\hline \multicolumn{15}{|c|}{ Long-Term Mean monthly discharge in Juba River (m3/s) } \\
\hline Station & $\operatorname{Area}(\mathrm{km} 2)$ & & Jan & Feb & Mar & Apr & May & Jun & Jul & Aug & Sep & Oct & Nov & Dec \\
\hline \multirow[t]{3}{*}{ Luuq } & \multirow[t]{3}{*}{160,000} & Mean & 41.6 & 24.2 & 31.4 & 150.4 & 275.1 & 198.3 & 189.5 & 242.6 & 270.7 & 391.6 & 302.1 & 110.9 \\
\hline & & Std. Dev. & 30.3 & 22.0 & 45.5 & 158.6 & 154.3 & 112.1 & 62.8 & 78.7 & 89.1 & 161.0 & 202.0 & 72.1 \\
\hline & & C.V. $\%$ & 73 & 91 & 145 & 105 & 56 & 57 & 33 & 32 & 33 & 41 & 67 & 65 \\
\hline \multirow[t]{3}{*}{ Bardheere } & \multirow[t]{3}{*}{216,730} & Mean & 47.3 & 30.0 & 36.0 & 148.6 & 294.2 & 21.4 & 188.3 & 239.3 & 270.5 & 394.2 & 330.0 & 123.5 \\
\hline & & Std. Dev. & 29.5 & 20.8 & 46.1 & 158.0 & 180.0 & 132.2 & 63.5 & 77.1 & 88.6 & 161.4 & 200.9 & 77.9 \\
\hline & & C.V. $\%$ & 62 & 69 & 128 & 106 & 61 & 62 & 34 & 32 & 33 & 41 & 61 & 63 \\
\hline \multirow[t]{3}{*}{ Mareere } & \multirow[t]{3}{*}{240,000} & Mean & 45.3 & 25.9 & 30.4 & 137.3 & 290.2 & 253.0 & 188.7 & 212.3 & 236.4 & 339.9 & 325.7 & 146.3 \\
\hline & & Std. Dev. & 32.0 & 23.0 & 40.5 & 139.9 & 175.4 & 159.0 & 72.2 & 81.9 & 91.6 & 121.9 & 165.6 & 124.4 \\
\hline & & C.V. \% & 71 & 89 & 133 & 102 & 60 & 63 & 38 & 39 & 39 & 36 & 51 & 85 \\
\hline \multirow[t]{3}{*}{ Kismaio } & \multirow[t]{3}{*}{278,000} & Mean & 54.3 & 31.6 & 28.4 & 117.3 & 254.9 & 227.1 & 183.8 & 224.9 & 248 & 319.8 & 313.5 & 146.5 \\
\hline & & Std. Dev. & 37.3 & 28.1 & 39.2 & 112.9 & 146.2 & 115.8 & 65.5 & 65.4 & 73.8 & 105.8 & 141.7 & 103.8 \\
\hline & & C.V. \% & 69 & 89 & 138 & 96 & 57 & 51 & 36 & 29 & 30 & 33 & 45 & 71 \\
\hline \multirow[t]{3}{*}{ Jamame } & \multirow[t]{3}{*}{268,800} & Mean & 50.5 & 23.4 & 21.7 & 96.7 & 233.2 & 205.2 & 167.4 & 211.3 & 247.1 & 308.8 & 311 & 142.8 \\
\hline & & Std. Dev. & 38.5 & 18.7 & 31 & 103.5 & 128.8 & 115.5 & 65.9 & 72.7 & 82.5 & 96.4 & 114.9 & 99.2 \\
\hline & & C.V. $\%$ & 76 & 80 & 143 & 107 & 55 & 56 & 39 & 34 & 33 & 31 & 37 & 30 \\
\hline
\end{tabular}

Long-Term Mean monthly discharge in Shabelle River (m3/s)

\begin{tabular}{|c|c|c|c|c|c|c|c|c|c|c|c|c|c|c|}
\hline Station & Area(km2) & & Jan & Feb & Mar & Apr & May & Jun & Jul & Aug & Sep & Oct & Nov & Dec \\
\hline \multirow[t]{3}{*}{ Belet Weyne } & \multirow[t]{3}{*}{207,000} & Mean & 13.5 & 13.8 & 30.0 & 79.8 & 151.2 & 82.7 & 57.0 & 110.0 & 151.8 & 129.6 & 77.5 & 36.9 \\
\hline & & Std. Dev. & 11.1 & 13.3 & 35.0 & 68.2 & 88.2 & 65.6 & 22.5 & 32.3 & 57.3 & 60.2 & 6.9 & 39.8 \\
\hline & & C.V. \% & $82 \%$ & $96 \%$ & $117 \%$ & $85 \%$ & $58 \%$ & $79 \%$ & $40 \%$ & $29 \%$ & $38 \%$ & $46 \%$ & $81 \%$ & $108 \%$ \\
\hline Bulu Burti & 231,000 & Mean & 14.3 & 9.8 & 14.5 & 31.9 & 65.6 & 56.1 & 40.8 & 67.3 & 74.8 & 71.9 & 57.2 & 31.7 \\
\hline
\end{tabular}




\begin{tabular}{|c|c|c|c|c|c|c|c|c|c|c|c|c|c|c|}
\hline & & Std. Dev. & 15.0 & 12.8 & 18.1 & 24.7 & 19.7 & 22.4 & 19.7 & 19.3 & 10.3 & 9.5 & 20.1 & 25.5 \\
\hline & & C.V. \% & $105 \%$ & $130 \%$ & $125 \%$ & $78 \%$ & $30 \%$ & $40 \%$ & $48 \%$ & $29 \%$ & $14 \%$ & $13 \%$ & $35 \%$ & $81 \%$ \\
\hline \multirow[t]{3}{*}{ M. Weyne } & \multirow[t]{3}{*}{255,300} & Mean & 17.2 & 13.1 & 21.1 & 53.6 & 104.5 & 74.5 & 52.0 & 98.3 & 122.8 & 111.4 & 74.6 & 37.5 \\
\hline & & Std. Dev. & 12.9 & 12.0 & 25.4 & 38.1 & 39.0 & 40.7 & 5.5 & 27.9 & 26.9 & 27.8 & 37.4 & 33.7 \\
\hline & & C.V. \% & $75 \%$ & $92 \%$ & $121 \%$ & $71 \%$ & $37 \%$ & $54 \%$ & $49 \%$ & $28 \%$ & $22 \%$ & $25 \%$ & $50 \%$ & $90 \%$ \\
\hline \multirow[t]{3}{*}{ Belcad } & \multirow[t]{3}{*}{272,700} & Mean & 15.8 & 9.0 & 22.8 & 37.2 & 74.6 & 50.5 & 43.9 & 78.3 & 91.7 & 84.6 & 65.3 & 34.0 \\
\hline & & Std. Dev. & 13.0 & 6.5 & 23.9 & 24.4 & 20.9 & 21.7 & 19.0 & 22.4 & 9.4 & 9.1 & 18.9 & 22.1 \\
\hline & & C.V. $\%$ & $82 \%$ & $72 \%$ & $105 \%$ & $66 \%$ & $28 \%$ & $43 \%$ & $43 \%$ & $29 \%$ & $10 \%$ & $11 \%$ & $29 \%$ & $65 \%$ \\
\hline \multirow[t]{3}{*}{ Afgoi } & \multirow[t]{3}{*}{278,000} & Mean & 14.2 & 9.6 & 14.7 & 34.7 & 70.9 & 57.4 & 40.0 & 72.8 & 84.8 & 79.2 & 60.4 & 32.4 \\
\hline & & Std. Dev. & 13.9 & 11.7 & 19.6 & 27.9 & 22.9 & 25.8 & 20.0 & 22.3 & 15.7 & 14.6 & 24.6 & 27.1 \\
\hline & & C.V. $\%$ & $98 \%$ & $122 \%$ & $133 \%$ & $8 \%$ & $32 \%$ & $45 \%$ & $50 \%$ & $31 \%$ & $18 \%$ & $18 \%$ & $41 \%$ & $84 \%$ \\
\hline \multirow[t]{3}{*}{ Awdgegle } & \multirow[t]{3}{*}{280,000} & Mean & 14.3 & 9.8 & 14.5 & 31.9 & 65.5 & 56.1 & 40.8 & 67.3 & 74.8 & 71.9 & 57.2 & 31.7 \\
\hline & & Std. Dev. & 15.0 & 12.8 & 18.1 & 24.7 & 19.7 & 22.4 & 19.7 & 19.3 & 10.3 & 9.5 & 20.1 & 25.5 \\
\hline & & C.V. \% & $105 \%$ & $130 \%$ & $125 \%$ & $78 \%$ & $30 \%$ & $40 \%$ & $48 \%$ & $29 \%$ & $14 \%$ & $13 \%$ & $35 \%$ & $81 \%$ \\
\hline
\end{tabular}


Appendix I. - Groundwater pumping capacity data

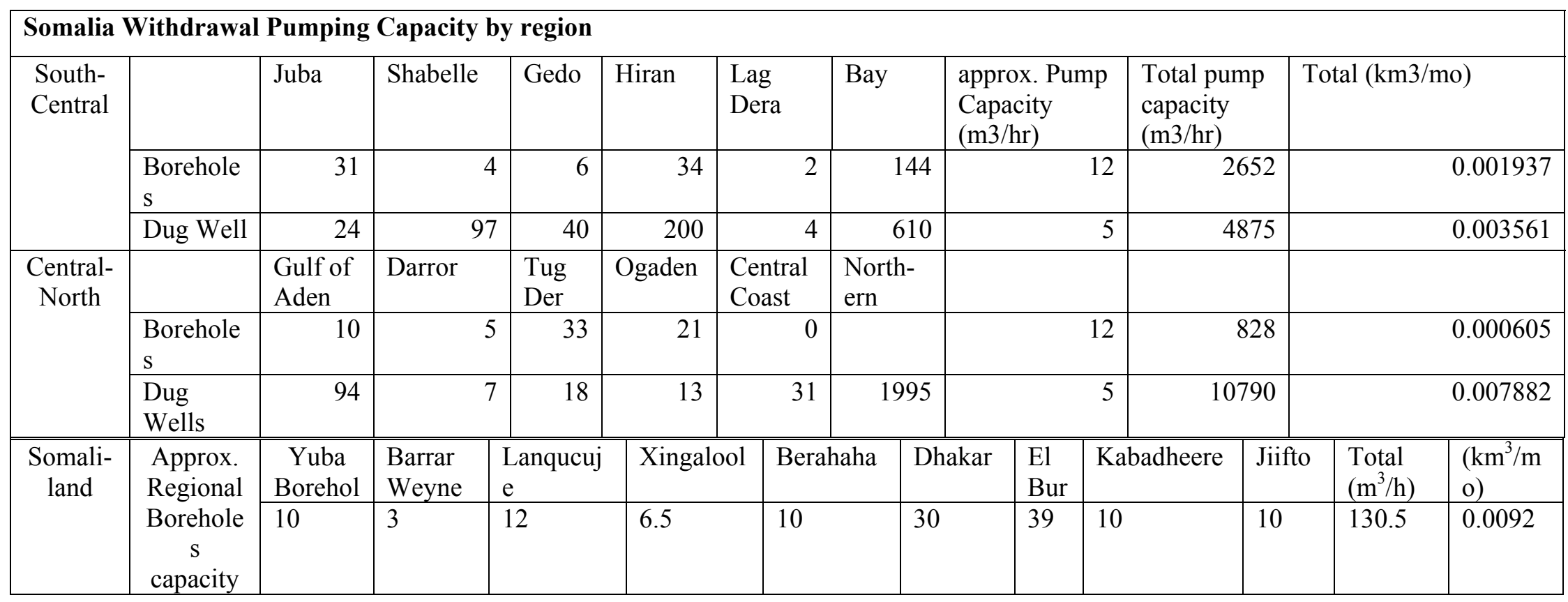

\section{PAMA Withdrawal Pumping Capacity by well registration (sample dataset)}

\begin{tabular}{|c|c|r|r|r|r|r|r|r|r|r|}
\hline $\begin{array}{c}\text { Reg } \\
\text { No. }\end{array}$ & Owner Name & $\begin{array}{c}\text { Well } \\
\text { Depth } \\
\text { (ft) }\end{array}$ & $\begin{array}{c}\text { Casing } \\
\text { Depth } \\
\text { (ft) }\end{array}$ & $\begin{array}{c}\text { Case } \\
\text { Dia } \\
\text { (in) }\end{array}$ & Drill Date & $\begin{array}{c}\text { Application } \\
\text { Date }\end{array}$ & $\begin{array}{c}\text { Water } \\
\text { Level }\end{array}$ & $\begin{array}{c}\text { Pump } \\
\text { Capacity } \\
\text { (GPM) }\end{array}$ & $\begin{array}{c}\text { UTM X } \\
\text { (meters) }\end{array}$ & $\begin{array}{c}\text { UTM Y } \\
\text { (meters) }\end{array}$ \\
\hline 599019 & $\begin{array}{c}\text { CITY OF } \\
\text { AVONDALE }\end{array}$ & 660 & 284 & 16 & $9 / 15 / 2003$ & $6 / 24 / 2003$ & 177 & 3000 & 381649.20 & 3704039.00 \\
\hline 625093 & $\begin{array}{c}\text { CAVE CREEK } \\
\text { WATER CO, }\end{array}$ & 213 & 213 & 16 & $1 / 1 / 1977$ & $6 / 11 / 1982$ & 25 & 160 & 411828.30 & 3744416.00 \\
\hline 214540 & $\begin{array}{c}\text { CITY OF } \\
\text { PHOENIX }\end{array}$ & 1868 & 1420 & 19 & $10 / 23 / 2007$ & $2 / 5 / 2007$ & 568 & 2500 & 406860.90 & 3732585.00 \\
\hline
\end{tabular}




\begin{tabular}{|c|c|c|c|c|c|c|c|c|c|c|}
\hline 549038 & $\begin{array}{c}\text { PHOENIX, CITY } \\
\text { OF, }\end{array}$ & 1350 & 1340 & 18 & $10 / 9 / 1995$ & $4 / 8 / 1995$ & 466 & 2250 & 409287.00 & 3727270.00 \\
\hline 583886 & $\begin{array}{c}\text { CITY OF } \\
\text { PHOENIX } \\
\text { WATER } \\
\text { SERVICES }\end{array}$ & 1460 & 1450 & 18 & $10 / 1 / 2001$ & $11 / 16 / 2000$ & 490 & 2500 & 411075.10 & 3724438.00 \\
\hline 560509 & $\begin{array}{c}\text { PHOENIX CITY } \\
\text { OF }\end{array}$ & 1609 & 1520 & 32 & & $1 / 23 / 1997$ & 488 & 2500 & 408633.00 & 3728081.00 \\
\hline 549037 & $\begin{array}{c}\text { PHOENIX, CITY } \\
\text { OF, }\end{array}$ & 1610 & 1600 & 18 & $10 / 20 / 1995$ & $8 / 4 / 1995$ & 610 & 1320 & 409325.60 & 3731992.00 \\
\hline 543024 & $\begin{array}{c}\text { PHOENIX, CITY } \\
\text { OF, }\end{array}$ & 1635 & 1625 & 36 & $12 / 15 / 1994$ & $4 / 15 / 1994$ & 598 & 1000 & 407885.20 & 3734393.00 \\
\hline 618749 & RAWLINGS,D L & 200 & 180 & 8 & $1 / 1 / 1962$ & $6 / 10 / 1982$ & 80 & 60 & 393114.40 & 3691005.00 \\
\hline
\end{tabular}




\begin{tabular}{|c|c|c|c|c|}
\hline Facility Name & Ownership & $\begin{array}{c}\text { City/Location } \\
\text { Served }\end{array}$ & $\begin{array}{l}\text { Population } \\
\text { Served }\end{array}$ & $\begin{array}{l}\text { Volume Treated/Generated } \\
\text { (acre-feet) }\end{array}$ \\
\hline $\begin{array}{c}\text { Agua Fria Wastewater (Verrado \& } \\
\text { Russell Ranch) }\end{array}$ & AZ /American Water & $\begin{array}{c}\text { Buckeye \& } \\
\text { Litchfield }\end{array}$ & 1,629 & 193 \\
\hline Anthem WWTP & AZ/American Water & Anthem & & 1,423 \\
\hline Arrowhead Ranch WWRF & City of Glendale & Glendale & 46,705 & 3,360 \\
\hline Avondale WWTF & City of Avondale & Avondale & 55,500 & 4,088 \\
\hline Buckeye WWTF & Buckeye, Town of & Buckeye & 15,119 & 448 \\
\hline Casa Blanca & Gila River Indian Tribe & NA & 300 & 34 \\
\hline Cave Creek & Cave Creek, Town of & Cave Creek & 3,650 & 134 \\
\hline Cave Creek WWTP & City of Phoenix & Phoenix & 169,000 & 1,893 \\
\hline $\begin{array}{l}\text { City of Chandler, Airport Rec. } \\
\text { Facility }\end{array}$ & City of Chandler & Chandler & 90,000 & 8,401 \\
\hline $\begin{array}{c}\text { City of Goodyear 157th Ave } \\
\text { WWTF }\end{array}$ & Goodyear, City of & Goodyear & 15,000 & 2,800 \\
\hline Desert Vista WWTF & $\begin{array}{c}\text { Pinal County - Desert Vista } \\
\text { Sanitary District }\end{array}$ & Pinal & 320 & 22 \\
\hline
\end{tabular}




\begin{tabular}{|c|c|c|c|c|}
\hline El Mirage WWTP & El Mirage, City of & El Mirage & 32,000 & 672 \\
\hline Fountain Hills WWTP & Fountain Hills & Fountain Hills & 21,000 & 2,083 \\
\hline Gold Canyon WWTF & Gold Canyon Sewer Co. & Apache Junction & 6,304 & 767 \\
\hline Johnson Ranch Utilities1 & Johnson Utilities LLC & Queen Creek & $\begin{array}{l}\text { see Johnson } \\
\text { Utilities LLC }\end{array}$ & see Johnson Utilities LLC \\
\hline Johnson Utilities LLC $^{1}$ & Johnson Utilities LLC & Queen Creek & 21,500 & 3,717 \\
\hline Kyrene WW System & Tempe, City of & Tempe & 79,304 & 4,256 \\
\hline Litchfield Park WWTP & Lichfield Park Services Co. & Litchfield Park & 17,907 & 3,365 \\
\hline Lone Butte WWTF & Chandler Public Works & Chandler & 45,000 & 6,721 \\
\hline Luke AFB WWTF & $\begin{array}{l}\text { U.S. Department of } \\
\text { Defense (Air Force) }\end{array}$ & Luke AFB & NA & 330 \\
\hline Mesa Northwest WWRP & City of Mesa & Mesa & 70,000 & 11,201 \\
\hline Neely WWTF & Gilbert, Town of & Gilbert & 17,000 & 8,289 \\
\hline $\begin{array}{c}\text { Northwest Regional WWTP } \\
\text { formerly Sun City West WWTP } 1^{2}\end{array}$ & AZ/American Water & Sun City West & 18,000 & 2,826 \\
\hline Ocotillo Reclamation Plant & City of Chandler & Chandler & 90,000 & 6,721 \\
\hline Pecan WRP & Johnson Utilities LLC & Queen Creek & $\begin{array}{l}\text { see Johnson } \\
\text { Utilities LLC }\end{array}$ & see Johnson Utilities LLC \\
\hline
\end{tabular}




\begin{tabular}{|c|c|c|c|c|}
\hline Peoria Beardsley WWTP & City of Peoria & Peroia & 38,755 & 2,800 \\
\hline Peoria Twin Buttes WRP & City of Peoria & Peoria & 310 & 246 \\
\hline Phoenix 91St Ave WWTP & City of Phoenix & Phoenix & $1,238,000$ & 138,892 \\
\hline Phoenix 23rd Ave WWTP & City of Phoenix & Phoenix & NA & 54,884 \\
\hline Queen Valley WWTF & Queen Valley S.D. & Queen Valley & 1,676 & 45 \\
\hline Rio Verde WWTF & Rio Verde Utilities & Maricopa & 1,620 & 167 \\
\hline San Tan WRP & Johnson Utilities LLC & Queen Creek & $\begin{array}{l}\text { see Johnson } \\
\text { Utilities LLC }\end{array}$ & see Johnson Utilities LLC \\
\hline Scottsdale Water Campus & City of Scottsdale & Scottsdale & 100,000 & 13,441 \\
\hline Scottsdale-Gainey Ranch WRF & City of Scottsdale & Scottsdale & 12,000 & 1,344 \\
\hline Section 11 WWTP & Johnson Utilities LLC & Queen Creek & $\begin{array}{l}\text { see Johnson } \\
\text { Utilities LLC }\end{array}$ & see Johnson Utilities LLC \\
\hline Southeast Mesa WRP & City of Mesa & Mesa & 35,000 & 8,961 \\
\hline Sun Lakes WWTP 1 & Pima Utilities & Sun Lakes & 10,050 & 1,206 \\
\hline Superior WWTF & Superior Sanitary District & Superior & 3,319 & 204 \\
\hline Superstition Mtn WWTF & $\begin{array}{l}\text { Superstition Mtn } \\
\text { Community }\end{array}$ & Superstition & 42,560 & 1,341 \\
\hline
\end{tabular}




\begin{tabular}{|c|c|c|c|c|}
\hline Surprise WRF & City of Surprise & Surprise & 35,000 & 4,256 \\
\hline Tolleson WWTF & City of Tolleson & Tolleson & 4,970 & 14,561 \\
\hline West Glendale WWTF & City of Glendale & Glendale & 70,000 & 7,841 \\
\hline Total & & & $\mathbf{2 , 6 6 7 , 9 9 5}$ & $\mathbf{3 2 4 , 3 8 3}$ \\
\hline
\end{tabular}


Appendix J. - Groundwater recharge data

Recharge Sites in the Phoenix AMA

\section{A. Underground Storage Facilities}

\begin{tabular}{|c|c|c|c|}
\hline FACILITY NAME & FACILITY NUMBER & $\begin{array}{c}\text { PERMITTED } \\
\text { AF/YEAR }\end{array}$ & $\begin{array}{l}\text { WATER } \\
\text { SOURCE }\end{array}$ \\
\hline \multirow[t]{2}{*}{ AGUA FRIA } & $71-569776.0004$ & \multirow[t]{2}{*}{100,000} & $\mathrm{C}$ \\
\hline & $71-569775.0004$ & & $\mathrm{C}$ \\
\hline ANTHEM (DESERT HILLS) & $71-566962.0000$ & 10,000 & $\mathrm{C}, \mathrm{E}$ \\
\hline ARROWHEAD & $71-591934.0000$ & 2,300 & $\mathrm{E}$ \\
\hline AVONDALE WETLANDS & $71-565257.0001$ & 15,000 & $\mathrm{C}, \mathrm{S}$ \\
\hline CAVE CREEK & $71-595199.0000$ & 8,961 & $\mathrm{E}$ \\
\hline CHANDLER HEIGHTS & $71-588551.0001$ & 2,240 & $\mathrm{E}$ \\
\hline CHANDLER INTEL & $71-541455.0001$ & 3,100 & $\mathrm{E}$ \\
\hline CHANDLER OCOTILLO & $71-583023.0004$ & 11,200 & $\mathrm{E}$ \\
\hline CHANDLER TUMBLEWEED & $71-560347.0000$ & 11,200 & $\mathrm{E}$ \\
\hline EL MIRAGE & $71-595207.0000$ & 2,016 & $\mathrm{E}$ \\
\hline FOUNTAIN HILLS & $71-591940.0000$ & 2,241 & $\mathrm{E}$ \\
\hline GILBERT MUNICIPAL (ASR) & $71-591935.0000$ & 2,240 & $\mathrm{E}$ \\
\hline GILBERT NEELY WILDLIFE HABITAT & $71-520379.0000$ & 3,314 & $\mathrm{E}$ \\
\hline GILBERT RIPARIAN PRESERVE & $71-564416.0000$ & 4,369 & C,E,S \\
\hline GILBERT SOUTH & $71-595198.0000$ & 10,098 & $\mathrm{CE}$ \\
\hline GLENDALE AIRPORT & $71-586730.0000$ & 7,841 & E \\
\hline GOLD CANYON & $71-591929.0000$ & 1,120 & $\mathrm{E}$ \\
\hline GOODYEAR EFFLUENT - SAT & $71-566367.0000$ & 3,360 & $\mathrm{E}$ \\
\hline
\end{tabular}




\begin{tabular}{|c|c|c|c|}
\hline $\begin{array}{l}\text { GRANITE REEF UNDERGROUND STORAGE PROJECT } \\
\text { (GRUSP) }\end{array}$ & $71-516371.0000$ & 200,000 & $\mathrm{C}, \mathrm{E}, \mathrm{S}$ \\
\hline HIEROGLYPHIC MTS. & $71-584466.0001$ & 35,000 & $\mathrm{C}$ \\
\hline KEN MCDONALD & $71-563943.0001$ & 3,400 & $\mathrm{E}$ \\
\hline LAKE PLEASANT & $71-205388.0000$ & 67 & $\mathrm{E}$ \\
\hline MESA NWWRP & $71-518105.0000$ & 8,963 & $\mathrm{E}$ \\
\hline NEW RIVER AGUA FRIA RECHARGE PROJECT (NAUSP) & $71-588558.0003$ & 75,000 & $\mathrm{C}, \mathrm{E}, \mathrm{S}$ \\
\hline NORTH GATEWAY & $71-595208.0000$ & 1,742 & $\mathrm{C}$ \\
\hline NORTH SCOTTSDALE & $71-583022.0001$ & 3,642 & $\mathrm{C}$ \\
\hline OCOTILLO & $71-546845.0002$ & 500 & $\mathrm{E}$ \\
\hline PEORIA WWTP - BEARDSLEY & $71-552497.0002$ & 17,920 & $\mathrm{E}$ \\
\hline RED MOUNTAIN & $71-535755.0001$ & 2,000 & $\mathrm{C}$ \\
\hline SUN CITY WEST & $71-534362.0003$ & 5,600 & $\mathrm{E}$ \\
\hline SUN LAKES & $71-560427.0001$ & 628 & $\mathrm{E}$ \\
\hline $\begin{array}{c}\text { SUPERSTITION MOUNTAINS COMMUNITIES FACILITIES } \\
\text { DISTRICT (SMCFD) }\end{array}$ & $71-584469.0000$ & 2,352 & $\mathrm{E}$ \\
\hline SUPERSTITION MTNS & $71-207702.000$ & 56,500 & $\mathrm{C}$ \\
\hline SURPRISE (SOUTH PLANT) & $71-562521.0002$ & 8,066 & $\mathrm{E}$ \\
\hline TARTESSO & $71-205381.0001$ & 20,163 & $\mathrm{E}$ \\
\hline TONOPAH DESERT & $71-593305.0002$ & 150,000 & $\mathrm{C}$ \\
\hline TRAMONTO & $71-591936.0002$ & 1,935 & $\mathrm{C}$ \\
\hline VERRADO & $71-207708.0006$ & 500 & $\mathrm{E}$ \\
\hline WATER CAMPUS & $71-560648.0002$ & 16,800 & $\mathrm{C}, \mathrm{E}$ \\
\hline
\end{tabular}




\begin{tabular}{|c|c|c|c|}
\hline WEST MARICOPA COMBINE & $71-550601.0000$ & 25,000 & $\mathrm{C}$ \\
\hline WEST MARICOPA COMBINE & $71-578112.0001$ & 25,000 & $\mathrm{C}$ \\
\hline WESTWORLD & $71-574911.0002$ & 1,000 & $\mathrm{C}$ \\
\hline \multicolumn{4}{|l|}{ B. Groundwater Savings Facilities } \\
\hline PERMITEE/FACILITY NAME & FACILITY NUMBER & $\begin{array}{c}\text { PERMITTED } \\
\text { AF/YEAR }\end{array}$ & $\begin{array}{l}\text { WATER } \\
\text { SOURCE }\end{array}$ \\
\hline CAWCD@CHANDLER HEIGHTS ID & $72-534753$ & 3,000 & $\mathrm{C}$ \\
\hline CAWCD@QUEEN CREEK ID & $72-534550.0003$ & 28,000 & $\mathrm{C}$ \\
\hline GILA RIVER INDIAN IDD & $72-211277.0000$ & 37,520 & $\mathrm{C}$ \\
\hline LITCHFIELD PARK SERVICE COMPANY (LPSCO) & $72-534978.0000$ & 105,000 & $\mathrm{E}$ \\
\hline MARICOPA WATER DISTRICT & $72-558246.0002$ & 40,000 & $\mathrm{C}$ \\
\hline NEW MAGMA IDD & $72-534888.0003$ & 54,000 & $\mathrm{C}$ \\
\hline ROOSEVELT ID & $72-572386.0001$ & 30,000 & $\mathrm{E}$ \\
\hline ROOSEVELT WATER CONSERVATION DISTRICT (RWCD) & $72-545695.0000$ & 105,000 & $\mathrm{C}, \mathrm{E}$ \\
\hline SRP & $72-553166.0002$ & 100,000 & $\mathrm{C}$ \\
\hline TONOPAH ID & $72-534439.0003$ & 15,000 & $\mathrm{C}$ \\
\hline
\end{tabular}


Appendix L. - Definition of System Structure

\section{State Variables (Stocks):}

Population $(\mathrm{x})=$

$$
x=\beta x-\alpha x+I
$$

Population $=($ birth rate $*$ population $)-($ death rate $*$ population $)+($ net immigration $)$

Surface Water Sources $\left(\mathrm{y}_{\mathrm{s}}\right)=$

$$
y_{S}=(\mathrm{P}+\phi+\Lambda+\Omega+\mathrm{N})-\left(\mathrm{E}+\Psi+W_{S}\right)
$$

Surface water sources $=($ precipitation to sources + river inflow + leaks to source + runoff to source + nonrecycled to source $)-($ evapotranspiration + river outflow + surface water withdrawal)

Groundwater Sources $\left(\mathrm{y}_{\mathrm{G}}\right)=$

$$
y_{G}=G-W_{G}
$$

Groundwater sources $=$ groundwater recharge - groundwater withdrawal

Stored Freshwater Supply $(\mathrm{z})=$

$$
z=W_{S}+W_{G}+R-K-L
$$

Stored freshwater supply $=$ surface water withdrawal + groundwater withdrawals + recycled water - supply collected - leaks

Functions:

Net Immigration $(\mathrm{I})=$

$$
I=I_{b} * \frac{\left(C-C_{t h}\right)}{C_{t h}}
$$

Net immigration $=$ base immigration rate $*($ consumption per capita - threshold consumption per capita) / threshold consumption per capita 
Groundwater Recharge rate $(\mathrm{G})=$

$$
G=\max (0,(f *(P-E)))
$$

Groundwater recharge rate $=$ maximum value of $(0$ or $($ infiltration rate $*$ (precipitation evapotranspiration)

Surface Water Withdrawal $\left(\mathrm{W}_{\mathrm{S}}\right)=$

$$
W_{S}=\min \left(\theta_{S} * \frac{y_{S}}{t}, \theta_{O} * \frac{\left(z_{M}-z\right)}{t}, W_{S M}\right) * \min \left(1,\left(\frac{y_{S}}{n_{S} * D}\right)\right)
$$

Surface water withdrawal $=$ minimum value of $($ surface water sources given a certain assured quantity through time, available space of freshwater supply storage given a certain assured quantity through time, or the maximum allowed surface water withdrawal rate) $*$ minimum value of $(1$ or the quantity of surface water sources that can meet effective demand for a given number of reserve months)

Groundwater Withdrawal $\left(\mathrm{W}_{\mathrm{G}}\right)=$

$$
W_{G}=\min \left(\theta_{G} * \frac{y_{G}}{t}, \theta_{O} * \frac{\left(z_{M}-z\right)}{t}, W_{G M}\right) * \min \left(1,\left(\frac{y_{G}}{n_{G} * D}\right)\right)
$$

Groundwater withdrawal $=$ minimum value of $($ groundwater sources given a certain assured quantity through time, available space of freshwater supply storage given a certain assured quantity through time, or the maximum allowed groundwater withdrawal rate) * minimum value of ( 1 or the quantity of groundwater sources that can meet effective demand for a given number of reserve months)

Supply Collection rate $(\mathrm{K})=$

$$
K=\max \left(0, \min \left(D, \frac{Z * \eta * \theta_{K}}{t}\right)-\Gamma\right)
$$


Supply collection rate $=$ maximum value of $(0$ or the minimum value of (effective

$$
\begin{aligned}
& \text { demand or the stored freshwater supply * transfer efficiency * a } \\
& \text { given assured collection value through time) - rooftop } \\
& \text { collection) }
\end{aligned}
$$

Leakage rate $(\mathrm{L})=$

$$
L=\left(\frac{1-\eta}{\eta}\right) * K
$$

Leakage rate $=(1-$ transfer efficiency/ transfer efficiency $) *$ supply collection rate Recycled Water rate $(\mathrm{R})=$

$$
R=\min \left(\theta_{O} * \frac{\left(Z_{M}-z\right)}{t}, \Sigma, R_{M}\right)
$$

Recycled water rate $=$ minimum value of (available freshwater storage space given a certain assured value, consumptive water to sewer rate, or the maximum recycling capacity)

Total Demand $(\mathrm{d})=$

$$
d=\delta x
$$

Total demand $=$ demand per capita $*$ population

Effective demand $(\mathrm{D})=$

$$
D=\frac{d}{\tau}
$$

Effective demand $=$ total demand/ technology factor Consumption per capita $(\mathrm{C})=$

$$
C=x i d z(K+\Gamma, x, 0)
$$

Consumption per capita $=0$ if population $=0$, otherwise $($ supply collection rate + rooftop collection rate)/ population)

Threshold consumption per capita $\left(\mathrm{C}_{\mathrm{th}}\right)=$ 


$$
C_{t h}=\mu *\left(\frac{\delta}{\tau}\right)
$$

Threshold consumption per capita $=$ a certain given threshold portion $*$ demand per capita/ technology factor

Death rate $(\alpha)=$

$$
\alpha=\operatorname{IFTHEN} \operatorname{ELSE}\left(C<C_{t h},\left(\alpha_{M}-\left(\alpha_{M}-\alpha_{m}\right) *\left(\frac{C}{C_{t h}}\right), \alpha_{m}\right)\right.
$$

Death rate $=$ if consumption per capita is less than the threshold consumption per capita, then maximum death rate - difference between maximum and minimum death rate * consumption per capita/threshold consumption per capita, otherwise minimum death rate

Leaks to sources $(\Lambda)=$

$$
\Lambda=\text { delay fixed }(L, \lambda, L)
$$

Leaks to sources $=$ leakage rate delayed by leak to sources delay, using initial value of leakage rate

Runoff to Sources $(\Omega)=$

$$
\Omega=\omega(1-\sigma)(K+\Gamma)
$$

Runoff to sources $=$ runoff to sources ratio $*$ nonconsumptive to runoff rate Non recycled to source rate $(\mathrm{N})=$

$$
N=v(\Sigma-R)
$$

Nonrecycled to source rate $=$ nonrecycled to sources ratio $*$ nonrecycled water Consumptive to Sewer rate $(\Sigma)=$

$$
\Sigma=\sigma(K+\Gamma)
$$

Consumptive to sewer rate $=$ consumptive to sewer ratio* (supply collection rate + rooftop collection rate) 


\section{Exogenous Variable:}

Precipitation rate $(\mathrm{P})$

Evapotranspiration rate $(\mathrm{E})$

River inflow rate $(\Phi)$

River outflow rate $(\Psi)$

\section{Descriptive Parameters:}

Minimum (Normal) death rate $\left(\alpha_{\mathrm{m}}\right)$

Maximum (Famine) death rate $\left(\alpha_{\mathrm{M}}\right)$

Birth rate $(\beta)$

Demand per capita $(\delta)$

Transfer efficiency $(\eta)$

Technology Factor $(\tau)$

Maximum capacity for stored freshwater supply $\left(\mathrm{z}_{\mathrm{M}}\right)$

Maximum surface water withdrawal rate $\left(\mathrm{W}_{\mathrm{SM}}\right)$

Maximum groundwater withdrawal rate $\left(\mathrm{W}_{\mathrm{GM}}\right)$

Maximum recycling capacity $\left(\mathrm{R}_{M}\right)$

Number of surface water reserved month $\left(n_{s}\right)$

Number of groundwater reserve months $\left(\mathrm{n}_{\mathrm{G}}\right)$

Infiltration rate $(\mathrm{f})$

Surface water assurance factor $\left(\theta_{\mathrm{s}}\right)$

Groundwater assurance factor $\left(\theta_{\mathrm{G}}\right)$

Overflow assurance factor $\left(\theta_{\mathrm{o}}\right)$ 
Collection assurance factor $\left(\theta_{\mathrm{K}}\right)$

Leak to sources time delay $(\lambda)$

Runoff to sources ratio $(\omega)$

Nonrecycled to sources ratio $(v)$

Consumptive to sewer ratio $(\sigma)$ 